\title{
MODELO PARA A TRANSFERÊNCIA TECNOLOGIA- PRODUTO SOB O RECORTE ANALÍTICO DE REDES COLABORATIVAS
}

Tese apresentada à Escola de Engenharia de São Carlos da Universidade de São Paulo, como parte dos requisitos necessários para a obtenção do Título de Doutor em Engenharia de Produção.

Área de Concentração: Processos e Gestão de Operações

Orientador: Professor Associado Fábio Müller Guerrini

São Carlos

2013 
AUTORIZO A REPRODUÇÃO TOTAL OU PARCIAL DESTE TRABALHO, POR QUALQUER MEIO CONVENCIONAL OU ELETRÔNICO, PARA FINS DE ESTUDO E PESQUISA, DESDE QUE CITADA A FONTE.

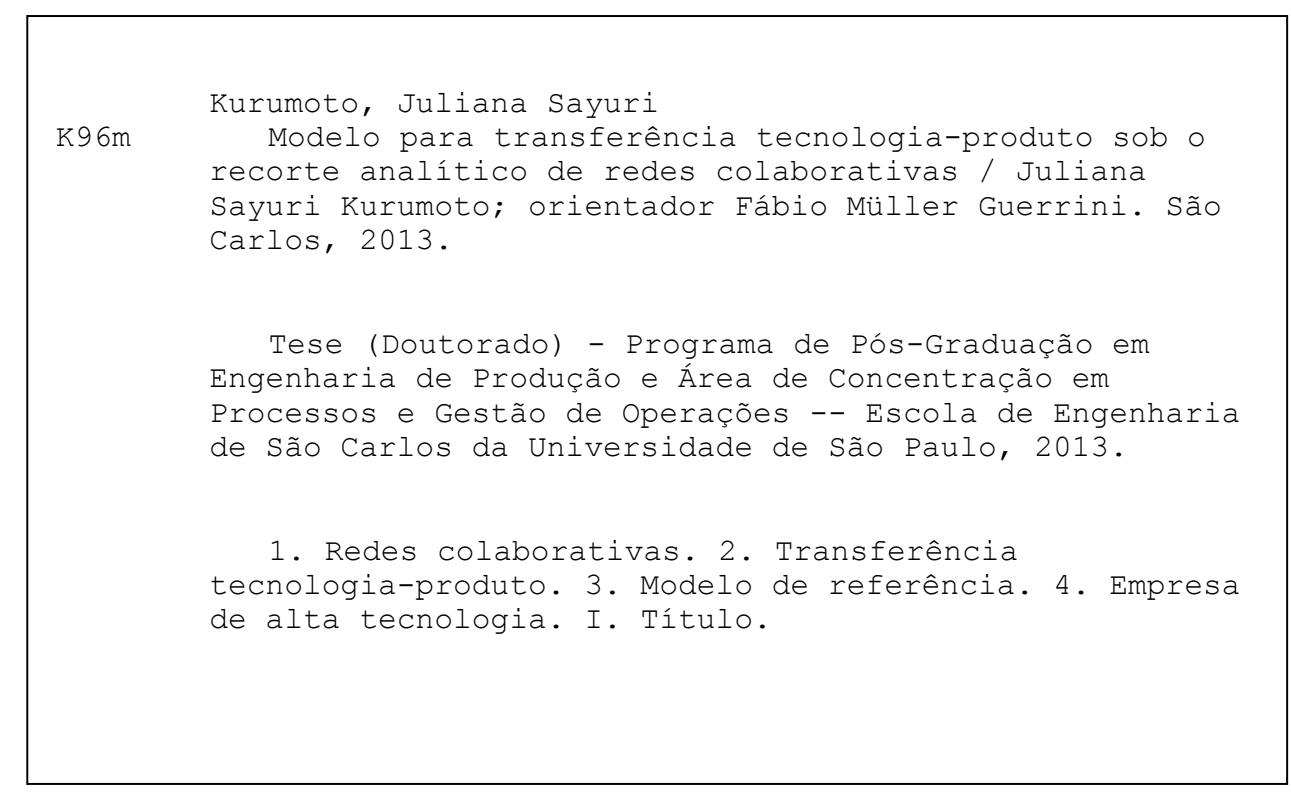




\section{FOLHA DE JULGAMENTO}

Candidata: Bacharel JULIANA SAYURI KURUMOTO.

Título da tese: "Modelo para a transferência tecnologia-produto sob o recorte analítico de redes colaborativas.".

Data da defesa: $15 / 03 / 2013$

\section{Comissão Julgadora:}

Prof. Associado Fábio Müller Guerrini (Orientador)

(Escola de Engenharia de São Carlos/EESC)

Prof. Associado Edmundo Escrivão Filho

(Escola de Engenharia de São Carlos/EESC)

Prof. Dr. Edson Walmir Cazarini

(Escola de Engenharia de São Carlos/EESC)

Prof. Dr. Sérgio Luis da Silva

(Universidade Federal de São Carlos)

Prof. Dr. Mário Sacomano Neto

(Universidade Metodista de Piracicaba/UNIMEP)

\section{Resultado:}

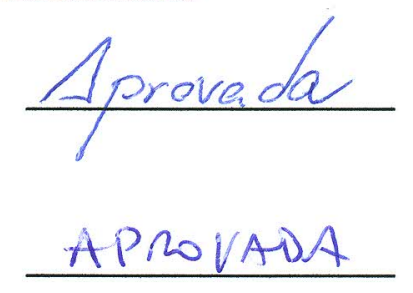

Aprovada

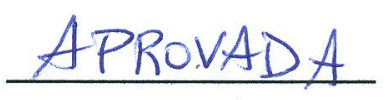

Coordenador do Programa de Pós-Graduação em Engenharia de Produção

Prof. Titular Henrique Rozenfeld

Presidente da Comissão de Pós-Graduação:

Prof. Titular Denis Vinicius Coury 



\section{DEDICATÓRIA}

Aos meus pais, Masaharu e Vera, a minha eterna gratidão por tudo que me ensinaram, pelos exemplos de vida e ser humano, pelo amor e apoio incondicional. 



\section{AGRADECIMENTOS}

À Deus, pelo dom da vida e por sempre estar ao meu lado.

Ao Professor Fábio Müller Guerrini, pela orientação, incentivo, dedicação e pela oportunidade de participar do grupo de pesquisa "Arquitetura para Redes Dinâmicas (AR-C)". Por seu profissionalismo e sabedoria que muito contribuiu para minha formação profissional.

Aos meus pais, Masaharu e Vera e à minha irmã Márcia que mesmo distante fisicamente estiveram sempre presente.

Ao Danilo, pelo apoio e pela compreensão ao longo desses anos.

Aos Professores Edmundo Escrivão Filho e Sergio Luis da Silva pelas contribuições apresentadas no exame de qualificação.

Aos Professores Mário Sacomano Neto, Edson Walmir Cazarini, Edmundo Escrivão Filho e Sergio Luis da Silva membros da banca de defesa, pela participação e pelas sugestões que enriqueceram o trabalho.

À todos os professores que por meio das disciplinas contribuíram para o meu conhecimento.

Aos colegas de Laboratório, em especial a Catarina, Lilian e Camila pela amizade e carinho.

Aos colegas do grupo de pesquisa: Larissa, Angelita, Cristina, Flávia, Adauto, Heber, Dani, Lucas e Murilo.

Aos funcionários da biblioteca e do Departamento de Engenharia de Produção pelo auxílio e prontidão.

À todas as empresas que contribuíram para a realização desta pesquisa.

À Coordenação de Aperfeiçoamento de Pessoal de Nível Superior (CAPES) pelo apoio financeiro concedido.

À todos o meu muito obrigado! 



\section{RESUMO}

KURUMOTO, J. S. Modelo para a transferência tecnologia-produto sob o recorte analítico de redes colaborativas. 2013. 200 p. Tese (Doutorado) - Escola de Engenharia de São Carlos, Universidade de São Paulo, São Carlos, 2013.

O processo de transferência tecnologia-produto é considerado uma competência essencial dentro das empresas desenvolvedoras de produtos inovadores e consiste em um relacionamento envolvendo uma empresa desenvolvedora da tecnologia denominada de fornecedora e outra denominada de usuária, que conduz esforços de desenvolvimento de produtos utilizando-se dessa tecnologia. A literatura aponta como o principal problema dessa transferência, a incerteza tecnológica, que dificulta a utilização efetiva da tecnologia e sua incorporação em novos produtos pela empresa usuária, comprometendo a eficácia desse processo e do desenvolvimento de produtos. Diante desse cenário o objetivo da pesquisa consiste em propor um modelo para o processo de transferência tecnologia-produto a partir do recorte analítico de redes colaborativas. Sabe-se que as redes podem contribuir com a geração, manutenção e ampliação das inovações nessas empresas, diminuindo a incerteza tecnológica e melhorando a habilidade das empresas em desenvolver novos produtos. Para atingir o objetivo da pesquisa foi utilizada a metodologia de modelagem organizacional Enterprise Knowledge Development (EKD) como base para a construção do modelo, sendo esta modelagem realizada por meio de estudos de casos em empresas de alta tecnologia. Diante dos resultados empíricos juntamente com a literatura foi proposto o modelo que visa auxiliar as empresas a utilizar os conceitos de redes colaborativas de forma sistemática e factível dentro do setor estudado, já que pesquisas prévias não trazem essa contribuição prática. Esse modelo pode orientar as empresas a estruturar ou reestruturar o processo de transferência tecnologia-produto para que seja colaborativo e não simplesmente uma relação de mercado.

Palavras-chave: Redes colaborativas; Transferência tecnologia-produto; Modelo de referência, Empresa de alta tecnologia. 



\begin{abstract}
KURUMOTO, J. S. Model for product-technology transfer under the analytical approach of collaborative networks. 2013. 200 p. Tese (Doutorado) - Escola de Engenharia de São Carlos, Universidade de São Paulo, São Carlos, 2013.

The product technology transfer process is considered a key competence in firms that develop innovative products. This process consists of Organizations who develop technology known as suppliers and recipient Organization who conduct the product development effort. The literature points the technological uncertainty as the main problem of the transfer, hindering the effective use of technology and its incorporation into new products by the user firm, compromising the effectiveness of this process and product development. Based on this scenario, the purpose of the research is to propose a model for the product technology transfer process from the analytical approach of collaborative networks. The collaborative networks contribute to the generation, maintenance, and extension of innovation, reducing uncertainty and improving the technological ability of firms to develop new products. In order to achieve the research objective, the organizational modeling methodology called Enterprise Knowledge Development (EKD) was used as the basis for developing the model. This modeling was performed by means of case studies in high-technology firms. Based on the empirical results and literature, the model was proposed in order to help firms in the sector studied, using the concepts of collaborative networks in a systematic way, since previous research did not present this practical contribution. Besides, this model can guide firms to structure or restructure the product technology transfer process in a collaborative way and not simply a market relationship.
\end{abstract}

Keywords: Collaborative networks; Product technology transfer; Reference model; Hightechnology firm. 



\section{LISTA DE FIGURAS}

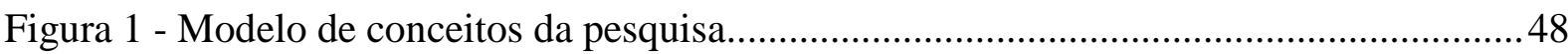

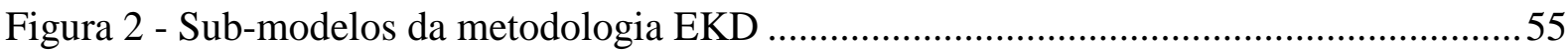

Figura 3 - Tipos de atividades envolvidas no processo do EKD ..........................................56

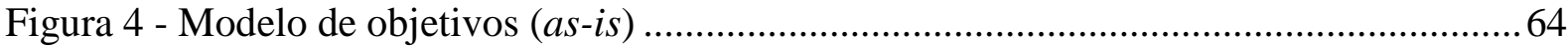

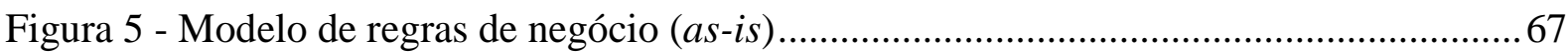

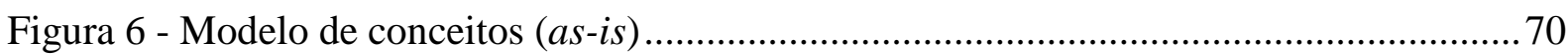

Figura 7 - Modelo de processo de negócio 1 (as-is) .................................................................. 72

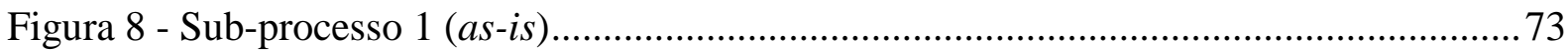

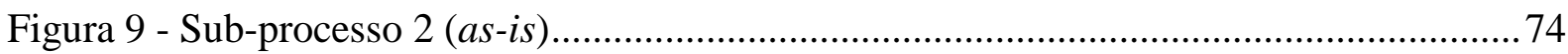

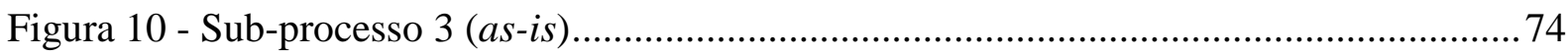

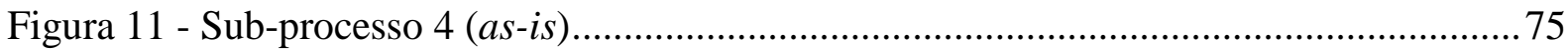

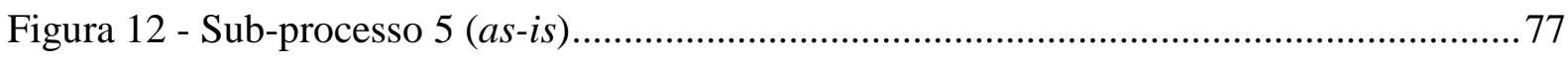

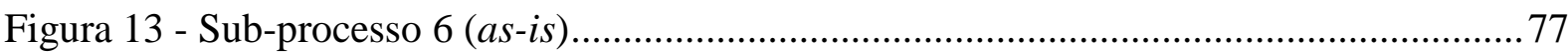

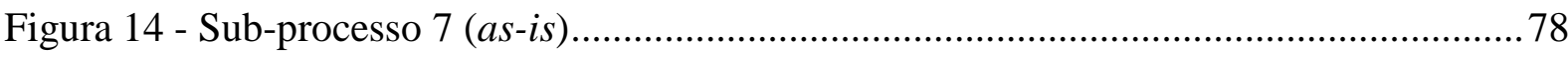

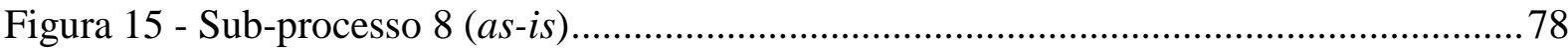

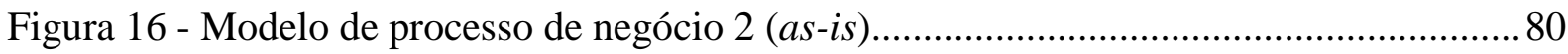

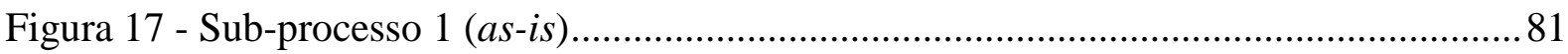

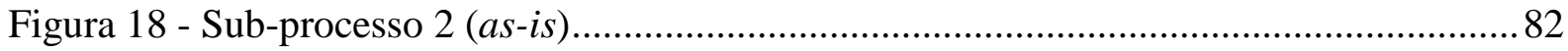

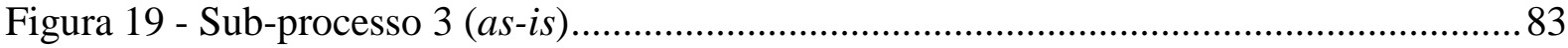

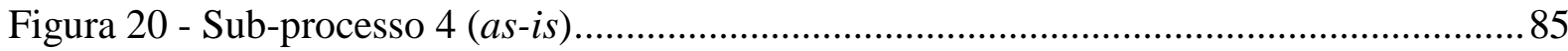

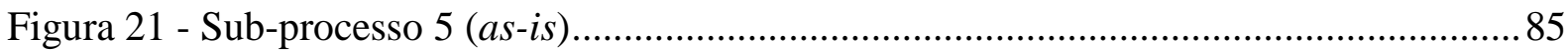

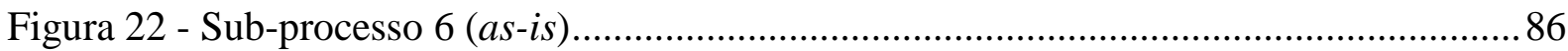

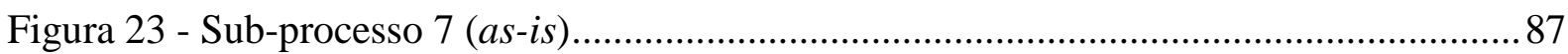

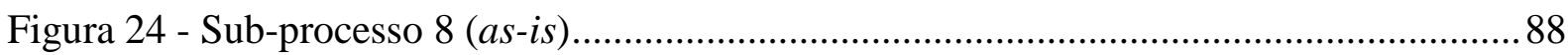




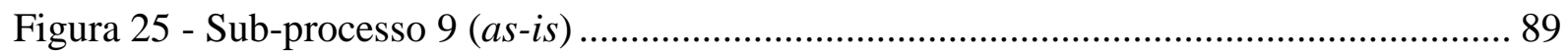

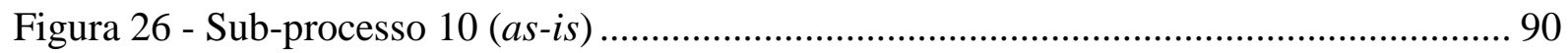

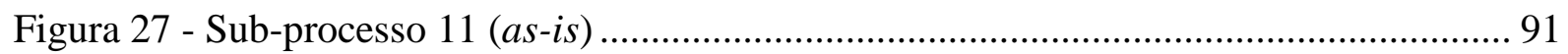

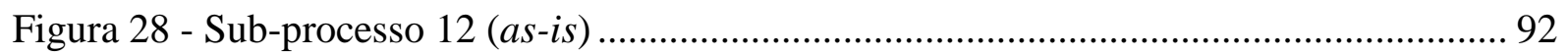

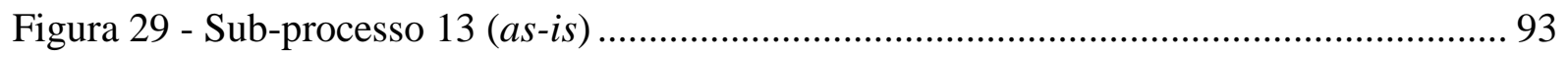

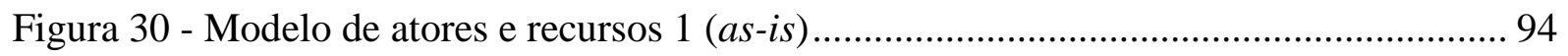

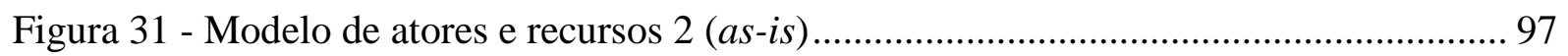

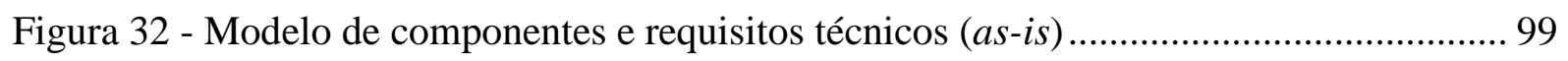

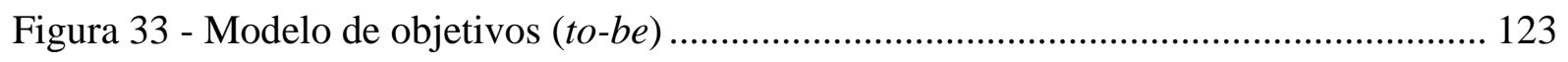

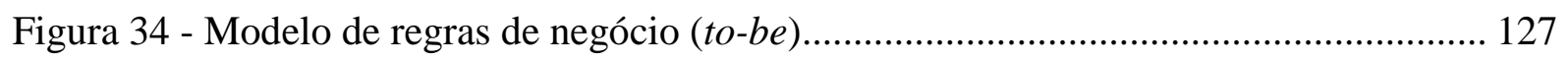

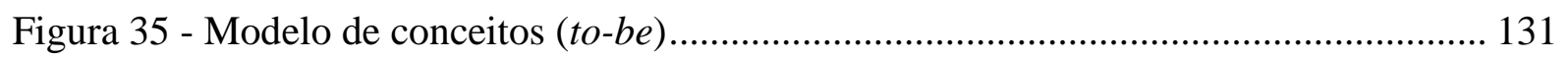

Figura 36 - Modelo de processo de negócio 1 (to-be) ......................................................... 133

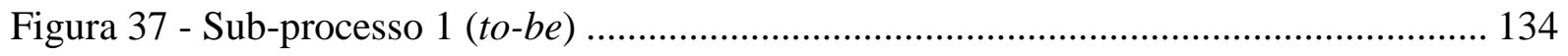

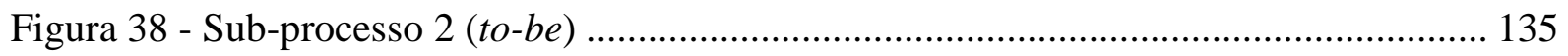

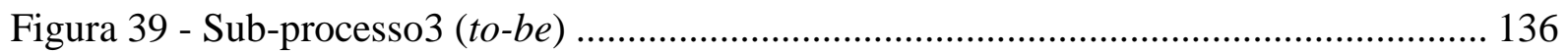

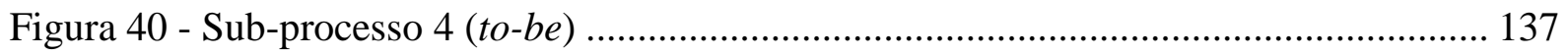

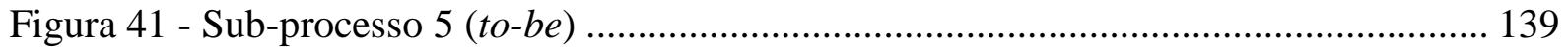

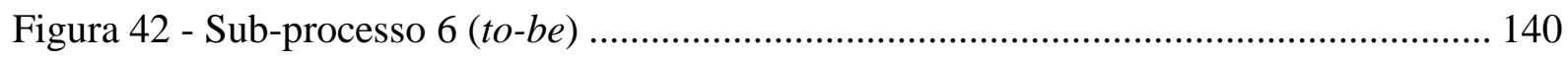

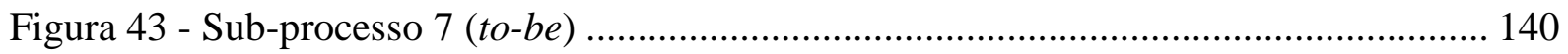

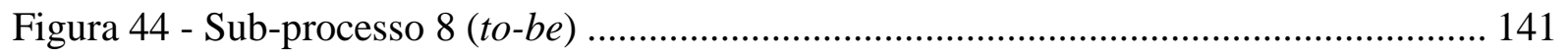

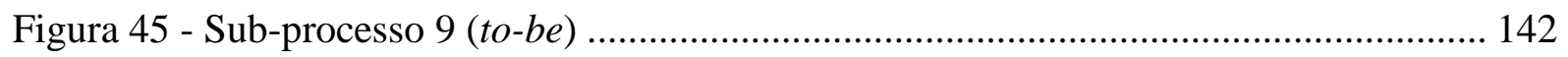

Figura 46 - Modelo de processo de negócio 2 (to-be) ......................................................... 144

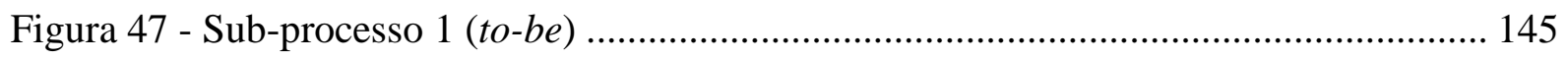

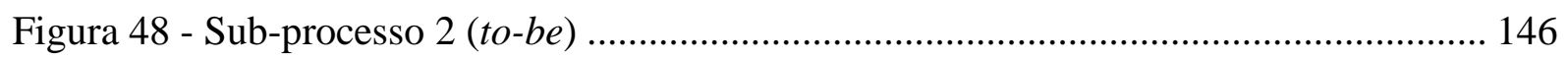

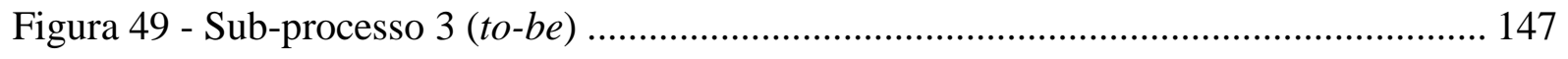

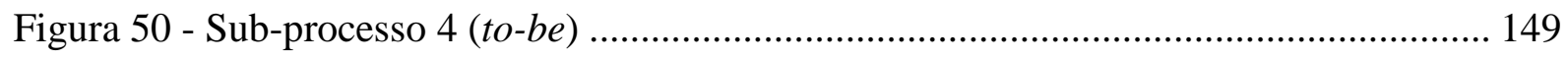




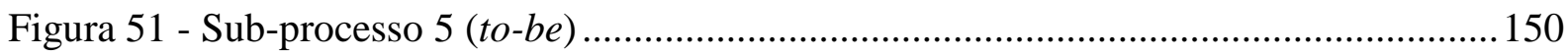

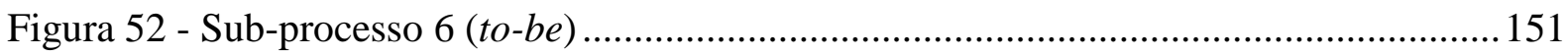

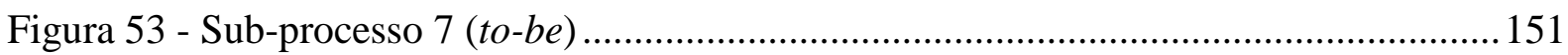

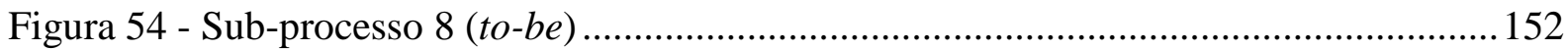

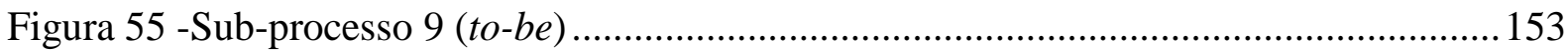

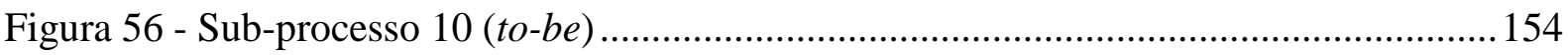

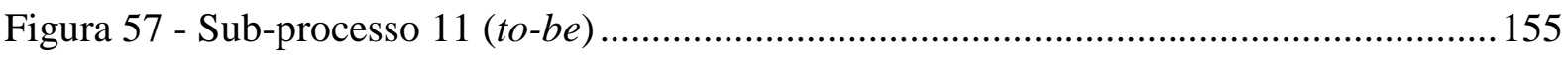

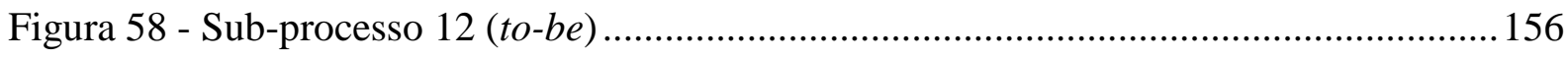

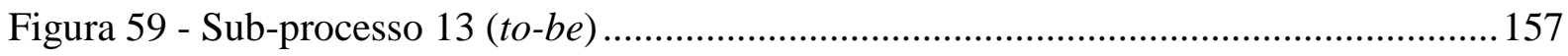

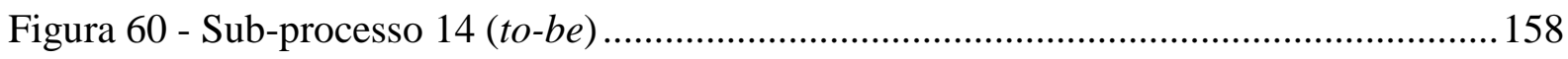

Figura 61 - Modelo de atores e recursos 1 (to-be) ............................................................ 160

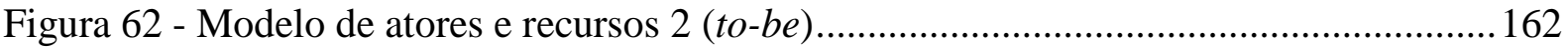

Figura 63 - Modelo de componentes e requisitos técnicos (to-be) ....................................... 164 



\section{LISTA DE QUADROS}

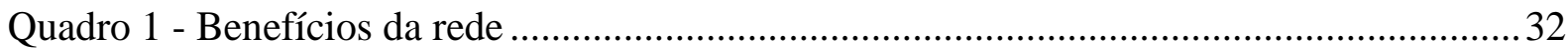

Quadro 2 - Barreiras à transferência de tecnologia ................................................................. 37

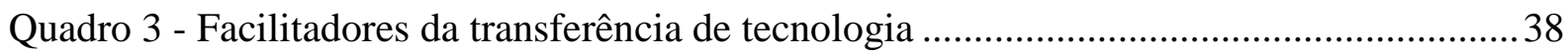

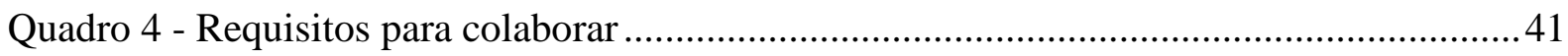

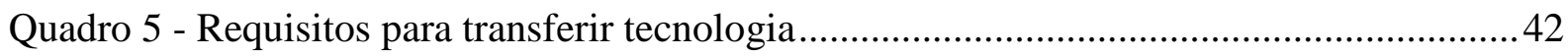

Quadro 6 - Classificação das metodologias de modelagem ..................................................53

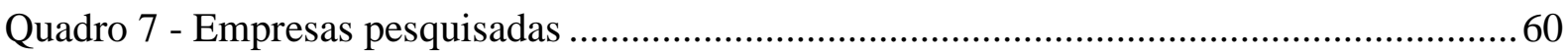

Quadro 8 - Componentes do protocolo de pesquisa ...........................................................61

Quadro 9 - Variáveis relacionadas à colaboração .............................................................. 102

Quadro 10 - Varáveis relacionadas à transferência de tecnologia....................................... 104

Quadro 11 - Variáveis relacionadas à transferência .......................................................... 106

Quadro 12 - Variáveis relacionadas à colaboração ........................................................... 107

Quadro 13 - Conceitos referentes ao modelo “As-Is" ........................................................... 109

Quadro 14 - Conceitos referentes ao modelo "need for change" ........................................... 112

Quadro 15 - Modelo de processo de transferência de tecnologia 1 ....................................... 113

Quadro 16 - Modelo de processo de transferência de tecnologia 2 .......................................116

Quadro 17 - Modelo de processo de transferência de tecnologia 3 ....................................116

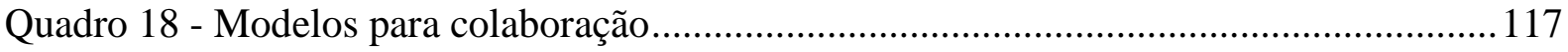

Quadro 19 - Variáveis relacionadas ao modelo de atores e recursos ...................................118

Quadro 20 - Variáveis relacionadas ao modelo de componentes e requisitos técnicos ..........120 



\section{LISTA DE ABREVIATURAS E SIGLAS}

ARIS - Architecture of Integrated Information Systems

BOM - Bill of material

CIMOSA - Computer Integrated Manufacturing Open System Architecture

CRM - Customer Relationship Management

EKD - Enterprise Knowledge Development

IPI - Imposto sobre Produtos Industrializados

OCDE - Organização para a Cooperação e Desenvolvimento Econômico

ParqTec - Parque Tecnológico

PERA - Purdue Enterprise Reference Architecture

PEST - Político, Econômico, Social e Tecnológico

PMEs - Pequenas e Médias Empresas

P\&D - Pesquisa e Desenvolvimento

SSCs - Sistemas, Subsistemas e Componentes

TT - Transferência de Tecnologia 



\section{SUMÁRIO}

1. INTRODUÇÃ

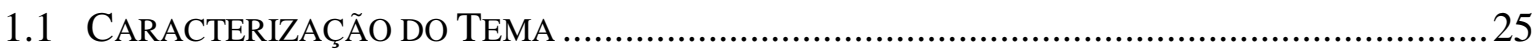

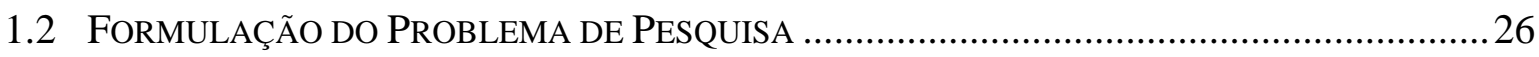

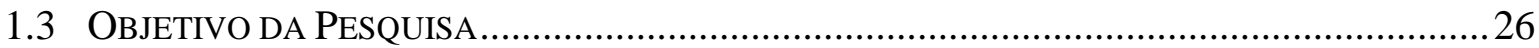

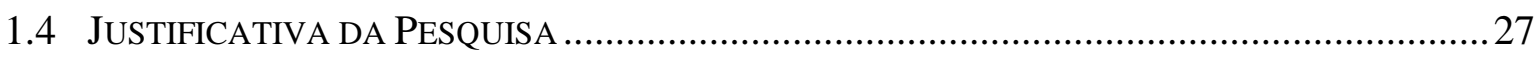

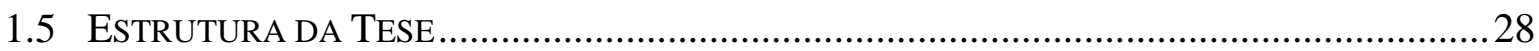

\section{REDES COLABORATIVAS NA TRANSFERÊNCIA TECNOLOGIA-PRODUTO31}

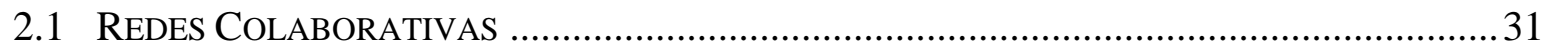

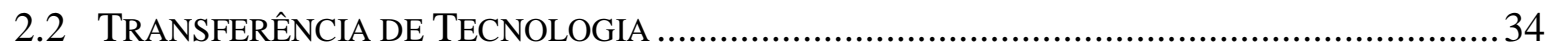

2.2.1 Conceitos de Transferência Tecnologia-Produto................................................... 35

2.2.2 Barreiras e facilitadores relacionados à transferência de tecnologia...................37

2.3 A CONTRIBUIÇÃO DAS REDES COLABORATIVAS PARA A TRANSFERÊNCIA TECNOLOGIA-

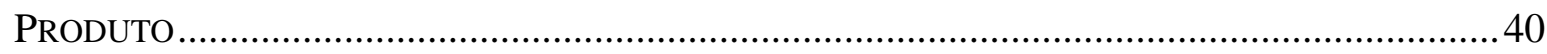

2.4 RECOMENDAÇÕES DA LITERATURA PARA TRANSFERIR TECNOLOGIA SOB A PERSPECTIVA

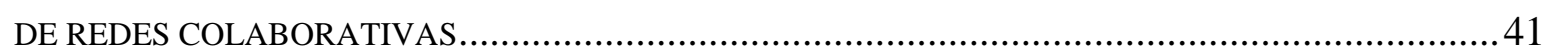

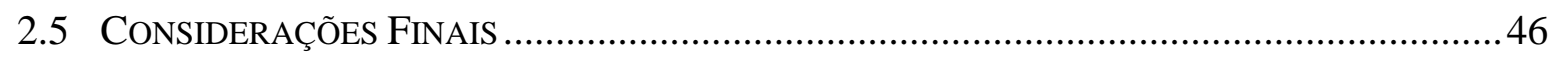

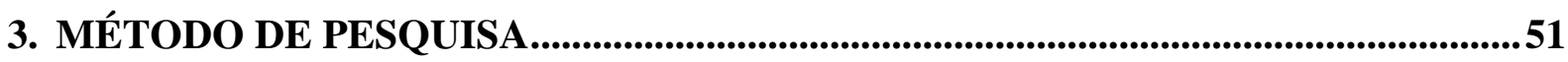

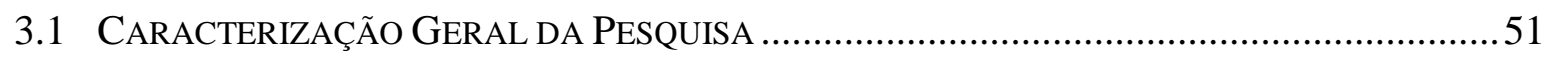

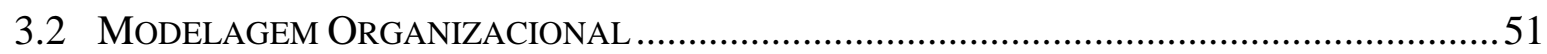

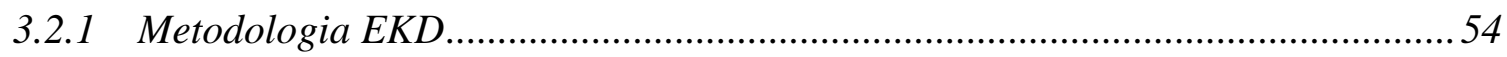

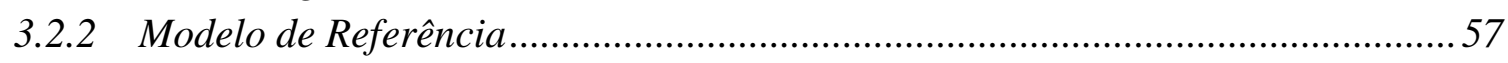

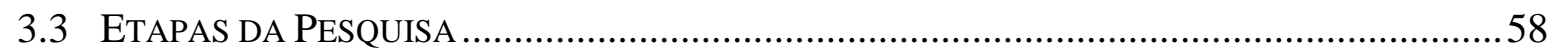

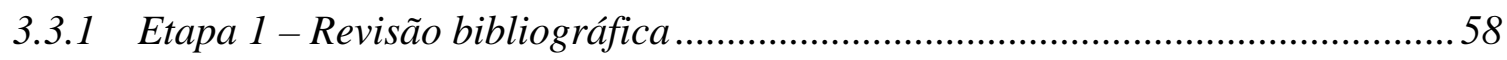

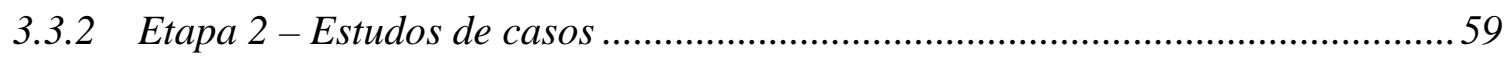

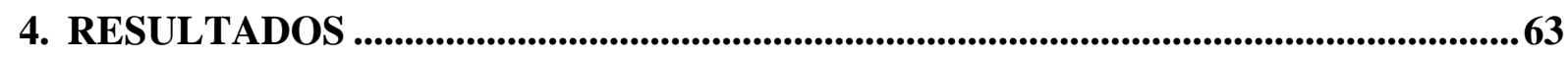

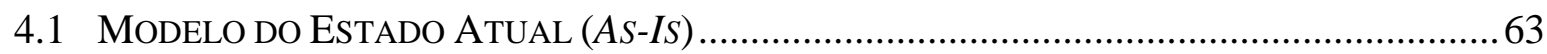

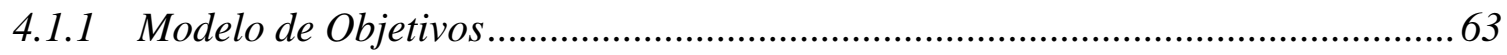

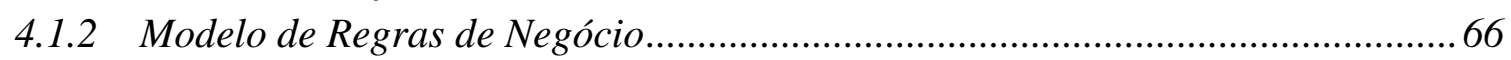

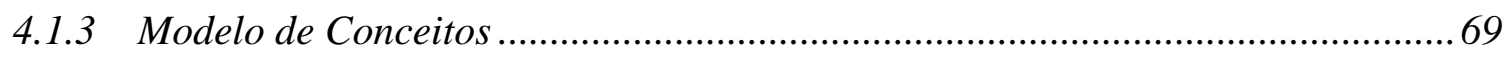

4.1.4 Modelo de Processo de Negócio a Partir do Desenvolvimento da Tecnologia ... 71

4.1.5 Modelo de Processo de Negócio a Partir da Necessidade do Cliente .................. 79

4.1.6 Modelo de Atores e Recursos: Relação entre Empresa e Cliente ......................... 93

4.1.7 Modelo de Atores e Recursos: Relação entre Empresa e Universidade ............... 96

4.1.8 Modelo de Componentes e Requisitos Técnicos..................................................... 98

4.2 ANALISANDO A NECESSIDADE PARA MUdANÇA (NEED FOR CHANGE) ......................... 101

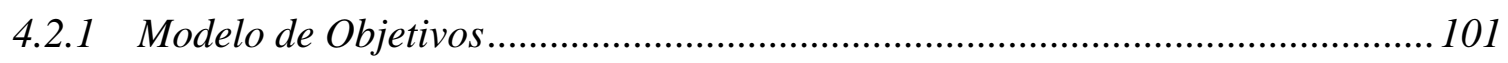

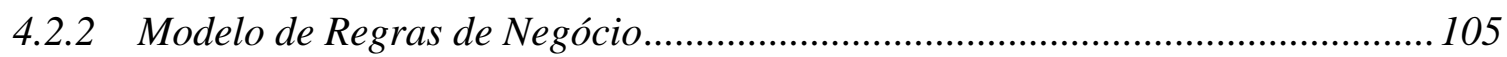

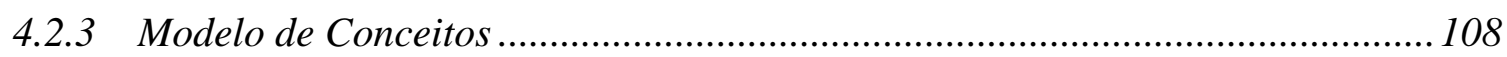

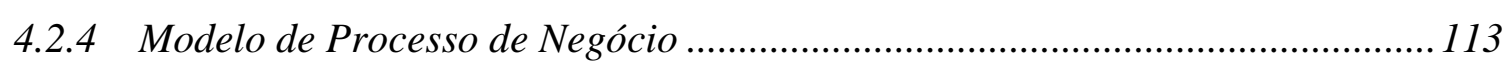




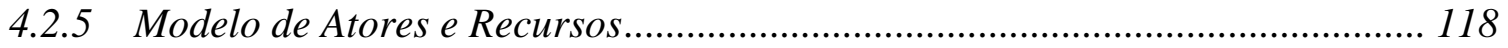

4.2.6 Modelo de Componentes e Requisitos Técnicos ............................................... 119

4.3 Modelo Proposto Pela Pesquisa (Estado Futuro ou To-BE) ........................... 122

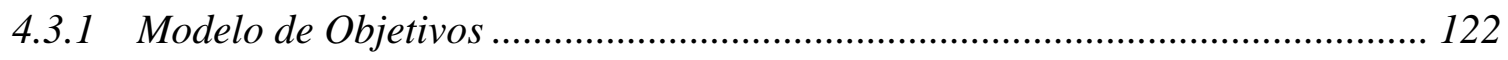

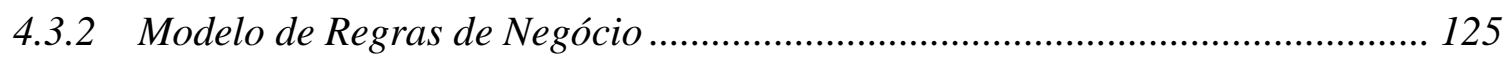

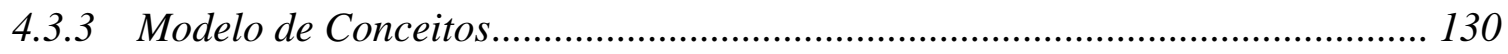

4.3.4 Modelo de Processo de Negócio a Partir do Desenvolvimento de Pesquisas... 132

4.3.5 Modelo de Processo de Negócio a Partir da Necessidade do Cliente................. 143

4.3.6 Modelo de Atores e Recursos: Relação entre Empresa e Cliente....................... 159

4.3.7 Modelo de Atores e Recursos: Relação entre Empresa e Universidade............. 161

4.3.8 Modelo de Componentes e Requisitos Técnicos ................................................ 163

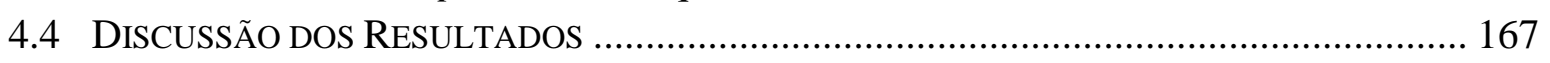

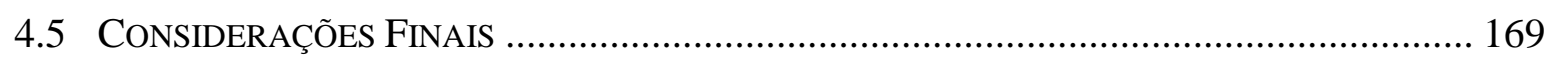

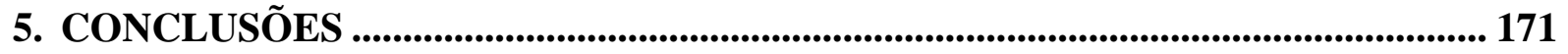

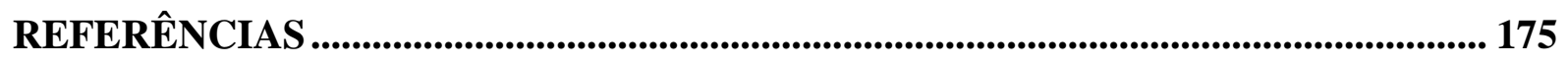

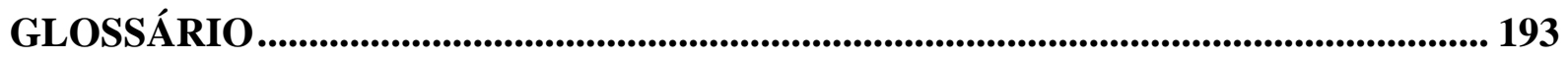

APÊNDICE A - ROTEIRO DE ENTREVISTAS ................................................... 195 


\section{INTRODUÇÃO}

O aumento da complexidade e do custo de desenvolvimento de produtos inovadores, os avanços das novas tecnologias e a necessidade de constantes inovações são fatores que influenciam a competitividade das organizações. Esse cenário exige que as empresas, principalmente de alta tecnologia, tenham capacidade de desenvolver novas tecnologias com menor custo e tempo de lançamento do produto (time-to-market), o que demanda competências e conhecimentos específicos que a empresa não possui.

Autores clássicos da área de desenvolvimento de produtos (CLARK; FUJIMOTO, 1991; CLARK; WHEELWRIGHT, 1993) destacam que uma alternativa para isso é a busca desses conhecimentos em fontes externas à empresa. Segundo Stock e Tatikonda (2000), aquisições eficazes e utilização de novas tecnologias de uma fonte externa podem contribuir para o sucesso operacional de uma empresa, pois a exigência de capacidade para desenvolver inovações faz com que a opção de formar todas as competências necessárias dentro da empresa seja menos viável.

Como decorrência desse contexto, está o processo de transferência tecnologiaproduto, definida por Tatikonda e Stock (2003), como a integração cuidadosa de tecnologias advindas de fontes externas em novos produtos. A transferência de tecnologia (TT) é um meio para as empresas minimizarem as dificuldades, melhorando sua produtividade, adaptabilidade e eficiência em suas alianças, expansão de mercado e sustentação da vantagem competitiva (CUI et al., 2006). Entretanto, incorporar tecnologias em diferentes produtos é uma atividade crítica, pois afeta o desenvolvimento do projeto em termos de qualidade do produto, o leadtime, atraso para disponibilizar o produto no mercado (IANSITI, 1998; NOBELIUS, 2004).

A transferência de tecnologia é essencial, principalmente quando se trata de pequenas e médias empresas (PMEs) se comparado com grandes empresas, pois as PMEs possuem recursos humanos e financeiros escassos, competência gerencial limitada (DE TONI; NASSIMBENI, 2003; O'REGAN; SIMS, 2008), dificultando antecipar-se às necessidades do mercado.

As pequenas e médias empresas tendem a manter internamente um grupo pequeno de competências tecnológicas e geralmente são capazes de alavancar seus limitados recursos de pesquisa e desenvolvimento (P\&D) de modo eficiente, seu êxito pode ser devido à sua capacidade de utilizar redes externas de forma mais eficiente (NOOTEBOOM, 1994). De acordo com Narula (2004), essas empresas usam quase o dobro dos gastos em P\&D com a colaboração do que as grandes empresas. Porém, existem limites sobre o que as PMEs podem 
fazer e quanto podem utilizar de recursos de P\&D externo, pois elas precisam manter um nível de limiar mínimo de capacidade interna. No entanto, as PMEs mais bem sucedidas têm sido capazes de manter sua posição competitiva através da utilização mais inteligente de P\&D externo. Mesmo que os custos sejam reduzidos através do uso de meios não-internos, eles permanecem não-triviais e, portanto, as restrições devido aos limites absolutos sobre os recursos permanecem.

Desse modo, as redes colaborativas representam uma solução interorganizacional para a inovação de produtos e serviços, pois permite a aprendizagem entre empresas por estimular e apoiar a difusão de um novo know-how e permitir a exploração de complementaridade em decorrência da fusão de diferentes competências tecnológicas (PYKA; KÜPPERS, 2002). Outros motivos estratégicos que levam a cooperação tecnológica são a redução do tempo de inovação, o acesso ao mercado e a influência da estrutura do mercado (HAGEDOORN, 1993).

As redes representam uma resposta complementar para a insegurança no desenvolvimento e uso de novas tecnologias, podendo reduzir as incertezas tecnológicas nas PMEs (DIEZ, 2002). Hewitt-Dundas (2006) destacam que elas podem proporcionar as PMEs estímulo e capacidade para inovar, enquanto a sua falta tem um efeito negativo sobre a probabilidade da inovação. Outros estudos como o de Doloreux (2004) e Fukugawa (2006) destacam que a capacidade para sustentar as redes em diferentes escalas regionais é a chave para a inovação nas PMEs. Já Calia, Guerrini e Moura (2007) identificaram através de um estudo de caso no setor metalúrgico que uma pequena empresa pode estruturar seu departamento de $\mathrm{P} \& \mathrm{D}$ de fora para dentro, desde que recursos-chave como o conhecimento em P\&D e o know-how em um processo específico provenientes das redes de inovação tecnológicas com institutos de pesquisa sejam internalizados pela empresa ao longo de seu processo de inovação. Camarinha-Matos e Afsarmanesh (2008) identificaram que nas sociedades industriais compostas principalmente de PMEs, como é o caso europeu, o envolvimento em uma rede de colaboração não só representa um fator de sobrevivência, mas também uma vantagem competitiva em face de cenários de turbulência de mercados.

Assuntos relacionados à rede são encontrados principalmente em pesquisas que envolvem setores de alta tecnologia, pois utilizam tecnologias muitas vezes complementares que exigem a integração de várias capacidades e bases tecnológicas. Dowling e Helm (2006), por exemplo, estudaram a cooperação entre empresas de alta tecnologia da Alemanha e verificaram que novas empresas buscam a cooperação para aumentar as chances de sucesso 
do produto no mercado enquanto que empresas experientes buscam parcerias com institutos de pesquisa para ter acesso à novas tecnologias para desenvolver novos produtos.

Para que as empresas participantes de uma rede possam superar a complexidade e os avanços tecnológicos é necessário conhecer, integrar e aplicar o conhecimento e know-how de diferentes locais, seja nacional ou internacional, de tal forma que possibilite diversificar a capacidade de inovação ${ }^{1}$ (RYCROFT; KASH, 2004).

\subsection{Caracterização do Tema}

As redes colaborativas são um conjunto de diferentes organizações com diversas competências, mas com interesses em comum que juntas constituem um conjunto de habilidades e recursos por um período até que o objetivo em comum seja atingido e que fazem uso de tecnologias de informação e comunicação para coordenar e apoiar suas atividades (CHITUC; TOSCANO; AZEVEDO, 2008).

O tema sobre redes colaborativas tem sido discutido com freqüência pela literatura, entretanto, é uma área de pesquisa considerada aberta e que está sendo consolidada como uma nova disciplina (CAMARINHA-MATOS; AFSARMANESH, 2005; CAMARINHAMATOS, AFSARMANESH; 2008; CAMARINHA-MATOS, 2009). Nesse sentido, encontram-se desafios a serem superados.

Apesar de ser um campo do conhecimento em desenvolvimento, as redes colaborativas já são reconhecidas como um caminho para as empresas sobreviverem em ambientes dinâmicos, nos quais as tecnologias, sociedade e mercados estão em constantes mudanças. Essas redes têm sido vistas também como forma de criar valor, pois permitem desenvolver novas capacidades para lidar com as incertezas, necessidades de inovações, customização em massa e concorrência (CAMARINHA-MATOS, 2009).

As redes colaborativas são consideradas instrumentos importantes para o desenvolvimento e o sucesso de empresas empreendedoras, por ser uma fonte de vantagem competitiva, tendo em vista que os elos entre as empresas são considerados fatores de transferência de conhecimento e tecnologia que, portanto, apoiam processos inovadores (DOWLING; HELM, 2006; OCDE, 2005).

\footnotetext{
${ }^{1}$ Definição no glossário (página 193)
} 
As redes, dependendo de sua configuração, podem influenciar significativamente o desempenho da inovação de produto e da transferência de tecnologia (DEBRESSON; AMESSE, 1991; AHUJA, 2000; PYKA; KÜPPERS, 2002; BULLINGER; AUERNHAMMER; GOMERINGER, 2004; FUKUGAWA, 2006; NIETO; SANTAMARÍA, 2007; HALLIKAS; KÄRKKÄINEN; LAMPELA, 2009). Apesar de serem estudos importantes para comprovar a importância da rede, ainda existe a necessidade de pesquisas com abordagens qualitativas para compreender a interface entre esses assuntos. Desta forma, pesquisa tem como tema a contribuição das redes colaborativas para a transferência tecnologia-produto.

\subsection{Formulação do Problema de Pesquisa}

Estudos têm apresentado a importância e os benefícios das redes colaborativas para desenvolver produtos inovadores (EMDEN; CALANTONE; DROGE, 2006; WU, 2012; BÜYÜKÖZKAN; ARSENYAN, 2012). Outras pesquisas têm destacado a importância de transferir cuidadosamente as tecnologias oriundas de fontes externas no desenvolvimento de produto (TATIKONDA; STOCK, 2003; NOBELIUS, 2004; CORMICAN; O'CONNOR, 2009). Isto porque o processo de gerenciar a aquisição e a incorporação da tecnologia é uma atividade complexa que envolve diferentes atores, mercados, recursos, processos organizacionais, e atitudes referentes à cooperação (KARLSSON; TAYLOR; TAYLOR, 2010).

De modo geral, o que se sabe sobre transferência está relacionado às práticas de gestão (JUGEND; SILVA, 2012) e mecanismos de integração (KARLSSON; TAYLOR; TAYLOR, 2010). Porém, faltam estudos que apresentem como deve ser o processo de transferência tecnologia-produto, considerando aspectos de redes colaborativas. Diante dessa lacuna, a questão de pesquisa resume-se em:

Como organizar o processo de transferência tecnologia-produto sob o recorte analítico de redes colaborativas?

\subsection{Objetivo da Pesquisa}

O objetivo da pesquisa é desenvolver um modelo de referência para redes colaborativas para a transferência tecnologia-produto. $\mathrm{O}$ modelo é desenvolvido com o propósito de que empresas possam iniciar um processo colaborativo dentro de um contexto de estudo específico. As redes podem trazer conhecimentos tecnológicos para as empresas 
usuárias gerando inovações que irão contribuir com a habilidade dessas empresas em compreender, utilizar, adaptar e aprimorar a tecnologia recebida e a sua efetiva incorporação em um novo produto.

Este objetivo é desdobrado nos seguintes objetivos secundários:

- Identificar empiricamente como ocorre o processo de transferência tecnologiaproduto e quais as práticas de redes colaborativas podem contribuir nesse processo;

- Desenvolver um modelo com o propósito de orientar as empresas a conduzir a colaboração no processo de transferência tecnologia-produto.

\subsection{Justificativa da Pesquisa}

As pequenas e médias empresas de alta tecnologia têm sido consideradas importantes para o desenvolvimento tecnológico e econômico, assim como para a revitalização de regiões periféricas (HEYDEBRECK; KLOFSTEN; MAIER, 2000; FONTES; COOMBS, 2001; GRINSTEIN; GOLDMAN, 2006). Essas empresas são conhecidas por investir, desenvolver ou utilizar tecnologias em partes do seu desenvolvimento de produto e produção, sendo seus produtos muitas vezes considerados complexos e que demanda diferentes conhecimentos (NORMAN, 2002; PARK, 2005; WU, 2012).

Pensar em PMEs de alta tecnologia parece ser um paradoxo, tendo em vista que elas têm um papel central no desenvolvimento da tecnologia, mas que em decorrência do porte, elas apresentam algumas carências como, por exemplo, a falta de recursos (PARTANEN et al., 2008). Pelo fato de apresentar essas características, estudos sugerem que essas empresas se alinhem a outras para complementar recursos e aumentar suas fontes de conhecimento (DOLOREUX, 2004; HEWITT-DUNDAS, 2006; FUKUGAWA, 2006; NORMAN, 2002; LÖFSTEN; LINDELÖF, 2005; HSU, 2005; ALBORS; SWEENEY; HIDALGO, 2005; COLOMBO; GRILLI; PIVA, 2006; FARIA; LIMA; SANTOS, 2010; WU, 2012).

Nesse sentido, as redes colaborativas direcionadas à inovação promovem o desenvolvimento tecnológico por meio da criação, geração e difusão de conhecimento, apoia o aprendizado entre empresas, permite compartilhar diversas competências tecnológicas, possibilita a complementaridade entre diversos campos de conhecimento (PYKA; KÜPPERS, 2002), permitindo que as empresas transfiram conhecimento e tecnologia que não estariam aptas para desenvolver (OCDE, 2005).

A transferência não é uma tarefa fácil em decorrência dos riscos e problemas que podem surgir ao longo do desenvolvimento do produto, além do que pode comprometer o 
tempo de lançamento no mercado, gerar custos excessivos e problemas de funcionalidade (IANSITI, 1998; NOBELIUS, 2004). Durante todo o processo de transferência é necessário que exista alto nível de interação entre os envolvidos em termos de comunicação, coordenação e cooperação (TATIKONDA; STOCK, 2003).

Há na literatura algumas propostas de modelos para transferência tecnologia-produto, como por exemplo, Jagoda, Maheshwari e Lonseth (2010); Lane (2009); Cormican e O'Connor (2009) e outros modelos direcionados para parcerias como Chesbrough (2007) e Emden, Calantone e Droge (2006). Esses modelos não relacionam a colaboração e a transferência tecnologia-produto, não ficando clara a interface entre eles. Os modelos referentes a cada um desses assuntos serão apresentados no Capítulo 2.

Portanto, essa tese é original por proporcionar uma visão sistêmica do processo de transferência tecnologia-produto e sua relação com as redes colaborativas. Essa visão é constituída dos seguintes itens: objetivos e regras do negócio, relação entre conceitos que permeiam a transferência e a colaboração, o processo de transferência por meio das redes colaborativas, os atores e recursos envolvidos nesse processo, além dos componentes e requisitos para um sistema de informação que apoia esse processo.

\subsection{Estrutura da Tese}

No Capítulo 1 são apresentados o contexto, os objetivos e a justificativa do trabalho. Neste capítulo é discutida a importância do processo de transferência de tecnologia para as empresas, principalmente as de pequeno e médio porte, além de abordar como as redes de inovação podem contribuir para este processo.

O Capítulo 2 refere-se à fundamentação teórica do trabalho que está dividida em quatro subseções. A primeira aborda as redes colaborativas, na qual são apresentados os conceitos, motivações, benefícios. A segunda subseção refere-se à transferência de tecnologia que aborda conceitos, barreiras e facilitadores. A terceira trata a contribuição das redes para a transferência da tecnologia. Na quarta subseção tem-se as considerações sobre a literatura.

No Capítulo 3 é descrito o método de pesquisa, no qual é subdividido em caracterização, modelagem e etapas da pesquisa.

O Capítulo 4 apresenta os resultados da pesquisa baseado em três etapas. A primeira aborda o estado atual das empresas que é uma compilação dos modelos das sete empresas. A segunda é a análise da necessidade da mudança, na qual se compara os dados empíricos com o 
teórico. A terceira é o modelo proposto por esta pesquisa. Posteriormente, são apresentadas as considerações finais referentes a este capítulo.

Por fim, o Capítulo 5 apresenta as conclusões da pesquisa, ou seja, as contribuições, limitações e sugestões de pesquisas futuras. 


\section{REDES COLABORATIVAS NA TRANSFERÊNCIA TECNOLOGIA-PRODUTO}

O objetivo desse capítulo é apresentar uma base teórica que apoia e fundamenta o desenvolvimento desta pesquisa, buscando compreender o relacionamento entre duas áreas de pesquisa: redes principalmente as colaborativas e a transferência de tecnologia.

Este capítulo divide-se em duas seções. A primeira aborda o assunto de redes colaborativas, na qual apresentam conceitos, motivações e benefícios. A segunda seção refere-se à transferência de tecnologia, na qual expõe sobre conceitos, barreiras e facilitadores.

\subsection{Redes Colaborativas}

A colaboração é definida como um processo, no qual instituições compartilham informações, recursos e responsabilidades para planejar, implementar e avaliar atividades em conjunto para atingir um objetivo comum. A colaboração implica em confiança, esforço e dedicação (CAMARINHA-MATOS; AFSARMANESH, 2006; CAMARINHA-MATOS et al., 2009). Além disso, é importante manter uma interação próxima e compreensiva para facilitar a troca de informação de conhecimento tácito, para criar competências tecnológicas e solucionar problemas de recursos e capacidades nem sempre disponíveis na empresa (SIU; BAO, 2008; TSAI, 2009).

Uma rede colaborativa é uma aliança constituída por diversas entidades que são autônomas, distribuídas geograficamente e heterogêneas no que se refere ao ambiente operacional, cultura, objetivos e capital social, mas que compartilham informação, recursos e responsabilidades para planejar, implementar e avaliar juntamente as atividades para atingir objetivos comuns e compatíveis. (CAMARINHA-MATOS; AFSARMANESH, 2008; CAMARINHA-MATOS et al., 2009).

Por se tornarem um mecanismo de difusão da inovação, essas redes tornaram-se um novo modo de organização voltada para a produção do conhecimento, sendo importantes para o desenvolvimento da capacidade de inovação, para a competitividade internacional e a criação de riqueza (KÜPPERS; PYKA, 2002; RAMPERSAD; QUESTER; TROSHANI, 2010). Além disso, com a cooperação, coordenação e comunicação entre os membros da rede há uma redução do caos no processo de inovação que eleva a probabilidade de desenvolver uma inovação de sucesso (OJASALO, 2008).

Entre os motivos para uma rede colaborativas ser formada encontram-se: (a) ter maior acesso ao conhecimento externo; (b) aprender e difundir informações; (c) reduzir 
incertezas tecnológicas, de investimentos individuais e de riscos de desenvolvimento de um novo conhecimento; (d) explorar complementaridades e sinergia pela junção de diferentes competências; (e) obter escalas econômicas de produção; (f) reduzir a dificuldade de entrada no mercado; (g) reduzir o período de desenvolvimento e inovação de novos produtos; (DEBRESSON; AMESSE, 1991; CAMARINHA-MATOS; ABREU, 2007; TSAI, 2009; KÜPPERS; PYKA, 2002; TIDD; BESSANT; PAVITT, 2005; VAN AKEN; WEGGEMAN, 2000).

Além disso, as redes colaborativas proporcionam benefícios para os seus membros. Alguns desses benefícios estão reunidos no Quadro 1.

\begin{tabular}{|c|c|}
\hline Benefícios & Autores \\
\hline Compartilhar riscos ${ }^{2}$ & $\begin{array}{l}\text { Van Aken e Weggeman (2000); Bullinger, } \\
\text { Auernhammer e Gomeringer (2004); Camarinha-Matos } \\
\text { e Abreu (2007); Debresson e Amesse (1991) }\end{array}$ \\
\hline Aumentar recursos ${ }^{3}$ & $\begin{array}{l}\text { Van Aken e Weggeman (2000); Fukugawa (2006); } \\
\text { Fuller-Love e Thomas (2004); Bullinger, } \\
\text { Auernhammer e Gomeringer (2004); Camarinha-Matos } \\
\text { e Abreu (2007) }\end{array}$ \\
\hline Acessar conhecimento ${ }^{4}$ & $\begin{array}{l}\text { Van Aken e Weggeman (2000); Fukugawa (2006); } \\
\text { Bullinger, Auernhammer e Gomeringer (2004) }\end{array}$ \\
\hline Obter economia de escala ${ }^{5}$ & $\begin{array}{l}\text { Fuller-Love e Thomas (2004); Camarinha-Matos e } \\
\text { Abreu (2007); Mancinelli e Mazzanti (2009) }\end{array}$ \\
\hline Compartilhar habilidades $^{6}$ & $\begin{array}{l}\text { Fuller-Love e Thomas (2004); Camarinha-Matos e } \\
\text { Abreu (2007); Mancinelli e Mazzanti (2009) }\end{array}$ \\
\hline Compartilhar informação $^{7}$ & Fuller-Love e Thomas (2004) \\
\hline Compartilhar custos $^{8}$ & $\begin{array}{l}\text { Camarinha-Matos e Abreu (2007); Debresson e } \\
\text { Amesse (1991) }\end{array}$ \\
\hline Desenvolver produtos robustos ${ }^{9}$ & Camarinha-Matos e Abreu (2007) \\
\hline Reduzir incerteza tecnológica ${ }^{10}$ & $\begin{array}{l}\text { Debresson e Amesse (1991); Diez (2002); Kim et al. } \\
\text { (2010) }\end{array}$ \\
\hline
\end{tabular}

Quadro 1 - Benefícios da rede

Bullinger, Auernhammer e Gomeringer (2004) apresentaram pré-requisitos para ser bem sucedidos nas redes colaborativas direcionadas a inovação e obter os benefícios oferecidos por uma rede, sendo:

- Adaptar a forma atual de trabalhar com as necessidades da rede;

- Desenvolver competências adicionais;

- Alinhar estratégias diferentes dos parceiros da rede, criando uma visão comum de resolução de problema na rede;

2, 3, 4, 5, 6, 7, 8, 9, 10 Definições no glossário 
- Integrar clientes no desenvolvimento da rede de inovação;

- Identificar e explorar ideias sistematicamente em redes;

- Formar parceria com instituto de pesquisa para renovar permanentemente o conhecimento tecnológico;

- $\quad$ Adquirir competência em rede de acordo com as capacidades individuais dos parceiros.

As redes colaborativas direcionadas a inovação são freqüentes em setores intensivos em tecnologia, no qual predomina complexidade de conhecimento e alta incerteza (HAGEDOORN; SCHAKENRAAD，1992; KAUFMANN; TÖDTLING, 2002; KELLEY; NAKOSTEEN, 2005; WUYTS et al., 2005). Segundo Rikkiev e Mäkinen (2009), durante as últimas quatro décadas houve uma tendência crescente no número de colaborações de $\mathrm{P} \& \mathrm{D}$ nesses setores, pois desenvolver inovações e novos produtos é crucial para a sobrevivência de empresas de alta tecnologia.

Além disso, recentes pesquisas vêm inserindo o tema redes colaborativas direcionadas a inovação no contexto das pequenas e médias empresas (PMEs), destacando a sua importância para esse tipo de empresas (DOLOREUX, 2004; ALBORS; SWEENEY; HIDALGO, 2005; FUKUGAWA, 2006; HEWITT-DUNDAS, 2006). Albors, Sweeney e Hidalgo (2005) e Street e Cameron (2007) destacaram que essas redes oferecem vantagens claras para as PMEs, tais como o compartilhamento de habilidades na transferência de tecnologia, conhecimentos tecnológicos, know-how, as questões regulamentares, organização e gestão, romper com a restrição de recursos e a limitação da capacidade de inovação entre outras.

Segundo Chesbrough (2003), as empresas estão cada vez mais dependentes de fontes externas para inovar, enfatizando as ideias, recursos e pessoas que estão dentro e fora das Organizações, que estão se tornando indispensável para a criação de uma inovação de sucesso para as PMEs. Quanto mais as empresas se engajarem em diferentes colaborações interorganizacionais, maiores são as chances de criar ou melhorar produtos que são comercialmente de sucesso (FAEMS; LOOY; DEBACKERE , 2005).

Nieto e Santamaría (2007), Zeng, Xie e Tam (2010) identificaram existir importantes relações entre a cooperação inter-firma, a cooperação com instituições intermediárias, a cooperação com organizações de pesquisa e o desempenho da inovação das PMEs. Para Zeng, Xie e Tam (2010) a cooperação inter-empresa tem o maior impacto na capacidade de inovação das PMEs. A cooperação vertical e horizontal com clientes, fornecedores e outras 
empresas desempenham um papel mais distinto no processo de inovação das PMEs que a cooperação horizontal com instituições de pesquisa, universidades ou faculdades, e agências governamentais.

Segundo Luukkonen (2001), em geral, as redes verticais (acordos com fornecedores, distruibuidores, clientes) ou mistas ${ }^{11}$ são mais frequentes do que as horizontais (acordos com competidores). De acordo com o autor, existem algumas diferenças entre as redes de PMEs e de grandes empresas, embora as diferenças não foram significativas estatisticamente. As PMEs têm uma proporção um pouco maior de redes puramente vertical e horizontal do que as grandes empresas, enquanto esta última teve mais rede do tipo mista com complexas estruturas de participante.

A colaboração com fornecedores auxilia a empresa a identificar potenciais problemas técnicos melhorando o tempo de desenvolvimento do novo produto (TSAI, 2009), pode estimular a criatividade, evitar falhas na concepção antes da produção, e mudanças de engenharia podem ser reduzidas (WANG; YEUNG; ZHANG, 2011). Já a colaboração com clientes provê beneficios quanto a identificação de oportunidadesde mercado, ter novas idéias sobre soluções, e identificar tendências antecipadamente (TSAI, 2009).

Ahuja (2000) pesquisou como as estruturas do relacionamento ${ }^{12}$ em redes de cooperação influenciam na inovação mensurada por meio do número de patentes da indústria química. $\mathrm{O}$ autor identificou que as relações diretas são apropriadas para obtenção de recursos e intercâmbio de conhecimento, enquanto as relações indiretas são adequadas para o acesso rápido a informações específicas.

Como pôde-se notar, os estudos estão mostrando a importância das redes colaborativas para o desenvolvimento da inovação, portanto, saber criar e gerenciar parceiros pode influenciar positivamente a organização. Quando se pensa em colaboração, outras habilidades também se tornam críticas como é o caso de ter capacidade para transferir e absorver tecnologias, entretanto, são assuntos tratados na próxima seção.

\subsection{Transferência de Tecnologia}

Nesta seção serão abordados os conceitos referentes ao termo tecnologia, posteriormente é apresentado o termo tecnologia-produto e o conceito de transferência. Além disso, são apresentadas as barreiras e facilitadores para transferir tecnologia.

\footnotetext{
11, 12 Definições no glossário
} 


\subsubsection{Conceitos de Transferência Tecnologia-Produto}

Um importante conceito a ser apresentado inicialmente é o termo "tecnologia", tendo em vista que este é utilizado por diversas áreas do conhecimento, possuindo, portanto, diferentes significados, ocasionando confusões (FREDDI, 2009). De modo geral, a tecnologia é considerada como algo tangível, ou seja, máquinas, equipamentos e intangível como habilidades e conhecimentos (DODGSON, 2000; BURGELMAN; MAIDIQUE; WHEELWRIGHT, 2001).

Outras definições englobam aspectos adicionais como é o caso de Schon (1967) e Abetti (1989) que definem a tecnologia como corpo de conhecimentos, ferramentas e técnicas, qualquer produto ou processo, qualquer equipamento físico ou método de ação ou criação decorrentes da ciência ou experiência prática, os quais são utilizados no desenvolvimento, projeto, produção e aplicação de produtos, processos, sistemas e serviços.

Neste trabalho, adota-se o conceito apresentado por Bohn (1994), Phaal, Farrukh e Probert, (2004) e Kaplan e Tripsas (2008) que consideram tecnologia como um conhecimento técnico ou know-how que pode ser aplicado em um artefato físico, melhorando a habilidade da empresa em oferecer produtos e serviços.

O termo tecnologia-produto é definido por Wickramasinghe e Garusinghe (2010) como uma tecnologia associada com o projeto, uso ou manutenção de um produto e o desenvolvimento de capacidades de gestão organizacional necessários para alavancar a otimização da tecnologia. Enquanto Osman-Gani e Jacobs (2005) consideram como ideias incorporadas em um objeto concreto. Tatikonda e Stock (2003) definem que o termo tecnologia-produto é a integração de tecnologias advindas de fontes externas em novos produtos.

O processo de gerenciar a aquisição, movimentação e incorporação da tecnologia entre entidades denomina-se transferência de tecnologia (TROTT, 2005; WICKRAMASINGHE; GARUSINGHE, 2010). Essas entidades podem ser países, empresas, ou mesmo indivíduos dependendo do ponto de vista da pesquisa (AUTIO; LAAMANEN, 1995). Cohen (2004) utiliza a mesma concepção para o termo transferência, porém considerando que a mesma ocorra dentro de uma empresa entre departamentos diferentes como, por exemplo, do laboratório para a manufatura.

Lane (2003) define a transferência de tecnologia como uma nova aplicação de uma tecnologia existente ou protótipos desenvolvidos por membros de múltiplos stakeholders, operando em instalações de pesquisa e desenvolvimento e visualizando coletivamente a 
transferência como uma opção viável para comercializar uma inovação ou atender necessidades por meio da combinação sinérgica de recursos. Como o próprio autor menciona essa definição contempla o que será transferido, quem está envolvido, onde ocorre, quando, por que e como.

Baseado nesses estudos considera-se para fins desta pesquisa a definição de transferência tecnologia-produto como um processo de gerenciar a aquisição, movimentação e incorporação de artefatos tangíveis e intangíveis vindos de fontes externas a uma determinada organização em produtos, visando comercializar uma inovação ou atender necessidades por meio da combinação sinérgica de recursos.

Para os produtos de alta tecnologia, essa transferência envolve toda uma gama de conhecimentos tecnológicos, de base científica para processos específicos, de conhecimentos e competências, através de um processo interativo em que os diferentes participantes especializados absorvem, assimilam, emitem e trocam conhecimentos em um contexto físico ou social (AUTIO; LAAMANEN, 1995; ROGERS, 2002; AUTIO; HAMERI; VUOLA, 2004). Hardy, Phillips e Lawrence (2003) e Aragon-Correa, Garcia-Morales e Cordo'n-Pozo, (2007) destacam que esse processo interativo não somente transfere o conhecimento existente entre as organizações, como também facilita a criação de novos conhecimentos e soluções de produto.

O processo de transferência de tecnologia geralmente ocorre entre uma organização de Pesquisa e Desenvolvimento (P\&D), que desenvolve a tecnologia por possuir conhecimentos técnicos especializados, e uma organização receptora, que muitas vezes não possuem, ou não podem ou não querem criar tecnologias, acabam aplicando a tecnologia desenvolvida por outras empresas, comercializando-a em um produto ou serviço que é vendido no mercado (ROGERS et al., 1998; STOCK; TATIKONDA, 2000; ROGERS; TAKEGAMI; YIN, 2001; BURATTI ; PENCO, 2001; PÉREZ; SÁNCHEZ, 2003).

A incorporação de tecnologias em diferentes produtos no final do desenvolvimento tecnológico representa a interface do desenvolvimento tecnológico com o desenvolvimento de produtos (SCHULZ et al., 2000) e é considerada crítica, pois afeta de maneira considerável o escopo do projeto, lead-time, custo e a qualidade de um novo produto (NOBELIUS, 2004).

No entanto, Tatikonda e Stock (2003) destacam que essa incorporação pela empresa usuária é difícil de ser realizada, em decorrência de imprevistos e riscos inerentes ao processo, trazendo diversos problemas para o desenvolvimento de produtos como custos excedentes, problemas de funcionalidades técnicas e atrasos no lançamento de produtos no mercado (IANSITI, 1998). Segundo Tatikonda e Stock (2003), isso ocorre pela incerteza tecnológica 
inerente à tecnologia recebida pela empresa usuária, e essa consiste na falta de conhecimento relacionado a como transferir e implementar uma tecnologia de interesse. Além disso, trata-se de uma atividade complexa que envolve interdependências e interações entre mercado e cliente, tecnologias e produtos, sistemas organizacionais e processos, estilos gerenciais e nível de envolvimento do empregado, e relacionamento fornecedor-receptor e suas respectivas atitudes para cooperação (KARLSSON; TAYLOR; TAYLOR, 2010).

\subsubsection{Barreiras e facilitadores relacionados à transferência de tecnologia}

Durante o processo de transferência de tecnologia, as empresas enfrentam diferentes barreiras que afetam o sucesso da transferência. Elas são compostas basicamente por três grupos: barreiras técnicas, regulatórias ou políticas, e pessoal ou institucional (GREINER; FRANZA, 2003). Estas barreiras estão detalhadas no Quadro 2.

\begin{tabular}{|c|c|c|}
\hline Barreiras & Tipos de barreiras & Autores \\
\hline \multirow{3}{*}{ Técnica } & Característica da tecnologia & $\begin{array}{l}\text { Leonard-Barton e Sinha (1993); Akhavan, Bagheri e } \\
\text { Jabbari (2008); Mostert e Buys (2008) }\end{array}$ \\
\hline & Natureza do conhecimento & $\begin{array}{l}\text { Simonin (1999); Tatikonda e Stock (2003); Pérez e } \\
\text { Sánchez (2003) }\end{array}$ \\
\hline & Risco & $\begin{array}{l}\text { Pérez e Sánchez (2003); Akhavan, Bagheri e Jabbari } \\
\text { (2008); Mostert e Buys (2008) }\end{array}$ \\
\hline \multirow{2}{*}{$\begin{array}{l}\text { Regulatória ou } \\
\text { política }\end{array}$} & $\begin{array}{l}\text { Falta de fundos; leis } \\
\text { governamentais }\end{array}$ & $\begin{array}{l}\text { Greiner e Franza (2003); Akhavan, Bagheri e Jabbari } \\
\text { (2008); Mostert e Buys (2008); Jasinski (2009) }\end{array}$ \\
\hline & Falta de recursos financeiros & Pérez e Sánchez (2003); Jasinski (2009) \\
\hline \multirow{7}{*}{$\begin{array}{l}\text { Pessoal ou } \\
\text { institucional }\end{array}$} & Falta de comunicação & $\begin{array}{l}\text { Cusumano e Elenkov (1994); Akhavan, Bagheri e } \\
\text { Jabbari (2008); Mostert e Buys (2008) }\end{array}$ \\
\hline & $\begin{array}{l}\text { Diferenças culturais e de } \\
\text { linguagem entre parceiros }\end{array}$ & $\begin{array}{l}\text { Mowery, Oxley e Silverman (1996); Lin e Berg } \\
\text { (2001); Akhavan, Bagheri e Jabbari (2008) }\end{array}$ \\
\hline & Falta de confiança & $\begin{array}{l}\text { Pinheiro, Leite e Castro (2003); Pérez e Sánchez } \\
\text { (2003); Mostert e Buys (2008) }\end{array}$ \\
\hline & Transferência de experiência & $\begin{array}{l}\text { Pinheiro, Leite e Castro (2003); Lin e Berg (2001); } \\
\text { Mostert e Buys (2008) }\end{array}$ \\
\hline & Falta de informação & Pérez e Sánchez (2003); Mostert e Buys (2008) \\
\hline & Falta de infraestrutura & Akhavan, Bagheri e Jabbari (2008) \\
\hline & Falta de pessoal e habilidade & Jasinski (2009) \\
\hline
\end{tabular}

Quadro 2 - Barreiras à transferência de tecnologia

Estudos anteriores de Bennett, Vaidya e Hongyu (1999) sobre projetos de transferência de tecnologia identificaram e detalharam as barreiras relacionadas a custos de transferência e operacionais, e riscos técnicos, de mercado e colaborativo que são particulares ao fornecedor e receptor, além daqueles que são comuns a ambos. 
De acordo com Saad, Cicmil e Greenwood (2002), as falhas nos projetos de transferência de tecnologia demonstram que um número significante de características (social, cultural, organizacional e econômico) pode tornar difícil, ou até mesmo impossível, a replicação de uma tecnologia previamente desenvolvida e utilizada por países desenvolvidos.

Para Rogers (2002) deve-se considerar: a) definir a unidade da estrutura organizacional que será responsável pela transferência da tecnologia; b) transferência de pessoal com o objetivo de transferir a tecnologia; c) formar redes entre organizações de P\&D e organizações receptoras; d) encorajar a formação de spin-offs de alta tecnologia; e) organizar conferências para criar diretrizes de prática sobre uma tecnologia.

Lee e Win (2004) relatam alguns benefícios que a transferência de tecnologia pode trazer para empresas e instituições de ensino e pesquisa, tais como: acesso as necessidades da economia, oportunidade de inserir os estudantes no mercado de trabalho, acesso a empresas de pesquisa básica e aplicada, melhoria na implementação da nova tecnologia, desenvolvimento de novos produtos e spin-offs, redução de custos, acesso as instalações físicas de universidades, ganho de conhecimento técnico, ganhos em serviços não disponíveis, novos mercados, melhoria da qualidade, redução do tempo de manufatura e lead time. Todos esses benefícios podem ser agrupados conforme a categorização de Bennett, Vaidya e Hongyu (1999) baseada em retorno financeiro, melhoria técnica e posicionamento estratégico.

Para que as barreiras na transferência sejam superadas, os benefícios sejam usufruídos pelas partes e o sucesso na transferência seja alcançado, faz-se necessário a utilização de alguns facilitadores que são apresentados no Quadro 3.

\begin{tabular}{|l|l|}
\hline \multicolumn{1}{|c|}{ Facilitadores } & \multicolumn{1}{c|}{ Autores } \\
\hline Treinamento & Wickramasinghe e Garusinghe (2010) \\
\hline $\begin{array}{l}\text { Participação de supervisores e alta } \\
\text { gerência }\end{array}$ & Wickramasinghe e Garusinghe (2010) \\
\hline Comunicação & $\begin{array}{l}\text { Jolly (1997); Rogers (2002); Greiner e } \\
\text { Franza (2003) }\end{array}$ \\
\hline Transferência de pessoas & Schulz et al. (2000); Nooteboom (2003) \\
\hline Capacidade de absorção ${ }^{13}$ & Knoben, Oerlemans e Rutten (2006) \\
\hline
\end{tabular}

Quadro 3 - Facilitadores da transferência de tecnologia

O treinamento e a participação de supervisores e alta gerência segundo Wickramasinghe e Garusinghe (2010), é um dos principais facilitadores na transferência da

\footnotetext{
${ }^{13}$ Definição no glossário
} 
tecnologia e no desenvolvimento da capacidade dos colaboradores, pois possibilita a aplicação de habilidades e conhecimentos nos projetos de transferência (KONTOGHIORGHES, 2001).

Apesar de a comunicação muitas vezes ser uma barreira ela também se torna um fator facilitador (JOLLY, 1997; ROGERS, 2002; GREINER; FRANZA, 2003) que corrobora não só para o sucesso da transferência (KREMIC, 2003), mas também para o funcionamento da rede (TATIKONDA; STOCK, 2003). Gibson e Smilor (1991) apontaram que quanto maior a interatividade e a comunicação entre os desenvolvedores da tecnologia e usuários, maior é a probabilidade de sucesso da aplicação de um produto/processo. Sung (2009) verificou estatisticamente que os canais de comunicação são significativos para alcançar o sucesso na transferência.

Outro fator que facilita a transferência da tecnologia é apontada por Schulz et al. (2000) e Nooteboom (2003). A transferência da tecnologia para projetos de produtos ocorre por meio da transferência de pessoas, ou seja, por times de transferência constituídos por engenheiros das áreas de desenvolvimento de produtos e de desenvolvimento da tecnologia. Para os autores aumentar a transferência de conhecimentos necessários para a incorporação de novas tecnologias e a aceitação das novas tecnologias pode até ser reforçada.

Quanto a capacidade de absorção, Knoben, Oerlemans e Rutten (2006), afirmam existir a facilidade em transferir tecnologia quando pessoas de habilidade de linguagem semelhante, com rotinas, cultura, valores e normas similares interagem. Isto possibilita que atores distantes geograficamente colaborem e reduz as dificuldades que muitos receptores possuem em absorver novas tecnologias (KNOBEN; OERLEMANS; RUTTEN, 2006).

O entendimento mútuo e a familiaridade são necessários para a colaboração, pois permite que exista confiança facilitando o sucesso da colaboração. Entretanto, muita familiaridade pode reduzir interesse para inovar por meio da colaboração. O desafio, portanto, é encontrar um parceiro com distância cognitiva suficiente para possibilitar aprender algo novo e que tenham similaridade de conhecimento para facilitar a aprendizagem organizacional, resultando positivamente na inovação e no desempenho da empresa (LANE; LUBATKIN, 1998; NOOTEBOOM et al., 2007).

Greiner e Franza (2003) identificaram que para a transferência ser bem sucedida algumas ações e atitudes devem ser consideradas para superar as diversas barreiras. Elas são classificadas em três tipos:

- Aspectos gerais: comunicação proativa, mensuração da eficácia da transferência, recomendações de organizações terceiras, tecnologia com valor tangível, recursos para 
desenvolvimento, teste de equipamentos e apoio ao usuário, procurar líderes chave, envolvimento antecipado do usuário;

- Aspectos formais: documentação clara, compartilhar informação, organização para liderar o esforço;

- Aspectos informais: credibilidade das partes envolvidas, capacidade para transmitir e receber informações, disposição das partes para comunicação.

\subsection{A Contribuição das Redes Colaborativas para a Transferência Tecnologia-Produto}

Alcançar a eficácia no processo de transferência é fundamental principalmente para as PMEs em decorrência do ambiente que elas enfrentam, ou seja, poucos recursos, pouco investimento em pesquisa e desenvolvimento, trabalham com incertezas e obstáculos à inovação, as redes reduzem a insegurança decorrente do desenvolvimento e utilização de novas tecnologias. Dessa forma, torna-se importante que as PMEs se relacionem com diferentes empresas, centros de pesquisa, fornecedores e clientes, formando uma rede de inovação densa, possibilitando compartilhar conhecimento e competências complementares, conseqüentemente melhorando o seu desempenho na transferência de tecnologia. (BULLINGER; AUERNHAMMER; GOMERINGER, 2004; LIN et al., 2009).

De acordo com Yao e McEvily (2000), as redes fornecem um contexto no qual os indivíduos envolvidos na transferência de conhecimento podem desenvolver a compreensão comum que é necessária para que o receptor compreenda plenamente a função do conhecimento fornecido por uma fonte. Isto torna mais fácil incorporar novos conhecimentos em atividades de desenvolvimento de produto. Os laços sociais podem, assim, auxiliar uma empresa a explorar um novo conhecimento científico e tecnológico.

Segundo Albors, Sweeney e Hidalgo (2005), na transferência de tecnologia por meio das redes, o esforço cooperativo de aprendizagem parece ser mais eficiente quando as PMEs participam. Trott, Cordey-Hayes e Seaton (1995) argumentam que a transferência de tecnologia terá sucesso se uma organização tiver capacidade para adquirir e principalmente assimilar e aplicar idéias, conhecimentos, artefatos de modo eficaz.

Reagan e McEvily (2003) pesquisaram a contribuição da estrutura da rede para o processo de transferência do conhecimento. Os autores verificaram que o efeito da força do laço sobre a transferência é maior quando o conhecimento a ser transferido é tácito, a densidade e diversidade da rede facilitam a transferência e que não variam com o tipo de conhecimento transferido. Para os autores é mais eficiente utilizar laços fortes para transferir 
conhecimento tácito e laços fracos para transferir conhecimento codificado, porém a transferência de conhecimento tácito exige maior motivação, esforço e habilidade.

Hansen, Mors e Lovas (2005) relacionaram em seus estudos os temas redes, transferência de tecnologia e compartilhamento de conhecimento. Segundo os autores as características dos laços de rede (forte ou fraco; concentrado ou frouxo) influenciam no compartilhamento do conhecimento e capacidade. Nieto e Santamaría (2007) e Lin et al. (2009) identificaram que a inserção na rede promove o acesso a diversas fontes de conhecimentos, permite que as empresas transfiram e apliquem esse conhecimento, oferecendo oportunidades para a aprendizagem organizacional das empresas. Entretanto, é necessário que exista a vontade de transformar a aprendizagem em rede em desempenho da transferência e capacidade de absorção para alavancar o conhecimento para melhorar o desempenho da transferência e desenvolver inovações.

Para Lin et al. (2009), as empresas melhoram o desempenho da transferência da tecnologia quando obtêm recursos da rede por meio de relações enraizadas ou aprendizagem das redes.

\subsection{Recomendações da literatura para transferir tecnologia sob a perspectiva de redes colaborativas}

Pesquisas sobre redes colaborativas apresentam um conjunto de requisitos (ver Quadro 4) que podem orientar as empresas sobre o que deve ser considerado no processo colaborativo. Esses requisitos podem minimizar as dificuldades da colaboração.

\begin{tabular}{|l|l|}
\hline \multicolumn{2}{|c|}{ Requisitos } \\
\hline A colaboração deve ter uma proposta & Camarinha-Matos e Afsarmanesh (2008) \\
\hline As partes devem concordam em colaborar & Camarinha-Matos e Afsarmanesh (2008) \\
\hline As partes devem conhecer as capacidades um do outro & Camarinha-Matos e Afsarmanesh (2008) \\
\hline $\begin{array}{l}\text { As partes devem compartilhar objetivos e ter uma visão } \\
\text { comum }\end{array}$ & $\begin{array}{l}\text { Camarinha-Matos e Afsarmanesh (2008); } \\
\text { Bullinger, Auernhammer e Gomeringer (2004) }\end{array}$ \\
\hline $\begin{array}{l}\text { Identificar os parceiros e trazê-los para junto, de acordo } \\
\text { com as capacidades individuais }\end{array}$ & $\begin{array}{l}\text { Camarinha-Matos e Afsarmanesh } \\
\text { Bullinger, Auernhammer e Gomeringer (2004) }\end{array}$ \\
\hline $\begin{array}{l}\text { Deve ser definido o escopo da colaboração e resultados } \\
\text { desejados }\end{array}$ & Camarinha-Matos e Afsarmanesh (2008) \\
\hline $\begin{array}{l}\text { Deve ser definida a estrutura da colaboração em termos } \\
\text { de liderança, regras, responsabilidades, tomada de } \\
\text { decisão, acesso a recursos, cronograma }\end{array}$ & $\begin{array}{l}\text { Camarinha-Matos e Afsarmanesh (2008); Mohan } \\
\text { e Rao (2005) }\end{array}$ \\
\hline $\begin{array}{l}\text { Devem ser definidas as políticas, como por exemplo, } \\
\text { tratamento para discordâncias / conflitos, } \\
\text { responsabilidade, recompensas e reconhecimento, e } \\
\text { propriedade dos bens gerados }\end{array}$ & Camarinha-Matos e Afsarmanesh (2008) \\
\hline
\end{tabular}




\begin{tabular}{|c|c|}
\hline Requisitos & Autores \\
\hline Devem ser definidas métricas para avaliação & Camarinha-Matos e Afsarmanesh (2008) \\
\hline $\begin{array}{lrlllll}\begin{array}{l}\text { Devem ser } \\
\text { contingência }\end{array} & \text { identificados } & \text { os riscos } & \text { e plano de } \\
\end{array}$ & Camarinha-Matos e Afsarmanesh (2008) \\
\hline Deve ser estabelecido compromisso de colaborar. & Camarinha-Matos e Afsarmanesh (2008) \\
\hline Deve ter ambiente que facilite a colaboração & Camarinha-Matos e Afsarmanesh (2008) \\
\hline Deve ter comunicação entre as partes & Mohan e Rao (2005); Deck e Strom (2002) \\
\hline Deve ter confiança & Mohan e Rao (2005) \\
\hline Deve ter clareza nos acordos e termos de adesão & Mohan e Rao (2005) \\
\hline Entregas devem ser definidas precisamente & Mohan e Rao (2005); Deck e Strom (2002) \\
\hline Relatórios devem ser elaborados periodicamente & Mohan e Rao (2005) \\
\hline $\begin{array}{l}\text { Devem ter sistemas de gestão e planejamento de projeto } \\
\text { eficaz }\end{array}$ & Mohan e Rao (2005) \\
\hline $\begin{array}{l}\text { Deve ser definido o contexto estratégico dos projetos } \\
\text { para determinar as oportunidades de colaboração, o valor } \\
\text { que pode prover para empresa, e identificar os } \\
\text { envolvidos que apoia o trabalho }\end{array}$ & Pertuzé et al. (2010) \\
\hline $\begin{array}{l}\text { Gestor de projeto deve facilitar a comunicação intra e } \\
\text { inter-organizacional. }\end{array}$ & Pertuzé et al. (2010) \\
\hline $\begin{array}{l}\text { A visão de como a colaboração pode ajudar a empresa } \\
\text { deve ser compartilhada com o parceiro }\end{array}$ & Pertuzé et al. (2010) \\
\hline $\begin{array}{l}\text { A empresa deve investir em um relacionamento a longo } \\
\text { prazo }\end{array}$ & Pertuzé et al. (2010) \\
\hline $\begin{array}{l}\text { A comunicação deve ser por meio de encontros regulares } \\
\text { e outros meios }\end{array}$ & Pertuzé et al. (2010) \\
\hline $\begin{array}{l}\text { Deve existir interação do time do parceiro com outras } \\
\text { áreas da empresa }\end{array}$ & Pertuzé et al. (2010) \\
\hline $\begin{array}{l}\text { Deve existir apoio da empresa durante e depois do } \\
\text { contrato }\end{array}$ & Pertuzé et al. (2010) \\
\hline Deve ser assinado um acordo de não divulgação & Slowinski, Hummel e Kumpf (2006) \\
\hline $\begin{array}{l}\text { Deve ser utilizado um sistema web (que seja seguro e } \\
\text { permita o fluxo de informação em tempo real }\end{array}$ & Deck e Strom (2002) \\
\hline
\end{tabular}

Quadro 4 - Requisitos para colaborar (conclusão)

Os requisitos apresentados no Quadro 5 indicam para as empresas o que é necessário ser feitos antes, durante e depois da colaboração. Segundo Camarinha-Matos e Afsarmanesh (2008), tais requisitos podem aumentar as chances de sucesso da parceria.

Com relação à transferência de tecnologia também encontram-se requisitos (ver Quadro 5) que apoiam a condução desses projetos. Eles se resumem em aspectos de comunicação, de relacionamento, e de projeto.

\begin{tabular}{|l|l|}
\hline \multicolumn{2}{|c|}{ Requisitos } \\
\hline Devem ser definidos escopo e estratégia da TT & Abraham e Bland (2011) \\
\hline $\begin{array}{l}\text { Devem ser definidos papéis e responsabilidades dos } \\
\text { envolvidos }\end{array}$ & $\begin{array}{l}\text { Abraham e Bland (2011); Cormican e O'Connor } \\
(2009)\end{array}$ \\
\hline Deve ter ferramenta de comunicação eficaz & Abraham e Bland (2011) \\
\hline Deve ser detalhada a freqüência dos encontros & Abraham e Bland (2011) \\
\hline As responsabilidades da equipe devem estar claras & Abraham e Bland (2011) \\
\hline $\begin{array}{l}\text { Deve ter contato "cara a cara" durante as etapas } \\
\text { iniciais do projeto e de aprovação }\end{array}$ & Abraham e Bland (2011) \\
\hline $\begin{array}{l}\text { Deve ser estabelecidos acordos de entendimento } \\
\text { mútuo sobre o que as partes farão }\end{array}$ & Lundquist (2003) \\
\hline
\end{tabular}

Quadro 5 - Requisitos para transferir tecnologia (continuação) 


\begin{tabular}{|l|l|}
\hline \multicolumn{1}{|c|}{ Requisitos } \\
\hline $\begin{array}{l}\text { Transferência acontecerá quando ambos confiar um no } \\
\text { outro para atender os termos do acordo }\end{array}$ & $\begin{array}{l}\text { Lundquist (2003); Santoro e Saparito (2006); Santoro } \\
\text { e Saparito (2003); Bosch-Sijtsema e Postma (2010); } \\
\text { Lee e Cavusgil (2006); Abbasnejad et al. (2011); } \\
\text { Dietrich et al. (2010) }\end{array}$ \\
\hline $\begin{array}{l}\text { Deve existir troca de informações com outras } \\
\text { organizações }\end{array}$ & $\begin{array}{l}\text { Bititci (2007); Bossink (2007); Faems, Janssens e van } \\
\text { Looy (2007); Schrader (1991) }\end{array}$ \\
\hline Deve ser elaborado contrato & Bozeman (2000); Bosch-Sijtsema e Postma (2010) \\
\hline $\begin{array}{l}\text { Knoben, Oerlemans e Rutten (2006); Sherwood e } \\
\text { Covin (2008); Chen e Tseng (2011); Cormican e } \\
\text { O'Connor (2009); }\end{array}$ \\
\hline Deve existir documentação & Easterby-Smith, Lyles e Tsang (2008) \\
\hline
\end{tabular}

Quadro 5 - Requisitos para transferir tecnologia (conclusão)

Os requisitos apresentados nos Quadros 4 e 5 são relatos de lições aprendidas ou de estudos que estatisticamente comprovaram que um requisito influencia positivamente na colaboração ou na transferência como é o caso do estudo de Bosch-Sijtsema e Postma (2010). Este estudo verificou que a confiança e o contrato influenciam em projetos de transferência de empresas participantes de uma cooperação.

Além dos requisitos, identificaram-se na literatura dois modelos que auxiliam no estabelecimento das parcerias de co-desenvolvimento e três modelos que auxiliam na transferência.

Para os modelos de parceria têm-se o de Emden, Calantone e Droge (2006) que visa à seleção de parceiros e o de Chesbrough e Schwartz (2007) que está direcionado a implementação de parcerias. Esses dois modelos são adotados nesta pesquisa por apoiar a formação da colaboração e a incorporação dessa prática no processo da empresa.

O modelo de Emden, Calantone e Droge (2006) propõe três atividades que visa analisar o alinhamento tecnológico, no qual verifica-se a capacidade técnica, complementaridade de recursos e as bases de conhecimento; o alinhamento estratégico, no qual verifica-se se as motivações e objetivos são correspondentes; e o alinhamento relacional, no qual verifica-se a compatibilidade cultural, flexibilidade para se adaptar a mudanças, e a orientação a longo prazo. Após cada uma dessas atividades têm-se as etapas de decisão, nas quais os envolvidos discutem o projeto e a parceria.

O modelo de Chesbrough e Schwartz (2007) propõe quatro atividades. A primeira é definir o objetivo da parceria; a segunda é avaliar as capacidades que a empresa necessita; a terceira é alinhar o modelo de negócio dos envolvidos; e a quarta é gerenciar a parceria pensando a longo prazo. 
Com relação aos modelos de transferência Jagoda, Maheshwari e Lonseth (2010) propõem um modelo para empresa que está adquirindo um equipamento. O modelo é composto por 6 macro-processos e etapas de decisão (gate).

Processo 1 - oportunidade tecnológica: a empresa verifica tendências de tecnologia, avalia o mercado, habilidades potenciais e recursos.

Processo 2 - pesquisa de tecnologia: se estabelece as especificações, avalia a habilidade de uso da tecnologia, identifica fornecedores e avalia as instituições que podem apoiar a empresa.

Processo 3 - negociação: discute-se questões de propriedade intelectual, responsabilidades dos envolvidos, mecanismos de transferência, canais de comunicação, e elaborar acordo de transferência.

Processo 4 - preparação para implementar o plano de transferência: refere-se a necessidade de mudança no ambiente da empresa receberá a máquina e ao planejamento do treinamento.

Processo 5 - implementação da transferência: identifica-se a necessidade de mudança do produto, realiza-se a formação do pessoal, formula-se arranjos com fornecedores.

Processo 6 - avaliação do impacto da transferência: avalia-se os resultados do projeto, identifica-se variações entre os resultados reais e esperados, e avalia-se a necessidade de melhoria da tecnologia.

O modelo de Jagoda, Maheshwari e Lonseth (2010) pode ser empregado tanto para transferência entre empresas de um mesmo país quanto para transferência entre países. Esse modelo se mostra interessante, pois apresenta uma preocupação em encontrar parceiros que possam contribuir com a transferência.

Outro modelo identificado na literatura é o de Lane (2009) que é constituído por três macro-processos: pesquisar, desenvolver, e produzir. O primeiro processo consiste em selecionar a idéia de um produto, realizar análise técnica e de mercado, definir conceito do produto, e construir um caso de negócio. O processo de desenvolvimento se constitui em iniciar práticas de co-desenvolvimento, desenvolver plano de implementação, alocar recursos, levantar as necessidades do cliente, identificar características do produto e das especificações, produzir e testar protótipo, validar com o cliente, e finalizar projeto e especificações técnicas. O processo produzir está relacionado as atividades de desenvolvimento da lista de materiais (bill of materials - BOM) preliminar, de planejamento de materiais, capacidade e produção, de planejamento e programação da engenharia, ferramentas e desenho de processo, de 
levantamento de custos, de marketing e vendas. O modelo de Lane (2009) também é interessante, pois a colaboração é base da atividade "iniciar prática de co-desenvolvimento".

Cormican e O'Connor (2009) apresentam um modelo de transferência que foca nas atividades em nível de projeto, ou seja, apresenta etapas que devem ser consideradas no planejamento, programação e execução da transferência. O modelo compreende cinco atividades sendo que a primeira é preparar time de transferência que deve ser composto por pessoas de diferentes áreas; a segunda atividade é elaborar plano de treinamento; a terceira é elaborar o plano de validação no qual define-se um processo que garanta uma saída do processo repetitivo, o tempo e o recurso necessários para realizar o trabalho; a quarta atividade é elaborar plano de projeto de transferência em que defini-se o tempo do projeto, a realização do treinamento, orçamento, e a sequência das atividades. Por fim, a última atividade é a transferência de informação e equipamento.

Cormican e O'Connor (2009) explicitam alguns fatores que podem afetar o processo de transferência, sendo eles: o estágio em que a tecnologia se encontra, a capacidade absorção do receptor, a distância geográfica, e as diferenças culturais. Apesar de não explicitar a colaboração, este trabalho irá considerar Jagoda, Maheshwari e Lonseth (2010), Lane (2009) e Cormican e O'Connor (2009), pois considera-se que suas atividades se complementam.

$\mathrm{Na}$ transferência de tecnologia sob a perspectiva de redes colaborativas pode envolver vários atores como os times das empresas compostos por engenheiros, gestor de projeto, técnicos, entre outros (CORMICAN; O'CONNOR, 2009); produtor (LANE, 1999), consumidor (LANE, 1999), provedor de recursos como governo e entidades privadas (LANE, 1999), fornecedor como universidade, centros de pesquisa, entre outros (BURATTI; PENCO, 2001; LANE, 1999; BOZEMAN, 2000), receptor como empresas que utilizam ou codesenvolve tecnologia (BURATTI; PENCO, 2001; LANE, 1999; BOZEMAN, 2000).

Quanto aos recursos que esses atores podem compartilhar ou utilizar tem-se os recursos físicos como instalações, máquinas, laboratórios, ferramentas (AUTIO; HAMERI; VUOLA, 2004; PLISSON et al., 2007; CAMARINHA-MATOS; AFSARMANESH, 2008; LEE; WIN, 2004), recursos tecnológicos como hardware e software (PLISSON et al., 2007; CAMARINHA-MATOS; AFSARMANESH, 2008), recursos humanos (PLISSON et al., 2007; CAMARINHA-MATOS; AFSARMANESH, 2008) e financeiro (CORMICAN; O'CONNOR, 2009), contratos e acordos (CAMARINHA-MATOS; AFSARMANESH, 2008).

Para que se possa gerenciar e monitorar esses projetos colaborativos é necessário que se tenha um sistema eficaz (MOHAN; RAO, 2005). Para que esse sistema atenda as 
necessidades desses projetos, a literatura aponta objetivos e requisitos que esse sistema deve cumprir. Entre os objetivos tem-se: compartilhar conhecimento (QURESHI; LIU; VOGEL, 2006), melhorar comunicação (SHEN et al., 2004), desenvolver plataforma colaborativa (HAN; CHIN; CHAE, 2007), gerenciar dados e informações (WULIANG; FANBO; DECAI, 2010; LIU et al., 2008), trocar informações (HAN; CHIN; CHAE, 2007; JIN; BOUTHILLIER, 2004), apoiar as decisões (CANIËLS; BAKENS, 2012), garantir comunicação entre os membros das equipes (RODRIGUEZ; AL-ASHAAB, 2005; SAEED, 2012).

Quanto aos requisitos de um sistema, a literatura recomenda que estes permitam: planejar e controlar o projeto (LIU et al., 2008; RAYMOND; BERGERON, 2008; SAEED, 2012); controlar acesso (BIENNIER; FAVREL, 2001; OJASALO, 2008); FRAME et al., 2009); disparar e-mails (BAFOUTSOU; MENTZAS, 2001); ser baseado na web (HAN, CHIN e CHAE, 2007; HUANG, HUANG e MAK, 2000, LI; QIU, 2006); garantir a segurança dos dados (OJASALO, 2008; RAYMOND; BERGERON, 2008); multiusuários (HAN; CHIN; CHAE, 2007; LIU et al., 2008; LI; QIU, 2006); avaliar desempenho do projeto/ time (SAEED, 2012); colaboração via intranet (BIENNIER; FAVREL, 2001); blogs, fóruns e wikis (CARBONE et al., 2012; SAEED, 2012); proteger cada envolvido na colaboração (BIENNIER; FAVREL, 2001); ferramenta síncrona e assíncrona (LI; QIU,2006); compartilhar documentos e arquivos (SAEED, 2012); ser de fácil uso e aprendizagem, ter flexibilidade, tempo de resposta rápido (RAYMOND; BERGERON, 2008); informação confiável e disponível no momento necessário (RAYMOND; BERGERON, 2008).

\subsection{Considerações Finais}

Esse capítulo teve a finalidade de apresentar os principais conceitos abordados nessa tese e que foram distribuídos na Seção 3.1 sobre redes colaborativas e na Seção 3.2 sobre transferência de tecnologia. Essas seções tiveram como objetivo apresentar uma compreensão sobre o assunto. Além disso, as motivações e benefícios das redes, as barreiras e facilitadores referentes à transferência apresentadas em suas respectivas seções auxiliaram no desenvolvimento do modelo de objetivos, pois permitiram simplificar a construção das questões para a identificação das variáveis desse modelo.

A Seção 3.3 foi importante para identificar a existência de uma relação entre os temas redes colaborativa e transferência de tecnologia. O que pode ser observado das pesquisas dos autores que relacionaram tais assuntos, é que apesar de serem estudos 
semelhantes realizados em diferentes anos, eles mostram que o assunto não está consolidado e que ainda se faz necessário identificar as contribuições ou impactos das redes em relação à transferência. Os estudos mostraram que diferentes formas de se estruturar a rede podem alcançar objetivos diferentes, portanto, é importante definir qual tipo de resultado se quer obter para então identificar os atores ideais para se relacionar.

A Seção 3.4 foi desenvolvida com a finalidade de identificar práticas ou recomendações relacionadas à colaboração e transferência que poderiam contribuir com o desenvolvimento do modelo. Dessa forma, essa seção foi importante para auxiliar no desenvolvimento dos modelos de regras de negócio, de processos de negócio, de atores e recursos, e de componentes e requisitos técnicos.

Dessa forma, o levantamento bibliográfico realizados nesse capítulo permitiu compreender melhor a extensão de cada um dos assuntos abordados neste trabalho, assim como seus conceitos e o relacionamento entre eles. A partir da revisão foi possível elaborar uma estrutura conceitual a partir do modelo de conceitos proposto por Bubenko Jr., Persson e Stirna (2001) para realizar modelagens organizacionais.

O modelo de conceitos especificamente é utilizado para definir "coisas" e "fenômenos" relacionados a outros modelos, representando diferentes informações e fluxos do modelo de processo de negócio (BUBENKO JR.; PERSSON; STIRNA, 2001). É composto por entidades (fenômeno e aplicação que deve ser entendida, caracterizada e definida), atributos (entidade que caracteriza outra entidade, uma propriedade de um tipo de objetivo), e relacionamentos binários de generalização ou especialização (ISA), ou de agregação (PartOF).

O relacionamento ISA é um tipo de relacionamento semântico entre entidades que permite generalizar um conceito e especificar outros que derivam dele, sendo a especificação parcial (quando existem instâncias de um conceito genérico que não é considerado) ou total (quando todas as instâncias de um conceito são consideradas). A propriedade mais significante para o relacionamento ISA está baseada na herança, tudo que é especificado para ser verdadeiro sobre um conceito genérico é também verdade para um conceito específico, significando que todos os atributos, seus valores e restrições são herdados de um nível mais genérico de conceitos para um nível mais específico. O relacionamento ISA é representado por um círculo e pode ser parcial (círculo sem preenchimento), e total (círculo com preenchimento).

O relacionamento PartOf ou de agregação é um relacionamento semântico no qual os conceitos são inter-relacionados. Refere-se à descrição de um relacionamento hierárquico ou 
uma estrutura de componentes, na qual existe um objeto que é composto por componentes, sendo o objeto representado em um nível superior e os componentes subordinados a ele. Este relacionamento é representado por um quadrado e pode ser parcial (quadrado sem preenchimento) ou total (quadrado com preenchimento).

O modelo de conceitos foi desenvolvido para compreender a relação entre redes colaborativas e transferência de tecnologia (ver Figura 3).

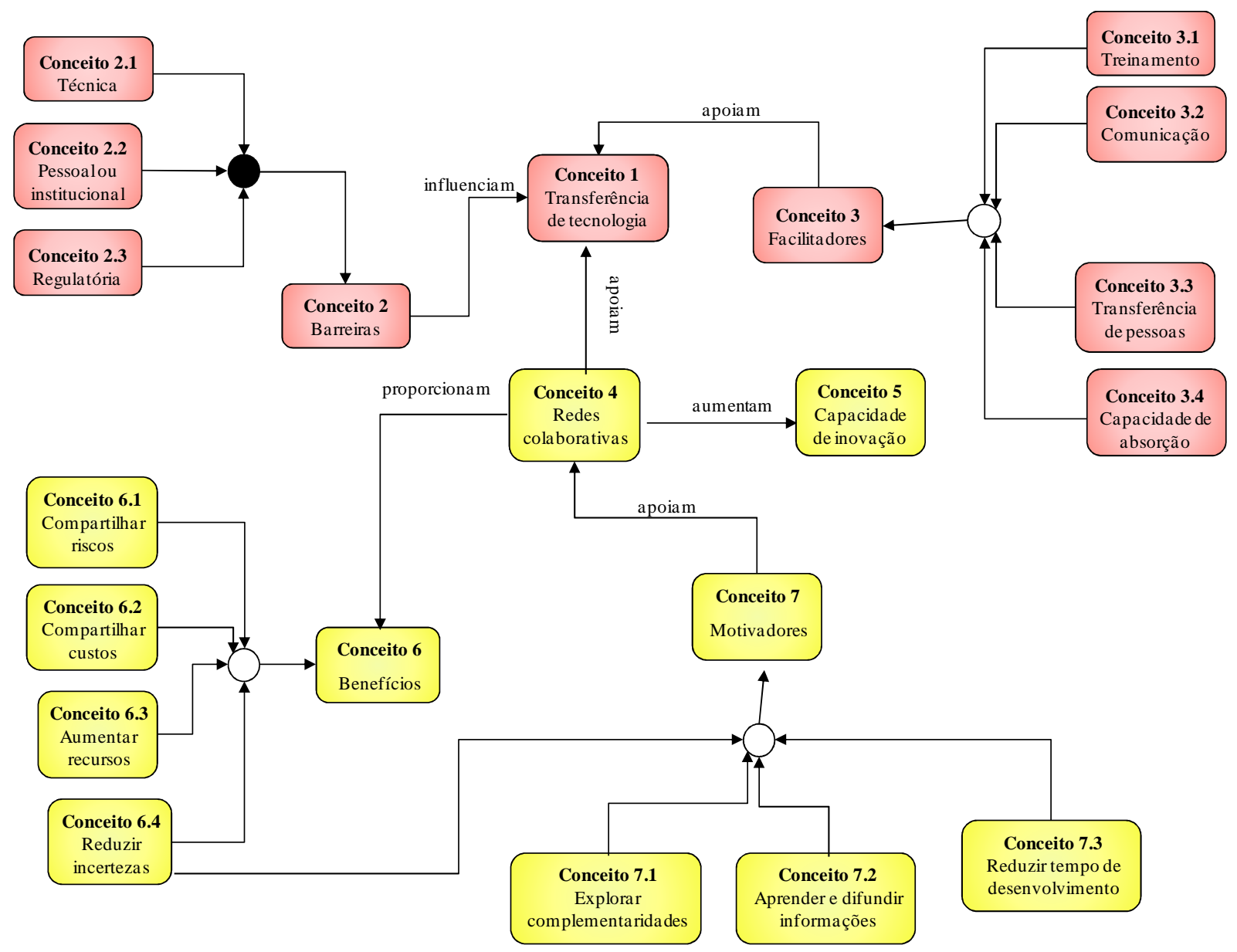

Figura 1 - Modelo de conceitos da pesquisa

De acordo com a Figura 1, a transferência de tecnologia (Conceito 1) é influenciada por diversas barreiras (Conceito 2) tanto técnicas (Conceito 2.1), pessoal ou institucional (Conceito 2.2) e regulatória (Conceito 2.3), mas apoiada por fatores facilitadores (Conceito 3) que auxiliam a superar as dificuldades do processo de transferência, tais como: treinamento (Conceito 3.1), comunicação (Conceito 3.2), transferência de pessoas (Conceito 3.3), capacidade de absorção (Conceito 3.4), entre outros.

As redes colaborativas (Conceito 4) auxiliam no aumento da capacidade de inovação (Conceito 5) das organizações e na transferência de tecnologia (Conceito 1), pois proporciona 
benefícios (Conceito 6) como o compartilhamento de riscos (Conceito 6.1) e custos (Conceito 6.2), aumento de recursos (Conceito 6.3), redução de incertezas (Conceito 6.4), entre outros.

Diferentes fatores motivadores (Conceito 7) contribuem para a formação das redes colaborativas (Conceito 4), sendo ele: exploração complementaridades (Conceito 7.1), aprendizagem e difusão de informações (Conceito 7.2), redução no tempo de desenvolvimento de um produto (Conceito 7.3), entre outros. 


\section{MÉTODO DE PESQUISA}

Neste capítulo são apresentadas as escolhas metodológicas da pesquisa, a técnica de modelagem utilizada e as etapas necessárias para o desenvolvimento do trabalho.

\subsection{Caracterização Geral da Pesquisa}

Para atingir o objetivo desta pesquisa em função do problema de pesquisa pressupor a questão "como" que deve ser analisada em certo grau de profundidade optou-se pela pesquisa com abordagem qualitativa com caráter descritivo e exploratório (YIN, 2001).

A abordagem qualitativa justifica-se, pois este estudo contemplou características inerentes a este tipo de abordagem de pesquisa, sendo elas (BOGDAN; BIKLEN, 1994):

- A pesquisa qualitativa tem como fonte direta de dados o ambiente natural, sendo o pesquisador o seu principal instrumento. Realmente, houve o contato direto do pesquisador com as empresas de alta tecnologia que possibilitou compreender e relacionar a colaboração e a transferência tecnologia-produto.

- Os dados coletados são predominantemente descritivos. O material obtido durante a pesquisa, ou seja, a gravação das conversas, o roteiro respondido e a modelagem possibilitaram descrever a situação atual das empresas com relação aos assuntos investigados.

- A preocupação com o processo é muito maior do que com o produto. O interesse do pesquisador ao estudar um determinado problema é verificar como ele se manifesta nas atividades, nos procedimentos e nas interações cotidianas.

A pesquisa é descritiva no que se refere à descrição de um processo de uma organização, no caso, o processo de transferência tecnologia-produto em empresas de alta tecnologia. A pesquisa descritiva tem como objetivo descrever a distribuição de um fenômeno em uma população, verificando, assim, os fatos (ZIKMUND, 2003; MALHOTRA; GROVER, 1998).

\subsection{Modelagem Organizacional}

Um modelo de empresa é uma descrição dos principais componentes, efeitos, processos de uma organização e como eles se relacionam uns com os outros. É essencialmente uma representação da organização do conhecimento sobre si mesma ou o que gostaria de se tornar. Da mesma forma, o nível de detalhe representada no modelo pode variar, dependendo da sua finalidade (KOUBARAKIS; PLEXOUSAKIS, 2002). 
O modelo de empresa pode ser utilizado por diferentes razões e propostas, por exemplo, na análise do negócio para a detecção de problema, na reengenharia de processo para definir um novo sistema, na engenharia de requisitos para definição de especificações, e na gestão do conhecimento ou aprendizagem organizacional para formar a base de propagação e ampliação do conhecimento (KIRIKOVA, 2000).

O objetivo de um modelo de empresa é fornecer a base para o entendimento comum, bem como a validação das operações comerciais e de recursos entre aqueles que estão realizando as funções do negócio e os responsáveis pela modelagem da empresa, ou seja, os responsáveis pela construção de modelos sobre as funções de negócio da empresa, dados de negócio e ciclos de negócios, bem como quaisquer outros modelos que são útil para descrever os estados da empresa (LIM; JUSTER; PENNINGTON, 1997). Além disso, o modelo de empresa pode identificar anomalias, inconsistências, ineficiências e oportunidades para a melhoria (KOUBARAKIS; PLEXOUSAKIS, 2002).

"Modelagem organizacional" é um nome genérico que refere-se a um conjunto de técnicas de modelagem conceitual para descrever a estrutura e processos de negócios de uma empresa, suas missões e objetivos em conjunto com aqueles objetivos que podem ser operacionalizados em componentes do sistema (LOUCOPOULOS; KAVAKLI, 1999).

Um número de conceitos básicos, técnicas e ferramentas, são necessários para o desenvolvimento de novos modelos de empresas. Modelagem de empresa destaca-se como a principal técnica que permite apresentar o conhecimento da empresa com o apoio de modelos construídos para a estrutura da empresa, organização e desempenho. Técnicas baseadas em modelagem garantem o acesso ao conhecimento da empresa necessário para realizar melhorias de processos, interoperabilidade, integração, coordenação e tomada de decisão entre empresas. (de la FUENTE; ROS; ORTIZ, 2010).

Os frameworks, os métodos e as técnicas de modelagem de empresa fornecem diferentes visões e descrições sobre as empresas e suas operações. Muitos métodos com apoio de softwares estão disponíveis no mercado. Cada método possui vantagens e desvantagens, além de serem limitados no que diz respeito à visão holística da organização (SHEN et al., 2004). O Quadro 6 apresenta a classificação de algumas das principais metodologias de modelagem de acordo com os conceitos de visões de Vernadat (1996), Sheer (1999, 2000) e Bubenko Jr., Persson e Stirna (2001):

- visão de objetivo: descreve a razão e a motivação para determinada atividade, os pontos fortes e fracos, os problemas e as oportunidades que podem trazer melhorias organizacionais; 
- visão de decisão: está relacionada com a definição e manutenção das regras de negócio que controlam a organização no sentido de definir e restringir ações;

- visão de atividade: também chamada de função, refere-se a sequiência de processos, tarefas para a transformação de informação ou material, as metas que direcionam a empresa e os softwares que a apoiam;

- visão de dados: refere-se a eventos e mensagens que iniciam ou finalizam atividades e informações relacionadas a determinados processo;

- visão de organização: está relacionado a recursos, hardware, estrutura organizacional, autoridades e responsabilidades;

- visão de informação: refere-se à entradas físicas e não físicas para a execução de um processo, assim como as saídas resultantes de uma determinada atividade;

- visão de processo: denominado também de controle, refere-se a documentação do relacionamento entre as visões, criando uma estrutura sistemática, a descrição das relações por completo, possibilitando uma visão holística de um determinado processo de negócio.

\begin{tabular}{|c|c|c|c|c|c|c|c|}
\hline \multirow{2}{*}{$\begin{array}{c}\text { Metodologias } \\
\text { de modelagem }\end{array}$} & \multicolumn{7}{|c|}{ Conceitos } \\
\cline { 2 - 9 } & Objetivo & Decisão & Atividade & Dados & Organização & Informação & Processo \\
\hline ARIS & - & - & $\mathrm{x}$ & $\mathrm{x}$ & $\mathrm{x}$ & $\mathrm{x}$ & $\mathrm{x}$ \\
\hline CIMOSA & - & - & $\mathrm{x}$ & $\mathrm{x}$ & $\mathrm{x}$ & $\mathrm{x}$ & $\mathrm{x}$ \\
\hline PERA & $\mathrm{x}$ & $\mathrm{x}$ & $\mathrm{x}$ & $\mathrm{x}$ & $\mathrm{x}$ & $\mathrm{x}$ & $\mathrm{x}$ \\
\hline EKD & $\mathrm{x}$ & $\mathrm{x}$ & $\mathrm{x}$ & $\mathrm{x}$ & $\mathrm{x}$ & $\mathrm{x}$ & $\mathrm{x}$ \\
\hline
\end{tabular}

Quadro 6 - Classificação das metodologias de modelagem

A metodologia CIMOSA (Computer Integrated Manufacturing Open System Architecture) propõe uma visão de que a empresa é uma grande coleção de processos de negócio executados por agentes sincronizados por eventos e mensagens (KOSANKE, 1995), sendo desenvolvida a modelagem de funções, informações, e aspectos organizacionais (KOSANKE, 1995; VERNADAT, 1996). A metodologia ARIS (Architecture of Integrated Information Systems) é focada na modelagem integrada de processos, essencialmente na engenharia de software e aspectos organizacionais de projetos de sistemas integrados, representado as visões de função, de dados, de organização, e controle (VERNADAT, 1996). Ambas as metodologias apresentam carências nas visões de objetivo e decisão.

A metodologia PERA (Purdue Enterprise Reference Architecture) foi criada para cobrir o ciclo de vida das Organizações desde a definição da missão até o nível operacional e obsolescência da empresa. Possui deficiências quanto à visão de processo ou controle, 
tratando de uma metodologia para planejamento. A metodologia EKD (Enterprise Knowledge Development) integra diferentes componentes organizacionais como objetivos com o modelo de processo (BUBENKO JR.; PERSSON; STIRNA, 2001), compreendendo todos os tipos de visões.

A maioria das metodologias de modelagem basicamente permite integrar e visualizar os processos com o auxílio da tecnologia de informação para representar adequadamente a complexidade dos processos organizacionais. Entretanto, segundo Loucopoulos e Kavakli (1999), muitos modelos ignoram assuntos importantes como: a estrutura social da empresa, quais são os papéis dos agentes da empresa, as razões, os objetivos, as motivações que definem a estrutura e os processos empresariais.

Portanto, nesta pesquisa adotou-se a metodologia de modelagem EKD para desenvolver o modelo de referência, tendo em vista que possui uma abrangência maior no que se refere às visões organizacionais, permitindo compreender como diferentes partes interagem, proporcionando a todos os envolvidos um olhar crítico e analítico sobre a organização. Nas próximas seções serão discutidos a metodologia EKD e conceitos de modelo de referência.

\subsubsection{Metodologia EKD}

A metodologia EKD apresenta um caminho controlado e sistemático de analisar, compreender, desenvolver e documentar uma organização e seus componentes por utilizar a modelagem de empresa. A proposta para aplicar o EKD é prover um entendimento claro de: (1) como a empresa funciona atualmente; (2) quais os requisitos e as razões para a mudança; (3) quais alternativas poderiam ser delineadas para encontrar estes requisitos; (4) quais são os critérios e argumentos para avaliar estas alternativas (BUBENKO JR.; PERSSON; STIRNA, 2001).

Segundo Bubenko Jr., Brash e Stirna (1998), a metodologia proporciona alguns benefícios:

- facilita a aprendizagem e a comunicação organizacional;

- auxilia a entender e promover as capacidades e processos da organização;

- desenvolve uma descrição estruturada do negócio para que os analistas da organização possam discutir e determinar mais claramente os objetivos; 
- produz um documento (chamado repositório de conhecimento) que possibilita raciocinar sobre o negócio, discutir mudanças, traçar a cadeia de componentes e decisões que possibilitam implementar diversas decisões e componentes de sistemas de informação.

A metodologia EKD representa várias visões da empresa por ser composta por seis sub-modelos, conforme a Figura 2.

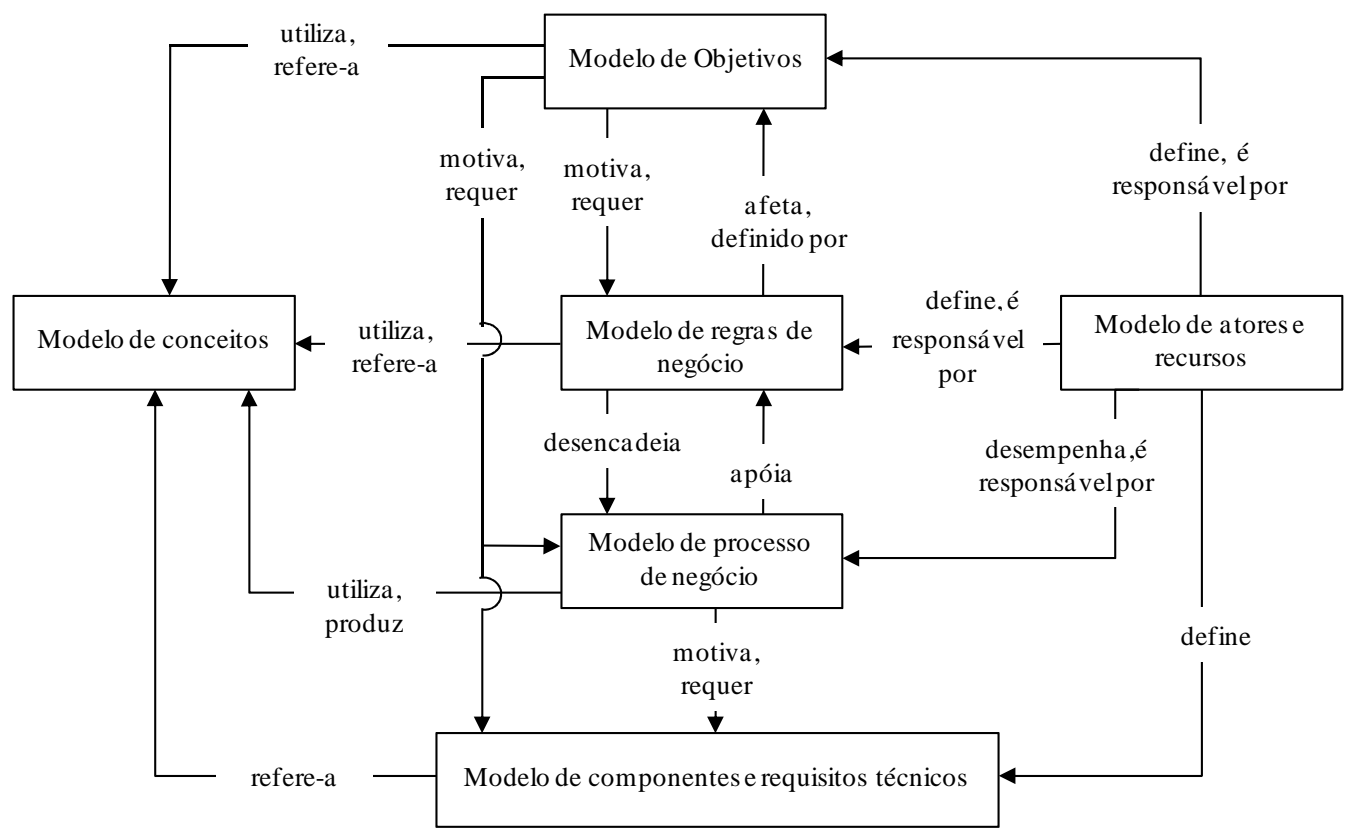

Figura 2 - Sub-modelos da metodologia EKD

Fonte: Adaptado de Bubenko Jr., Persson e Stirna (2001)

O Modelo de Objetivos como o próprio nome diz representa os objetivos da organização, descrevendo o que a empresa quer atingir ou evitar;

O Modelo de Regras de Negócio é utilizado para definir as regras consistentes com o Modelo de Objetivos, sendo visto como a operacionalização dos objetivos;

O Modelo de Conceitos é utilizado para definir coisas e fenômenos referentes a outros modelos, representado conceitos, atributos e relacionamentos;

O Modelo de Processo de Negócio define os processos, sua interação e o manuseio de informações e materiais;

O Modelo de Atores e Recursos descreve como diferentes atores e recursos estão relacionados e como estão relacionados com os modelos de objetivos e de processo de negócio;

O Modelo de Requisitos e Componentes Técnicos é utilizado para definir requisitos para um sistema de informação (subsistemas ou componentes técnicos) que apoiará os objetivos, os processos e os atores da organização. 
Bubenko Jr, Persson e Stirna (2001) sugerem que os modelos sejam desenvolvidos por meio de uma abordagem participativa seguindo algumas instruções como:

a. antes de realizar as sessões de modelagem deve-se selecionar os participantes;

b. a sessão de modelagem é preparada, definindo os objetivos e cronograma;

c. a sessão de modelagem é realizada conforme o cronograma. Durante as sessões o facilitador é o ator crucial como gestor do processo de comunicação do grupo e como detentor do conhecimento do método;

d. depois das sessões, os modelos são documentados por meio de algumas ferramentas computacionais e uma sessão passo-a-passo é realizada com os participantes para validar os modelos;

e. baseados nos modelos documentados, novas sessões de modelagem são preparadas e realizadas até que o problema tenha sido suficientemente analisados.

A metodologia de modelagem EKD compreende três processos, nos quais os participantes estão envolvidos, sendo: diagnóstico, que consistem em modelar a situação atual e identificar a necessidade de mudança; compreensão, que refere-se a interpretação, entendimento, deliberação e discussão do estado atual e futuro da empresa; e desenvolvimento, nas quais são discutidas e modeladas as situações e cenários alternativos futuros, conforme mostra a Figura 3.

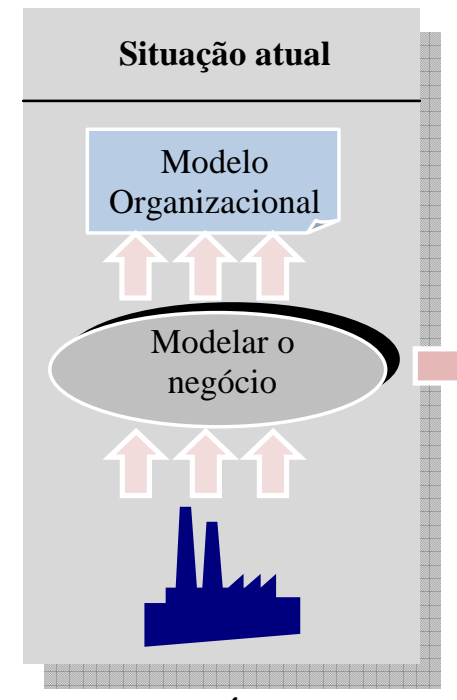

DIAGNÓSTICO

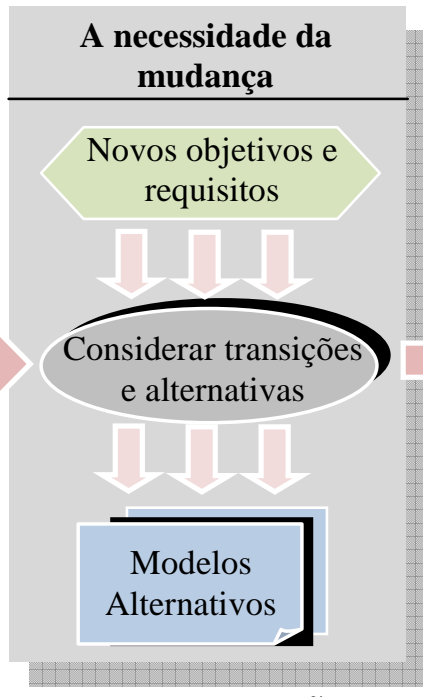

COMPREENSÃO

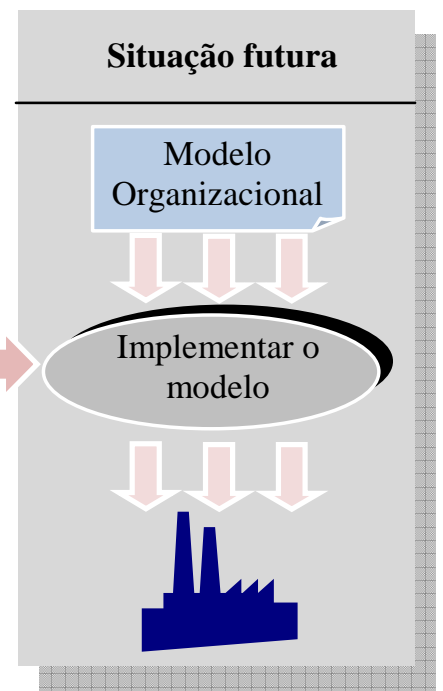

DESENVOLVIMENTO

Figura 3 - Tipos de atividades envolvidas no processo do EKD Fonte: adaptado de Bubenko Jr.; Persson; Stirna (2001).

Nesse sentido, realizou-se a etapa de diagnóstico, a qual envolveu a modelagem da situação atual das organizações com a finalidade de identificar as necessidades de mudanças. Posteriormente, realizou-se uma comparação do estado atual da empresa com uma situação 
futura que incorpora práticas apresentada pela literatura com o objetivo de desenvolver um modelo que seja de referência para empresas com características semelhantes.

\subsubsection{Modelo de Referência}

Modelo de referência é um modelo que pode ser usado para o desenvolvimento ou avaliação de um modelo particular (VERNADAT, 1996) e que podem ser desenvolvidos a partir de situações do mundo real (melhores práticas) ou de teorias. Os modelos distinguem-se em modelos de procedimentos ou de implementação de software e modelos de negócios como processamento de pedidos ou lançamentos de produtos. (SCHEER; NÜTTGENS, 2000). Dessa forma, o modelo prevê benefícios para seguintes aplicações (FETTKE; LOSS, 2003):

- Desenvolvimento de software: uso de linguagem que permite descrição uniforme de software;

- Configuração do sistema de informação: os modelos apoiam a customização de sistemas;

- Interface com o usuário: o modelo orienta o usuário de um sistema de informação por meio de procedimentos;

- Descrição da organização: descreve a estrutura organizacional ou processos;

- Re-engenharia do processo de negócio: descreve a realidade, identifica pontos fracos e agiliza os processos de negócio;

- Gestão do conhecimento: documenta conhecimento e permite estabelecer comunicação entres atores dentro da organização.

Segundo Matook e Indulska (2009) e Reinhartz-Berger, Soffer e Sturm (2010), modelos de referência recomendam práticas comuns de negócio que são conhecidas em uma variedade de organização. Esses modelos são reutilizáveis e eficientes para apoiar o projeto de um processo em determinadas empresas específicas. O seu principal objetivo é agilizar o desenho de modelos empresariais e habilitar as organizações a aplicar o conhecimento.

Fettke e Loos (2007) apresentam três características encontradas na literatura que classificam um modelo de referência:

- Melhores práticas: o modelo de referência provê melhores práticas para conduzir o negócio;

- Aplicabilidade universal: modelo não representa um negócio particular; 
- Reusabilidade: estrutura conceitual que pode ser reutilizado em diversos projetos de sistema de informação.

O modelo de referência pode ser utilizado para diferentes propostas (REINHARTZBERGER; SOFFER; STURM, 2010, AHLEMANN, 2009, HERNÁNDEZ; MULA; FERRIOLS, 2008): a) criar processos de negócio padrões que podem ser utilizados em várias Organizações; b) guiar projetos de novos processos de negócio; c) realizar treinamento; d) melhorar comunicação entre os envolvidos no processo; e) comparar processos; f) apoiar a implementação de um sistema empresarial; g) reduzir tempo e custo de desenvolvimento e; h) reduzir riscos de falhas.

O termo modelo de referência abordado nesta pesquisa refere-se à visão do modelo de negócio. O modelo de referência foi desenvolvido considerando as práticas teóricas e empíricas relacionadas à colaboração e transferência tecnologia-produto. No capítulo a seguir são apresentadas as práticas presentes na literatura.

\subsection{Etapas da Pesquisa}

Esta pesquisa foi desenvolvida em duas etapas. A primeira foi o levantamento bibliográfico, no qual buscou-se compreender os principais conceitos referentes a gestão colaborativa e a transferência tecnologia-produto e a relação entre eles. A segunda etapa foi a realização de um estudo de casos com as empresas de alta tecnologia que possibilitou conhecer as motivações e dificuldades da colaboração e da transferência, além de permitir realizar as modelagens da situação atual das empresas. Posteriormente, diante dos dados coletados tanto da literatura quanto das empresas foi elaborado o modelo de transferência tecnologia-produto.

\subsubsection{Etapa 1 - Revisão bibliográfica}

A pesquisa bibliográfica considera duas áreas de pesquisa relacionadas a redes interorganizacionais, gestão da tecnologia e inovação. Primeiramente, foram definidas as bases de dados a serem pesquisadas, sendo: Science Direct, Web of Science, Compendex,e Emerald. As palavras-chave utilizadas para realizar as buscas compreenderam "transferência de tecnologia", "colaboração", "redes colaborativas". No primeiro momento do levantamento dos artigos as buscas não foram restringidas por área e nem por ano, em decorrência da importância de se considerar os artigos recentes para compreender o estado atual em que se 
encontram as pesquisas e de considerar trabalhos que não são recentes por se tratar de autores clássicos em cada assunto.

Posteriormente, os artigos foram selecionados a partir da análise de títulos e resumos, priorizando os artigos de periódicos com fator de impacto. Foram identificados artigos de diferentes áreas desde informática até antropologia. Em decorrência dessa interdisciplinaridade foi necessário definir critérios de inclusão para iniciar a seleção dos artigos, sendo eles: a) artigos que abordavam as redes colaborativas; b) artigos que consideraram a transferência de tecnologia como a movimentação de artefatos tangíveis e intangíveis no processo de inovação.

Em um segundo momento, novas pesquisas foram realizadas buscando a combinação de palavras-chave por meio da utilização de operadores boleanos "and" e "or". Além disso, foi utilizada a ferramenta de mapa de citações da base Web of Science que consiste em uma representação gráfica que mostra os relacionamentos entre as referências citadas (backward) por um artigo e as que citaram (forward) esse mesmo artigo após a sua publicação (SMALL, 1999).

É importante mencionar que durante a realização das novas buscas foram consideradas publicações que não possui fator de impacto, mas que se enquadrava nos critérios de inclusão. Ademais trabalhos de congressos, livros e relatórios formaram uma fonte secundária de referências que também contribuíram para a construção do referencial teórico.

A revisão da literatura que apoiou o desenvolvimento do modelo da pesquisa foi realizada em conjunto com os casos, pois ela constituiu em uma das etapas da metodologia de modelagem EKD, sendo esta etapa a análise da necessidade de mudança (need for change).

\subsubsection{Etapa 2 - Estudos de casos}

O método estudo de caso permite compreender a natureza e a complexidade de um determinado fenômeno (VOSS; TSIKRIKTSIS; FROHLIC, 2002). Assim, um motivo que contribuiu para escolha foi a escassez de trabalhos que abordavam a interação entre os assuntos de redes colaborativas e transferência tecnologia-produto por meio da abordagem qualitativa.

Os estudos de casos foram realizados em empresas de alta tecnologia, pois elas têm um importante papel no desenvolvimento e comercialização de tecnologia (KIRWAN, van der SIJDE; GROEN, 2006), o que possibilitou compreender a transferência tecnologia- 
produto. Além disso, são empresas com maior propensão para estabelecer acordos de colaboração (FARIA; LIMA; SANTOS, 2010). As empresas pesquisadas são de micro, pequena e médio porte, segundo o critérios de classificação do Sebrae (2011), sendo que: empresas com até 19 colaboradores são consideradas micro empresas; de 20 a 99 colaboradores são empresas de pequeno porte; de 100 a 499 colaboradores são empresas de médio porte; e acima de 500. Essas empresas foram o objeto de estudo tendo em vista que elas possuem diversas dificuldades já citadas na Seção 3.4 e que se apoiam na colaboração como um dos caminhos para minimizar seus problemas (OKAMURO, 2007; HANNA; WALSH, 2008; NIETO; SANTAMARIA, 2010).

As empresas foram selecionadas por conveniência, ou seja, aquelas que aceitaram agendar a entrevista e também indicações o que facilitou o acesso a algumas empresas. Foram realizados contatos com doze empresas, sendo oito delas entrevistadas e as outras quatro não deram um retorno sobre a possibilidade de agendar uma entrevista. Os dados de uma empresa não puderam ser utilizados por se tratar de uma empresa de serviço. Optou-se por estudos de casos múltiplos, pois permitem uma pesquisa robusta, aumentam a validade externa e colaboraram para proteger contra viés do observador (YIN, 2001; EISENHARDT E GRAEBNER, 2007; BARRATT; CHOI; LI, 2011). Segundo Eisenhardt (1989), em estudos de casos múltiplos o número ideal de casos a serem pesquisados é de 4 a 10 casos. Seguindo esta recomendação, foram realizados sete estudos de casos. O Quadro 7 apresenta características das empresas pesquisadas.

\begin{tabular}{|c|c|c|c|c|}
\hline Empresa & Porte & Mercado & Ano de fundação & Entrevistado \\
\hline 1 & Micro & $\begin{array}{l}\text { Sucro-alcooleiro, } \\
\text { automação industrial }\end{array}$ & 1991 & Supervisor de projetos \\
\hline 2 & Pequena & Reparação automotivo & 1980 & $\begin{array}{c}\text { Gerente de } \\
\text { desenvolvimento }\end{array}$ \\
\hline 3 & Média & Médico, espacial, defesa & 1985 & $\begin{array}{l}\text { Gerente de escritório de } \\
\text { projetos }\end{array}$ \\
\hline 4 & Micro & Energia \& utilities e segurança & 2003 & Diretor \\
\hline 5 & Micro & $\begin{array}{llr}\text { Indústria } & \text { de } & \text { tecido, } \\
\text { concessionária } & \text { de trator, entre } \\
\text { outros } & \end{array}$ & 1987 & Responsável pelo P\&D \\
\hline 6 & Pequena & $\begin{array}{l}\text { Linha branca, motopeças, } \\
\text { implemento agrícola }\end{array}$ & 1996 & Diretor industrial \\
\hline 7 & Micro & $\begin{array}{l}\text { Farmacêutico, industrial, } \\
\text { hospitalar, entre outros }\end{array}$ & 2005 & Gerente \\
\hline
\end{tabular}

Quadro 7 - Empresas pesquisadas

A coleta de dados foi realizada por meio de entrevistas semi-estruturada com o responsável pela área de Pesquisa e Desenvolvimento. A entrevista e a gravação foram 
utilizadas como fonte de coleta de dados de experiências, de percepções e de interpretações de pessoas envolvidas na área analisada (YIN, 2001; SHAH; CORLEY, 2006). Um roteiro de entrevistas (apresentado no Apêndice A) constituído de 3 seções temáticas foi utilizado para orientar a pesquisadora, sendo a primeira referente a caracterização da colaboração, a segunda sobre a caracterização transferência de tecnologia e a terceira para orientar a modelagem. Cada entrevista teve duração de aproximadamente 1 hora e 30 minutos. Entretanto, visitas adicionais foram necessárias em todas as empresas para fazer a verificação dos modelos com os entrevistados. Conversas por e-mail também foram utilizadas como um meio para esclarecer dúvidas e complementar os modelos. A coleta de dados foi realizada entre agosto de 2011 e setembro de 2012.

Um importante instrumento para a realização do estudo de caso é o protocolo de pesquisa que segundo Yin (2001), pois aumenta a confiabilidade da pesquisa e destina-se a orientar o pesquisador ao conduzir o estudo de caso por servir como um lembrete para a entrevista e uma lista de verificação para se certificar de que todos os assuntos sejam abordados (VOSS; TSIKRIKTSIS; FROHLIC, 2002). O Quadro 8 resume os componentes do protocolo para esta pesquisa.

\begin{tabular}{|l|l|}
\hline \multicolumn{2}{|c|}{ Protocolo da pesquisa } \\
\hline Questão do estudo & $\begin{array}{l}\text { Como organizar o processo de transferência tecnologia- } \\
\text { produto sob o recorte analítico de redes colaborativas? }\end{array}$ \\
\hline Unidade de análise & Projetos de transferência tecnologia-produto \\
\hline Local & Empresas de alta tecnologia \\
\hline Validade dos construtos & $\begin{array}{l}\text { Utilização de fontes múltiplas de evidência (entrevistas, } \\
\text { observações direta) }\end{array}$ \\
\hline Validade interna & Adequação do trabalho de Lin et al. (2009) \\
\hline Confiabilidade & Protocolo de estudo de caso \\
\hline
\end{tabular}

Quadro 8 - Componentes do protocolo de pesquisa

O tratamento dos dados ocorreu mediante a sistematização das informações por meio da metodologia de modelagem EKD. Para isso, foi necessário utilizar às anotações do pesquisador e ouvir várias vezes as gravações das entrevistas para compor o modelo individual de cada empresa que, posteriormente, colaborou na composição do modelo "as-is". O desenvolvimento do modelo "as-is" se deu pela junção de todas as informações apresentadas por cada empresa, ou seja, não foram desconsiderados quaisquer dados levantados durante a entrevista, pois o pesquisador considerou que podem existir outras empresas com dados semelhantes. 
Para compor a análise "need for change" foi necessário comparar a literatura com o modelo "as-is". Para isso, criaram-se tabelas, nas quais foram listadas informações mencionadas pelas empresas e pela literatura referentes aos seis modelos do EKD. Nestas tabelas, encontram-se informações que a literatura aponta, mas que as empresas não mencionaram e vice-versa. Essa análise contribuiu para o desenvolvimento do modelo "to-be"

Por fim, o modelo "to-be" que é o modelo proposto sistematiza e incorpora as recomendações da literatura. Portanto, este modelo é constituído com as informações do modelo "as-is" mais as práticas apresentadas pela literatura e que não são realizadas pelas empresas. No próximo capítulo são apresentados os resultados desse tratamento.

É importante mencionar que durante a coleta e o tratamento dos dados, o pesquisador foi o principal instrumento para a realização destas etapas da pesquisa. Primeiro, porque no decorrer das entrevistas, a pesquisadora foi desenvolvendo os esboços iniciais dos modelos conforme o entendimento obtido da resposta dos entrevistados, permitindo eliminar possíveis dúvidas que poderiam surgir posteriormente. Segundo foi a preocupação da pesquisadora durante o uso do Power Point para construir os modelos de forma a não deixá-los visualmente confusos no momento da leitura.

Do ponto de vista da pesquisadora a metodologia EKD é de fácil uso no que se refere à utilização ou não de um software para realizar a modelagem, ou seja, pode-se utilizar postit, desenhar manualmente, utilizar Power Point, Visio, entre outras formas. Além disso, a flexibilidade da metodologia não deixa engessado a representação dos modelos, permitindo que o usuário represente o nível de detalhe desejado. Outro ponto interessante dessa flexibilidade é que o usuário pode utilizar de sua criatividade para desenvolver as atividades de diagnóstico, compreensão e desenvolvimento do EKD. Neste caso, a pesquisadora fez uso do levantamento teórico e empírico para desenvolver tais atividades ao invés de ser realizada dentro do que cada empresa gostaria de alcançar.

Com relação às dificuldades tem-se: reunir várias pessoas de uma empresa, principalmente quando a modelagem não está diretamente relacionada a um problema que a empresa quer resolver, as questões sugeridas pelo guia do EKD nem sempre são entendidas pelos entrevistados, o que exige que o pesquisador adapte a questão. Outra dificuldade é com relação à modelagem de várias empresas de setores diferentes, além do volume de informações obtidos, o que exige cuidado e atenção por parte de quem vai utilizar todos os dados. Outros aspectos positivos e dificuldades foram relatados pelos criadores da metodologia e podem ser encontrado no guia disponível no seguinte endereço web: ftp://ftp.dsv.su.se/users/js/d3_km_using_ekp.pdf. 


\section{RESULTADOS}

Este capítulo apresenta os resultados originados a partir da pesquisa de campo e da literatura que resultaram no modelo proposto por esta pesquisa. Inicialmente, na Seção 5.1 é apresentado o modelo do estado atual (as-is) que representa a realidade ou estado atual de todas as empresas. A Seção 5.2 refere-se à avaliação da necessidade de mudança (need for change). Por fim, a Seção 5.3 apresenta o modelo do estado futuro (to-be) que é o modelo proposto por esta pesquisa.

\subsection{Modelo do Estado Atual (As-Is)}

O modelo do estado atual (as-is) como o próprio nome indica representa a modelagem da situação atual das empresas. Esse modelo pode ser utilizado para realizar um diagnóstico, pois permite explicitar problemas e identificar oportunidades de melhorias a partir do desenvolvimento dos diferentes pontos de vista da organização que tratam dos atores, papéis, recursos, processos de negócio, objetivos, regras entre outros (ROLLAND; NURCAN; GROSZ, 2000).

\subsubsection{Modelo de Objetivos}

A Figura 4 apresenta o modelo de objetivos que norteia a transferência tecnologiaproduto.

As empresas possuem diversos objetivos entre eles tem-se: obter lucro (Objetivo 4), lançar novos produtos (Objetivo 15), desenvolver novos produtos (Objetivo 5) o que permite ser competitivo no mercado interno e externo (Objetivo 6), crescer em termos de faturamento/ lucro (Objetivo 7), obter excelência na resolução dos problemas dos clientes (Objetivo 8), e aumentar participação de mercado (Objetivo 16).

Para lançar novos produtos (Objetivo 15) é importante estruturar a organização para usar bem o conhecimento (Oportunidade 4) que por sua vez apoia obter novos clientes (Objetivo 1.2) e acompanhar as alterações de legislação que podem influenciar no produto da empresa (Política 5). Entretanto, o avanço tecnológico (Problema 30) influencia no lançamento de novos produtos (Objetivo 15). 


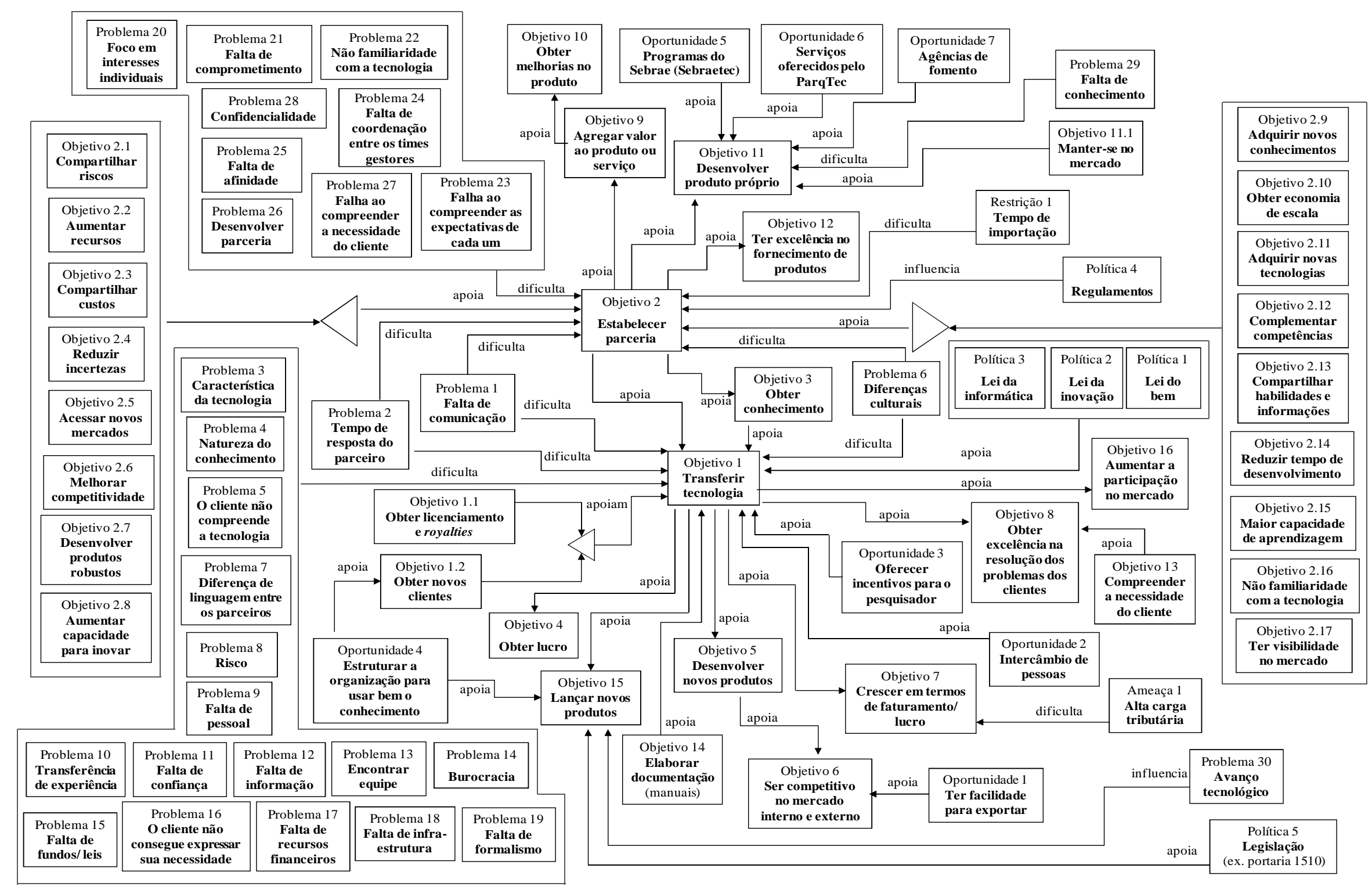

Figura 4 - Modelo de objetivos (as-is) 
Para alcançar o objetivo de ser competitivo principalmente no mercado externo (Objetivo 6) é necessário ter facilidade para exportar (Oportunidade 1).Crescer em termos de faturamento/lucro tem sido difícil em decorrência da alta carga tributária (Ameaça 1). Obter excelência na resolução dos problemas dos clientes (Objetivo 8) é possível quando a empresa compreende a necessidade do cliente (Objetivo 13).

Um dos caminhos que as empresas possuem para atingir os objetivos 4 (obter lucro), 15 (lançar novos produtos), 5 (desenvolver novos produtos), 7 (crescer em termos de faturamento/ lucro) e 8 (obter excelência na resolução dos problemas dos clientes) é a transferência de tecnologia (Objetivo 1).

Para transferir tecnologia (Objetivo 1) a empresa se apoia na obtenção de licenciamento e royalties (Objetivo 1.1), em novos clientes (Objetivo 1.2), nas leis da informática (Política 3), da inovação (Política 2) e do bem (Política 1), na obtenção de conhecimento (Objetivo 3) e, no estabelecimento de parceria (Objetivo 2). Oferecer incentivos para o pesquisador (Oportunidade 3) e realizar intercâmbio de pessoas (Oportunidade 2) são alguns dos meios que podem facilitar e incentivar a transferência (Objetivo 1).

Vários problemas dificultam transferir tecnologia (Objetivo 1), sendo: falta de comunicação (Problema 1), tempo de reposta do parceiro (Problema 2), característica da tecnologia (Problema 3), natureza do conhecimento (Problema 4), cliente que não compreende a tecnologia (Problema 5), diferenças culturais (Problema 6), diferença de linguagem entre parceiros (Problema 7), risco (Problema 8), falta de pessoal (Problema 9), transferência de experiência (Problema 10), falta de confiança (Problema 11), falta de informação (Problema 12), encontrar equipe (Problema 13), burocracia (Problema 14), falta de fundos/ leis (Problema 15), cliente que não consegue expressar sua necessidade (Problema 16), falta de recursos financeiros (Problema 17), falta de infraestrutura (Problema 18) e falta de formalismo (Problema 19).

Estabelecer parceria (Objetivo 2) apoia a empresa obter conhecimento (Objetivo 3) que conseqüentemente apoia a transferência (Objetivo 1), apoia ter excelência no fornecimento de produtos (Objetivo 12), desenvolver produto próprio (Objetivo 11) e agregar valor ao produto ou serviço (Objetivo 9) que por sua vez apoia obter melhorias no produto (Objetivo 10).

Desenvolver produto próprio (Objetivo 11) apoia a empresa se manter no mercado (Objetivo 11.1). Uma barreira encontrada para atingir o objetivo 11 é a falta de conhecimento (Problema 13). Serviços prestados por algumas instituições auxiliam no desenvolvimento do produto próprio (Objetivo 4) são os programas do Sebrae, principalmente o SebraeTec 
(Oportunidade 1), os serviços oferecidos pelo ParqTec - Parque Tecnológico (Oportunidade 2), e as agências de fomento (Oportunidade 3).

Ao estabelecer parcerias (Objetivo 2) alguns problemas são identificados como foco em interesse individuais (Problema 20), falta de comprometimento (Problema 21), não familiaridade com a tecnologia (Problema 22), falha ao compreender as expectativas de cada um (Problema 23), falta de coordenação entre os times gestores (Problema 24), falta de afinidade (Problema 25), criar parceria (Problema 26), falha ao compreender a necessidade do cliente (Problema 27), confidencialidade (Problema 28), e tempo de importação de peças (Restrição 1).

As empresas estabelecem parcerias (Objetivo 2) por diferentes motivos, dentre eles estão: compartilhar riscos (Objetivo 2.1), aumentar recursos (Objetivo 2.2), compartilhar custos (Objetivo 2.3), reduzir incertezas (Objetivo 2.4), acessar novos mercados (Objetivo 2.5), melhorar competitividade (Objetivo 2.6), desenvolver produtos robustos (Objetivo 2.7), aumentar capacidade para inovar (Objetivo 2.8), adquirir novos conhecimentos (Objetivo 2.9), obter economia de escala (Objetivo 2.10), adquirir novas tecnologias (Objetivo 2.11), complementar competências (Objetivo 2.12), compartilhar habilidades e informações (Objetivo 2.13), reduzir tempo de desenvolvimento (Objetivo 2.14), maior capacidade de aprendizagem (Objetivo 2.15), não familiaridade com a tecnologia (Objetivo 2.16), e ter visibilidade de mercado (Objetivo 2.17). Além disso, existem regulamentos (Política 4) que interferem no aumento da demanda de determinados produtos das empresas exigindo a necessidade de estabelecer parcerias (Objetivo 2) para suprir essa demanda.

\subsubsection{Modelo de Regras de Negócio}

A Figura 5 apresenta o modelo de regras de negócio que norteia a transferência tecnologia-produto.

Transferir tecnologia (Objetivo 1) apoia as empresas a obter lucro (Objetivo 4) desenvolver produto próprio (Objetivo 5), lançar novos produtos (Objetivo 15), aumentar participação no mercado (Objetivo 16), e obter excelência na resolução dos problemas dos clientes (Objetivo 8). 


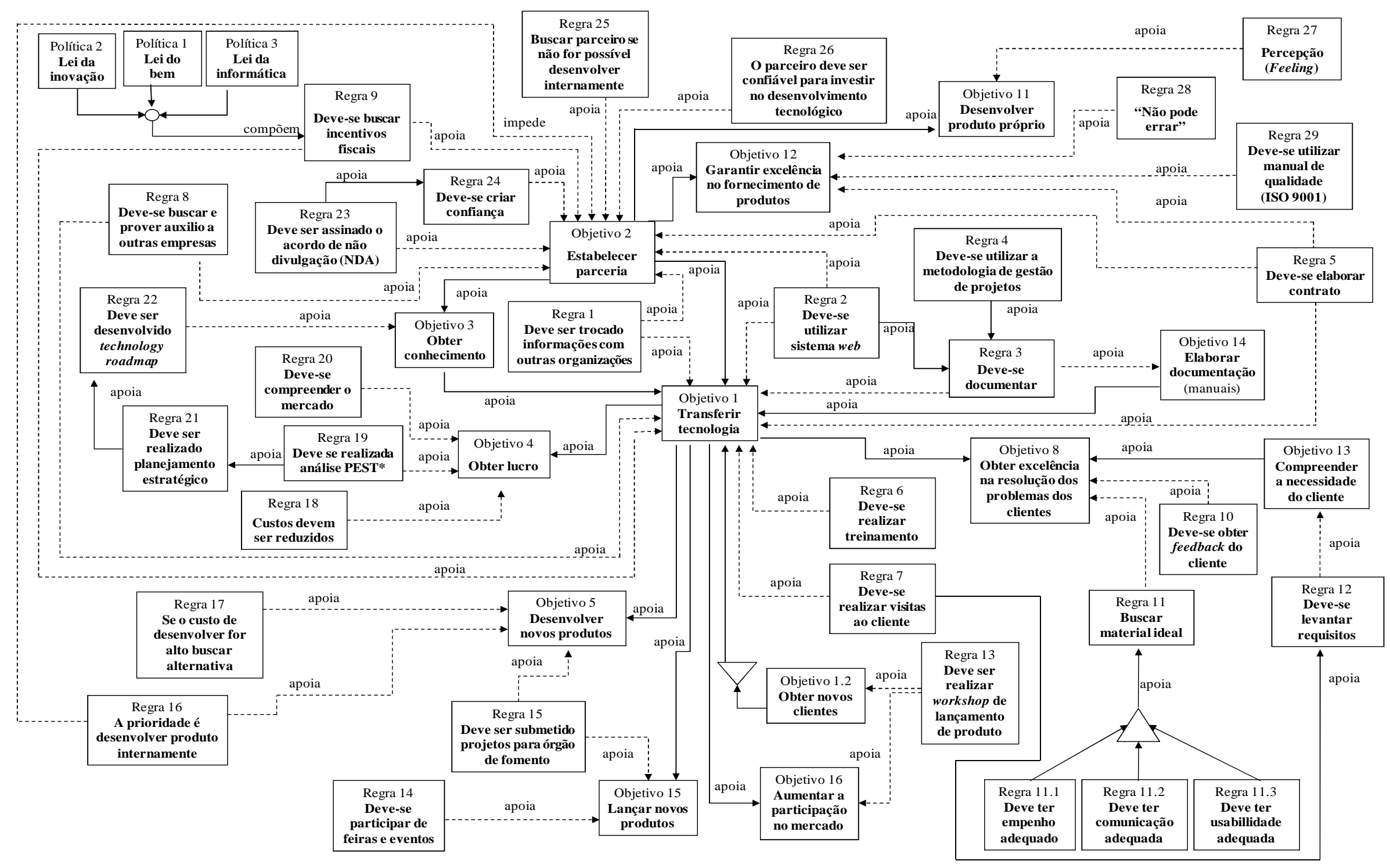

Figura 5 - Modelo de regras de negócio (as-is) 
Para obter lucro (Objetivo 4) existem algumas regras. Os custos devem ser reduzidos (Regra 18), deve ser realizada a análise política, econômica, social e tecnológica - PEST (Objetivo 19) e por fim deve-se compreender o mercado (Regra 20). A análise PEST (Objetivo 19) apoia a realização do planejamento estratégico (Regra 21) que por sua vez apoia o desenvolvimento do mapeamento da tecnologia conhecido como technology roadmap (Regra 22) que auxilia obter conhecimento (Objetivo 3).

Para desenvolver novos produtos (Objetivo 5) a prioridade é desenvolver produto internamente (Regra 16), deve-se buscar alternativas se o custo de desenvolver for alto (Regra 17), e deve-se submeter projeto para órgão de fomento (Regra 15). A submissão do projeto (Regra 15) apoia a empresa alcançar o objetivo de lançar novos produtos (Objetivo 15) que também é apoiado pela regra de participar de feiras e eventos (Regra 14).

Os objetivos aumentar a participação no mercado (Objetivo 16) e obter novos clientes (Objetivo 1.2) são apoiados pela regra de realizar workshop de lançamento de produto (Regra 13).

Obter excelência na resolução dos problemas dos clientes (Objetivo 8) é apoiado pelo retorno do cliente (Regra 10), pela busca de material ideal (Regra 11) em termos de empenho adequado (Regra 11.1), comunicação adequada (Regra 11.2) e usabilidade adequada (Regra 11.3), e por compreender a necessidade do cliente (Objetivo 13).

Para compreender a necessidade do cliente (Objetivo 13) é necessário levantar requisitos (Regra 12). A realização de visitas ao cliente (Regra 7) é um dos meios que auxiliam a levantar os requisitos (Regra 12).

Para transferir tecnologia (Objetivo 1) as empresas se apoiam na troca de informação com outras organizações (Regra 1) que também auxilia no estabelecimento de parceria (Objetivo 2), na utilização de um sistema web (Regra 2) que por sua vez apoia documentar (Regra 3). Para documentar (Regra 3) utiliza-se uma metodologia de gestão de projetos (Regra 4). Ao documentar (Regra 3) é possível alcançar o objetivo de elaborar documentação - manuais (Regra 14) que auxilia transferir tecnologia (Objetivo 1).

A transferência (Objetivo 1) é apoiada ainda pela regra elaborar contrato (Regra 5), realizar treinamento (Regra 6), realizar visitas ao cliente (Regra 7), buscar e prover auxilio a outras empresas (Regra 8), buscar incentivos fiscais (Regra 9) no que se refere a lei da inovação (Política 2), lei do bem (Política 1), e lei da informática (Política 3).

Estabelecer parcerias (Objetivo 2) apoia transferir tecnologia (Objetivo 1), obter conhecimento (Objetivo 3), ter excelência no fornecimento de produtos (Objetivo 12) e desenvolver produto próprio (Objetivo 11). 
Garantir excelência no fornecimento de produtos (Objetivo12) é apoiado pelas regras elaborar contrato (Regra 5), utilizar manual de qualidade (Regra 29) e a filosofia de "não poder errar" (Regra 28). Desenvolver produto próprio é apoiado pela percepção (Regra 27).

O objetivo de estabelecer parceria (Objetivo 2) é apoiado pelas regras trocar informações com outras organizações (Regra 1), utilizar sistema web (Regra 2), elaborar contrato (Regra 5), buscar e prover auxílio a outras organizações (Regra 8), assinar acordo de não divulgação (Regra 23) que por sua vez apoia criar confiança (Regra 24), buscar incentivos fiscais (Regra 9), buscar parceiro se não for possível desenvolver internamente (Regra 25), e o parceiro deve ser confiável para investir no desenvolvimento tecnológico (Regra 26). A regra de priorizar o desenvolvimento do produto internamente (Regra 16) impede estabelecer parceria (Objetivo 2).

\subsubsection{Modelo de Conceitos}

A Figura 6 apresenta o modelo de conceitos que norteia a transferência tecnologiaproduto.

A transferência de tecnologia (Objetivo 1) é influenciada pela cultura organizacional (Conceito 8) e pela característica da tecnologia (Conceito 20) em termos de novidade (Conceito 21), complexidade (Conceito 22) e grau do conhecimento tácito (Conceito 23).

O conhecimento (Conceito 12) é um conceito importante para transferir tecnologia (Objetivo 1) e apoiar o objetivo de desenvolver produto próprio (Objetivo 11).

A comunicação (Conceito 9) apoia as empresas estabelecer parcerias (Objetivos 2) e transferir tecnologia (Objetivo 1) e é influenciada pela diferença de linguagem (Conceito 10).

Documentos (Conceito 16) como manuais (Conceito 17), requisito (Conceito 18) e homologação (Conceito 19), royalties e licenciamento (Conceito 24), aplicação da tecnologia (Conceito 25), informação (Conceito 26), sistemas web (Conceito 27), lei da informática (Conceito 28), lei da inovação (Conceito 29), validação da tecnologia (Conceito 30), treinamentos (Conceito 31), formalismo (Conceito 32), equipe (Conceito 33), lei do bem (Conceito 34), confidencialidade (Conceito 35) e infra-estrutura (Conceito 36) também são conceitos que apoiam o objetivo de transferir tecnologia (Objetivo 1). 


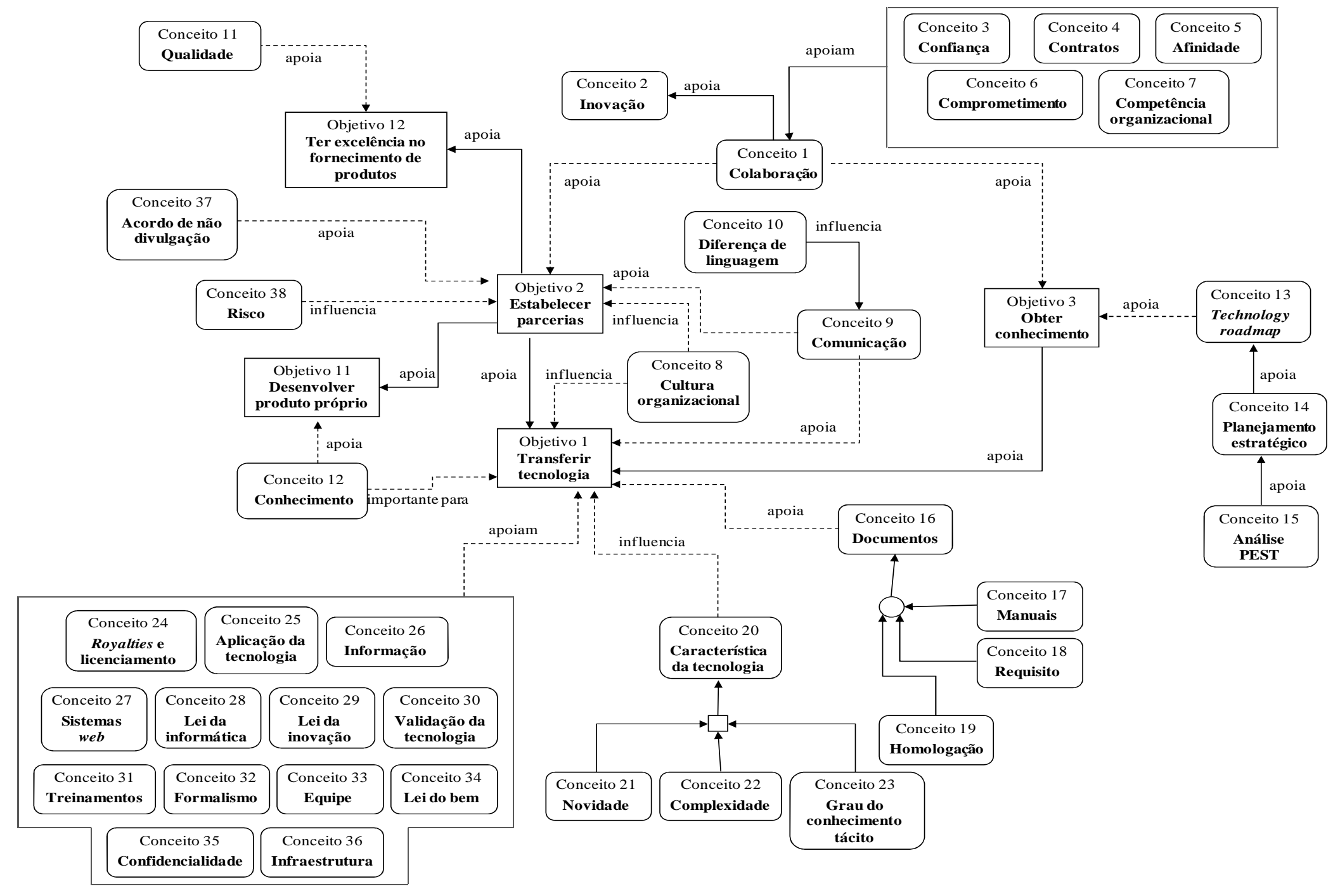

Figura 6 - Modelo de conceitos (as-is) 
Para obter conhecimento (Objetivo 3) que auxilia transferir tecnologia (Objetivo 1) é importante realizar o technology roadmap (Conceito 13) que é apoiado pelo planejamento estratégico (Conceito 14) que por sua vez é apoiado pela análise PEST (Conceito 15).

Estabelecer parcerias (Objetivo 2) é influenciado pelo risco (Conceito 38) e é apoiado pelos conceitos de acordo de não divulgação (Conceito 37) e de colaboração (Conceito 1) que também apoia o objetivo obter conhecimento (Objetivo 3). O conceito de colaboração apoia a inovação (Conceito 2) e é auxiliado pelos conceitos de confiança (Conceito 3), contratos (Conceito 4), afinidade (Conceito 5), comprometimento (Conceito 6) e competência organizacional (Conceito 7).

Estabelecer parcerias (Objetivo 2) apoia ter excelência no fornecimento de produtos (Objetivo 12) que é amparado pelo conceito de qualidade (Conceito 11).

\subsubsection{Modelo de Processo de Negócio a Partir do Desenvolvimento da Tecnologia}

A Figura 7 apresenta o modelo de processo de negócio que norteia a transferência tecnologia-produto a partir do desenvolvimento de pesquisas.

O processo de transferência de tecnologia é composto por 8 processos realizados pela empresa e um processo externo realizado pelo parceiro. Inicia-se com os interesses em desenvolver novos produtos que são discutidos em reuniões entre os membros da diretoria. Posteriormente, o departamento de P\&D em conjunto com a diretoria e o departamento comercial executa a atividade de prospecção tecnológica (Processo 1) criando um portfólio de ideias. Essas ideias passam por uma análise de viabilidade técnica (Processo 2) pelo departamento de P\&D que resulta nas especificações do produto ou sistemas, subsistemas e componentes (SSCs).

Diante das especificações e de informações sobre fontes de fomento ou incentivos, o produto começa a ser desenvolvido sob a responsabilidade do departamento de P\&D (Processo 4) que desenvolve especificações de soluções. Ao realizar a análise de viabilidade (Processo 2) é desempenhado também a análise de fazer ou comprar (make or buy) a tecnologia (Processo 3) pelo departamento de P\&D e a diretoria. Quando é decidido pela elabora-se o contrato, a lista de requisitos tecnológicos, define-se a programação de entregas e desenvolve-se os protótipos ou códigos ou desenhos que são compartilhados com o parceiro responsável pelo desenvolvimento (Processo Externo 1). 


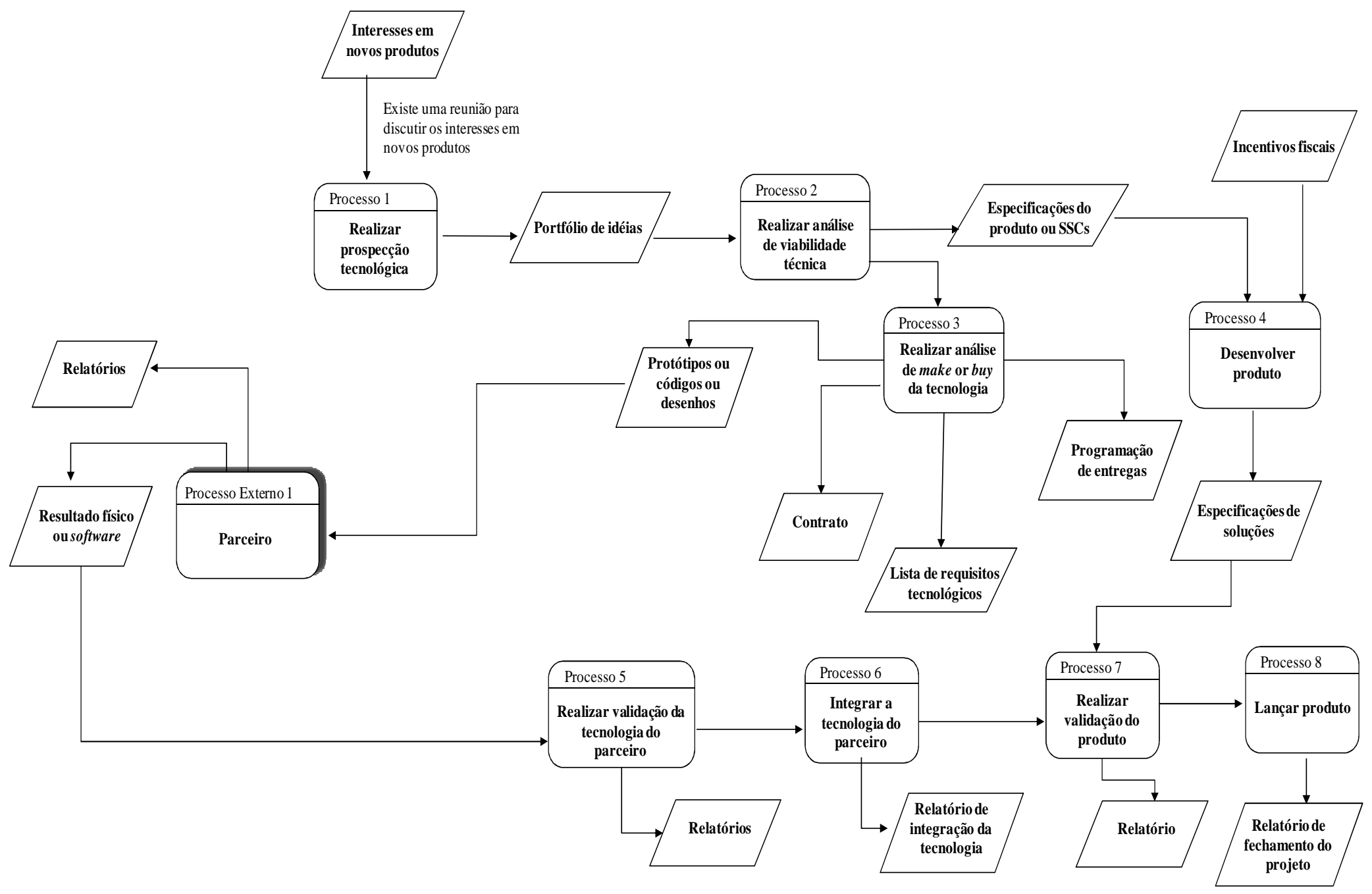

Figura 7 - Modelo de processo de negócio 1 (as-is) 
Como resultado final das atividades realizadas pelo parceiro tem-se o resultado físico ou software que passará por uma validação (Processo 5) pelo departamento de P\&D que produzirá os relatórios. Depois da tecnologia validada a mesma é integrada ao produto da empresa (Processo 6) e é gerado um relatório técnico do produto. Posteriormente, ocorre a validação do produto (Processo 7) pelo cliente no qual são gerados relatórios e por fim o lançamento (Processo 8).

Quando a opção da empresa é o desenvolvimento interno não existem os processos 5 e 6 .

A seguir apresenta-se o detalhamento de cada processo.

\section{Processo 1: Realizar Prospecção Tecnológica}

A Figura 8 apresenta o processo realizar prospecção tecnológica.

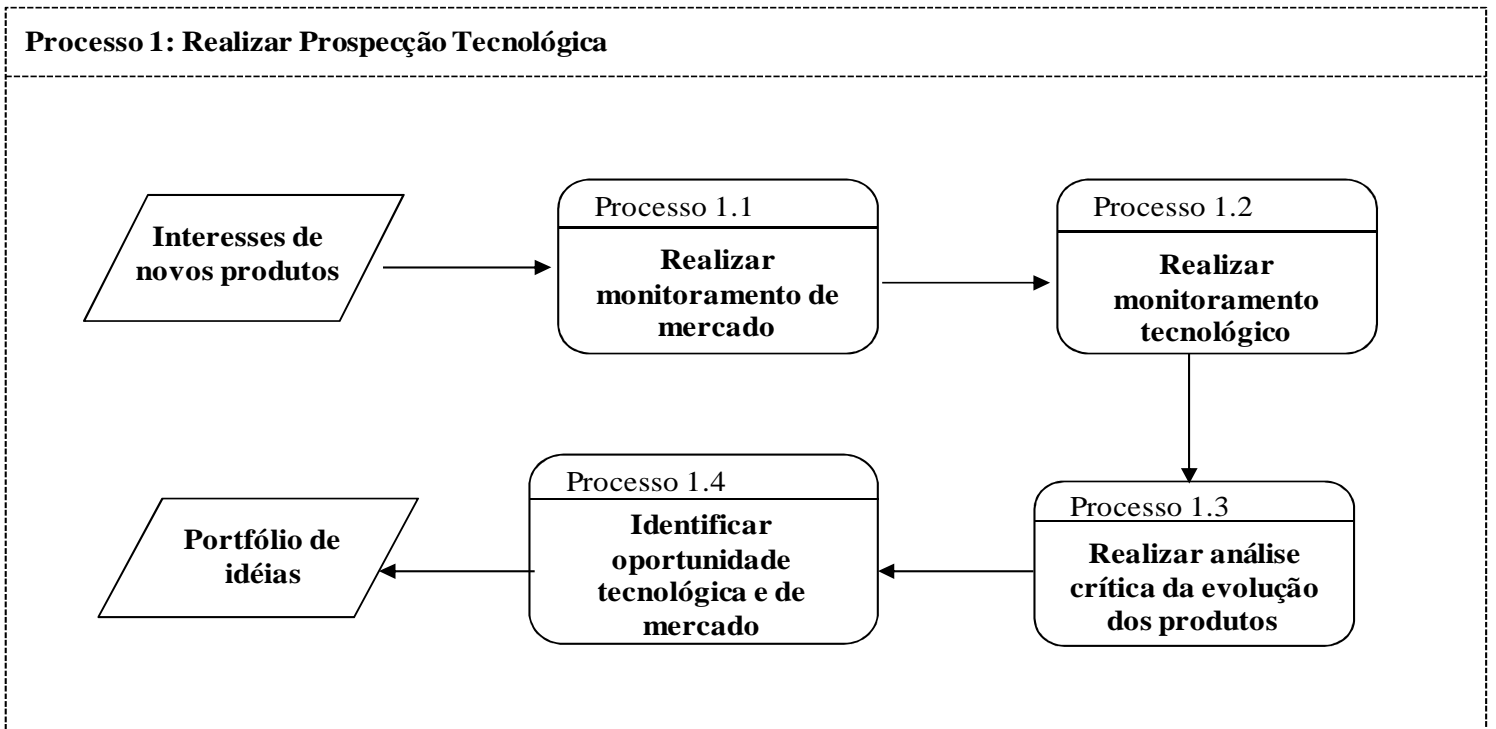

Figura 8 - Sub-processo 1 (as-is)

O interesse em novos produtos é a principal informação para iniciar a prospecção tecnológica (Processo 1). Diante desses interesses, é realizado o monitoramento de mercado (Processo 1.1) para identificar ou acompanhar tendências e lançamento de produtos no mercado, o monitoramento tecnológico (Processo 1.2) para acompanhar os avanços científicos e tecnológicos, uma análise crítica da evolução dos produtos (Processo 1.3) para identificar problemas relevantes visando a solução dos mesmos. Posteriormente, é feita a identificação de oportunidade tecnológica e de mercado (Processo 1.4) que resulta na definição do portfólio de ideias. 


\section{Processo 2: Realizar Análise de Viabilidade Técnica}

A Figura 9 apresenta o processo realizar análise de viabilidade tecnológica.

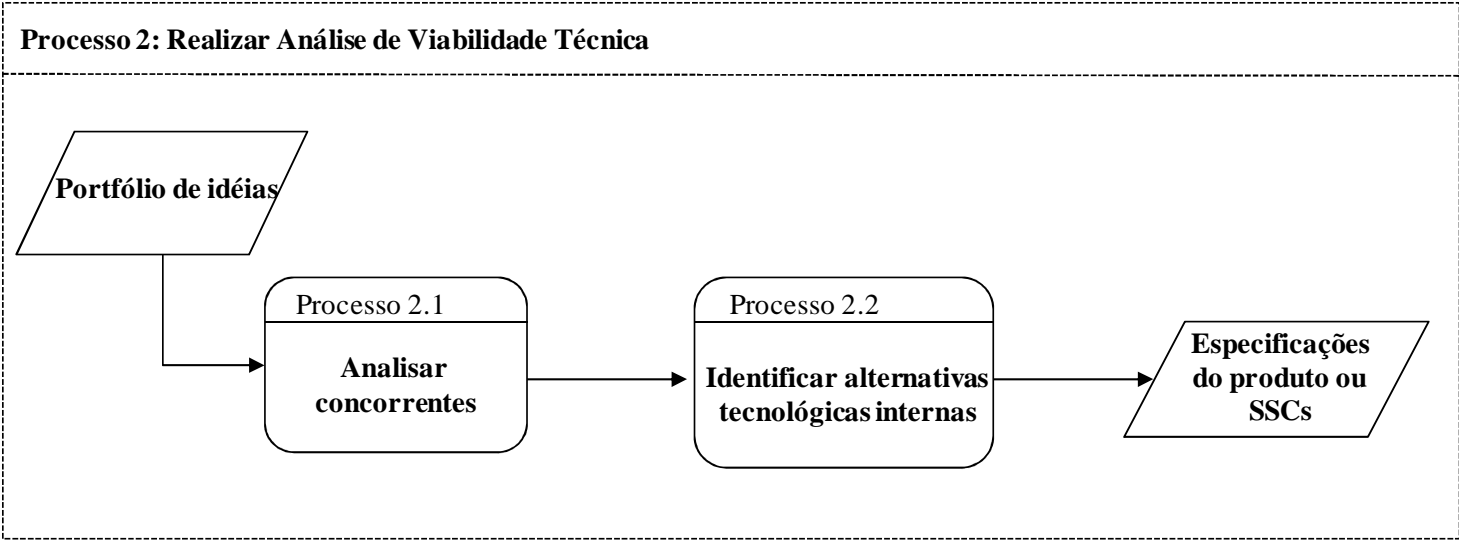

Figura 9 - Sub-processo 2 (as-is)

A partir do portfólio de ideias são analisados os possíveis concorrentes (Processo 2.1) para verificar a tecnologia que eles utilizam, como eles fazem o produto. Logo após os produtos dos concorrentes são analisados e identificam-se alternativas tecnológicas desenvolvidas pela empresa (Processo 2.2) e são definidas as especificações do produto ou SSCs.

\section{Processo 3: Realizar Análise de Make or Buy da Tecnologia}

A Figura 10 apresenta o processo realizar análise de make or buy da tecnologia.

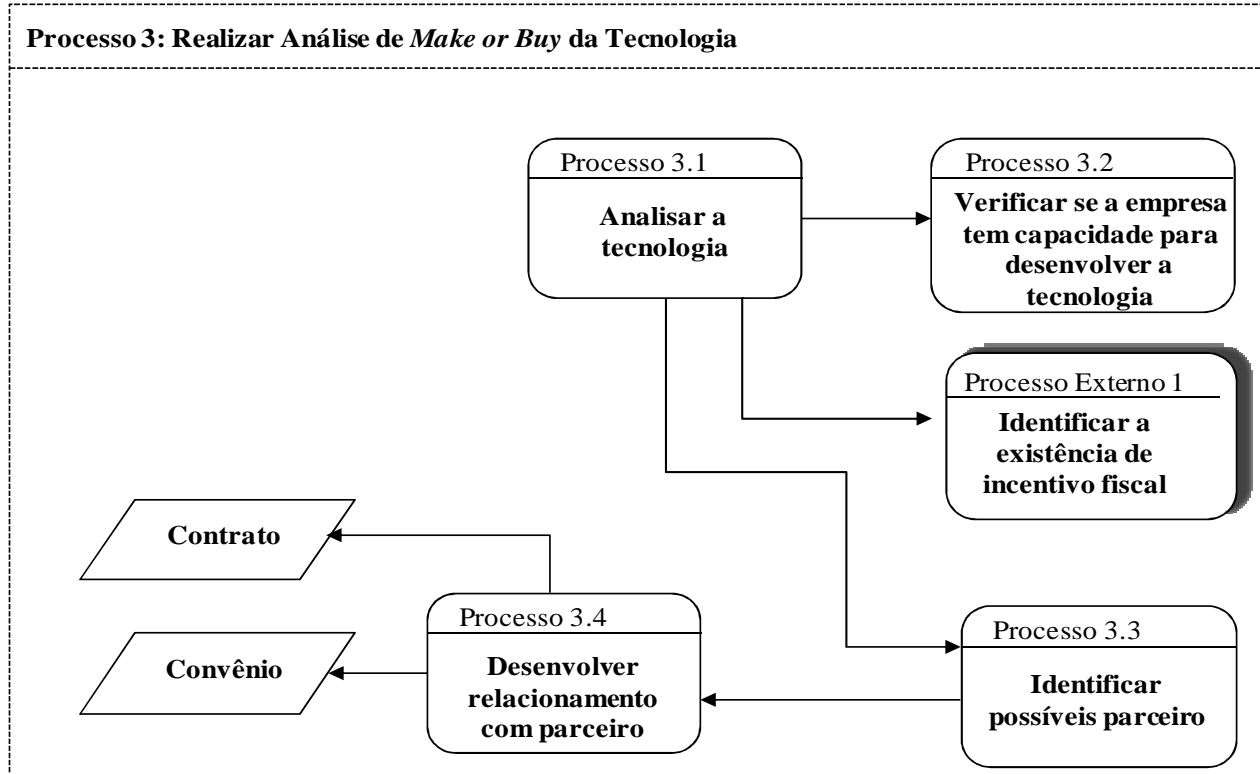

Figura 10 - Sub-processo 3 (as-is) 
A análise de make or buy da tecnologia (Processo 3) ocorre concomitantemente com o processo de desenvolvimento de produto (Processo 4) e inicia com a análise da tecnologia (Processo 3.1) na qual avalia-se os custos de produção e aquisição. Posteriormente, verificase a capacidade da empresa para desenvolver a tecnologia (Processo 3.2), ou seja, verifica-se os equipamentos, habilidades disponíveis na empresa para desempenhar ou apoiar determinada atividade. Ainda, após o processo 3.1, identifica-se a existência de incentivo fiscal (Processo Externo 1) que possa apoiar o desenvolvimento e também busca-se um parceiro (Processo 3.3) que possua as qualificações necessárias para desenvolver determinada tecnologia. Identificado o parceiro, é desenvolvido o relacionamento com o parceiro (Processo 3.4) que resultam em convênios e contratos.

\section{Processo 4: Desenvolver produto}

A Figura 11 apresenta o processo desenvolver produto.

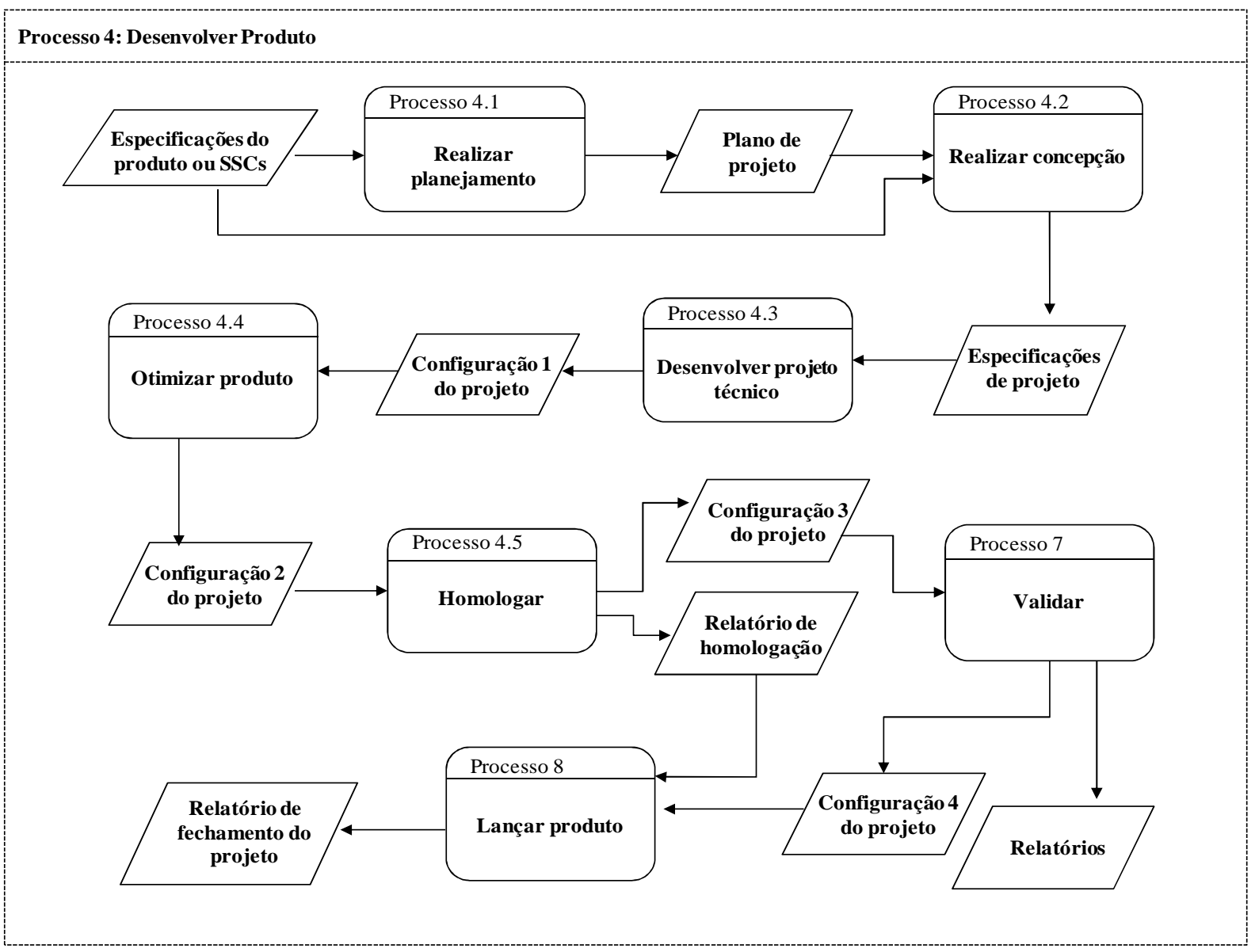

Figura 11 - Sub-processo 4 (as-is)

O desenvolvimento do produto (Processo 4) é constituído por 7 etapas. A primeira é o planejamento do projeto (Processo 4.1) que tem como entrada as especificações do produto 
ou SSCs. Desse planejamento (Processo 4.1) resulta o plano de projeto com informações sobre cronograma do projeto, alocação de recursos, custos e riscos do projeto.

O plano de projeto e as especificações do produto são informações utilizadas na etapa de concepção (Processo 4.2). Nesta etapa são definidos requisitos técnicos de concepção de produto, são desenvolvidos modelos técnicos e de custo do produto. Como resultado dessa etapa tem-se as especificações do projeto.

As especificações do projeto são entrada para a etapa de projeto técnico (Processo 4.3) que tem como atividades a incorporação de novas tecnologias, aquisição de materiais e componentes e o desenvolvimento e a realização de testes de protótipo. Ao final desta etapa tem-se a configuração 1 do projeto.

A configuração 1 do projeto é entrada para a etapa de otimização (Processo 4.4) que tem por objetivo aumentar a robustez, a confiabilidade do produto e melhorar aspectos físicos do produto. Como resultado desta etapa tem-se a configuração 2 do projeto.

A configuração 2 do projeto é entrada para a etapa de homologação (Processo 4.5). Nesta etapa é desenvolvida a embalagem do produto, é elaborada uma documentação técnica detalhada sobre a fabricação e montagem, o produto é fabricado, montado e integrado, os protótipos são testados e cálculos de capabilidade do processo são realizados. No final desta etapa tem-se a configuração 3 do projeto e é criado um relatório de homologação informando as modificações que foram necessárias.

A configuração 3 do projeto é entrada para a etapa de validação (Processo 7) onde são planejados a validação e a certificação do produto de acordo com as normas técnicas, protótipos piloto são fabricados, montados e integrados para que passe por um processo de experimentação pelos potenciais clientes. Realizam-se testes de certificação. No final desta etapa tem-se a configuração 4 do projeto e relatórios.

A configuração 4 do projeto e o relatório de homologação são entradas para a etapa de lançamento (Processo 8). Nesta etapa é desenvolvido um plano de marketing do produto, plano de produção, é projetada a logística de distribuição, o sistema de gestão da empresa é alimentado, o produto é monitorado até que o volume de produção atinja as metas estabelecidas no planejamento do projeto. Ao final desta etapa tem-se o relatório de fechamento do projeto.

\section{Processo 5: Realizar Validação da Tecnologia do Parceiro}

A Figura 12 apresenta o processo realizar validação da tecnologia do parceiro. 
Processo 5: Realizar Validação da Tecnologia do Parceiro

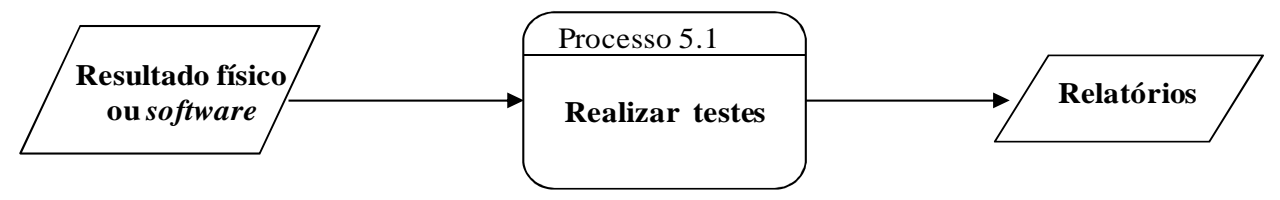

Figura 12 - Sub-processo 5 (as-is)

De posse do artefato físico ou software desenvolvido pelo parceiro, a empresa realiza testes (Processo 5.1) para verificar características e desempenho do produto. Por fim, é elaborado relatórios.

\section{Processo 6: Integrar Tecnologia do Parceiro}

A Figura 13 apresenta o processo integrar tecnologia do parceiro.

Processo 6: Integrar a Tecnologia do Parceiro

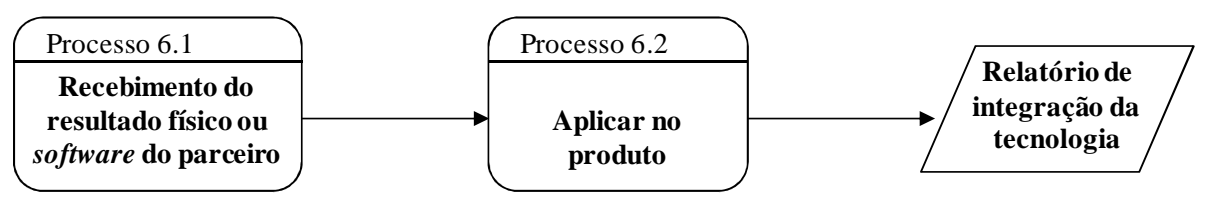

Figura 13 - Sub-processo 6 (as-is)

A empresa recebe o artefato físico ou software do parceiro (Processo 6.1) com as melhorias implementadas se necessário. Então esse artefato é aplicado (incorporado) no produto da empresa (Processo 6.2), gerando um relatório da integração da tecnologia, ou seja, um relatório técnico do produto.

\section{Processo 7: Realizar Validação do produto}

A Figura 14 apresenta o processo realizar validação do produto. 


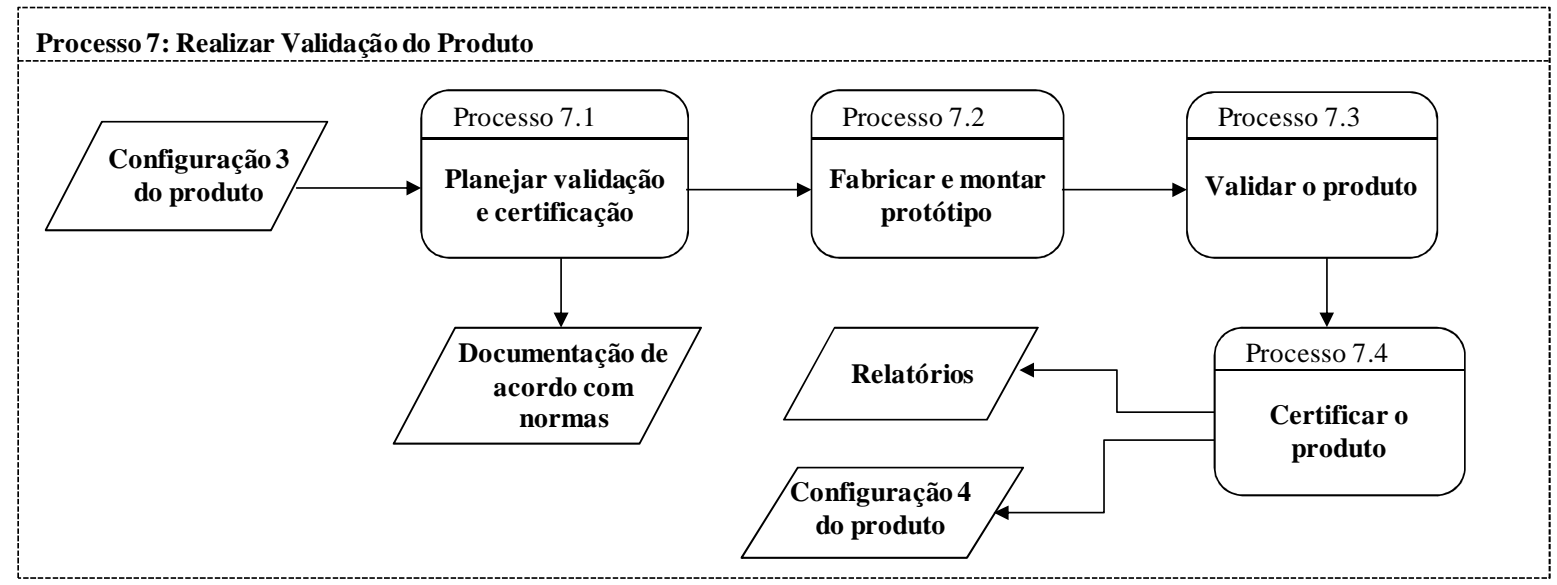

Figura 14 - Sub-processo 7 (as-is)

A configuração 3 do projeto é entrada para a etapa de validação (Processo 7) onde é planejada a validação e a certificação do produto (Processo 7.1). Como resultado dessa etapa tem-se os documentos do produto de acordo com as normas técnicas. Posteriormente, o protótipo piloto é fabricado, montado e integrado (Processo 7.2) para que passe por um processo de experimentação pelos potenciais clientes (Processo 7.3). Validado o produto, o mesmo é submetido a testes de certificação (Processo 7.4). No final desta etapa tem-se a configuração 4 do projeto e relatórios.

\section{Processo 8: Lançar produto}

A Figura 15 apresenta o processo lançar produto.

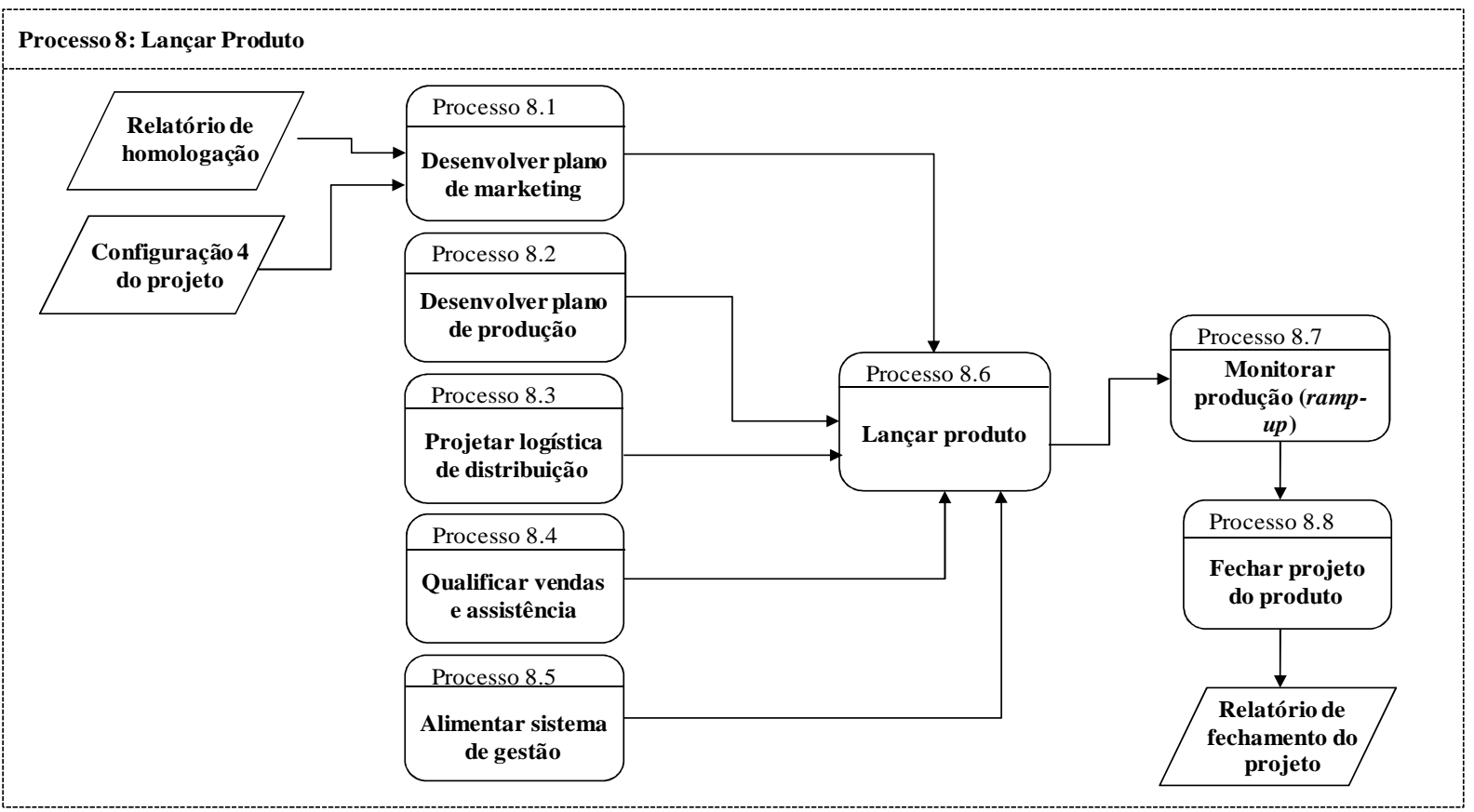

Figura 15 - Sub-processo 8 (as-is) 
A configuração 4 do projeto e o relatório de homologação são entradas para a etapa de lançamento (Processo 8). Nesta etapa é desenvolvido um plano de marketing do produto (Processo 8.1), plano de produção (Processo 8.2), é projetada a logística de distribuição (Processo 8.3), o pessoal de vendas e de assistência recebem qualificação (Processo 8.4), o sistema de gestão da empresa é alimentado (Processo 8.5), o produto então é lançado (Processo 8.6), e posteriormente, é monitorado o volume de produção (Processo 8.7) até que atinja as metas estabelecidas no planejamento do projeto. Por fim, o projeto do produto é finalizado (Processo 8.8). Ao final desta etapa tem-se o relatório de fechamento do projeto.

\subsubsection{Modelo de Processo de Negócio a Partir da Necessidade do Cliente}

A Figura 16 apresenta o modelo de processo de negócio que norteia a transferência tecnologia-produto a partir da necessidade do cliente.

O processo de transferência de tecnologia é composto por 2 diferentes fluxos de processos. O primeiro fluxo refere-se ao processo de desenvolvimento da tecnologia e o segundo pelo processo de desenvolvimento de produto.

O primeiro fluxo inicia com o processo realizar abertura do projeto (Processo 1) no qual o cliente e o departamento comercial estão envolvidos e que resulta nos documentos de termo de abertura do projeto e no contrato. Esses dois documentos são entradas para o processo coletar requisitos (Processo 2) no qual o cliente, o departamento de P\&D ou engenharia ou projetos participam. Após a coleta de requisitos (Processo 2) inicia-se o desenvolvimento da tecnologia ou solução (Processo 3) pelo departamento de P\&D, compras e cliente participam e que resulta no protótipo. Esse protótipo é validado internamente (Processo 4) pelo departamento de P\&D e que resulta no relatório de desenvolvimento. Posteriormente, inicia-se o processo de adaptar a tecnologia para o cliente (Processo 5) no qual o cliente, departamento comercial e de P\&D estão envolvidos e que origina a documentação do desenvolvimento da tecnologia e a tecnologia adaptada. Diante da tecnologia adaptada é realizada a validação com o cliente (Processo 6) que resulta na documentação para treinamento e no contrato de produção. Logo após é realizada a aplicação da tecnologia no produto do cliente (Processo 7) em que o cliente e o departamento de P\&D participam. Por fim é realizado a pós-venda (Processo 8) pela assistência técnica ou equipe de suporte que emite um relatório de manutenção ou serviço. 


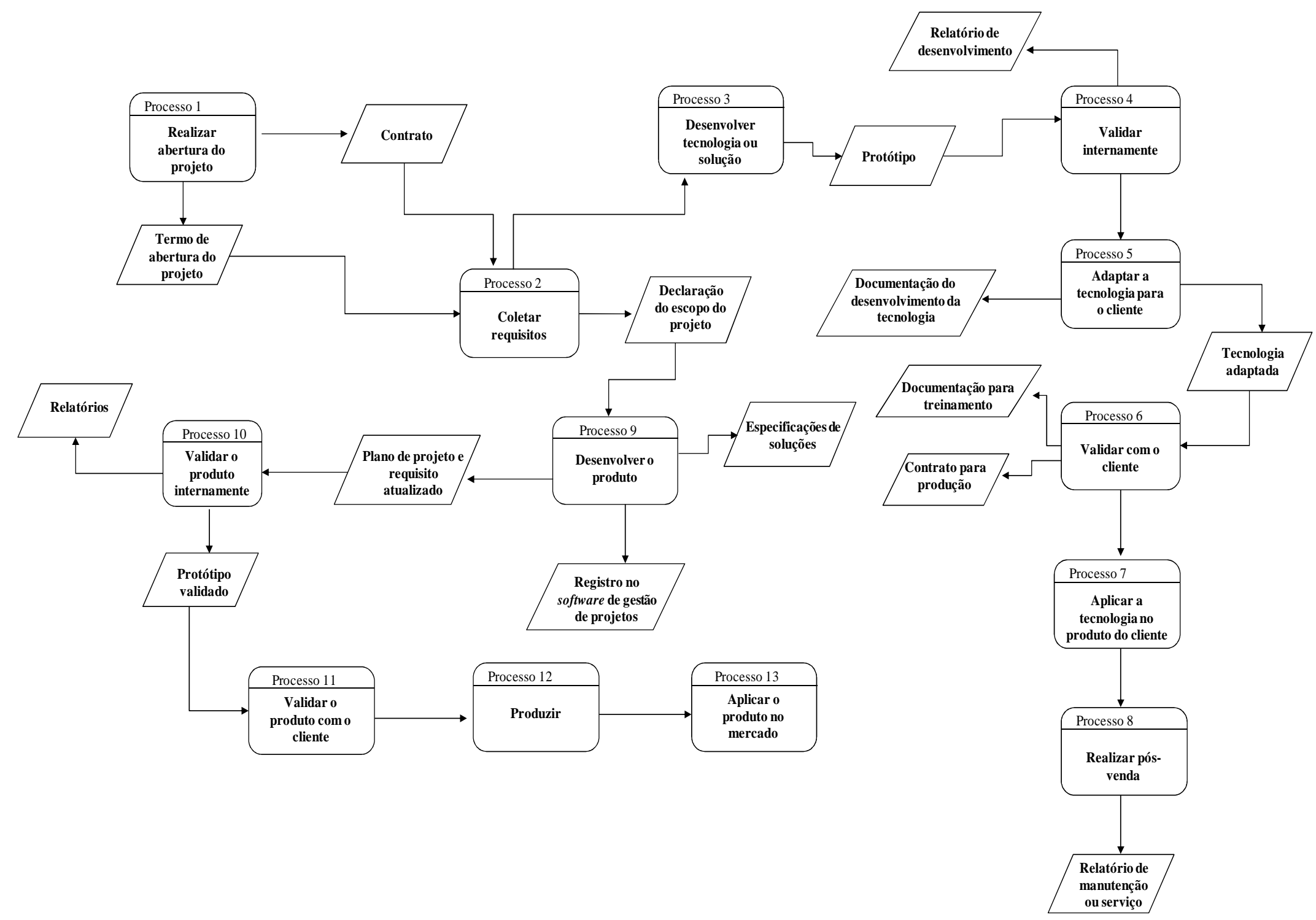

Figura 16 - Modelo de processo de negócio 2 (as-is) 
O segundo fluxo inicia com o processo realizar abertura do projeto (Processo 1) no qual o cliente e o departamento comercial estão envolvidos e que resulta nos documentos de termo de abertura do projeto e no contrato. Esses dois documentos são entradas para o processo coletar requisitos (Processo 2) no qual o cliente, o departamento de P\&D ou engenharia ou projetos participam e que resulta na declaração do escopo do projeto. Essa declaração é entrada para o desenvolvimento do produto (Processo 9) realizado pelo departamento de $\mathrm{P} \& \mathrm{D}$ e que resulta nas especificações de soluções, registro no software de gestão de projetos e plano do projeto e requisito atualizado. O plano de projeto é entrada para validar o produto internamente (Processo 10) que é desempenhado pelo departamento de $\mathrm{P} \& \mathrm{D}$ e que resulta em relatórios e protótipo validado. Posteriormente, o cliente valida o produto (Processo 11) e é iniciada a produção (Processo 12). Por fim, é aplicado o produto no mercado (Processo 13) no qual o cliente e o departamento comercial participam.

\section{Processo 1: Realizar abertura do projeto}

A Figura 17 apresenta o processo realizar abertura do projeto.

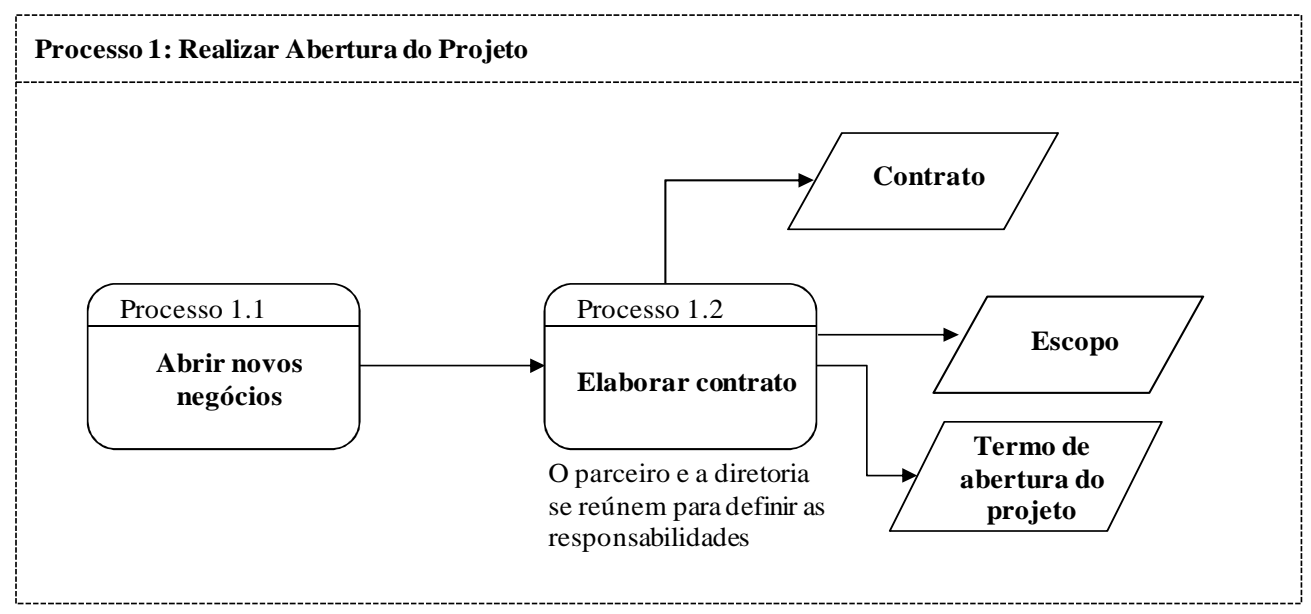

Figura 17 - Sub-processo 1 (as-is)

A abertura do projeto (Processol) consiste de dois sub-processos: abrir novos negócios (Processo 1.1) e elaborar contrato (Processo 1.2). Abrir novos negócios (Processo 1.1) está relacionado ao desenvolvimento de um novo produto ou a expansão de alguma área que a empresa trabalha. O processo elaborar contrato (Processo 1.2) acontece por meio de reuniões entre o parceiro e a diretoria para definir responsabilidades de cada uma das partes. Como resultado tem-se contrato, o escopo e o termo de abertura do projeto. 


\section{Processo 2: Coletar requisitos}

A Figura 18 apresenta o processo coletar requisitos.

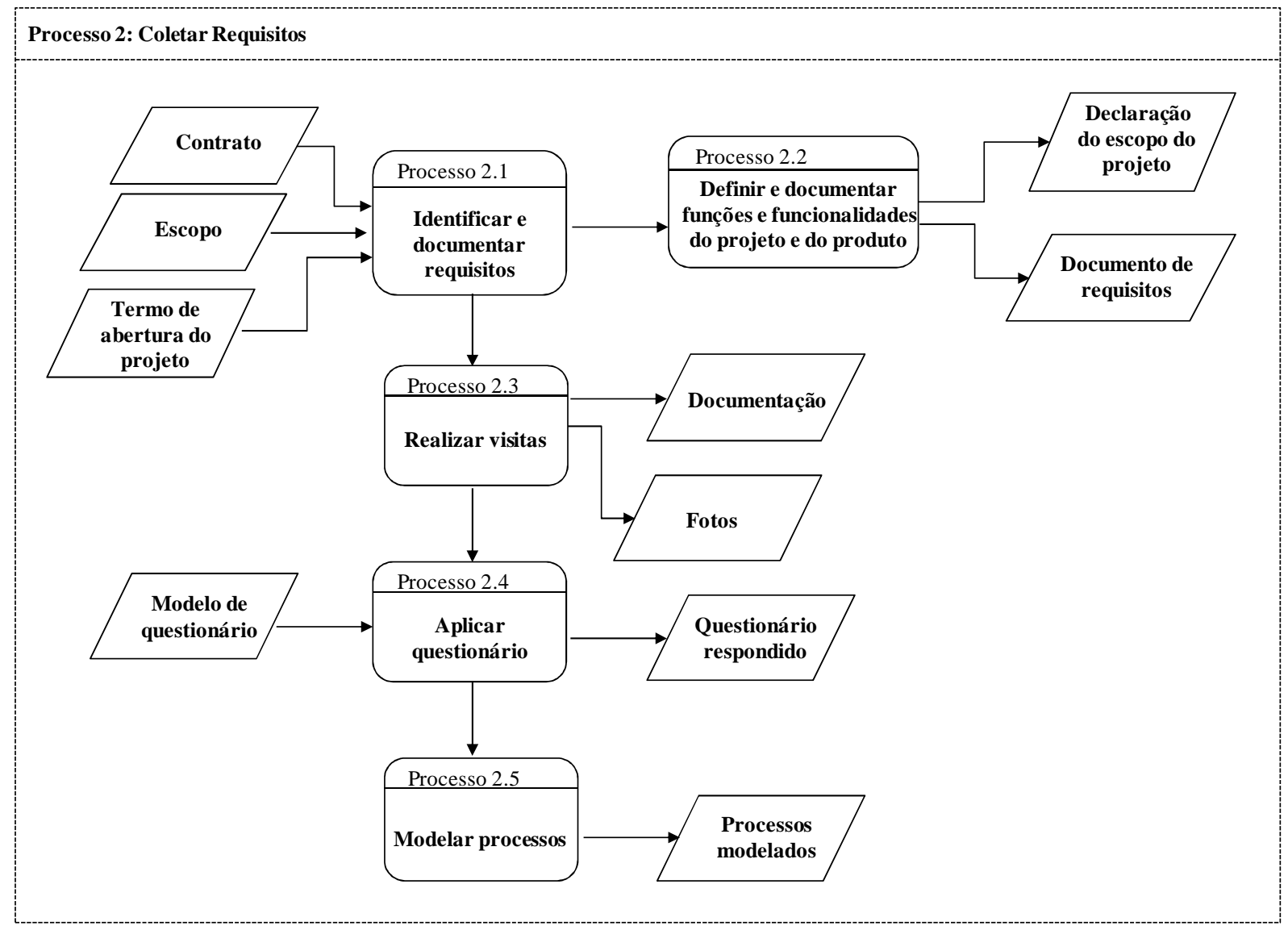

Figura 18 - Sub-processo 2 (as-is)

O contrato, o escopo e o termo de abertura do projeto são documentos que formalizam o início do projeto. A partir desses documentos inicia-se a identificação e documentação dos requisitos (Processo 2.1) e posteriormente defini-se e documentam-se as funções e funcionalidades do projeto e do produto (Processo 2.2) que resulta na declaração do escopo do projeto e no documento de requisitos. São realizadas visitas ao cliente (Processo 2.3) que originam documentos e fotos. Posteriormente, tem-se a etapa aplicar questionário (Processo 2.4), no qual utiliza-se de um modelo de questionário e que resulta no questionário respondido. Por fim, deve-se modelar processo (Processo 2.5) que gera um documento sobre os processos modelados.

\section{Processo 3: Desenvolver tecnologia}

A Figura 19 apresenta o processo desenvolver tecnologia. 


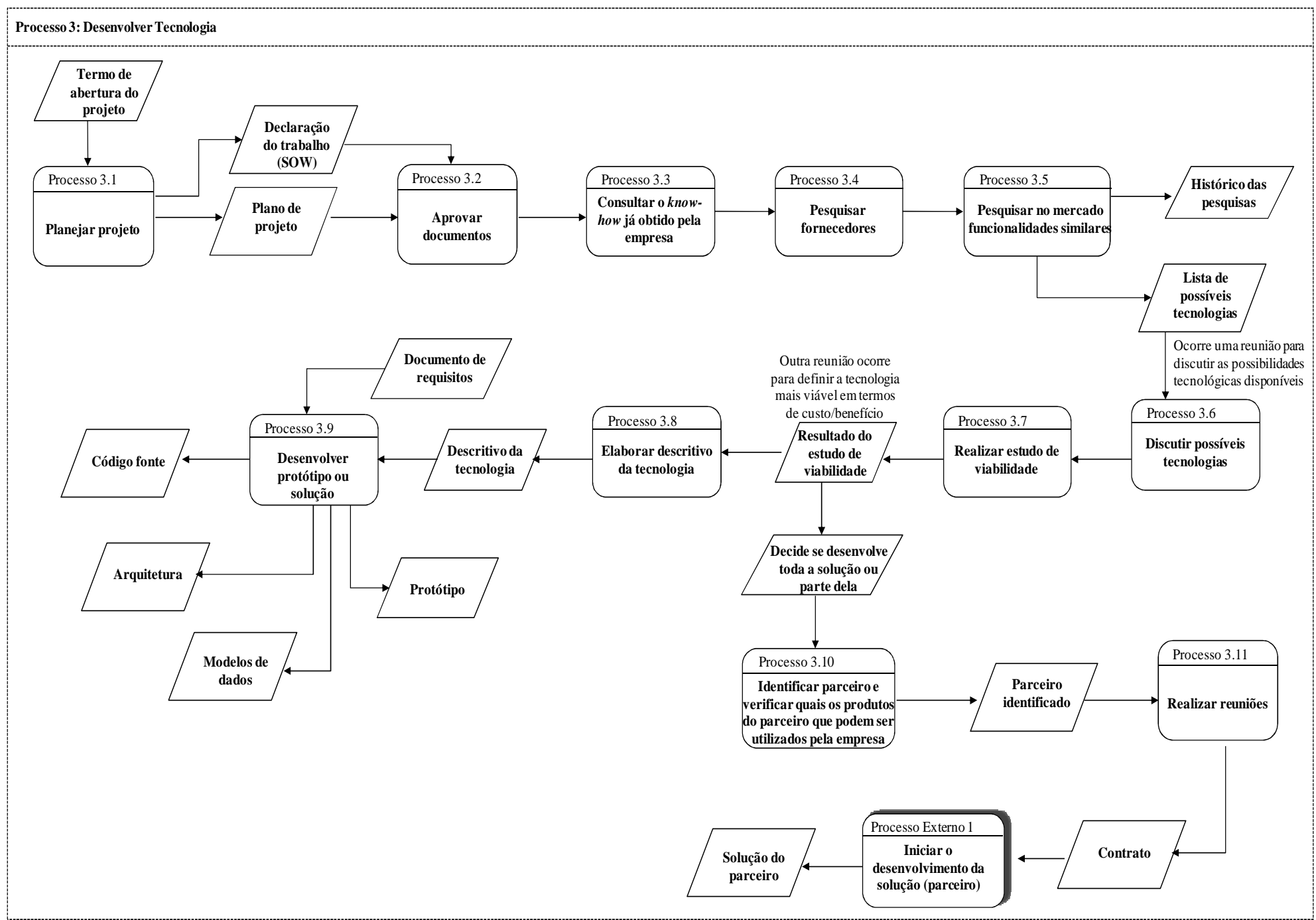

Figura 19 - Sub-processo 3 (as-is) 
Depois de coletar os requisitos (Processo 2) inicia-se a etapa planejar projeto (Processo 3.1). Nessa etapa identifica-se os envolvidos, a equipe, estima-se a duração do projeto, elaboram-se os documentos de declaração de trabalho e o plano de projeto, e o cliente deve aprovar tais documentos (Processo 3.2).

Posteriormente, é realizada uma consulta do know-how já obtido pela empresa (Processo 3.3) para verificar a existência de um conhecimento que possa ser utilizado ou melhorado. Também são realizadas pesquisas de fornecedores de peças ou tecnologias (Processo 3.4) para o desenvolvimento do projeto. Além disso, são realizadas pesquisas no mercado para verificar produtos que possam ter funcionalidades similares (Processo 3.5). Depois de buscar todas as informações necessárias, a empresa armazena um histórico de suas pesquisas e gera uma lista de possíveis tecnologias a ser desenvolvidas.

Logo após ocorre uma reunião para discutir as possibilidades tecnológicas disponíveis (Processo 3.6) e realizar o estudo de viabilidade (Processo 3.7). Diante do resultado deste estudo ocorre outra reunião para definir a tecnologia mais viável em termos de custo/benefício e também é decidido se a empresa desenvolver toda a solução ou parte dela. Caso é decida-se desenvolver parte da solução, a empresa identifica possíveis parceiros e verifica quais os produtos do parceiro que podem ser utilizado pela empresa (Processo 3.10). Sendo o parceiro identificado realizam-se reuniões (Processo 3.11) que resultam em um contrato que é o documento de entrada para o parceiro iniciar o desenvolvimento da solução (Processo Externo 1).

Após o resultado do estudo de viabilidade é desenvolvido o descritivo da tecnologia (Processo 3.8) que contém informações sobre as especificações da tecnologia. Esse documento junto com o documento de requisitos é a entrada para o desenvolvimento do protótipo ou solução (Processo 3.9) que resulta em documentos de código fonte, arquitetura, modelo de dados, e protótipo.

\section{Processo 4: Validar internamente}

A Figura 20 apresenta o processo validar internamente. 


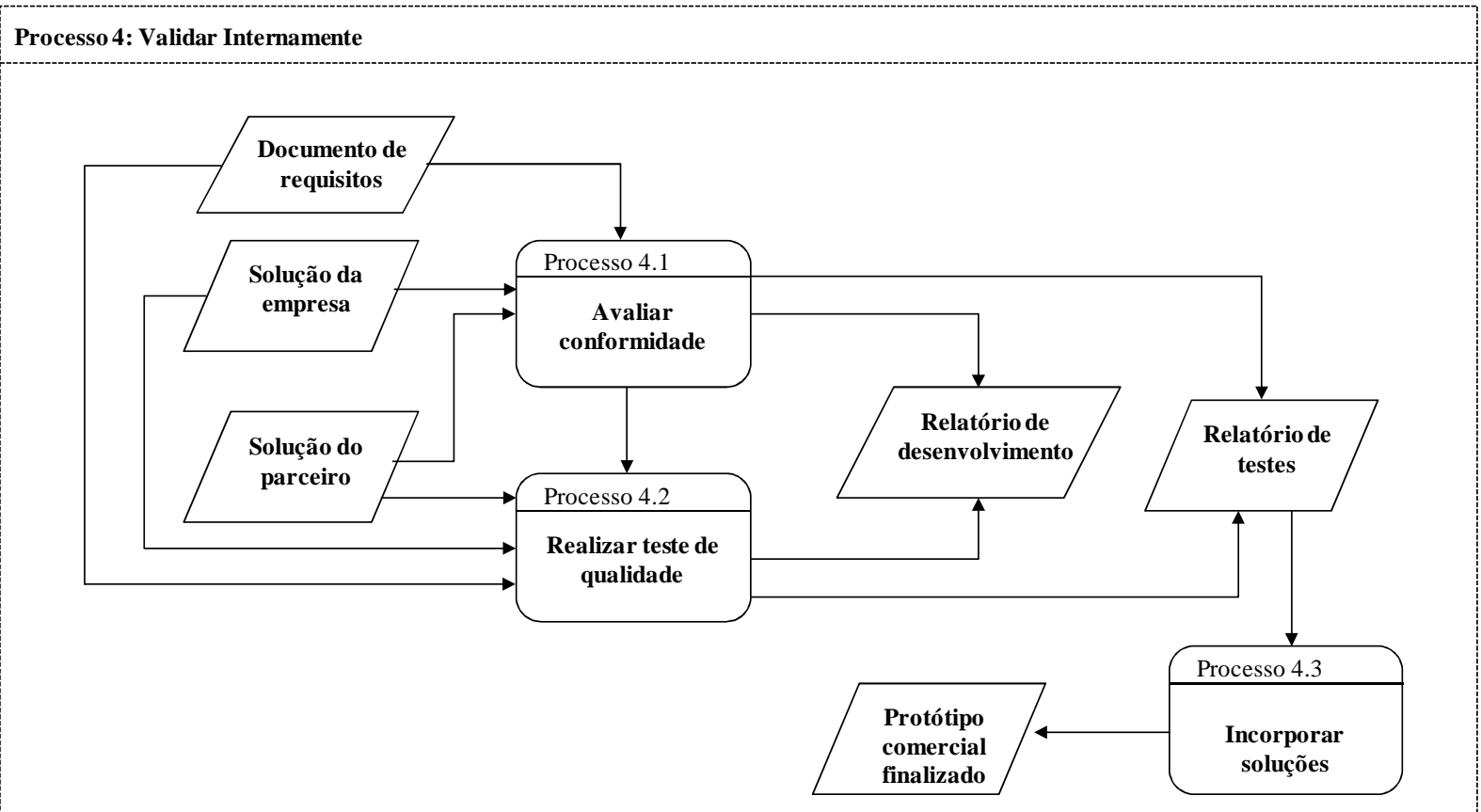

Figura 20 - Sub-processo 4 (as-is)

Diante da solução da empresa e do parceiro e do documento de requisitos é avaliada a conformidade (Processo 4.1) e realizado testes de qualidade (Processo 4.2) que resultam em relatórios de desenvolvimento e de testes. Posteriormente, inicia-se a etapa incorporar soluções (Processo 4.3) que por sua vez apresenta o protótipo comercial finalizado.

\section{Processo 5: Adaptar tecnologia para o cliente}

A Figura 21 apresenta o processo adaptar tecnologia para o cliente.

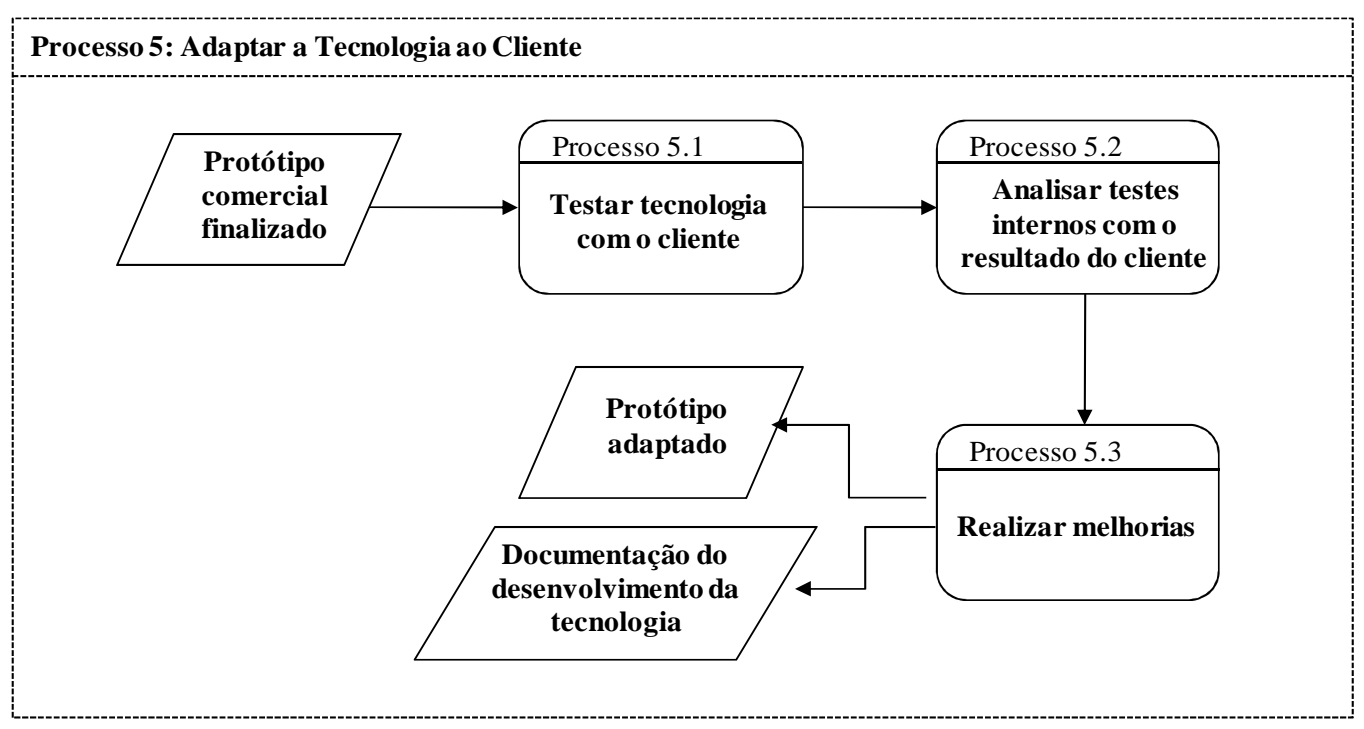

Figura 21 - Sub-processo 5 (as-is) 
Diante do protótipo comercial finalizado é realizado testes no cliente (Processo 5.1) considerando seu ambiente. Posteriormente, são analisados os resultados obtidos em testes realizados pela empresa e pelo cliente (Processo 5.2) para que se possa identificar problemas e então realizar melhorias (Processo 5.3) de acordo com a necessidade do cliente. Por fim, é desenvolvida a documentação sobre o desenvolvido da tecnologia.

\section{Processo 6: Validar com cliente}

A Figura 22 apresenta o processo validar tecnologia com o cliente.

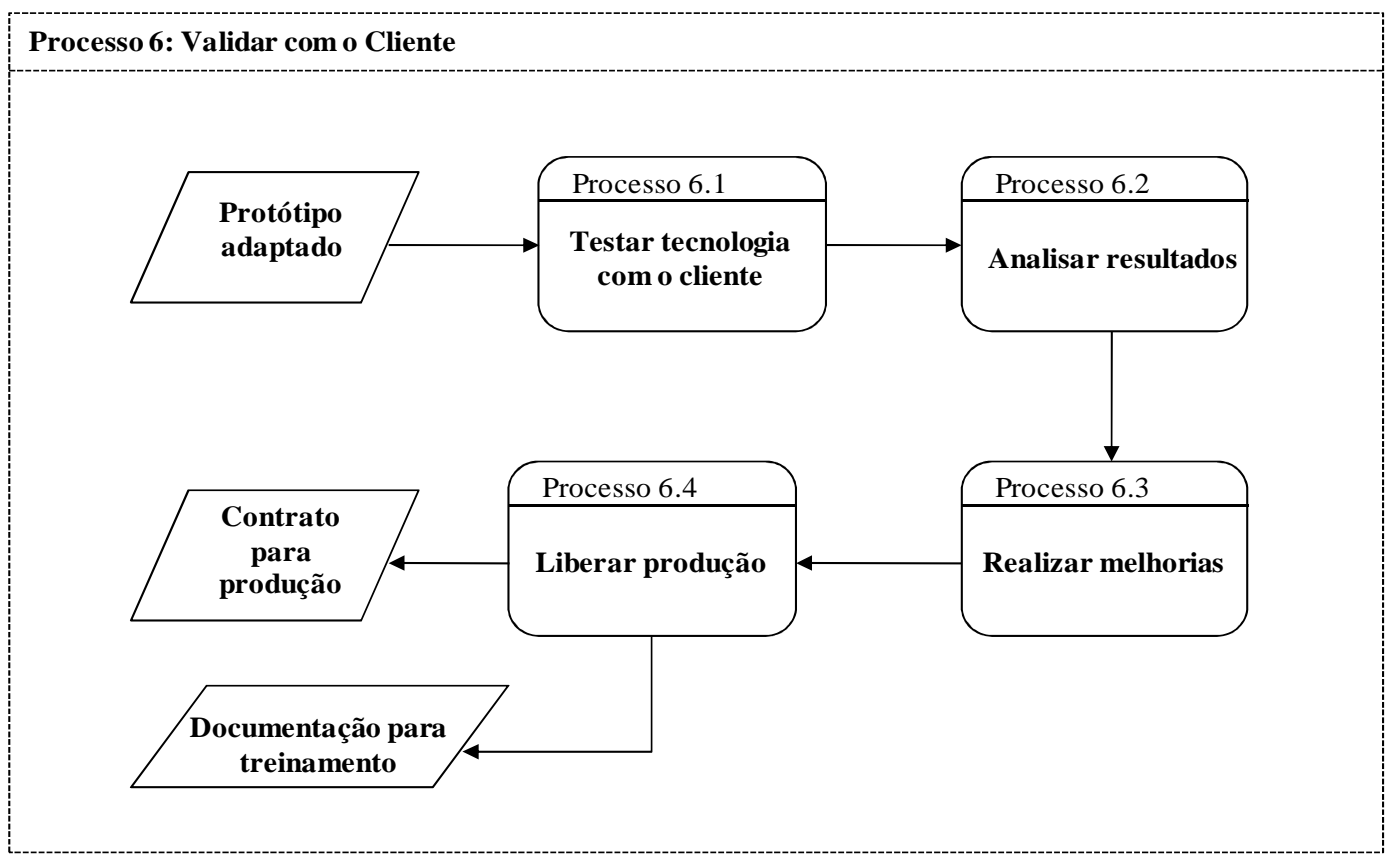

Figura 22 - Sub-processo 6 (as-is)

O protótipo adaptado é validado com o cliente (Processo 6 ) por meio de novos testes (Processo 6.1) e então é analisado os resultados (Processo 6.2). Caso necessário realizam-se as melhorias (Processo 6.3). Quando estiver de acordo com a necessidade do cliente é liberase a produção em escala (Processo 6.4) e elabora-se o contrato para produção e a documentação para treinamento.

\section{Processo 7: Aplicar a tecnologia no produto do cliente}

A Figura 23 apresenta o processo aplicar a tecnologia no produto do cliente. 
Processo 7: Aplicar a Tecnologia no Produto do Cliente

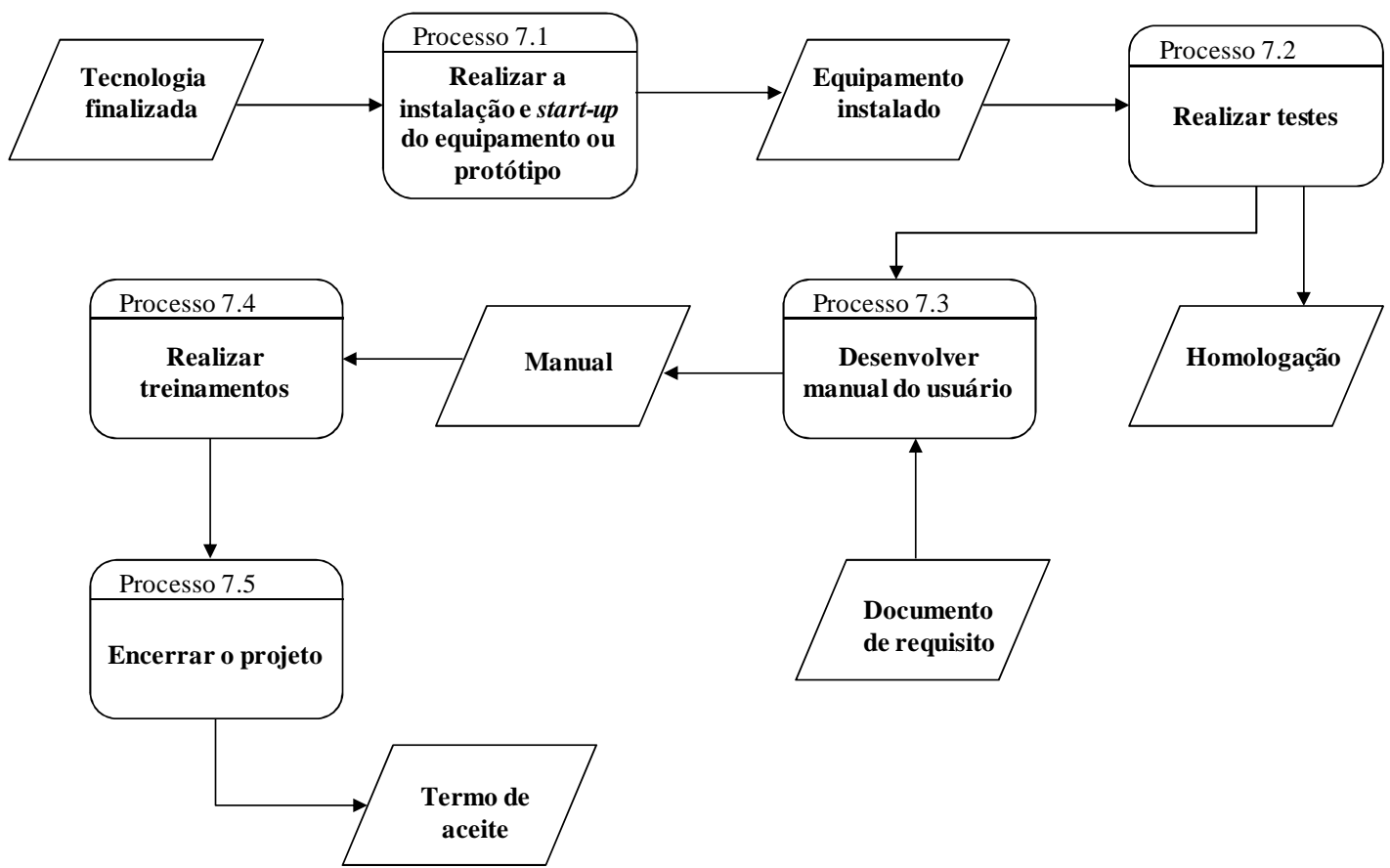

Figura 23 - Sub-processo 7 (as-is)

A partir da tecnologia finalizada é realizada a instalação e o funcionamento inicial (start-up) do equipamento ou protótipo (Processo 7.1). Com o equipamento instalado realizam-se testes (Processo 7.2) para validar a solução que resulta na homologação. Logo após desenvolve-se o manual do usuário (Processo 7.3) a partir do documento de requisito. Diante do manual realiza-se o treinamento (Processo 7.4) e encerra-se o projeto (Processo 7.5) que resulta em termo de aceite.

\section{Processo 8: Realizar pós-venda}

A Figura 24 apresenta o processo realizar pós-venda. 


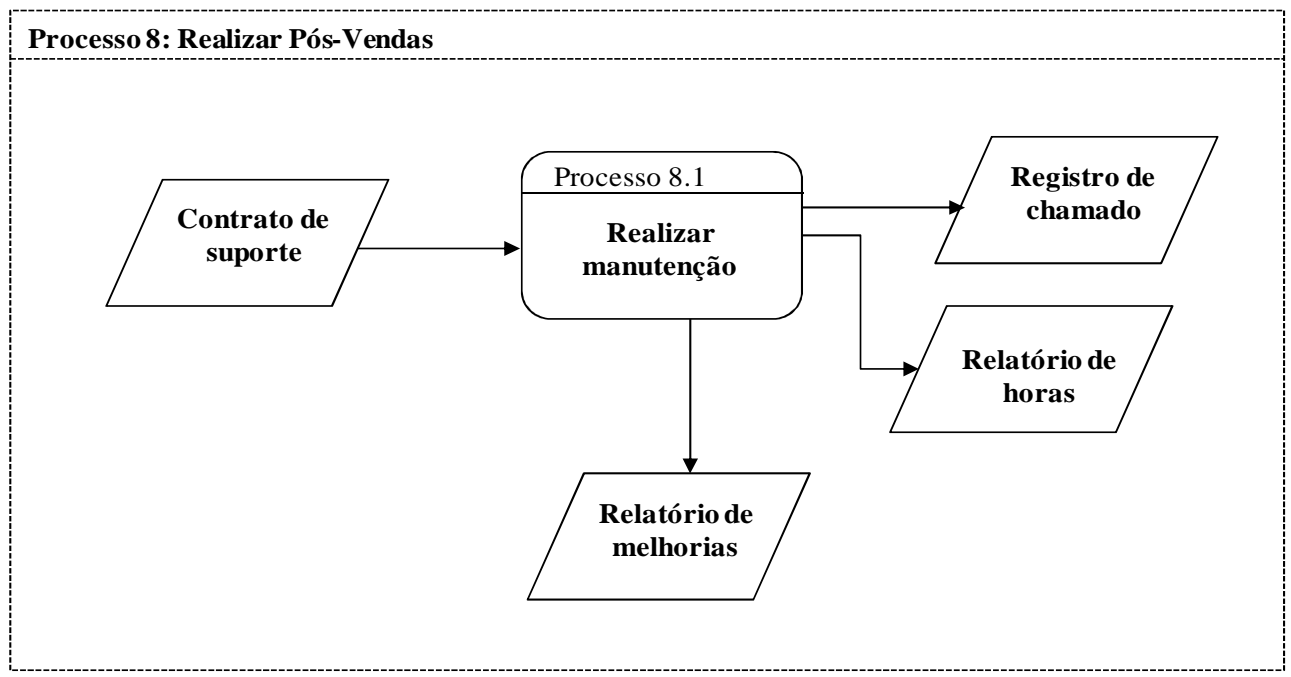

Figura 24 - Sub-processo 8 (as-is)

A partir do contrato de suporte realiza-se a manutenção do software e/ou equipamento (Processo 8.1) que resulta no registro de chamado, no relatório de horas e de melhorias.

\section{Processo 9: Desenvolver produto}

A Figura 25 apresenta o processo desenvolver produto.

O processo inicia-se com o desenvolvimento da visão (Processo 9.1) que tem por objetivo descrever o produto delimitando, por exemplo, as suas características e funções. Como resultado desse processo, geram-se os desenhos e esboços. Em seguida, desenvolve-se o plano de entregas (Processo 9.2) que define a programação das entregas e iterações, resultando no plano de entregas do projeto. Posteriormente, realiza-se a análise financeira (Processo 9.3) que resulta na análise de viabilidade econômica. Por fim, é realizada análise de risco (Processo 9.4). Todos os documentos gerados nessa etapa constituem o plano de projeto inicial.

A partir do plano de projeto inicial definem-se as especificações do produto (Processo 9.5) que geram as especificações iniciais do produto. A partir das especificações desenvolvem-se as concepções do produto (Processo 9.6) que resultam em conceitos de design e modelos virtuais. 


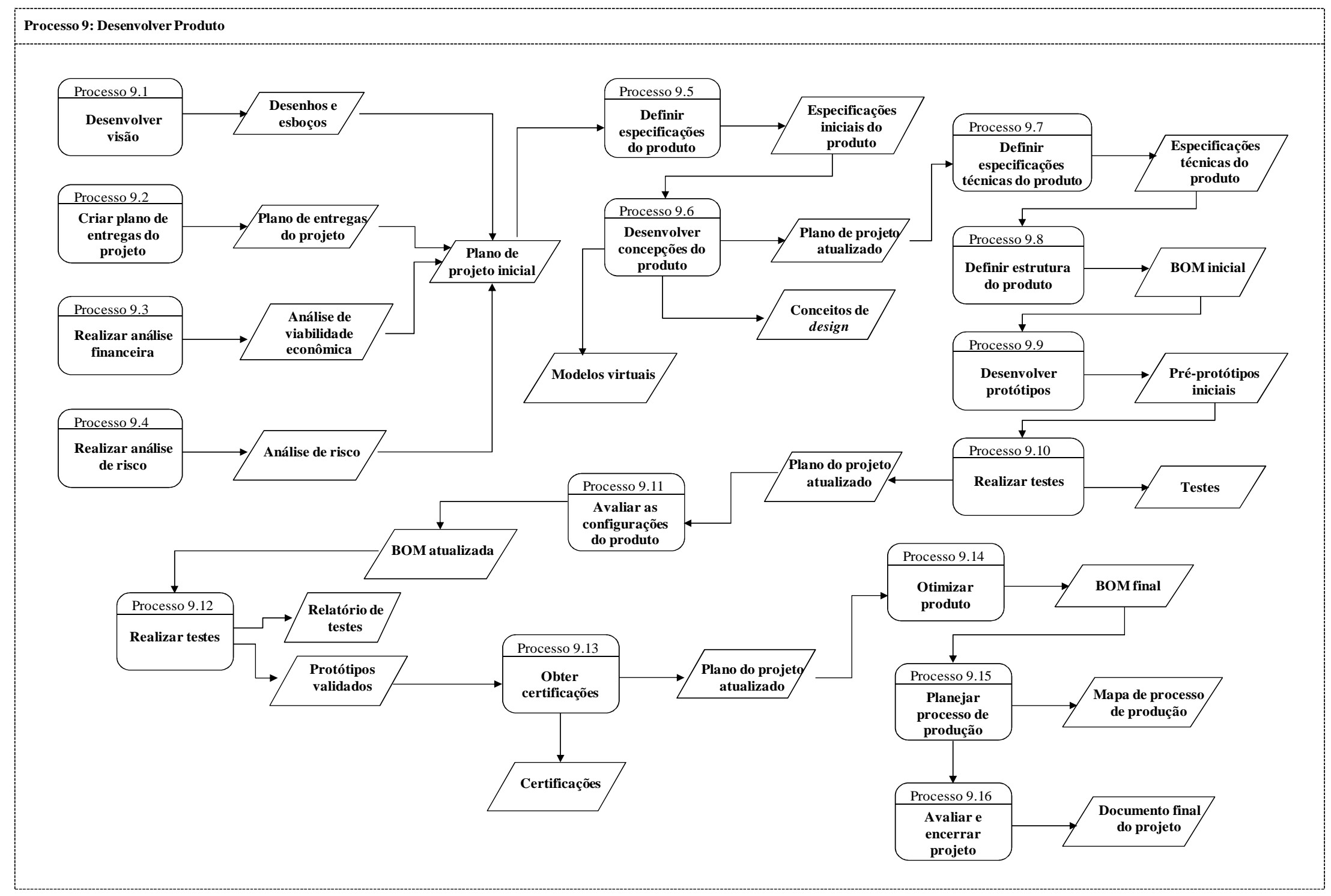

Figura 25 - Sub-processo 9 (as-is) 
A partir do plano do projeto atualizado definem-se as especificações técnicas do produto (Processo 9.7). Diante das especificações definem-se a estrutura do produto (Processo 9.8) que resulta na lista de materiais (BOM) inicial. A BOM é utilizada para desenvolver o protótipo (Processo 9.9) que resulta em pré-protótipos inicias que são testados (Processo 9.10) e emitido relatório de testes.

A partir do plano do projeto atualizado inicia-se a avaliação das configurações do produto (Processo 9.11) que resultam na BOM atualizada. A BOM é utilizada como entrada para realizar testes (Processo 9.12) que resulta em relatório de testes e protótipos validados. Diante do protótipo validado inicia-se a certificação (Processo 9.13) que resulta no produto certificado.

Diante do plano do projeto atualizado, o produto é otimizado (Processo 9.14) resultando na BOM final. Posteriormente, planeja-se o processo de produção (Processo 9.15) que define o mapa do processo de produção. Por fim, o projeto é avaliado e encerrado (Processo 9.16) resultando no documento final do projeto.

\section{Processo 10: Validar produto internamente}

A Figura 26 apresenta o processo validar produto internamente.

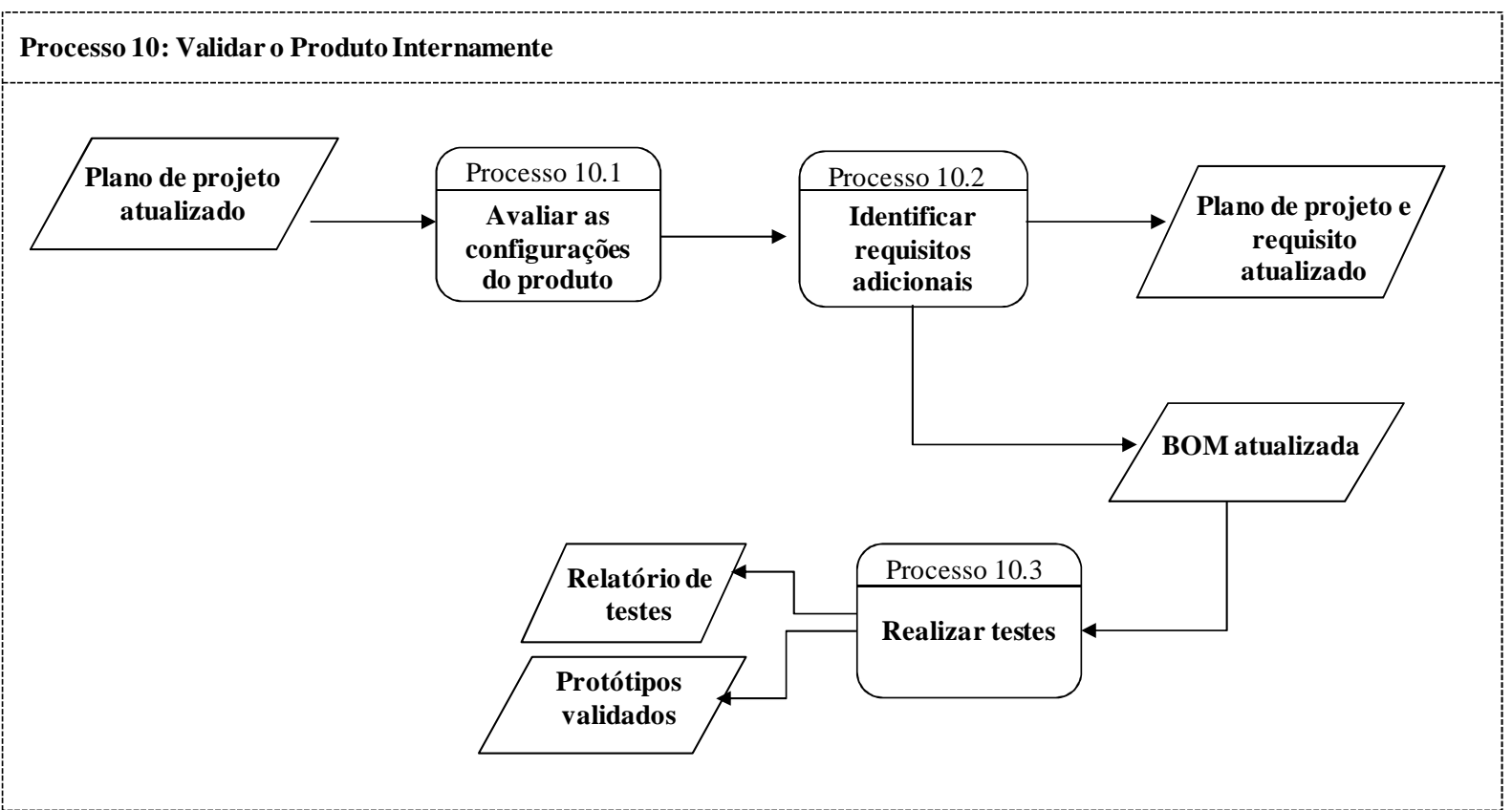

Figura 26 - Sub-processo 10 (as-is)

A partir do plano do projeto atualizado inicia-se a avaliação das configurações do produto (Processo 10.1). Logo após, identificam-se os requisitos adicionais (Processo 10.2) 
que resultam no plano de projeto e requisito atualizado e na BOM atualizada. Por fim, diante da BOM realizam-se os testes (Processo 10.3) que resultam em relatório de testes e protótipos validados.

\section{Processo 11: Validar o produto com o cliente}

A Figura 27 apresenta o processo validar produto com o cliente.

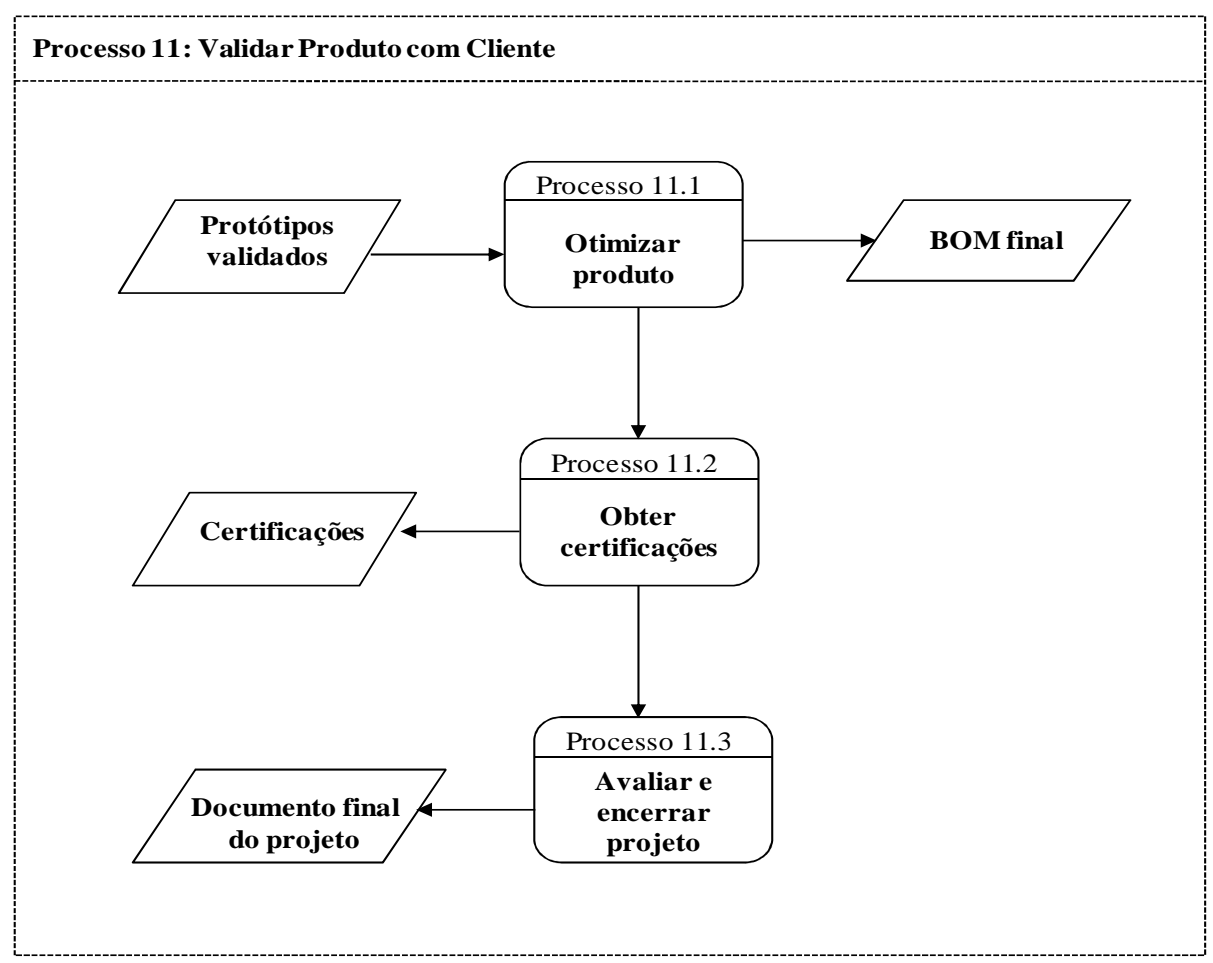

Figura 27 - Sub-processo 11 (as-is)

Com os protótipos validados inicia-se a otimização do produto (Processo 11.1) para melhorar o produto que resulta na BOM final. Posteriormente, tem-se a obtenção da cerificação (Processo 11.2) que resulta na certificação do produto. Por fim, o projeto é avaliado e encerrado (Processo 11.3) que resulta no documento final do projeto.

\section{Processo 12: Produzir}

A Figura 28 apresenta o processo produzir. 


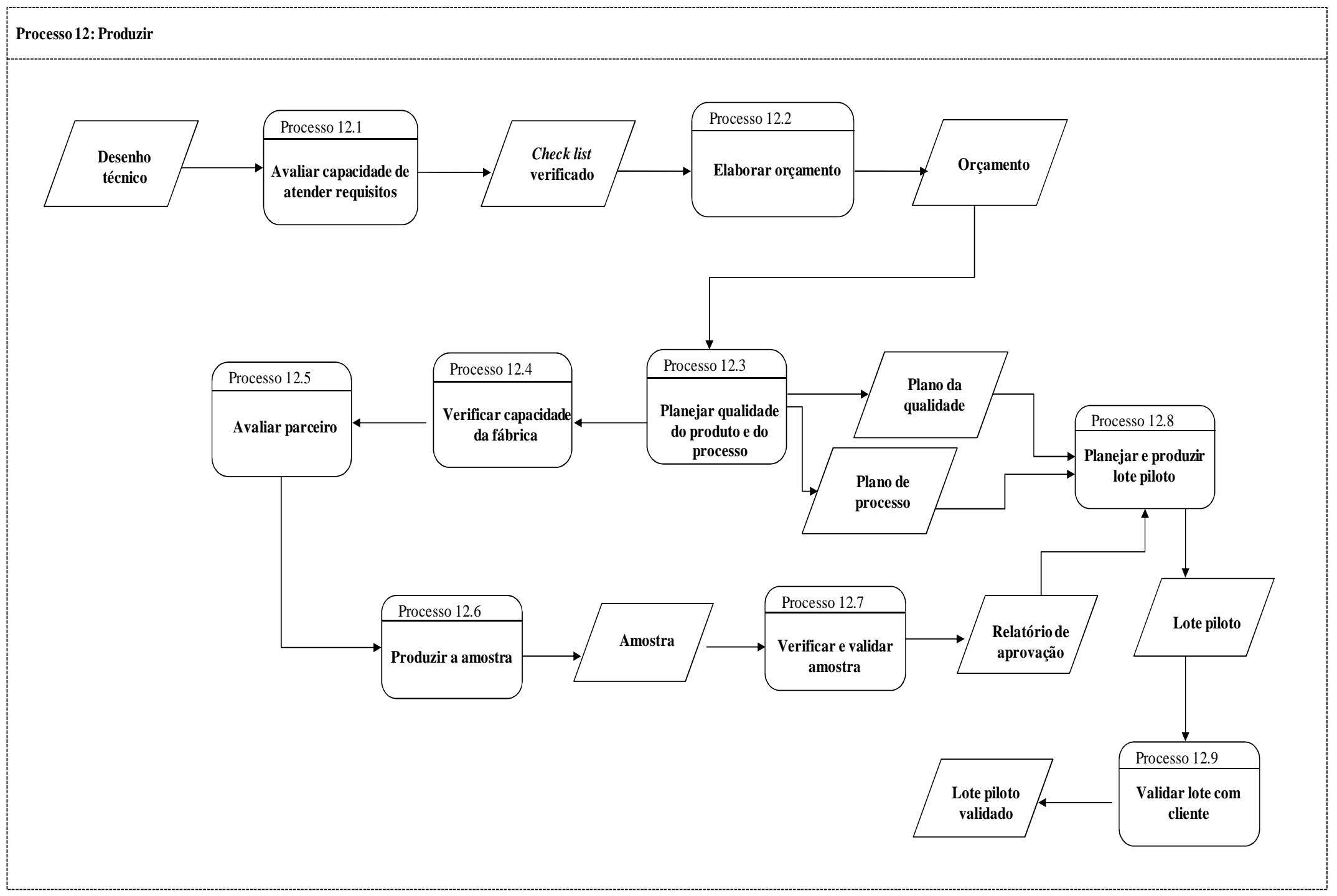

Figura 28 - Sub-processo 12 (as-is) 
A partir do desenho técnico, a empresa avalia a capacidade de atender os requisitos do cliente (Processo 12.1). Esse processo é baseado em um check list que busca verificar se a empresa já possui os fornecedores necessários, se tem maquinário para produzir, como será a embalado, entre outros fatores. Com o check list verificado, elabora-se o orçamento (Processo 12.2) que deve ser aprovado pelo cliente.

Com a aprovação do orçamento pelo cliente, a empresa realiza o planejamento da qualidade do produto e processo (Processo 12.3) que tem por objetivo planejar a realização do produto. Como resultado do Processo 12.3 tem-se o plano da qualidade e o plano de processo. Posteriormente, é verificada a capacidade da fábrica (Processo 12.4) e parceiros são avaliados (Processo 12.5), principalmente quando há a necessidade da participação de um novo parceiro.

Logo após, é produzida a amostra (Processo 12.6). De posse da amostra, a empresa realiza a verificação e validação da mesma (Processo 12.7) e emite um relatório de aprovação. Diante desse relatório, dos planos de qualidade e de processo, inicia-se o planejamento e a produção do lote piloto (Processo 12.8). Após o lote piloto ser produzido, o mesmo é encaminhado ao cliente para validação (Processo 12.9).

\section{Processo 13: Aplicar produto no mercado}

A Figura 29 apresenta o processo aplicar produto no mercado.

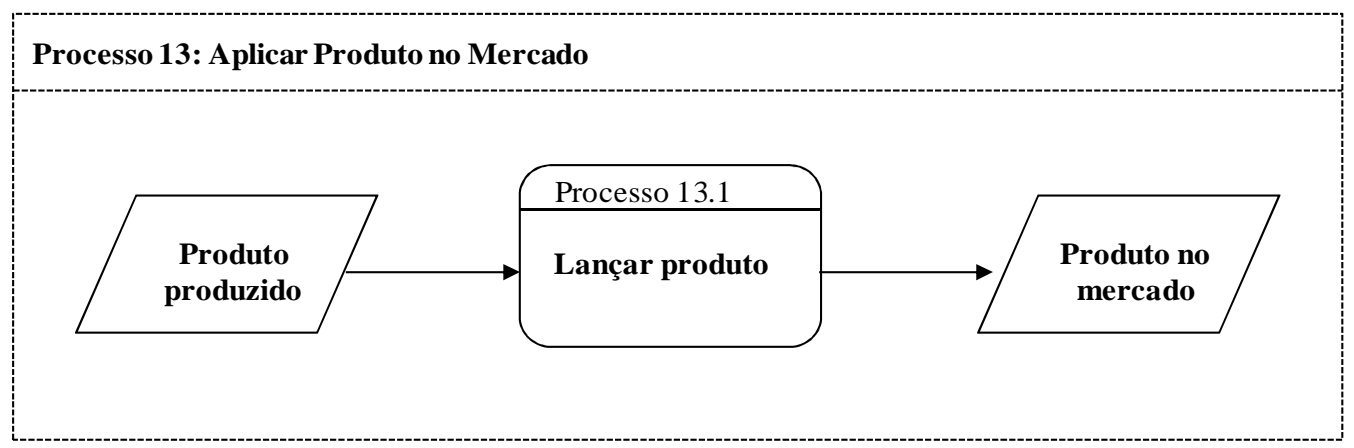

Figura 29 - Sub-processo 13 (as-is)

O produto produzido é lançado no mercado (Processo 13.1).

\subsubsection{Modelo de Atores e Recursos: Relação entre Empresa e Cliente}

A Figura 30 apresenta o modelo de atores e recursos que norteia a transferência tecnologia-produto na relação entre empresa e cliente. 


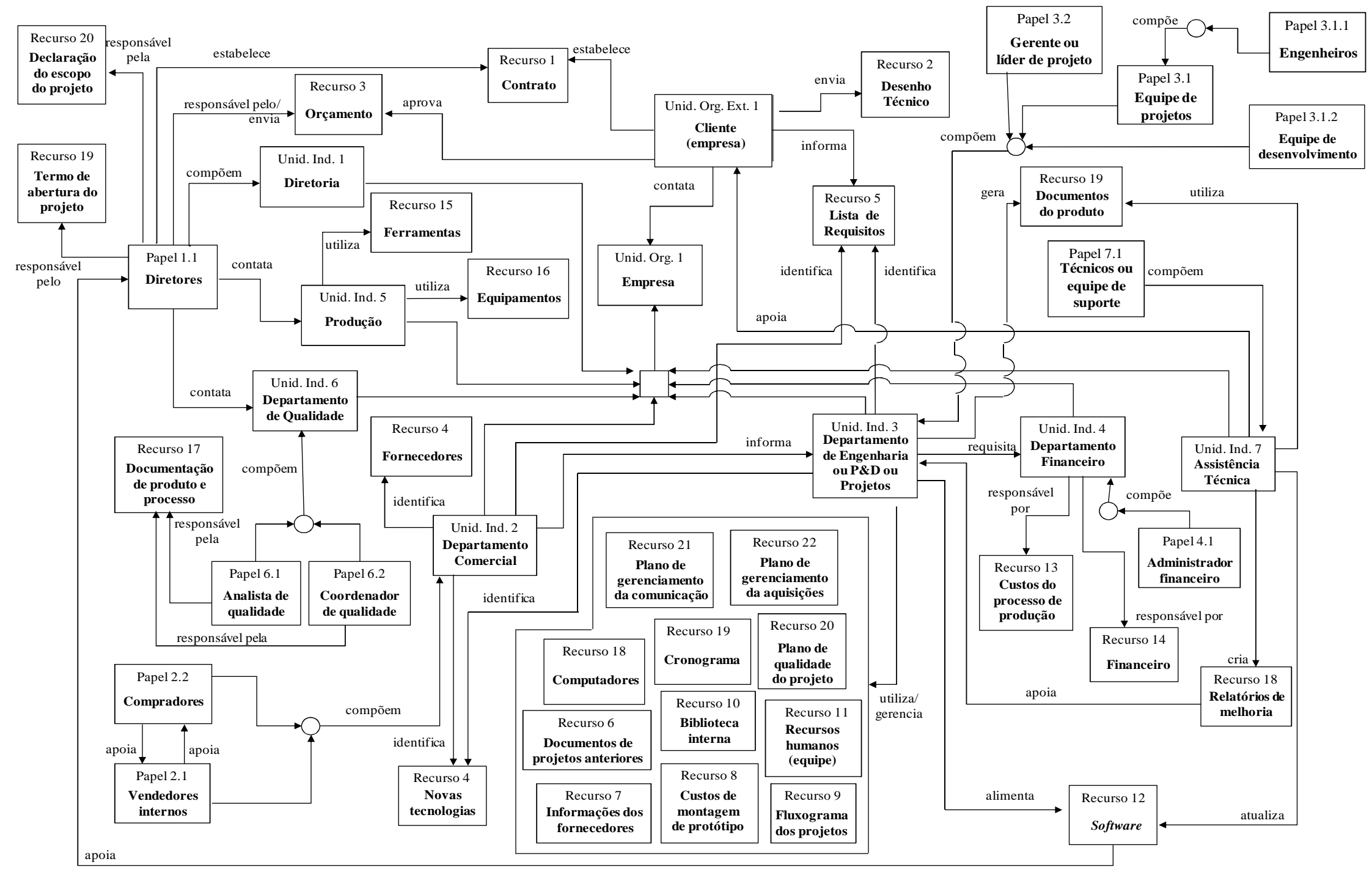

Figura 30 - Modelo de atores e recursos 1 (as-is) 
Os principais envolvidos no processo de transferência são a empresa (Unidade Organizacional 1) e o cliente (Unidade Organizacional Externa 1). O cliente (Unidade Organizacional Externa 1) contata a empresa (Unidade Organizacional 1) e é responsável por enviar o desenho técnico (Recurso 2), informar os requisitos (Recurso 5) e aprovar orçamento (Recurso 3).

A empresa (Unidade Organizacional 1) possui sete departamentos participando do processo: a diretoria (Unidade Individual 1), produção (Unidade Individual 5), departamento de qualidade (Unidade Individual 6), departamento comercial (Unidade Individual 2), departamento de engenharia ou P\&D ou projetos (Unidade Individual 3), departamento financeiro (Unidade Individual 4), e assistência técnica (Unidade Individual 7).

A diretoria (Unidade Individual 1) é composta por diretores (Papel 1.1)que é responsável pelo termo de abertura (Recurso 19), pela declaração do escopo do projeto (Recurso 20), por estabelecer o contrato (Recurso 1) junto com o cliente (Unidade Organizacional Externa 1), por enviar o orçamento (Recurso 3), e por contatar a produção (Unidade Individual 5) e o departamento de qualidade (Unidade Individual 6).

O departamento de qualidade é composto pelo analista de qualidade (Papel 6.1) e pelo coordenador de qualidade (Papel 6.2) que são responsáveis pela documentação de produto e processo (Recurso 17).

O departamento comercial (Unidade Individual 2) é composto por vendedores internos (Papel 2.1) e compradores (Papel 2.2). O departamento comercial (Unidade Individual 2) é responsável por identificar fornecedores (Recurso 4), novas tecnologias (Recurso 4), identificar a lista de requisitos (Recurso 5), e informar o departamento de engenharia (Unidade Individual 3).

O departamento de engenharia (Unidade Individual 3) é constituído pelo gerente ou líder de projeto (Papel 3.2) e pela equipe de projetos (Papel 3.1) que por sua vez é composta por engenheiros (Papel 3.1.1) e pela equipe de desenvolvimento (Papel 3.1.2). O departamento de engenharia (Unidade Individual 3) é responsável por gerar o documento do produto (Recurso 19), alimentar software (Recurso 12), identificar novas tecnologias (Recurso 4), gerenciar os planos de comunicação (Recurso 21), de aquisições (Recurso 22), de qualidade do projeto (Recurso 20), cronograma (Recurso 19), recursos humanos (Recurso 11), utilizar computadores (Recurso 18), documentos de projetos anteriores (Recurso 6), biblioteca interna (Recurso 10), informações dos fornecedores (Recurso 7), fluxograma dos projetos (Recurso 9), e custos de montagem de protótipo (Recurso 8). Além disso, o 
departamento de engenharia (Unidade Individual 3) requisita o departamento financeiro (Unidade Individual 4).

O departamento financeiro (Unidade Individual 4) é constituído pelo administrador financeiro (Papel 4.1). O departamento é responsável pelos custos do processo de produção (Recurso 13) e pelo financeiro (Recurso 14).

A assistência técnica (Unidade Individual 7) é formada por técnicos ou equipe de suporte (Papel 7.1). A assistência técnica (Unidade Individual 7) utiliza documento do produto (Recurso 19), atualiza software (Recurso 12), cria relatórios de melhoria (Recurso 18) que apoia o departamento de engenharia (Unidade Individual 3), e apoia o cliente (Unidade Organizacional Externa 1).

\subsubsection{Modelo de Atores e Recursos: Relação entre Empresa e Universidade}

A Figura 31 apresenta o modelo de atores e recursos que norteia a transferência tecnologia-produto na relação entre empresa e universidade.

Os principais envolvidos no processo de transferência são a empresa (Unidade Organizacional 1) e a universidade (Unidade Organizacional Externa 1). A empresa (Unidade Organizacional 1) contata a universidade (Unidade Organizacional Externa 1) para desenvolver uma parceria. Ambas estabelecem o contrato (Recurso 2). A universidade (Unidade Organizacional Externa 1) é constituída por grupos de pesquisa (Unidade Individual 1.1) que utilizam laboratórios. Os grupos de pesquisa (Unidade Individual 1.1) são compostos por professores (Papel 1.1.2) e alunos (Papel 1.1.1).

$\mathrm{Na}$ empresa (Unidade Organizacional 1) há a diretoria (Unidade Individual 1) e o departamento de Engenharia ou P\&D (Unidade Individual 2) envolvidos no processo de transferência.

A diretoria (Unidade Individual 1) é composta pela diretoria de P\&D (Papel 1.1), diretoria de produção (Papel 1.2), diretoria de tecnologia de processo (Papel 1.3) e controladoria (Papel 1.4). Todas as diretorias apoiam o departamento de engenharia ou P\&D (Unidade Individual 2). A controladoria (Papel 1.4) é responsável por verifica os incentivos fiscais (Regra 3) e controlar o recurso financeiro (Recurso 5). 


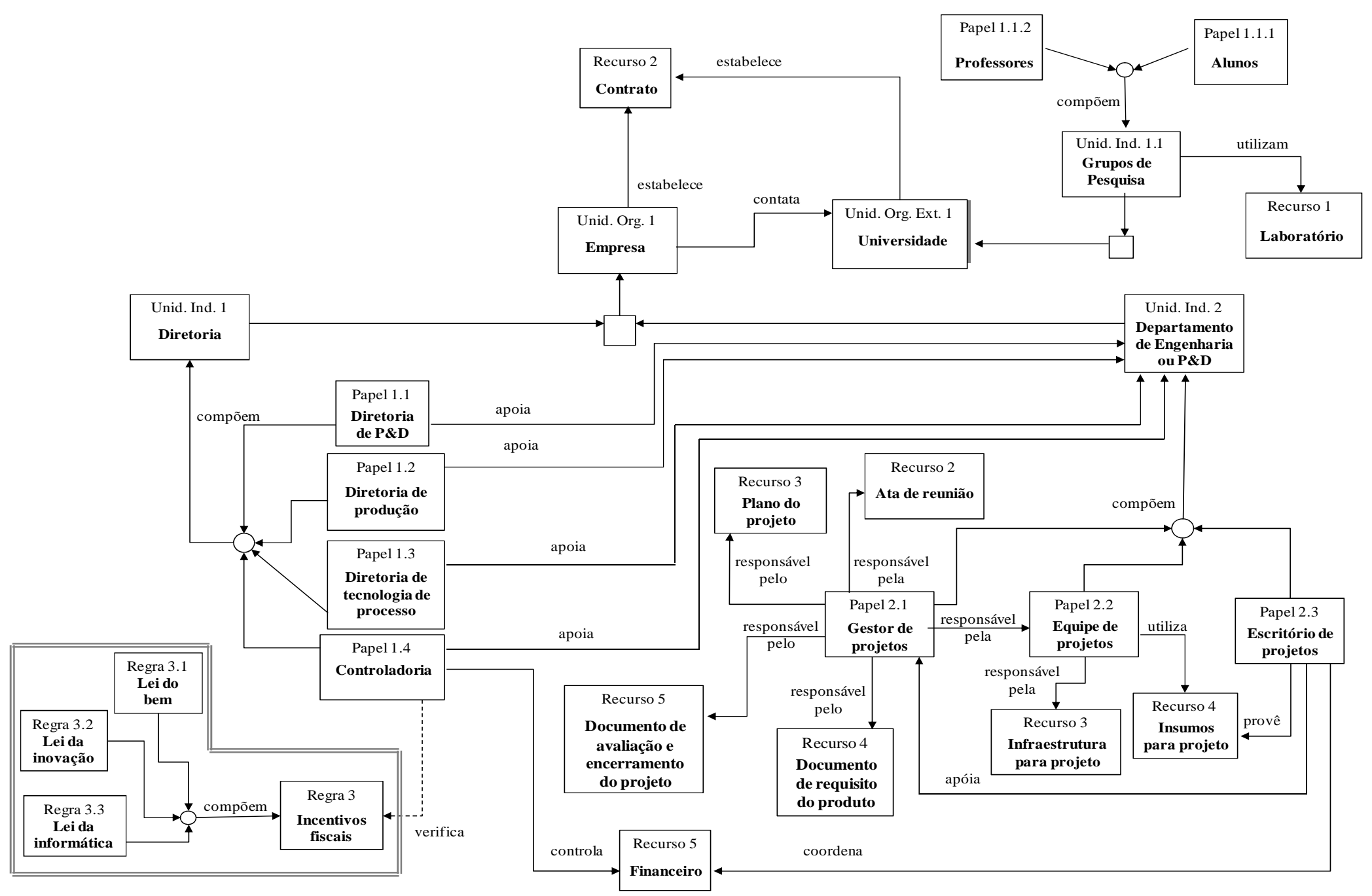

Figura 31 - Modelo de atores e recursos 2 (as-is) 
O departamento de engenharia ou P\&D (Unidade Individual 2) é composto pelo gestor de projetos (Papel 2.1), equipe de projetos (Papel 2.2) e escritório de projetos (Papel 2.3). O gestor de projetos (Papel 2.1) é responsável pela ata de reunião (Recurso 2), pelo plano do projeto (Recurso 3), documento de avaliação e encerramento do projeto (Recurso 5), documento de requisito do produto (Recurso 4) e pela equipe de projetos (Papel 2.2). A equipe de projetos (Papel 2.2) é responsável pela infra-estrutura para o projeto (Recurso 3) e utiliza insumos para projeto (Recurso 4) providos pelo escritório de projetos (Papel 2.3) que por sua vez também coordena o recurso financeiro (Recurso 5).

\subsubsection{Modelo de Componentes e Requisitos Técnicos}

A Figura 32 apresenta o modelo de componentes e requisitos técnicos que norteia a transferência tecnologia-produto.

O sistema de informação tem como objetivos gerenciar portfólio de projetos (Objetivo SI 1) em termos de gerenciar tempo (Objetivo SI 1.1), gerenciar recursos humanos (Objetivo SI 1.3), gerenciar recursos financeiros (Objetivo SI 1.2), e planejar e controlar o desenvolvimento do projeto (Objetivo SI 1.4), melhorar comunicação (Objetivo SI 2), apoiar as decisões gerenciais (Objetivo SI 3), obter informações (Objetivo SI 4), trocar informações (Objetivo SI 5), manter as pessoas atualizadas em relação ao projeto (Objetivo SI 6), prover informações para o cliente (Objetivo SI 7), gerenciar dados e informações (Objetivo SI 8), gerenciar produção (Objetivo SI 9), agilizar a identificação de informações (Objetivo SI 10), desenvolver plataforma colaborativa (Objetivo SI 11), e garantir comunicação entre os membros das equipes (Objetivo SI 12).

Para gerenciar portfólio de projetos (Objetivo SI 1), o sistema deve permitir a gestão visual (Requisito Funcional SI 5), disparar avisos por e-mail (Requisito Funcional SI 3), aderir a diferentes métodos de gestão de projetos (Requisito Funcional SI 4), permitir documentar funcionalidade do sistema (Requisito Funcional SI 6), e gerar indicadores (Requisito Funcional SI 1) que apoia avaliar o andamento do projeto (Requisito Funcional SI 2). 


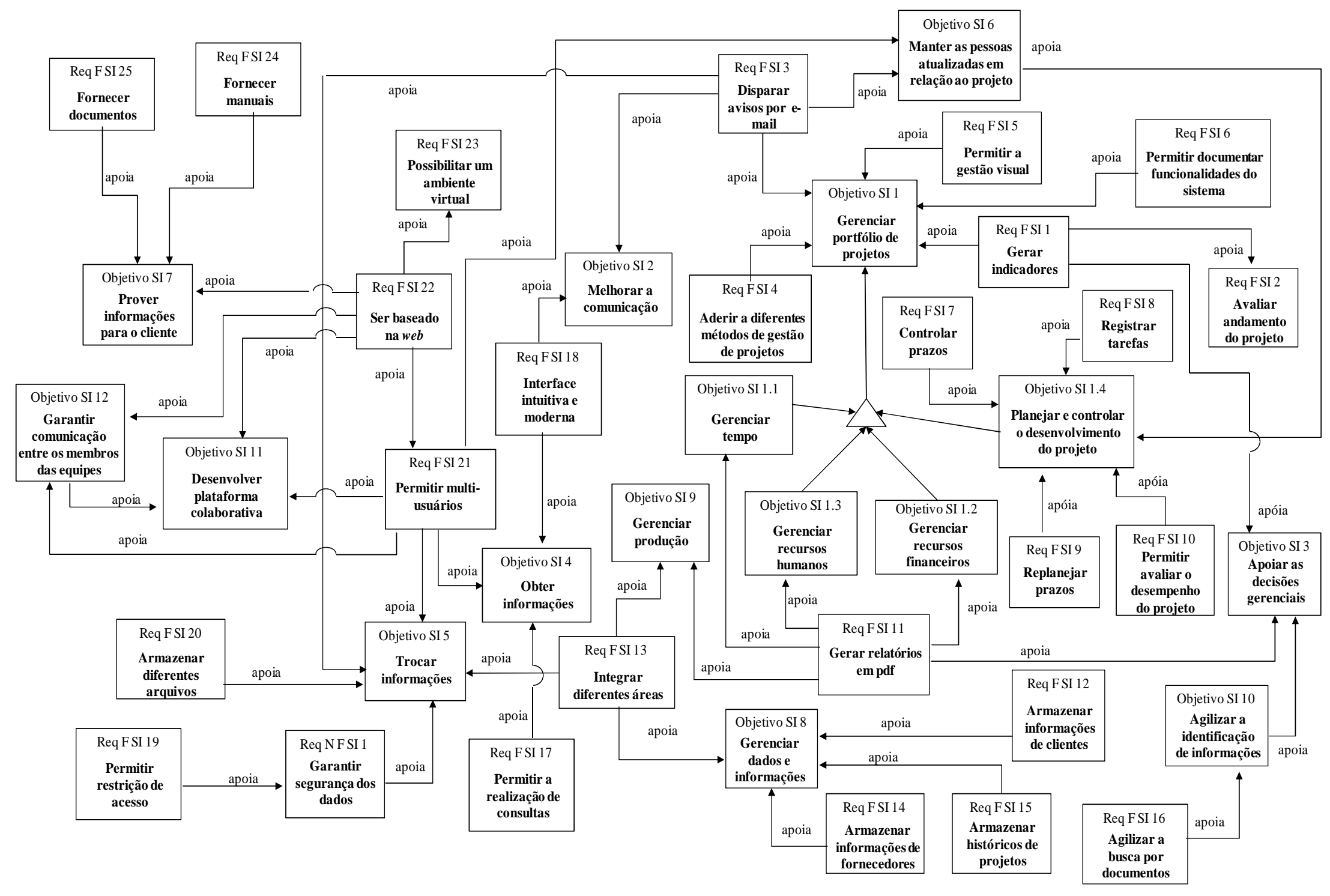

Figura 32 - Modelo de componentes e requisitos técnicos (as-is) 
Para gerenciar tempo (Objetivo SI 1.1), gerenciar recursos humanos (Objetivo SI 1.3) e recursos financeiros (Objetivo SI 1.2) o sistema deve gerar relatórios em pdf (Requisito Funcional SI 11). Para planejar e controlar o andamento do projeto (Objetivo SI 1.4) o sistema deve permitir controlar prazo (Requisito Funcional SI 7), registrar tarefas (Requisito Funcional SI 8), replanejar prazos (Requisito Funcional SI 9), permitir avaliar o desempenho do projeto (Requisito Funcional SI 10), e manter as pessoas atualizadas em relação ao projeto (Objetivo SI 6).

Para melhorar a comunicação (Objetivo SI 2), o sistema deve disparar avisos por $e$ mail (Requisito Funcional SI 3) e ter uma interface intuitiva e moderna (Requisito Funcional SI 18).

Para apoiar as decisões gerenciais (Objetivo SI 3), o sistema deve gerar relatórios em pdf (Requisito Funcional SI 11), gerar indicadores (Requisito Funcional SI 1), e agilizar a identificação de informações (Objetivo SI 10).

Para obter informações (Objetivo SI 4) é necessário que o sistema tenha uma interface intuitiva e moderna (Requisito Funcional SI 18), que permita multiusuários (Requisito Funcional SI 21) e realização de consultas (Requisito Funcional SI 17).

Para trocar informações (Objetivo SI 5), o sistema deve garantir a segurança dos dados (Requisito Não Funcional SI 1) por meio da restrição de acesso (Requisito Funcional SI 19), deve armazenar diferentes arquivos (Requisito Funcional SI 20), disparar avisos por $e$ mail (Requisito Funcional SI 3), e permitir multiusuários (Requisito Funcional SI 21). Para permitir multiusuários (Requisito Funcional SI 21), o sistema deve ser baseado na web (Requisito Funcional SI 22) o que possibilita também um ambiente virtual (Requisito Funcional SI 23).

Para manter as pessoas atualizadas em relação ao projeto (Objetivo SI 6), o sistema deve disparar e-mails (Requisito Funcional SI 3) e permitir multiusuários (Requisito Funcional SI 21).

Para prover informações para o cliente (Objetivo SI 7), o sistema deve ser baseado na web (Requisito Funcional SI 22), fornecer documentos (Requisito Funcional SI 25) e fornecer manuais (Requisito Funcional SI 4).

Para gerenciar dados e informações (Objetivo SI 8), o sistema deve armazenar informações de fornecedores (Requisito Funcional SI 14), armazenar histórico de projetos (Requisito Funcional SI 15), armazenar informações de clientes (Requisito Funcional SI 12), e integrar diferentes áreas (Requisito Funcional SI 13). 
Para gerenciar a produção (Objetivo SI 9) é necessário integrar diferentes áreas (Requisito Funcional SI 13) e gerar relatórios em pdf (Requisito Funcional SI 11).

Para agilizar a identificação de informações (Objetivo SI10), o sistema deve agilizar a busca por documentos (Requisito Funcional SI 16).

Para desenvolver uma plataforma colaborativa (Objetivo SI 11) e garantir a comunicação entre os membros das equipes (Objetivo SI 12), o sistema deve ser baseado na web (Requisito Funcional SI 22), permitir multiusuário (Requisito Funcional SI 21).

\subsection{Analisando a Necessidade para Mudança (Need for Change)}

Nesta seção, a transferência tecnologia-produto é analisada considerando a literatura sobre redes colaborativas. Os modelos " $a s$-is" apresentados na Seção 5.1 são comparados com a literatura de redes colaborativas para analisar a necessidade de mudança com o objetivo de entender e discutir o estado atual e futuro para melhorar a organização.

Para cada modelo foram criados quadros que relacionam a literatura e os relatos das empresas. Os tópicos que encontram-se sem uma referência foram apontados pelas empresas e não foram identificados autores citando tal tópico e há também situações que a literatura referencia e que as empresas não mencionaram.

Esta seção inicia com a apresentação do modelo de objetivos seguido pelos modelos de regras de negócio, conceitos, processos, atores e recursos, e componentes e requisitos técnicos.

\subsubsection{Modelo de Objetivos}

O Quadro 9 apresenta as variáveis que compõem o modelo de objetivos, ou seja, motivações/ objetivos, problemas relacionados à colaboração. Enquanto que o Quadro 10 apresenta as motivações/ objetivos, problemas relacionados à transferência tecnologiaproduto.

Com relação às motivações/ objetivos para colaborar (ver Quadro 9), pode-se observar que a maioria dos tópicos referentes a essas motivações encontradas na literatura também são citadas pelas empresas. As empresas 6 e 7 buscam alcançar um número maior de objetivos. A empresa 6, por exemplo, tem parcerias por estar tentando desenvolver produto próprio para se manter no mercado, mas não tem know-how suficiente para isso o que resulta na necessidade de buscar auxílio de outras instituições para alcançar seu objetivo. 


\begin{tabular}{|c|c|c|c|c|c|c|c|c|c|}
\hline \multirow{2}{*}{$\begin{array}{c}\text { Variáveis } \\
\text { do modelo } \\
\text { de objetivos }\end{array}$} & \multirow{2}{*}{ Tópico } & \multirow{2}{*}{ Autores } & \multicolumn{7}{|c|}{ Empresas } \\
\hline & & & 1 & 2 & 3 & 4 & 5 & 6 & 7 \\
\hline \multirow{18}{*}{$\begin{array}{l}\text { Motivações/ } \\
\text { objetivos } \\
\text { para } \\
\text { colaborar }\end{array}$} & Compartilhar riscos & $\begin{array}{l}\text { Van Aken e Weggeman (2000); } \\
\text { Bullinger, Auernhammer e } \\
\text { Gomeringer (2004); Camarinha-Matos } \\
\text { e Abreu (2007); Debresson e Amesse } \\
\text { (1991); Un, Cuervo-Cazurra e } \\
\text { Asakawa (2010); Chiesa e Manzini } \\
\text { (1998); Narula (2004); Bayona, } \\
\text { García-Marco e Huerta (2001) }\end{array}$ & & & & & & & \\
\hline & 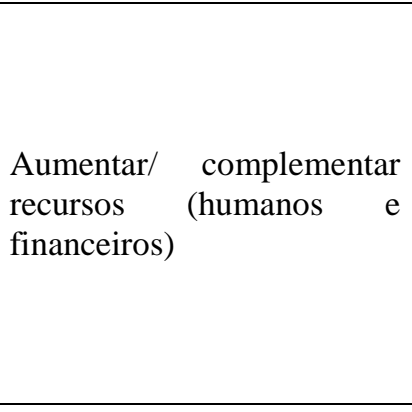 & 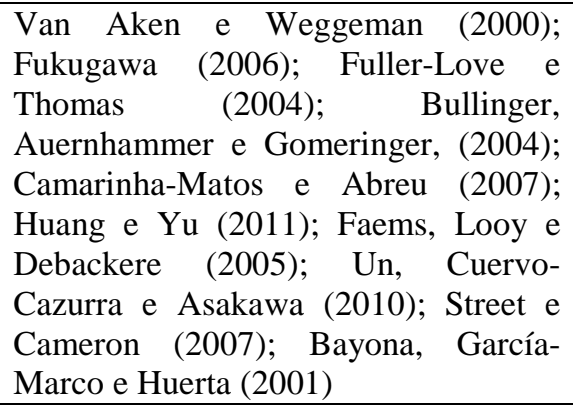 & & & & & & & \\
\hline & $\begin{array}{lr}\text { Adquirir } & \text { novos } \\
\text { conhecimentos } & \mathrm{e} \\
\text { tecnologias } & \end{array}$ & $\begin{array}{l}\text { Van Aken e Weggeman (2000); } \\
\text { Fukugawa (2006); Bullinger, } \\
\text { Auernhammer e Gomeringer, (2004); } \\
\text { Un, Cuervo-Cazurran e Asakawa } \\
\text { (2010), Tsai (2009) }\end{array}$ & & & & & & & \\
\hline & Economia de escala & $\begin{array}{lll}\text { Fuller-Love e } & \text { Thomas } & \text { (2004); } \\
\text { Camarinha-Matos e Abreu } & \text { (2007); } \\
\text { Mancinelli e Mazzanti (2009). }\end{array}$ & & & & & & & \\
\hline & $\begin{array}{l}\text { Compartilhar habilidades e } \\
\text { informações }\end{array}$ & $\begin{array}{l}\text { Fuller-Love e Thomas (2004); } \\
\text { Camarinha-Matos e Abreu (2007); } \\
\text { Mancinelli e Mazzanti (2009); Fuller- } \\
\text { Love e Thomas (2004) }\end{array}$ & & & & & & & \\
\hline & Compartilhar custos & $\begin{array}{l}\text { Camarinha-Matos e Abreu (2007); } \\
\text { Debresson e Amesse (1991); Narula } \\
\text { (2004) }\end{array}$ & & & & & & & \\
\hline & $\begin{array}{l}\text { Desenvolver produtos } \\
\text { robustos }\end{array}$ & Camarinha-Matos e Abreu (2007) & & & & & & & \\
\hline & Reduzir incertezas & Diez (2002); Hagedoorn (1993) & & & & & & & \\
\hline & $\begin{array}{l}\text { Aumentar capacidade para } \\
\text { inovar }\end{array}$ & $\begin{array}{l}\text { Zeng, Xie e Tam (2010); Camarinha- } \\
\text { Matos e Abreu (2007) }\end{array}$ & & & & & & & \\
\hline & Acessar novos mercados & Narula (2004); Hagedoorn (1993) & & & & & & & \\
\hline & $\begin{array}{ll}\begin{array}{l}\text { Maior capacidade } \\
\text { aprendizagem }\end{array} & \text { de } \\
\end{array}$ & $\begin{array}{l}\begin{array}{l}\text { Lin, Fang e Fang (2009); Wuyts } \\
(2005)\end{array} \\
\end{array}$ & & & & & & & \\
\hline & $\begin{array}{ll}\text { Reduzir tempo } & \text { de } \\
\text { desenvolvimento }\end{array}$ & Un, Cuervo-Cazurra e Asakawa (2010) & & & & & & & \\
\hline & Complementar competência & $\begin{array}{l}\text { Un, Cuervo-Cazurra e Asakawa } \\
(2010) ; \text { Perks e Jeffery (2006) }\end{array}$ & & & & & & & \\
\hline & $\begin{array}{l}\text { Não familiaridade com a } \\
\text { tecnologia }\end{array}$ & $\begin{array}{l}\text { Cassiman e Veugelers (2000); Kotabe, } \\
\text { Martin e Domoto (2003) }\end{array}$ & & & & & & & \\
\hline & Melhorar competitividade & $\begin{array}{l}\text { Knoben, Oerlemans e Rutten (2006); } \\
\text { Dowling e Helm (2006); }\end{array}$ & & & & & & & \\
\hline & Transferir conhecimento & Knudsen (2007) & & & & & & & \\
\hline & $\begin{array}{l}\text { Reduzir custos de serviços } \\
\text { de atendimento ao cliente }\end{array}$ & & & & & & & & \\
\hline & Obter maior confiabilidade & & & & & & & & \\
\hline
\end{tabular}

Quadro 9 - Variáveis relacionadas à colaboração (continuação) 


\begin{tabular}{|c|c|c|c|c|c|c|c|c|c|}
\hline \multirow{2}{*}{\begin{tabular}{|c|}
$\begin{array}{c}\text { Variáveis do } \\
\text { modelo de } \\
\text { objetivos }\end{array}$ \\
\end{tabular}} & \multirow{2}{*}{ Tópico } & \multirow{2}{*}{ Autores } & \multicolumn{7}{|c|}{ Empresas } \\
\hline & & & 1 & 2 & 3 & 4 & 5 & 6 & 7 \\
\hline \multirow{21}{*}{$\begin{array}{l}\text { Problemas } \\
\text { relacionados } \\
\text { à } \\
\text { colaboração }\end{array}$} & Agregar valor ao produto & & & & & & & & \\
\hline & Falta de confiança & $\begin{array}{l}\text { Williams (2005); Bititci et al. } \\
\text { (2007); Powell, Koput e Smith- } \\
\text { Doerr (1996) }\end{array}$ & & & & & & & \\
\hline & Foco em interesses individuais & Bititci et al. (2007) & & & & & & & \\
\hline & Falta de comprometimento & $\begin{array}{l}\text { Bititci et al. (2007); Mohan e } \\
\text { Rao (2005) }\end{array}$ & & & & & & & \\
\hline & $\begin{array}{l}\text { Falha ao compreender a } \\
\text { necessidade de cada um }\end{array}$ & Bititci et al. (2007) & & & & & & & \\
\hline & Falta de comunicação & Bititci et al. (2007) & & & & & & & \\
\hline & $\begin{array}{l}\text { Falha ao compreender as } \\
\text { expectativas de cada um }\end{array}$ & Bititci et al. (2007) & & & & & & & \\
\hline & $\begin{array}{l}\text { Falta de coordenação entre os } \\
\text { times gestores }\end{array}$ & Bititci et al. (2007) & & & & & & & \\
\hline & Estilo de liderança diferente & Bititci et al. (2007) & & & & & & & \\
\hline & Diferença cultural & $\begin{array}{l}\text { Chen (2004); Chiesa e Manzini } \\
\text { (1998); Mohan e Rao (2005) }\end{array}$ & & & & & & & \\
\hline & $\begin{array}{l}\text { Falha ao compreender a } \\
\text { necessidade do cliente }\end{array}$ & Bititci et al. (2007) & & & & & & & \\
\hline & $\begin{array}{l}\text { Falta de um sistema operacional } \\
\text { para gerenciar as atividades }\end{array}$ & Bititci et al. (2007) & & & & & & & \\
\hline & Diferença procedural & $\begin{array}{l}\text { Chen (2004); Emden, Calantone } \\
\text { e Droge (2006) }\end{array}$ & & & & & & & \\
\hline & Diferenças de linguagem & Chiesa e Manzini (1998) & & & & & & & \\
\hline & Diferentes objetivos estratégicos & Mohan e Rao (2005) & & & & & & & \\
\hline & $\begin{array}{l}\text { Não definir muito bem detalhes } \\
\text { da parceria }\end{array}$ & Mohan e Rao (2005) & & & & & & & \\
\hline & $\begin{array}{l}\text { Parceiros não dispostos a } \\
\text { cumprir os termos do acordo }\end{array}$ & Mohan e Rao (2005) & & & & & & & \\
\hline & $\begin{array}{l}\begin{array}{l}\text { Mudança de objetivos do } \\
\text { parceiro }\end{array} \\
\end{array}$ & Mohan e Rao (2005) & & & & & & & \\
\hline & Tempo de resposta do parceiro & & & & & & & & \\
\hline & Criar parceria & & & & & & & & \\
\hline & Falta de afinidade & & & & & & & & \\
\hline
\end{tabular}

Quadro 9 - Variáveis relacionadas à colaboração (conclusão)

Quanto aos problemas referentes à colaboração (Quadro 9), nota-se que a literatura apresenta diferentes problemas que também são os mesmos enfrentados pelas empresas. Os problemas mais citados pelas empresas são a falha em compreender a necessidade do cliente seguido pelo foco em interesses individuais, falta de comunicação, e tempo de resposta do parceiro. Este último problema foi citado pelas empresas, mas não foi identificado relatos na literatura.

Ao comparar a literatura com as respostas das empresas (Quadro 10) observa-se que a literatura aponta um número maior de motivações/ objetivos para transferir tecnologia do que as empresas mencionaram. Uma possível explicação para isso é o fato da literatura apresentar uma visão mais estratégica da transferência. 


\begin{tabular}{|c|c|c|c|c|c|c|c|c|c|}
\hline \multirow{2}{*}{$\begin{array}{l}\text { Variáveis do } \\
\text { modelo de } \\
\text { objetivos } \\
\end{array}$} & \multirow[b]{2}{*}{ Tópico } & \multirow[b]{2}{*}{ Autores } & \multicolumn{7}{|c|}{ Empresas } \\
\hline & & & 1 & 2 & 3 & 4 & 5 & 6 & 7 \\
\hline \multirow{19}{*}{$\begin{array}{l}\text { Motivações/ } \\
\text { objetivos } \\
\text { para } \\
\text { transferir }\end{array}$} & Abrir novas empresas & Lundquist (2003) & & & & & & & \\
\hline & Abrir novos negócios & Lundquist (2003) & & & & & & & \\
\hline & Reduzir riscos & Lundquist (2003) & & & & & & & \\
\hline & $\begin{array}{l}\text { Desenvolver novos } \\
\text { produtos }\end{array}$ & Lundquist (2003) & & & & & & & \\
\hline & Ter sucesso na tecnologia & Lundquist (2003) & & & & & & & \\
\hline & Ter liderança em mercados & Lundquist (2003) & & & & & & & \\
\hline & Impactar o mercado & Lundquist (2003) & & & & & & & \\
\hline & $\begin{array}{l}\text { Desenvolver melhores } \\
\text { pesquisas }\end{array}$ & Lundquist (2003) & & & & & & & \\
\hline & $\begin{array}{l}\text { Desenvolver tecnologias } \\
\text { avançadas }\end{array}$ & Lundquist (2003) & & & & & & & \\
\hline & $\begin{array}{l}\text { Ter acesso a habilidades e } \\
\text { talentos }\end{array}$ & Lundquist (2003) & & & & & & & \\
\hline & Acessar conhecimento & Lundquist (2003) & & & & & & & \\
\hline & Obter lucro & Lundquist (2003) & & & & & & & \\
\hline & $\begin{array}{ll}\text { Obter } & \text { vantagem } \\
\text { competitiva } & \\
\end{array}$ & Lundquist (2003) & & & & & & & \\
\hline & $\begin{array}{l}\text { Ter imagem positiva, } \\
\text { visibilidade e reputação }\end{array}$ & Lundquist (2003) & & & & & & & \\
\hline & $\begin{array}{l}\text { Desenvolvimento } \\
\text { econômico }\end{array}$ & Lundquist (2003) & & & & & & & \\
\hline & $\begin{array}{l}\text { Adquirir tecnologia de } \\
\text { produto }\end{array}$ & Bennett, Vaidya e Hongyu (1999) & & & & & & & \\
\hline & $\begin{array}{l}\text { Obter licenciamento } \mathrm{e} \\
\text { royalties }\end{array}$ & & & & & & & & \\
\hline & $\begin{array}{l}\text { Aumentar participação no } \\
\text { mercado }\end{array}$ & & & & & & & & \\
\hline & Obter novos clientes & & & & & & & & \\
\hline \multirow{7}{*}{$\begin{array}{l}\text { Problemas } \\
\text { relacionados } \\
\text { à } \\
\text { transferência }\end{array}$} & Característica da tecnologia & $\begin{array}{l}\text { Leonard-Barton e Sinha (1993); } \\
\text { Akhavan, Bagheri e Jabbari (2008); } \\
\text { Mostert e Buys (2008) }\end{array}$ & & & & & & & \\
\hline & Natureza do conhecimento & $\begin{array}{l}\text { Simonin (1999); Tatikonda e Stock } \\
\text { (2003); Pérez e Sánchez (2003) }\end{array}$ & & & & & & & \\
\hline & Risco & $\begin{array}{l}\text { Pérez e Sánchez (2003); Akhavan, } \\
\text { Bagheri e Jabbari (2008); Mostert e } \\
\text { Buys (2008); Greiner e Franza } \\
(2003) \text {; Lane (2003) }\end{array}$ & & & & & & & \\
\hline & $\begin{array}{l}\text { Falta de fundos e leis } \\
\text { governamentais }\end{array}$ & $\begin{array}{l}\text { Greiner e Franza (2003); Akhavan, } \\
\text { Bagheri e Jabbari (2008); Mostert e } \\
\text { Buys (2008); Jasinski (2009) }\end{array}$ & & & & & & & \\
\hline & $\begin{array}{l}\text { Falta de recursos } \\
\text { financeiros }\end{array}$ & $\begin{array}{l}\text { Pérez e Sánchez (2003); Jasinski } \\
(2009) ; \text { Lane (2003) }\end{array}$ & & & & & & & \\
\hline & Falta de comunicação & $\begin{array}{l}\text { Greiner e Franza (2003); Cusumano e } \\
\text { Elenkov (1994); Akhavan, Bagheri e } \\
\text { Jabbari (2008); Mostert e Buys } \\
\text { (2008); Lane (2003) }\end{array}$ & & & & & & & \\
\hline & Diferenças culturais & $\begin{array}{l}\text { Mowery, Oxley e Silverman (1996); } \\
\text { Lin e Berg (2001); Akhavan, Bagheri } \\
\text { e Jabbari (2008) }\end{array}$ & & & & & & & \\
\hline
\end{tabular}

Quadro 10 - Varáveis relacionadas à transferência de tecnologia (continuação) 


\begin{tabular}{|c|c|c|c|c|c|c|c|c|c|}
\hline \multirow{2}{*}{$\begin{array}{c}\text { Variáveis do } \\
\text { modelo de } \\
\text { objetivos } \\
\end{array}$} & \multirow[b]{2}{*}{ Tópico } & \multirow[b]{2}{*}{ Autores } & \multicolumn{7}{|c|}{ Empresas } \\
\hline & & & 1 & 2 & 3 & 4 & 5 & 6 & 7 \\
\hline \multirow{20}{*}{$\begin{array}{l}\text { Problemas } \\
\text { relacionados } \\
\text { à } \\
\text { transferência }\end{array}$} & $\begin{array}{l}\text { Diferença de linguagem } \\
\text { entre parceiros }\end{array}$ & $\begin{array}{l}\text { Mowery, Oxley e Silverman (1996); } \\
\text { Lin e Berg (2001); Akhavan, Bagheri } \\
\text { e Jabbari (2008) }\end{array}$ & & & & & & & \\
\hline & Falta de confiança & $\begin{array}{l}\text { Powell, Koput e Smith-Doerr (1996); } \\
\text { Pinheiro, Leite e Castro (2003); Pérez } \\
\text { e Sánchez (2003); Mostert e Buys } \\
(2008)\end{array}$ & & & & & & & \\
\hline & $\begin{array}{l}\text { Transferência } \quad \text { de } \\
\text { experiência }\end{array}$ & $\begin{array}{l}\text { Greiner e Franza (2003); Pinheiro, } \\
\text { Leite e Castro(2003); Lin e Berg } \\
\text { (2001); Mostert e Buys (2008); Lane } \\
(2003)\end{array}$ & & & & & & & \\
\hline & Falta de informação & $\begin{array}{l}\text { Greiner e Franza (2003); Pérez e } \\
\text { Sánchez (2003); Mostert e Buys } \\
(2008)\end{array}$ & & & & & & & \\
\hline & Falta de pessoal & Jasinski (2009) & & & & & & & \\
\hline & Falta de competência & Jasinski (2009) & & & & & & & \\
\hline & Falta de infraestrutura & & & & & & & & \\
\hline & Retorno sobre investimento & Lane (2003) & & & & & & & \\
\hline & $\begin{array}{l}\text { Altos custos associados à } \\
\text { transferência }\end{array}$ & Jasinski (2009) & & & & & & & \\
\hline & Ajuda limitada do governo; & Jasinski (2009) & & & & & & & \\
\hline & Normas legais e burocracia & Jasinski (2009) & & & & & & & \\
\hline & $\begin{array}{l}\text { Deficiência no sistema de } \\
\text { informação }\end{array}$ & Jasinski (2009) & & & & & & & \\
\hline & Questões comerciais & & & & & & & & \\
\hline & Falta de confidencialidade & & & & & & & & \\
\hline & Falta de formalismo & & & & & & & & \\
\hline & Encontrar a equipe & & & & & & & & \\
\hline & $\begin{array}{llll}\begin{array}{l}\text { Tempo de } \\
\text { parceiro }\end{array} & \text { resposta do } \\
\end{array}$ & Lane (2003) & & & & & & & \\
\hline & Burocracia & & & & & & & & \\
\hline & $\begin{array}{l}\text { Cliente não consegue } \\
\text { expressar sua necessidade }\end{array}$ & & & & & & & & \\
\hline & $\begin{array}{l}\text { Cliente não compreende a } \\
\text { tecnologia }\end{array}$ & & & & & & & & \\
\hline
\end{tabular}

Quadro 10 - Variáveis relacionadas à transferência de tecnologia (conclusão)

Quanto aos problemas relacionados à transferência os mais citados pelas empresas foram as características da tecnologia, o risco, falta de recursos, e o tempo de resposta do parceiro.

\subsubsection{Modelo de Regras de Negócio}

O Quadro 11 refere-se às regras relacionadas à transferência. Enquanto que o Quadro 12 apresenta as variáveis que compõem o modelo de regras de negócio relacionado à colaboração. 
Ao observar o Quadro 11 e 12, nota-se que as regras direcionadas tanto para a colaboração quanto para a transferência apresentadas pela literatura são pouco utilizadas pelas empresas. As regras que apoiam a maioria das empresas nesses dois assuntos são: deve ter confiança, deve ser redigido um contrato e deve existir documentação.

\begin{tabular}{|c|c|c|c|c|c|c|c|c|c|}
\hline \multirow{2}{*}{$\begin{array}{c}\text { Variáveis do } \\
\text { modelo de } \\
\text { regras }\end{array}$} & \multirow[b]{2}{*}{ Tópico } & \multirow[b]{2}{*}{ Autores } & \multicolumn{7}{|c|}{ Empresas } \\
\hline & & & 1 & 2 & 3 & 4 & 5 & 6 & 7 \\
\hline \multirow{15}{*}{$\begin{array}{c}\text { Regras } \\
\text { relacionadas à } \\
\text { transferência }\end{array}$} & $\begin{array}{l}\text { Devem ser definidos escopo e } \\
\text { estratégia da TT }\end{array}$ & Abraham e Bland (2011) & & & & & & & \\
\hline & $\begin{array}{l}\text { Devem ser definidos papéis e } \\
\text { responsabilidades } \\
\text { envolvidos }\end{array}$ & $\begin{array}{l}\text { Abraham e Bland (2011); } \\
\text { Cormican e O'Connor (2009) }\end{array}$ & & & & & & & \\
\hline & $\begin{array}{l}\text { Deve ter ferramenta de } \\
\text { comunicação eficaz }\end{array}$ & Abraham e Bland (2011) & & & & & & & \\
\hline & $\begin{array}{l}\text { Deve ser detalhada a freqüência } \\
\text { dos encontros }\end{array}$ & Abraham e Bland (2011) & & & & & & & \\
\hline & $\begin{array}{l}\text { As responsabilidades da equipe } \\
\text { devem estar claras }\end{array}$ & Abraham e Bland (2011) & & & & & & & \\
\hline & $\begin{array}{l}\text { Deve ter contato "cara a cara" } \\
\text { durante as etapas iniciais do } \\
\text { projeto e de aprovação }\end{array}$ & Abraham e Bland (2011) & & & & & & & \\
\hline & $\begin{array}{l}\text { Deve ser estabelecidos acordos } \\
\text { de entendimento mútuo sobre o } \\
\text { que as partes farão }\end{array}$ & Lundquist (2003) & & & & & & & \\
\hline & $\begin{array}{l}\text { Transferência acontecerá } \\
\text { quando ambos confiar um no } \\
\text { outro para atender os termos do } \\
\text { acordo }\end{array}$ & $\begin{array}{l}\text { Lundquist (2003); Santoro e } \\
\text { Saparito (2006); Santoro e } \\
\text { Saparito (2003); Bosch- } \\
\text { Sijtsema e Postma (2010); Lee } \\
\text { e Cavusgil } \\
\text { Abbasnejad et al. (2006); } \\
\text { Dietrich et al. (2010) } \\
\end{array}$ & & & & & & & \\
\hline & $\begin{array}{llr}\text { Deve existir } & \text { troca } & \text { de } \\
\text { informações } & \text { com } & \text { outras } \\
\text { organizações } & & \\
\end{array}$ & $\begin{array}{l}\text { Bititci (2007); Bossink (2007); } \\
\text { Faems, Janssen e van Looy } \\
\text { (2007); Schrader (1991) }\end{array}$ & & & & & & & \\
\hline & Deve ser elaborado contrato & $\begin{array}{l}\text { Bozeman (2000); Bosch- } \\
\text { Sijtsema e Postma (2010) }\end{array}$ & & & & & & & \\
\hline & $\begin{array}{l}\text { Devem ser realizadas visitas ao } \\
\text { cliente }\end{array}$ & $\begin{array}{l}\text { Knoben, Oerlemans e Rutten } \\
\text { (2006); Sherwood e Covin } \\
\text { (2008); Chen e Tseng (2011); } \\
\text { Cormican e O'Connor (2009); }\end{array}$ & & & & & & & \\
\hline & Deve existir documentação & $\begin{array}{l}\text { Easterby-Smith, Lyles e Tsang } \\
(2008)\end{array}$ & & & & & & & \\
\hline & $\begin{array}{lll}\begin{array}{l}\text { Deve-se } \\
\text { fiscais }\end{array} & \text { buscar incentivos } \\
\end{array}$ & & & & & & & & \\
\hline & $\begin{array}{l}\text { Deve-se buscar e prover auxílio } \\
\text { a outras empresas }\end{array}$ & & & & & & & & \\
\hline & $\begin{array}{l}\text { Deve ser utilizado um sistema } \\
\text { web }\end{array}$ & & & & & & & & \\
\hline
\end{tabular}

Quadro 11 - Variáveis relacionadas à transferência

Ao observar o Quadro 11 é possível notar que a literatura apresenta regras relacionadas ao projeto de transferência, a comunicação e relacionamento dos envolvidos. Dessas regras, as empresas fazem uso de algumas referentes à comunicação e relacionamento. 


\begin{tabular}{|c|c|c|c|c|c|c|c|c|c|}
\hline \multirow{2}{*}{$\begin{array}{c}\text { Variáveis do } \\
\text { modelo de } \\
\text { regras }\end{array}$} & \multirow[b]{2}{*}{ Tópico } & \multirow[b]{2}{*}{ Autores } & \multicolumn{7}{|c|}{ Empresas } \\
\hline & & & 1 & 2 & 3 & 4 & 5 & 6 & 7 \\
\hline \multirow{19}{*}{$\begin{array}{l}\text { Regras } \\
\text { relacionadas } \\
\text { à } \\
\text { colaboração }\end{array}$} & A colaboração deve ter uma proposta & $\begin{array}{ll}\text { Camarinha-Matos } & \text { e } \\
\text { Afsarmanesh (2008) } & \\
\end{array}$ & & & & & & & \\
\hline & $\begin{array}{llll}\text { As partes devem concordam em } \\
\text { colaborar }\end{array}$ & $\begin{array}{ll}\text { Camarinha-Matos } & \text { e } \\
\text { Afsarmanesh (2008) } & \\
\end{array}$ & & & & & & & \\
\hline & $\begin{array}{l}\text { As partes devem conhecer as } \\
\text { capacidades um do outro }\end{array}$ & $\begin{array}{ll}\text { Camarinha-Matos } & \text { e } \\
\text { Afsarmanesh (2008) } & \\
\end{array}$ & & & & & & & \\
\hline & $\begin{array}{l}\text { As partes devem compartilhar objetivos } \\
\text { e ter uma visão comum }\end{array}$ & $\begin{array}{l}\text { Camarinha-Matos e } \\
\text { Afsarmanesh (2008); } \\
\text { Bullinger, Auernhammer } \\
\text { e Gomeringer (2004) }\end{array}$ & & & & & & & \\
\hline & $\begin{array}{l}\text { Identificar os parceiros e trazê-los para } \\
\text { junto, de acordo com as capacidades } \\
\text { individuais }\end{array}$ & $\begin{array}{l}\text { Camarinha-Matos e } \\
\text { Afsarmanesh (2008); } \\
\text { Bullinger, Auernhammer } \\
\text { e Gomeringer (2004) }\end{array}$ & & & & & & & \\
\hline & $\begin{array}{lllll}\text { Deve ser } & \text { definido } & \text { o escopo } & \text { da } \\
\text { colaboração e resultados desejados } & \end{array}$ & $\begin{array}{ll}\text { Camarinha-Matos } & \text { e } \\
\text { Afsarmanesh (2008) }\end{array}$ & & & & & & & \\
\hline & $\begin{array}{l}\text { Deve ser definida a estrutura da } \\
\text { colaboração em termos de liderança, } \\
\text { regras, responsabilidades, tomada de } \\
\text { decisão, acesso a recursos, cronograma }\end{array}$ & $\begin{array}{l}\text { Camarinha-Matos e } \\
\text { Afsarmanesh (2008); } \\
\text { Mohan; Rao (2005) }\end{array}$ & & & & & & & \\
\hline & $\begin{array}{l}\text { Devem ser definidas as políticas, como } \\
\text { por exemplo, tratamento para } \\
\text { discordâncias } / \text { conflitos, } \\
\text { responsabilidade, recompensas e } \\
\text { reconhecimento, e propriedade dos bens } \\
\text { gerados }\end{array}$ & $\begin{array}{l}\text { Camarinha-Matos } \\
\text { Afsarmanesh (2008) }\end{array}$ & & & & & & & \\
\hline & $\begin{array}{l}\text { Devem ser definidas métricas para } \\
\text { avaliação }\end{array}$ & $\begin{array}{l}\text { Camarinha-Matos e } \\
\text { Afsarmanesh (2008); } \\
\text { Deck e Strom (2002) }\end{array}$ & & & & & & & \\
\hline & $\begin{array}{l}\text { Devem ser identificados os riscos e } \\
\text { plano de contingência }\end{array}$ & $\begin{array}{ll}\text { Camarinha-Matos } & \text { e } \\
\text { Afsarmanesh (2008) } & \end{array}$ & & & & & & & \\
\hline & $\begin{array}{l}\text { Deve ser estabelecido compromisso de } \\
\text { colaborar. }\end{array}$ & $\begin{array}{l}\text { Camarinha-Matos } \\
\text { Afsarmanesh (2008) }\end{array}$ & & & & & & & \\
\hline & $\begin{array}{l}\text { Deve ter ambiente que facilite a } \\
\text { colaboração }\end{array}$ & $\begin{array}{ll}\text { Camarinha-Matos } & \text { e } \\
\text { Afsarmanesh (2008) } & \\
\end{array}$ & & & & & & & \\
\hline & Deve ter comunicação entre as partes & $\begin{array}{l}\text { Mohan e Rao (2005); } \\
\text { Deck } \\
\text { e Strom (2002) }\end{array}$ & & & & & & & \\
\hline & Deve ter confiança & Mohan e Rao (2005) & & & & & & & \\
\hline & $\begin{array}{l}\text { Deve ter clareza nos acordos e termos de } \\
\text { adesão }\end{array}$ & Mohan e Rao (2005) & & & & & & & \\
\hline & $\begin{array}{l}\text { Entregas devem ser claras e definidas } \\
\text { precisamente }\end{array}$ & $\begin{array}{l}\text { Mohan e Rao (2005); } \\
\text { Deck e Strom (2002) }\end{array}$ & & & & & & & \\
\hline & $\begin{array}{l}\text { Relatórios devem ser elaborados } \\
\text { periodicamente }\end{array}$ & Mohan e Rao (2005) & & & & & & & \\
\hline & $\begin{array}{l}\text { Devem ter sistemas de gestão e } \\
\text { monitoramento de projeto eficaz }\end{array}$ & Mohan e Rao (2005) & & & & & & & \\
\hline & $\begin{array}{l}\text { Deve ser definido o contexto estratégico } \\
\text { dos projetos para determinar as } \\
\text { oportunidades de colaboração, o valor } \\
\text { que pode prover para empresa, e } \\
\text { identificar os envolvidos que apoia o } \\
\text { trabalho }\end{array}$ & Pertuzé et al. (2010) & & & & & & & \\
\hline
\end{tabular}

Quadro 12 - Variáveis relacionadas à colaboração (continuação) 


\begin{tabular}{|c|c|c|c|c|c|c|c|c|c|}
\hline \multirow{2}{*}{$\begin{array}{l}\text { Variáveis do } \\
\text { modelo de } \\
\text { regras } \\
\end{array}$} & \multirow[b]{2}{*}{ Tópico } & \multirow[b]{2}{*}{ Autores } & \multicolumn{7}{|c|}{ Empresas } \\
\hline & & & 1 & 2 & 3 & 4 & 5 & 6 & 7 \\
\hline \multirow{14}{*}{$\begin{array}{l}\text { Regras } \\
\text { relacionadas à } \\
\text { colaboração }\end{array}$} & $\begin{array}{l}\text { Gerente de projeto deve } \\
\text { facilitar a comunicação intra e } \\
\text { inter-organizacional. }\end{array}$ & Pertuzé et al. (2010) & & & & & & & \\
\hline & $\begin{array}{llll}\text { A visão } & \text { de } & \text { como } & \text { a } \\
\text { colaboração } & \text { pode } & \text { ajudar } & \text { a } \\
\text { empresa } & \text { deve } & \text { ser } \\
\text { compartilhada com o parceiro }\end{array}$ & Pertuzé et al. (2010) & & & & & & & \\
\hline & $\begin{array}{l}\text { A empresa deve investir em } \\
\text { um relacionamento a longo } \\
\text { prazo }\end{array}$ & Pertuzé et al. (2010) & & & & & & & \\
\hline & $\begin{array}{l}\text { A comunicação deve ser por } \\
\text { meio de encontros regulares e } \\
\text { outros meios }\end{array}$ & Pertuzé et al. (2010) & & & & & & & \\
\hline & $\begin{array}{l}\text { Deve existir interação do time } \\
\text { do parceiro com outras áreas } \\
\text { da empresa }\end{array}$ & Pertuzé et al. (2010) & & & & & & & \\
\hline & $\begin{array}{l}\text { Deve existir apoio da empresa } \\
\text { durante e depois do contrato }\end{array}$ & Pertuzé et al. (2010) & & & & & & & \\
\hline & Deve ser redigido um contrato & & & & & & & & \\
\hline & $\begin{array}{l}\text { Buscar e prover auxílio a } \\
\text { outras empresas }\end{array}$ & & & & & & & & \\
\hline & $\begin{array}{l}\text { Deve ser assinado um acordo } \\
\text { de não divulgação }\end{array}$ & $\begin{array}{l}\text { Slowinski, Hummel e Kumpf } \\
(2006)\end{array}$ & & & & & & & \\
\hline & $\begin{array}{l}\text { A busca de parceiro ocorre se } \\
\text { não for possível desenvolver } \\
\text { interno }\end{array}$ & & & & & & & & \\
\hline & $\begin{array}{l}\text { Prioridade é desenvolver } \\
\text { produto internamente }\end{array}$ & & & & & & & & \\
\hline & Buscar incentivos fiscais & & & & & & & & \\
\hline & $\begin{array}{l}\text { O parceiro deve ter ISO } 9001 \\
\text { ou um sistema de gestão } \\
\text { estruturado }\end{array}$ & & & & & & & & \\
\hline & $\begin{array}{l}\text { Deve ser utilizado um sistema } \\
\text { web (que seja seguro e } \\
\text { permita o fluxo de informação } \\
\text { em tempo real }\end{array}$ & Deck e Strom (2002) & & & & & & & \\
\hline
\end{tabular}

Quadro 12 - Variáveis relacionadas à colaboração (conclusão)

Quanto às regras de colaboração apresentadas no Quadro 12, nota-se que as empresas fazem pouco uso delas. Duas regras utilizadas pela empresa 2 restringem a colaboração, sendo: a prioridade é desenvolver produto internamente e a busca de parceiro ocorre se não for possível desenvolver internamente.

\subsubsection{Modelo de Conceitos}

O Quadro 13 apresenta os conceitos que estão presentes nos modelos apresentado na Seção 5.1. 


\begin{tabular}{|c|c|c|c|}
\hline $\begin{array}{l}\text { Modelo de } \\
\text { Conceitos }\end{array}$ & Conceito & Definição & Autores \\
\hline \multirow{13}{*}{$\begin{array}{l}\text { Modelo } \\
\text { "AS-IS" }\end{array}$} & Colaboração & $\begin{array}{l}\text { Processo no qual as instituições compartilham } \\
\text { informação, recursos, e responsabilidades para } \\
\text { juntamente planejar, implementar, e avaliar } \\
\text { atividades para atingir um objetivo comum e } \\
\text { gerar valor conjuntamente }\end{array}$ & $\begin{array}{l}\text { Camarinha-Matos et } \\
\text { al. (2009) }\end{array}$ \\
\hline & Confiança & $\begin{array}{l}\text { É a expectativa de que a outra parte irá executar } \\
\text { uma ação que é desejável para o outro, } \\
\text { particularmente em uma situação que envolve } \\
\text { algum elemento de risco. }\end{array}$ & $\begin{array}{l}\text { Tatikonda e Stock } \\
(2003)\end{array}$ \\
\hline & Afinidade & $\begin{array}{l}\text { Refere-se a similaridades no modo de ver as } \\
\text { coisas, nas opiniões e atividades }\end{array}$ & $\begin{array}{l}\text { Corsten, Gruen e } \\
\text { Peyinghaus (2011) }\end{array}$ \\
\hline & Contrato & $\begin{array}{l}\text { Acordo formal que provê vínculo legalmente } \\
\text { institucional, no qual são especificados direitos, } \\
\text { deveres e responsabilidades. Além disso, } \\
\text { determina o conteúdo da troca, divisão dos } \\
\text { resultados e penalidades por violar } \\
\text { especificações contratuais. }\end{array}$ & $\begin{array}{l}\text { Luo (2002); Poppo e } \\
\text { Zenger (2002) }\end{array}$ \\
\hline & $\begin{array}{l}\text { Acordo de não- } \\
\text { divulgação }\end{array}$ & $\begin{array}{l}\text { É um documento que permite que as pessoas de } \\
\text { diferentes empresas compartilhem informações } \\
\text { de propriedade, como capacidade técnica, } \\
\text { requisitos de aplicação, modelos de negócio, } \\
\text { mercado, entre outras. }\end{array}$ & $\begin{array}{l}\text { Slowinski, Hummel e } \\
\text { Kumpf (2006) }\end{array}$ \\
\hline & $\begin{array}{l}\text { Competência } \\
\text { organizacional }\end{array}$ & $\begin{array}{l}\text { É a combinação de recurso organizacional } \\
\text { (tangível e intangível) e de processos que, } \\
\text { juntos, agregam valor e sustentam a vantagem } \\
\text { competitiva. }\end{array}$ & Lewis (2001) \\
\hline & Comprometimento & $\begin{array}{l}\text { É a crença que o relacionamento contínuo com } \\
\text { o parceiro é tão importante a ponto de justificar } \\
\text { o esforço para desenvolvimento e manutenção } \\
\text { do mesmo. }\end{array}$ & 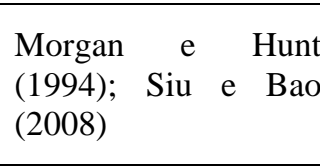 \\
\hline & Inovação & $\begin{array}{l}\text { Uma inovação é a implementação de um } \\
\text { produto (bem ou serviço) novo ou } \\
\text { significativamente melhorado, ou um processo, } \\
\text { ou um novo método de marketing, ou um novo } \\
\text { método organizacional nas práticas de negócios, } \\
\text { na organização do local de trabalho ou nas } \\
\text { relações externas. }\end{array}$ & OCDE (2005) \\
\hline & Comunicação & Refere-se à troca de informação & $\begin{array}{l}\text { Tatikonda e Stock } \\
(2003)\end{array}$ \\
\hline & $\begin{array}{l}\text { Diferença de } \\
\text { linguagem }\end{array}$ & $\begin{array}{l}\text { É a divergência ao compreender a natureza das } \\
\text { coisas, como por exemplo, questões técnicas, } \\
\text { padronização de processos, produtos e, rotina }\end{array}$ & $\begin{array}{l}\text { Malik (2002); } \\
\text { Cusumano e Elenkov } \\
(1994)\end{array}$ \\
\hline & $\begin{array}{l}\text { Technology } \\
\text { roadmap }\end{array}$ & $\begin{array}{l}\text { É uma técnica que permite analisar ao longo do } \\
\text { tempo a programação para o desenvolvimento } \\
\text { da tecnologia, o desenvolvimento do produto e } \\
\text { o mercado }\end{array}$ & $\begin{array}{l}\text { Phaal, Farrukh e } \\
\text { Probert (2004) }\end{array}$ \\
\hline & Documento & $\begin{array}{l}\text { É um meio físico e as informações registradas } \\
\text { nele que geralmente possui durabilidade e pode } \\
\text { ser lido por uma pessoa ou uma máquina. }\end{array}$ & PMI (2004) \\
\hline & Manual & $\begin{array}{l}\text { Documento que fornece instruções sobre como } \\
\text { fazer ou operar as coisas. }\end{array}$ & Hornby (2005) \\
\hline
\end{tabular}

Quadro 13 - Conceitos referentes ao modelo “As-Is” (continuação) 


\begin{tabular}{|c|c|c|c|}
\hline $\begin{array}{l}\text { Modelo de } \\
\text { Conceitos }\end{array}$ & Conceito & Definição & Autores \\
\hline \multirow{13}{*}{$\begin{array}{l}\text { Modelo } \\
\text { "AS-IS" }\end{array}$} & Requisitos & $\begin{array}{l}\text { São especificações do produto que apoia o } \\
\text { desenvolvimento do mesmo e que são utilizados } \\
\text { para avaliar/comparar com o resultado do projeto }\end{array}$ & $\begin{array}{l}\text { McKay, Pennington e } \\
\text { Baxter (2001) }\end{array}$ \\
\hline & $\begin{array}{c}\text { Cultura } \\
\text { organizacional }\end{array}$ & $\begin{array}{l}\text { A cultura organizacional é constituída por crenças } \\
\text { que permite que os membros de uma organização } \\
\text { compartilhe propósitos comuns e coordene suas } \\
\text { ações a fim de atingir determinados objetivos. A } \\
\text { cultura de uma organização inclui sua história, } \\
\text { normas, princípios e premissas, que são mantidos } \\
\text { por meio de histórias, rituais, memorandos, } \\
\text { documentos e conversas diárias. }\end{array}$ & Rogers et al. (1998) \\
\hline & Homologação & $\begin{array}{l}\text { É certificar que o produto está de acordo com as } \\
\text { normas e requisitos, além da sua funcionalidade }\end{array}$ & $\begin{array}{l}\text { Rozenfeld et al. } \\
(2006)\end{array}$ \\
\hline & Equipe & $\begin{array}{l}\text { É um conjunto de indivíduos que são } \\
\text { interdependentes em decorrência das tarefas que } \\
\text { executam e estão inseridos em um sistema como, } \\
\text { por exemplo, departamentos. }\end{array}$ & Henttonen (2010) \\
\hline & $\begin{array}{l}\text { Planejamento } \\
\text { estratégico }\end{array}$ & $\begin{array}{l}\text { Envolve um conjunto de atividades que elabora e } \\
\text { formula planos a nível da organização que } \\
\text { estabelece objetivos gerais e flexíveis, estratégias } \\
\text { e políticas, define metas, indicadores de } \\
\text { desempenho e alocação de recursos, ou seja, } \\
\text { conduz a organização para a sua visão do futuro }\end{array}$ & $\begin{array}{l}\text { Spee e Jarzabkowski } \\
(2011) ; \text { Stonehouse } \\
\text { e Pemberton (2002) }\end{array}$ \\
\hline & Análise PEST & $\begin{array}{l}\text { É uma ferramenta para analisar oportunidades e } \\
\text { ameaças do ambiente político, econômico, social } \\
\text { e tecnológico que o negócio opera. }\end{array}$ & Healey (1994) \\
\hline & $\begin{array}{l}\text { Característica da } \\
\text { tecnologia }\end{array}$ & $\begin{array}{l}\text { Refere-se ao grau de incerteza da tecnologia em } \\
\text { relação à novidade, complexidade e conhecimento } \\
\text { tácito. }\end{array}$ & $\begin{array}{l}\text { Stock e Tatikonda } \\
(2000)\end{array}$ \\
\hline & Novidade & $\begin{array}{l}\text { Refere-se ao grau da experiência anterior com a } \\
\text { tecnologia e o grau de mudança na tecnologia em } \\
\text { relação à tecnologia anterior }\end{array}$ & $\begin{array}{l}\text { Stock e Tatikonda } \\
(2000)\end{array}$ \\
\hline & Complexidade & $\begin{array}{l}\text { Refere-se ao nível de interdependência entre } \\
\text { componentes, a interdependência entre a } \\
\text { tecnologia e os elementos externos e o escopo da } \\
\text { tecnologia }\end{array}$ & $\begin{array}{l}\text { Stock e Tatikonda } \\
(2000)\end{array}$ \\
\hline & $\begin{array}{l}\text { Grau do } \\
\text { conhecimento } \\
\text { tácito }\end{array}$ & $\begin{array}{l}\text { Conhecimento não codificado incorporado pela } \\
\text { tecnologia, ou seja, grau de codificação, } \\
\text { maturidade da tecnologia, e estruturação de partes } \\
\text { de um sistema, por exemplo. }\end{array}$ & $\begin{array}{l}\text { Stock e Tatikonda } \\
(2000)\end{array}$ \\
\hline & Qualidade & $\begin{array}{l}\text { O conceito de qualidade empregado neste } \\
\text { trabalho está relacionado a abordagem de } \\
\text { qualidade no usuário, ou seja, o grau pelo qual o } \\
\text { produto satisfaz a necessidade do cliente; e } \\
\text { também a abordagem baseada em manufatura, ou } \\
\text { seja, a conformidade do produto em relação as } \\
\text { especificações. }\end{array}$ & Garvin (1984) \\
\hline & Conhecimento & $\begin{array}{l}\text { É a informação que está na mente das pessoas: é a } \\
\text { informação personalizada (que pode ou não ser } \\
\text { novo, único, útil ou preciso) relacionadas a fatos, } \\
\text { procedimentos, conceitos, interpretações, idéias, } \\
\text { observações e julgamentos. }\end{array}$ & $\begin{array}{l}\text { Alavi e Leidner } \\
(2001)\end{array}$ \\
\hline & $\begin{array}{l}\text { Royalties e } \\
\text { licenciamento }\end{array}$ & $\begin{array}{l}\text { É a aquisição do direito da patente ou da } \\
\text { tecnologia de uma organização mediante } \\
\text { pagamento }\end{array}$ & Steensma (1996) \\
\hline
\end{tabular}

Quadro 13 - Conceitos referentes ao modelo “As-Is” (continuação) 


\begin{tabular}{|c|c|c|c|}
\hline $\begin{array}{l}\text { Modelo de } \\
\text { Conceitos }\end{array}$ & Conceito & Definição & Autores \\
\hline \multirow{12}{*}{$\begin{array}{l}\text { Modelo } \\
\text { "AS-IS" }\end{array}$} & Aplicar tecnologia & $\begin{array}{l}\text { Disponibilizar a tecnologia para ser empregado } \\
\text { em diferentes produtos e ou mercado. }\end{array}$ & $\begin{array}{l}\text { Dodgson, Gann e } \\
\text { Salter (2006) }\end{array}$ \\
\hline & Informação & $\begin{array}{l}\text { Mensagem utilizada por um remetente para } \\
\text { representar um ou mais conceitos dentro de um } \\
\text { processo de comunicação, destinado a aumentar } \\
\text { o conhecimento do receptor }\end{array}$ & Zins (2007) \\
\hline & Sistemas web & $\begin{array}{l}\text { É um sistema que permite o acesso por meio da } \\
\text { internet. É uma classe de sistema que muda a } \\
\text { natureza das interações de negócio externo e, } \\
\text { portanto o modelo de negócio. }\end{array}$ & Lowe (2003) \\
\hline & Formalismo & $\begin{array}{l}\text { Manipulação de algo de acordo com certas } \\
\text { regras }\end{array}$ & Cioffi (2006) \\
\hline & Lei da informática & $\begin{array}{l}\text { E uma lei que concede incentivos fiscais } \\
\text { (redução do imposto sobre produtos } \\
\text { industrializados) para empresas produtoras de } \\
\text { alguns hardwares e que tenham práticas em } \\
\text { investir em P\&D }\end{array}$ & $\begin{array}{l}\text { Ministério da Ciência e } \\
\text { Tecnologia (2012) }\end{array}$ \\
\hline & Lei da inovação & $\begin{array}{l}\text { É uma lei que estabelece medidas de incentivos } \\
\text { à inovação e à pesquisa científica e tecnológica } \\
\text { no ambiente produtivo. Estimula as alianças } \\
\text { estratégicas e desenvolvimento de projetos } \\
\text { cooperativos, estimula a participação de } \\
\text { instituições de ciência e tecnologia no processo } \\
\text { de inovação e, incentiva a inovação na empresa. }\end{array}$ & $\begin{array}{l}\text { Ministério da Ciência e } \\
\text { Tecnologia (2012) }\end{array}$ \\
\hline & Validar tecnologia & $\begin{array}{l}\text { Significa entregar a prova dos resultados } \\
\text { potenciais para ser transformado em um produto } \\
\text { comercialmente explorável ou serviço. Esta } \\
\text { prova pode ser obtida de várias maneiras } \\
\text { diferentes: pesquisa de mercado, } \\
\text { desenvolvimento de protótipo, testes, entre } \\
\text { outros. }\end{array}$ & Huylebroeck (1999) \\
\hline & Treinamento & $\begin{array}{l}\text { É um processo para adquirir conhecimento e } \\
\text { desenvolver habilidades requeridas para } \\
\text { desempenhar determinada função. }\end{array}$ & $\begin{array}{l}\text { Chaudhry e Fen } \\
\text { (2006); CMMI (2006) }\end{array}$ \\
\hline & Lei do bem & $\begin{array}{l}\text { É uma lei que oferece incentivos fiscais (como } \\
\text { dedução do imposto de renda e contribuição } \\
\text { sobre lucro liquido para dispêndios de P\&D, } \\
\text { redução do imposto de produtos industrializados } \\
\text { - IPI para compras de máquinas, entre outros) } \\
\text { para empresas que desenvolvem inovações } \\
\text { tecnológicas, ou seja, investem em P\&D }\end{array}$ & $\begin{array}{l}\text { Ministério da Ciência e } \\
\text { Tecnologia (2012) }\end{array}$ \\
\hline & Confidencialidade & $\begin{array}{l}\text { É considerado confidencial quando uma pessoa } \\
\text { mantém as informações recebidas para si } \\
\text { mesma, ou seja, mantém sigilo. }\end{array}$ & Li e Zhang (2008) \\
\hline & Infraestrutura & $\begin{array}{l}\text { É a capacidade (recursos tangíveis e intangíveis } \\
\text { e sistemas) exigida para apoiar o crescimento e } \\
\text { o desenvolvimento de uma empresa, assim } \\
\text { como as operações diárias. }\end{array}$ & $\begin{array}{l}\text { Flamholtz e Hua } \\
(2003)\end{array}$ \\
\hline & Risco & $\begin{array}{l}\text { Um evento ou condição que pode ou não } \\
\text { ocorrer, mas se ocorre impactará a capacidade } \\
\text { de atingir os objetivos do projeto }\end{array}$ & Kahn (2005) \\
\hline
\end{tabular}

Quadro 13 - Conceitos referentes ao modelo “As-Is” (conclusão) 
As definições apresentadas no Quadro 13 esclarece os termos apresentados nos outros sub-modelos do EKD, evitando que existam interpretações diferentes entre os participantes de um processo, permitindo que todos tenham uma linguagem comum.

O Quadro 14 apresenta conceitos que estão presentes nos quadros dessa seção. Os conceitos tiveram origem nos objetivos, nas regras e assim por diante que foram identificados na literatura e que não estão presentes no modelo "as-is".

\begin{tabular}{|c|c|c|c|}
\hline $\begin{array}{l}\text { Modelo de } \\
\text { Conceitos }\end{array}$ & Conceito & Definição & Autores \\
\hline \multirow{12}{*}{$\begin{array}{l}\text { Modelo } \\
\text { "Need for } \\
\text { change" }\end{array}$} & $\begin{array}{l}\text { Estrutura da } \\
\text { colaboração }\end{array}$ & $\begin{array}{l}\text { Estrutura em termos de liderança, regras, } \\
\text { responsabilidades, tomada de decisão, acesso a } \\
\text { recursos, cronograma }\end{array}$ & $\begin{array}{lr}\text { Camarinha } & \text { Matos e } \\
\text { Afsarmanesh } & (2008) ; \\
\text { Mohan e Rao (2005) }\end{array}$ \\
\hline & $\begin{array}{l}\text { Políticas para } \\
\text { colaboração }\end{array}$ & $\begin{array}{l}\text { Referem-se ao tratamento para discordâncias / } \\
\text { conflitos, responsabilidade, recompensas e } \\
\text { reconhecimento, e propriedade dos bens gerados }\end{array}$ & $\begin{array}{l}\text { Camarinha Matos e } \\
\text { Afsarmanesh (2008) }\end{array}$ \\
\hline & $\begin{array}{l}\text { Gerente de } \\
\text { projeto }\end{array}$ & $\begin{array}{l}\text { A pessoa designada pela organização executora } \\
\text { para atingir os objetivos do projeto }\end{array}$ & PMI (2004) \\
\hline & $\begin{array}{l}\text { Plano de } \\
\text { contingência }\end{array}$ & $\begin{array}{l}\text { Um plano para lidar com eventos os quais a } \\
\text { ocorrência, o tempo, a gravidade não podem ser } \\
\text { previstos }\end{array}$ & Kahn (2005) \\
\hline & Entrega & $\begin{array}{l}\text { (Saídas/Entradas). Qualquer produto, resultado } \\
\text { ou capacidade para realizar um serviço } \\
\text { exclusivo e verificável que devem ser } \\
\text { produzidos para terminar um processo, uma fase } \\
\text { ou um projeto. }\end{array}$ & PMI (2004) \\
\hline & $\begin{array}{l}\text { Ferramenta } \\
\text { síncrona }\end{array}$ & $\begin{array}{l}\text { São ferramentas que permitem a comunicação } \\
\text { em tempo real para usuários que trabalham } \\
\text { juntos em um mesmo tempo e diferentes } \\
\text { lugares. Exemplo: áudio/ vídeo conferência, } \\
\text { chat, entre outros }\end{array}$ & $\begin{array}{l}\text { Li e Qiu, 2006; Rodriguez } \\
\text { e Al-Ashaab, } 2005\end{array}$ \\
\hline & $\begin{array}{l}\text { Ferramenta } \\
\text { assíncrona }\end{array}$ & $\begin{array}{l}\text { São ferramentas que permitem a comunicação e } \\
\text { colaboração em diferentes tempos e diferentes } \\
\text { lugares. Exemplo: e-mail, download de um } \\
\text { arquivo de uma base de dados, entre outros }\end{array}$ & $\begin{array}{l}\text { Li e Qiu, 2006; Rodriguez } \\
\text { e Al-Ashaab, } 2005\end{array}$ \\
\hline & $\begin{array}{l}\text { Plano de } \\
\text { transferência }\end{array}$ & $\begin{array}{l}\text { Documento que define o tempo da transferência, } \\
\text { o treinamento, a seqüência da transferência, e o } \\
\text { orçamento }\end{array}$ & $\begin{array}{l}\text { Cormican e O'Connor } \\
(2009)\end{array}$ \\
\hline & Caso de negócio & $\begin{array}{l}\text { O caso define o produto e projeto, incluindo a } \\
\text { justificativa do projeto e o plano de ação ou de } \\
\text { negócio. Geralmente é definido antes da decisão } \\
\text { de desenvolver. }\end{array}$ & Kahn (2005) \\
\hline & $\begin{array}{l}\text { Modelo de } \\
\text { negócio }\end{array}$ & $\begin{array}{l}\text { Conjunto de atividades que uma empresa } \\
\text { executa, como executa, quando ele executa, } \\
\text { como usa seus recursos, dada a sua indústria, a } \\
\text { criação de valor superior ao cliente ... e colocar- } \\
\text { se em posição de valor adequado }\end{array}$ & $\begin{array}{l}\text { Vanhaverbeke e Cloodt } \\
\text { (2006) }\end{array}$ \\
\hline & $\begin{array}{l}\text { Alinhamento } \\
\text { relacional }\end{array}$ & $\begin{array}{l}\text { Verificar se as culturas são compatíveis , a } \\
\text { propensão a mudança/ adaptação e a orientação } \\
\text { a longo prazo (fazer sacrifícios no curto prazo } \\
\text { para alcançar resultados à longo prazo). }\end{array}$ & $\begin{array}{l}\text { Emden, Calantone e } \\
\text { Droge (2006) }\end{array}$ \\
\hline & $\begin{array}{l}\text { Alinhamento } \\
\text { estratégico }\end{array}$ & $\begin{array}{l}\text { Verificar se a motivação e o objetivo são } \\
\text { correspondentes }\end{array}$ & $\begin{array}{l}\text { Emden, Calantone e } \\
\text { Droge (2006) }\end{array}$ \\
\hline
\end{tabular}

Quadro 14 - Conceitos referentes ao modelo "need for change" (continuação) 


\begin{tabular}{|c|c|c|c|}
\hline $\begin{array}{l}\text { Modelo de } \\
\text { Conceitos }\end{array}$ & Conceito & Definição & Autores \\
\hline $\begin{array}{l}\text { Modelo } \\
\text { "Need for } \\
\text { change" }\end{array}$ & $\begin{array}{l}\text { Alinhamento } \\
\text { tecnológico }\end{array}$ & $\begin{array}{l}\text { Verificar a capacidade técnica (exemplo, ter } \\
\text { tecnologia inovadora ou conhecimento - } \\
\text { expertise em uma área), complementariedade } \\
\text { de recurso (exemplo, ter habilidade ou } \\
\text { conhecimento de mercado complementar) e } \\
\text { sobreposição das bases de conhecimento (ter } \\
\text { base de conhecimento similar para } \\
\text { compreender o novo conhecimento e sua } \\
\text { aplicação) }\end{array}$ & $\begin{array}{l}\text { Emden, Calantone } \\
\text { Droge }(2006)\end{array}$ \\
\hline
\end{tabular}

Quadro 14 - Conceitos referentes ao modelo “need for change” (conclusão)

Os conceitos "estrutura da colaboração", "políticas para colaboração", "gerente de projeto", "plano de contingência" e, "entrega" estão presentes nas regras de negócio relacionadas a colaboração apresentadas no Quadro 12. Já os conceitos de "ferramenta síncrona" e "assíncrona" referem-se ao modelo de componentes e requisitos técnicos, enquanto que "plano de transferência", "caso de negócio", "modelo de negócio", "alinhamento tecnológico", "alinhamento estratégico" e, "alinhamento relacional" são oriundos do modelo de processo de negócio.

\subsubsection{Modelo de Processo de Negócio}

O Quadro 15 apresenta o modelo de processo de transferência de Jagoda, Maheshwari e Lonseth (2010). O modelo de transferência de tecnologia apresenta uma característica que envolve uma relação de compra e venda. Algumas das atividades desse modelo são realizadas pelas empresas. A atividade realizada por todas as empresas é "identificar mudanças a serem feitas no produto ou processo, de acordo com as condições locais".

\begin{tabular}{|c|c|c|c|c|c|c|c|c|c|}
\hline \multirow{2}{*}{ Autores } & \multirow{2}{*}{ Processos } & \multirow{2}{*}{ Sub-Processos } & \multicolumn{7}{|c|}{ Empresas } \\
\hline & & & 1 & 2 & 3 & 4 & 5 & 6 & 7 \\
\hline \multirow{5}{*}{$\begin{array}{l}\text { Jagoda, } \\
\text { Maheshwari } \\
\text { e Lonseth } \\
\text { (2010) }\end{array}$} & \multirow{4}{*}{$\begin{array}{c}\text { P1: } \\
\text { oportunidade } \\
\text { tecnológica }\end{array}$} & $\begin{array}{l}\text { Criar comitê de direcção TT para gerenciar o projeto } \\
\text { TT; }\end{array}$ & & & & & & & \\
\hline & & $\begin{array}{l}\text { Desenvolver roteiros de tecnologia para identificar as } \\
\text { tendências futuras; }\end{array}$ & & & & & & & \\
\hline & & $\begin{array}{l}\text { Realizar uma avaliação preliminar de mercado para } \\
\text { identificar as tendências e preferências dos clientes }\end{array}$ & & & & & & & \\
\hline & & $\begin{array}{l}\text { Realizar avaliação técnica para identificar as } \\
\text { habilidades potenciais e recursos exigido }\end{array}$ & & & & & & & \\
\hline & Gate 1 & Confirmar tecnologia identificada & & & & & & & \\
\hline
\end{tabular}

Quadro 15 - Modelo de processo de transferência de tecnologia 1 (continuação)

Fonte: Jagoda, Maheshwari e Lonseth (2010) 


\begin{tabular}{|c|c|c|c|c|c|c|c|c|c|}
\hline \multirow{2}{*}{ Autores } & \multirow{2}{*}{ Processos } & \multirow{2}{*}{ Sub-Processos } & \multicolumn{7}{|c|}{ Empresas } \\
\hline & & & 1 & 2 & 3 & 4 & 5 & 6 & 7 \\
\hline \multirow{22}{*}{$\begin{array}{l}\text { Jagoda, } \\
\text { Maheshwari } \\
\text { e Lonseth } \\
\text { (2010) }\end{array}$} & \multirow{5}{*}{$\begin{array}{l}\text { P2: } \\
\text { Pesquisar } \\
\text { tecnologia }\end{array}$} & $\begin{array}{l}\text { Estabelecer um conjunto claro de especificações para } \\
\text { a tecnologia em questão. }\end{array}$ & & & & & & & \\
\hline & & $\begin{array}{l}\text { Detalhar como a tecnologia procurada pode aumentar } \\
\text { a competitividade. }\end{array}$ & & & & & & & \\
\hline & & $\begin{array}{l}\text { Avaliar a extensão pela qual a habilidade de usar a } \\
\text { tecnologia está disponível na empresa, as lacunas a } \\
\text { serem superadas, e os compromissos de recursos. }\end{array}$ & & & & & & & \\
\hline & & $\begin{array}{l}\text { Desenvolver um perfil de fornecedor e uma lista de } \\
\text { empresas que são capazes de transferir a tecnologia } \\
\text { desejada. }\end{array}$ & & & & & & & \\
\hline & & $\begin{array}{l}\text { Investigar e avaliar a assistência potencial que podem } \\
\text { estar disponíveis a partir de instituições } \\
\text { governamentais e locais. }\end{array}$ & & & & & & & \\
\hline & Gate 2 & Confirmar projeto & & & & & & & \\
\hline & \multirow{8}{*}{ P3: Negociar } & $\begin{array}{l}\text { Finalizar uma base para avaliação da tecnologia e } \\
\text { proteção de propriedade intelectual }\end{array}$ & & & & & & & \\
\hline & & $\begin{array}{l}\text { Concordar com a contribuição de cada partido e } \\
\text { responsabilidades. }\end{array}$ & & & & & & & \\
\hline & & $\begin{array}{l}\text { Criar mecanismos para a transferência de tecnologias } \\
\text { codificadas (manual) e não-codificadas (treinamento) }\end{array}$ & & & & & & & \\
\hline & & $\begin{array}{l}\text { Criar canais eficazes de comunicação entre ambas as } \\
\text { partes. }\end{array}$ & & & & & & & \\
\hline & & $\begin{array}{l}\text { Consultar as autoridades do governo para garantir a } \\
\text { concordância com políticas governamentais (esta é } \\
\text { empregada quando se trata de transferência } \\
\text { internacional) }\end{array}$ & & & & & & & \\
\hline & & $\begin{array}{l}\text { Decidir o mecanismo mais apropriado (s) para } \\
\text { transferir a tecnologia. }\end{array}$ & & & & & & & \\
\hline & & $\begin{array}{l}\text { Chegar a um acordo sobre os valores de pagamento, } \\
\text { procedimentos e prazos. }\end{array}$ & & & & & & & \\
\hline & & Preparar um acordo TT detalhada. & & & & & & & \\
\hline & Gate 3 & Finalizar e aprovar acordo & & & & & & & \\
\hline & \multirow{6}{*}{$\begin{array}{l}\text { P4: Preparar } \\
\text { para } \\
\text { implementar } \\
\text { plano de } \\
\text { projeto TT }\end{array}$} & $\begin{array}{l}\text { Determinar mudanças a serem feitas na estrutura } \\
\text { organizacional e no projeto do trabalho (refere-se a } \\
\text { empresa que adquiriu por exemplo uma máquina) }\end{array}$ & & & & & & & \\
\hline & & $\begin{array}{l}\text { Identificar mudanças a serem feitas no sistema de } \\
\text { gestão do conhecimento e regimes políticos. }\end{array}$ & & & & & & & \\
\hline & & $\begin{array}{l}\text { Desenvolver treinamentos e a programação para } \\
\text { realizá-los }\end{array}$ & & & & & & & \\
\hline & & $\begin{array}{l}\text { Estabelecer medidas para construir boas relações } \\
\text { entre o pessoal de transferência. }\end{array}$ & & & & & & & \\
\hline & & Formular plano de implementação do projeto de TT. & & & & & & & \\
\hline & & $\begin{array}{l}\text { Estabelecer metas para ajudar a fortalecer a gestão e } \\
\text { controle de projetos }\end{array}$ & & & & & & & \\
\hline & Gate 4 & Aprovar plano de implementação & & & & & & & \\
\hline
\end{tabular}

Quadro 15 - Modelo de processo de transferência de tecnologia 1 (continuação)

Fonte: Jagoda, Maheshwari e Lonseth (2010) 


\begin{tabular}{|c|c|c|c|c|c|c|c|c|c|}
\hline \multirow{2}{*}{ Autores } & \multirow{2}{*}{ Processos } & \multirow{2}{*}{ Sub-Processos } & \multicolumn{7}{|c|}{ Empresas } \\
\hline & & & 1 & 2 & 3 & 4 & 5 & 6 & 7 \\
\hline \multirow{14}{*}{$\begin{array}{l}\text { Jagoda, } \\
\text { Maheshwari, } \\
\text { Lonseth } \\
\text { (2010) }\end{array}$} & \multirow{7}{*}{$\begin{array}{l}\text { P5: } \\
\text { Implementar } \\
\text { a TT }\end{array}$} & $\begin{array}{l}\text { Identificar mudanças a serem feitas no produto ou } \\
\text { processo, de acordo com as condições locais. }\end{array}$ & & & & & & & \\
\hline & & $\begin{array}{l}\text { Recrutar pessoal qualificado já não disponíveis na } \\
\text { organização. }\end{array}$ & & & & & & & \\
\hline & & $\begin{array}{l}\text { Realizar programas de formação para o pessoal } \\
\text { existente. }\end{array}$ & & & & & & & \\
\hline & & Desenvolver um plano de remuneração melhorada. & & & & & & & \\
\hline & & $\begin{array}{l}\text { Formular arranjos com fornecedores auxiliares de } \\
\text { materiais, peças e serviços. }\end{array}$ & & & & & & & \\
\hline & & Manter ligações com as autoridades governamentais. & & & & & & & \\
\hline & & $\begin{array}{l}\text { Colocar em funcionamento a tecnologia transferida } \\
\text { no ou antes do cronograma }\end{array}$ & & & & & & & \\
\hline & Gate 5 & Implementar auditoria & & & & & & & \\
\hline & \multirow{5}{*}{$\begin{array}{l}\text { P6: Avaliar } \\
\text { impacto da } \\
\text { transferência }\end{array}$} & $\begin{array}{l}\text { Avaliar os resultados reais do projeto TT de mercado, } \\
\text { financeira, perspectivas tecnológicas } \\
\text { organizacionais. }\end{array}$ & & & & & & & \\
\hline & & $\begin{array}{l}\text { Identificar variações (se aplicável) entre os resultados } \\
\text { reais e esperados. }\end{array}$ & & & & & & & \\
\hline & & Avaliar a adequação das medidas corretivas. & & & & & & & \\
\hline & & $\begin{array}{l}\text { Analisar a viabilidade de melhorar a tecnologia } \\
\text { transferida }\end{array}$ & & & & & & & \\
\hline & & $\begin{array}{l}\text { Identificar novas tecnologias ou complementares que } \\
\text { poderiam ser transferidas para consolidar os ganhos } \\
\text { obtidos }\end{array}$ & & & & & & & \\
\hline & Gate 6 & Desenvolver guia pós atividade TT & & & & & & & \\
\hline
\end{tabular}

Quadro 15 - Modelo de processo de transferência de tecnologia 1 (conclusão)

Fonte: Jagoda, Maheshwari e Lonseth (2010)

Uma das razões para que a maioria das atividades relativas aos processos 4,5 e 6 do modelo de Jagoda, Maheshwari e Lonseth (2010) não estarem presentes nas empresas pesquisadas é o fato de ter sido analisado projetos conjuntos de desenvolvimentos de tecnologia e produto (ou seja, de co-desenvolvimento), no qual o processo de transferência está inserido. Assim, comparando, por exemplo, os processos de avaliação propostos pelo modelo do Quadro 15 com a avaliação realizada pelas empresas possuem um enfoque diferente. O primeiro preocupa-se em avaliar os retornos obtidos a partir da aquisição, enquanto que as empresas avaliam o desenvolvimento e desempenho do projeto.

Outro modelo de transferência de tecnologia é apresentado no Quadro 16. Esse modelo que foi proposto por Lane (2009) é o que apresenta um maior número de atividades semelhantes com aquelas realizadas pelas empresas, principalmente as relacionados aos processos "pesquisar" e "desenvolver". 


\begin{tabular}{|c|c|c|c|c|c|c|c|c|c|}
\hline \multirow{2}{*}{ Autores } & \multirow{2}{*}{ Processos } & \multirow{2}{*}{ Sub-Processos } & \multicolumn{7}{|c|}{ Empresas } \\
\hline & & & 1 & 2 & 3 & 4 & 5 & 6 & 7 \\
\hline \multirow{20}{*}{$\begin{array}{c}\text { Lane } \\
(2009)\end{array}$} & \multirow{3}{*}{ Pesquisar } & Definir conceito/produto & & & & & & & \\
\hline & & Realizar avaliação preliminar & & & & & & & \\
\hline & & Consturir caso de negócio & & & & & & & \\
\hline & \multirow{9}{*}{ Desenvolver } & Iniciar práticas de co-desenvolvimento & & & & & & & \\
\hline & & Desenvolver plano de implementação & & & & & & & \\
\hline & & Alocar recursos & & & & & & & \\
\hline & & Reunir, analisar, priorizar necessidades do cliente & & & & & & & \\
\hline & & Identificar características do produto e especificações & & & & & & & \\
\hline & & Produzir modelos de protótipo & & & & & & & \\
\hline & & Testar modelos & & & & & & & \\
\hline & & Testar protótipo e validar modelo com cliente & & & & & & & \\
\hline & & Finalizar projeto e especificações técnicas & & & & & & & \\
\hline & \multirow{8}{*}{ Produzir } & Desenvolver a BOM preliminar & & & & & & & \\
\hline & & Planejar materiais & & & & & & & \\
\hline & & Planejar capacidade e produção & & & & & & & \\
\hline & & Planejar e programar engenharia & & & & & & & \\
\hline & & Planejar e programar ferramentas e desenho do processo & & & & & & & \\
\hline & & Estimar custos utilizando BOM preliminar & & & & & & & \\
\hline & & Revisar status/necessidades & & & & & & & \\
\hline & & Finalizar atividades e marketing e vendas & & & & & & & \\
\hline
\end{tabular}

Quadro 16 - Modelo de processo de transferência de tecnologia 2

Fonte: Lane (2009)

A empresa 6 é a única que não realiza o processo de pesquisa e também possui um menor número de atividades referentes ao desenvolvimento. Isto se deve a característica da empresa que atua no setor de mecânica de precisão. No caso da empresa, a atividade reunir, analisar, priorizar necessidades do cliente não é realizada em decorrência de ter sido analisado o desenvolvimento da tecnologia a partir de pesquisas e não da necessidade do mercado.

O Quadro 17 apresenta o modelo de transferência de Cormican e O’Connor (2009).

\begin{tabular}{|c|c|c|c|c|c|c|c|c|c|}
\hline \multirow{2}{*}{ Autores } & \multirow{2}{*}{ Processos } & \multirow{2}{*}{ Sub-Processos } & \multicolumn{7}{|c|}{ Empresas } \\
\hline & & & 1 & 2 & 3 & 4 & 5 & 6 & 7 \\
\hline \multirow{5}{*}{$\begin{array}{l}\text { Cormican } \\
\text { e } \\
\text { O'Connor } \\
(2009)\end{array}$} & - & Preparar time de transferência & & & & & & & \\
\hline & - & Elaborar plano de treinamento & & & & & & & \\
\hline & - & Elaborar plano de validação & & & & & & & \\
\hline & - & Elaborar plano do projeto de transferência & & & & & & & \\
\hline & - & Transferir informação e equipamento & & & & & & & \\
\hline
\end{tabular}

Quadro 17 - Modelo de processo de transferência de tecnologia 3

Fonte: Cormican, O’Connor (2009) 
A empresa 7 é a única que mencionou o treinamento como uma das atividades realizadas no processo de transferência por ser um serviço para dar suporte a tecnologia desenvolvida por eles. As atividades comuns a todas as empresas foram: preparar time de transferência, elaborar plano de validação e, transferir informação e equipamento.

O Quadro 18 apresenta dois modelos identificados na literatura que auxilia no estabelecimento de parcerias. O primeiro modelo é de Emden, Calantone e Droge (2006) que propõe um conjunto de atividades para selecionar parceiros. O segundo modelo foi proposto por Chesbrough e Schwartz (2007) que apresenta atividades para implementar parcerias de co-desenvolvimento.

\begin{tabular}{|c|c|c|c|c|c|c|c|c|c|}
\hline \multirow{2}{*}{ Autores } & \multirow{2}{*}{ Processos } & \multirow{2}{*}{ Sub-Processos } & \multicolumn{7}{|c|}{ Empresas } \\
\hline & & & 1 & 2 & 3 & 4 & 5 & 6 & 7 \\
\hline \multirow{11}{*}{$\begin{array}{l}\text { Emden, } \\
\text { Calantone e } \\
\text { Droge } \\
(2006)\end{array}$} & \multirow{3}{*}{$\begin{array}{l}\text { Alinhamento } \\
\text { tecnológico }\end{array}$} & Verificar a capacidade técnica (competência) & & & & & & & \\
\hline & & $\begin{array}{l}\text { Identificar complementaridade de conhecimento de } \\
\text { mercado e de recurso técnico }\end{array}$ & & & & & & & \\
\hline & & Analisar a sobreposição das bases de conhecimento & & & & & & & \\
\hline & Decisão 1 & $\begin{array}{l}\text { Desenvolver um entendimento mútuo da tecnologia } \\
\text { e suas implicações para o mercado }\end{array}$ & & & & & & & \\
\hline & \multirow{2}{*}{$\begin{array}{l}\text { Alinhamento } \\
\text { estratégico }\end{array}$} & Verificar se as motivações são correspondentes & & & & & & & \\
\hline & & $\begin{array}{l}\text { Verificar se os objetivos são correspondentes e/ ou } \\
\text { não conflitantes }\end{array}$ & & & & & & & \\
\hline & Decisão 2 & $\begin{array}{l}\text { Estabelecer o time para desenvolver as } \\
\text { especificações do projeto }\end{array}$ & & & & & & & \\
\hline & \multirow{3}{*}{$\begin{array}{l}\text { Alinhamento } \\
\text { relacional }\end{array}$} & Verificar compatibilidade cultural & & & & & & & \\
\hline & & Verificar a propensão para se adaptar & & & & & & & \\
\hline & & $\begin{array}{l}\text { "Fazer sacrifícios no curto prazo para obter } \\
\text { resultados no longo prazo" (orientação a longo } \\
\text { prazo) }\end{array}$ & & & & & & & \\
\hline & Decisão 3 & $\begin{array}{l}\text { Determinar a viabilidade financeira e jurídica do } \\
\text { projeto de co-desenvolvimento e aceitação } \\
\text { organizacional }\end{array}$ & & & & & & & \\
\hline \multirow{4}{*}{$\begin{array}{l}\text { Chesbrough } \\
\text { e Schwartz } \\
\quad(2007)\end{array}$} & \multirow{4}{*}{$\begin{array}{l}\text { Implementar } \\
\text { parcerias de co- } \\
\text { desenvolvimento }\end{array}$} & Definir o objetivo do seu negócio & & & & & & & \\
\hline & & Avaliar as capacidades requeridas & & & & & & & \\
\hline & & $\begin{array}{l}\text { Determinar o grau de alinhamento do modelo de } \\
\text { negócio com o seu parceiro }\end{array}$ & & & & & & & \\
\hline & & $\begin{array}{l}\text { No gerenciamento da parceria, pensar no futuro da } \\
\text { colaboração - não apenas na necessidade atual }\end{array}$ & & & & & & & \\
\hline
\end{tabular}

Quadro 18 - Modelos para colaboração

Como pode ser observado no Quadro 16, as empresas não realizam nenhuma das atividades propostas pela literatura. Isso pode significar que pelo fato das empresas não estarem interessadas em colaborar por diferentes motivos elas não possuem tais atividades. 
Outra possibilidade é que as empresas tenham tido dificuldade em colaborar por não ter atividades que pudessem orientá-las.

\subsubsection{Modelo de Atores e Recursos}

O Quadro 19 apresenta as variáveis que compõem o modelo atores e recursos. Os atores encontrados na literatura também estão participando no processo de transferência das empresas exceto os distribuidores e varejistas, consumidor (usuário final) e provedor de recursos (governo e entidades privadas). Quanto aos recursos, poucos foram encontrados nas literaturas de transferência e de colaboração.

\begin{tabular}{|c|c|c|c|c|c|c|c|c|c|}
\hline \multirow{2}{*}{$\begin{array}{c}\text { Variáveis do } \\
\text { modelo de atores } \\
\text { e recursos } \\
\end{array}$} & \multirow{2}{*}{ Tópico } & \multirow[b]{2}{*}{ Autores } & \multicolumn{7}{|c|}{ Empresas } \\
\hline & & & 1 & 2 & 3 & 4 & 5 & 6 & 7 \\
\hline \multirow{7}{*}{ Atores e papéis } & $\begin{array}{l}\text { Time (compreendem gestor de projeto, } \\
\text { manufatura e engenheiros, supervisor de } \\
\text { produção, técnicos de processo e } \\
\text { operadores, entre outros) }\end{array}$ & $\begin{array}{l}\text { Cormican e O'Connor } \\
(2009)\end{array}$ & & & & & & & \\
\hline & Distribuidores, varejista & Lane (1999) & & & & & & & \\
\hline & Consumidor (usuários finais) & Lane (1999) & & & & & & & \\
\hline & $\begin{array}{llll}\text { Provedor de recursos } & \text { (governos } \\
\text { entidades privadas) }\end{array}$ & Lane (1999) & & & & & & & \\
\hline & $\begin{array}{l}\text { Fornecedor (universidade, centros de } \\
\text { pesquisa ou departamento de P\&D de } \\
\text { empresas) }\end{array}$ & $\begin{array}{l}\text { Buratti e Penco (2001); } \\
\text { Lane (1999); Bozeman } \\
(2000)\end{array}$ & & & & & & & \\
\hline & $\begin{array}{l}\text { Receptor (empresas que podem usar ou } \\
\text { co-desenvolver a tecnologia. Exemplo: } \\
\text { agências governamentais, setor privado } \\
\text { de manufatura) }\end{array}$ & $\begin{array}{l}\text { Buratti e Penco (2001); } \\
\text { Lane (1999); Bozeman } \\
(2000)\end{array}$ & & & & & & & \\
\hline & Diretores & & & & & & & & \\
\hline \multirow{5}{*}{ Recursos } & $\begin{array}{l}\text { Recursos físicos (instalações } \\
\text { laboratórios, máquinas, ferramentas }\end{array}$ & $\begin{array}{l}\text { Autio, Hameri e Vuola } \\
\text { (2004); Plisson et al. } \\
(2007) \text {; Camarinha- } \\
\text { Matos e Afsarmanesh } \\
(2008) \text {; Lee e Win } \\
(2004)\end{array}$ & & & & & & & \\
\hline & $\begin{array}{l}\text { Recursos tecnológicos (hardware e } \\
\text { software) }\end{array}$ & $\begin{array}{l}\text { Plisson et al. (2007); } \\
\text { Camarinha-Matos e } \\
\text { Afsarmanesh (2008) }\end{array}$ & & & & & & & \\
\hline & Recursos humanos (indivíduos) & $\begin{array}{l}\text { Plisson et al. (2007); } \\
\text { Camarinha-Matos e } \\
\text { Afsarmanesh (2008) }\end{array}$ & & & & & & & \\
\hline & Financeiro (orçamento, fundos) & $\begin{array}{l}\text { Cormican e O'Connor } \\
(2009) \text {; Lee e Win } \\
(2004)\end{array}$ & & & & & & & \\
\hline & Contratos e acordos & $\begin{array}{ll}\text { Camarinha-Matos } & \text { e } \\
\text { Afsarmanesh (2008) } & \end{array}$ & & & & & & & \\
\hline
\end{tabular}

Quadro 19 - Variáveis relacionadas ao modelo de atores e recursos (continuação) 


\begin{tabular}{|c|c|c|c|c|c|c|c|c|c|}
\hline \multirow{2}{*}{$\begin{array}{c}\text { Variáveis do } \\
\text { modelo de atores } \\
\text { e recursos }\end{array}$} & \multirow[b]{2}{*}{ Tópico } & \multirow[b]{2}{*}{ Autores } & \multicolumn{7}{|c|}{ Empresas } \\
\hline & & & 1 & 2 & 3 & 4 & 5 & 6 & 7 \\
\hline \multirow{14}{*}{ Recursos } & Fornecedores & & & & & & & & \\
\hline & Novas tecnologias & & & & & & & & \\
\hline & Informações de fornecedores & & & & & & & & \\
\hline & Custos de montagem de protótipo & & & & & & & & \\
\hline & Biblioteca interna & & & & & & & & \\
\hline & Relatório de melhoria & & & & & & & & \\
\hline & Custos do processo de produção & & & & & & & & \\
\hline & Ata de reunião & & & & & & & & \\
\hline & Infraestrutura para projeto & & & & & & & & \\
\hline & Insumos para projeto & & & & & & & & \\
\hline & Informações de fornecedores & & & & & & & & \\
\hline & Notas & & & & & & & & \\
\hline & $\begin{array}{l}\text { Documentos do produto e processo } \\
\text { (desenho técnico; lista de requisitos }\end{array}$ & & & & & & & & \\
\hline & $\begin{array}{l}\text { Documentos de projetos (documentos } \\
\text { de projetos anteriores; fluxograma do } \\
\text { projeto; plano do projeto inicial; } \\
\text { documento de avaliação e encerramento } \\
\text { do projeto; termo de abertura, } \\
\text { declaração do escopo, plano de } \\
\text { comunicação, qualidade, aquisição; } \\
\text { cronograma) }\end{array}$ & & & & & & & & \\
\hline
\end{tabular}

Quadro 19 - Variáveis relacionadas ao modelo de atores e recursos (conclusão)

Como pode ser observado no Quadro 19, os recursos identificados na literatura são os físicos, tecnológicos, humanos, financeiros, além dos contratos e acordos que regem a relação das empresas com outras Organizações. Os outros recursos que foram indicados pelas empresas estão relacionados ao desenvolvimento do projeto e do produto.

\subsubsection{Modelo de Componentes e Requisitos Técnicos}

O Quadro 20 apresenta as variáveis que compõem o modelo de componentes e requisitos técnicos. Observa-se que poucos objetivos do sistema de informação para apoiar a transferência e a colaboração foram identificados na literatura. Os principais objetivos mencionados pelas empresas foram trocar informações, apoiar as decisões, planejar e controlar o andamento do projeto, melhorar comunicação e gerenciar portfólio de projetos.

Com relação aos requisitos funcionais que um sistema deve ter, os que se destacaram entre as empresas foram: armazenar diferentes arquivos, gerar relatórios em pdf, permitir planejar e controlar projetos, disparar avisos por e-mail, ser baseado na web, e permitir multiusuários. 


\begin{tabular}{|c|c|c|c|c|c|c|c|c|c|}
\hline \multirow{2}{*}{$\begin{array}{l}\text { Variáveis do modelo } \\
\text { de componentes e } \\
\text { requisitos técnicos } \\
\end{array}$} & \multirow[b]{2}{*}{ Tópico } & \multirow[b]{2}{*}{ Autores } & \multicolumn{7}{|c|}{ Empresas } \\
\hline & & & 1 & 2 & 3 & 4 & 5 & 6 & 7 \\
\hline \multirow{18}{*}{ Objetivos do SI } & Compartilhar conhecimento & $\begin{array}{l}\text { Qureshi, Liu e Vogel } \\
(2006)\end{array}$ & & & & & & & \\
\hline & Gerenciar portfólio de projetos & & & & & & & & \\
\hline & Gerenciar tempo & & & & & & & & \\
\hline & Gerenciar recursos financeiros & & & & & & & & \\
\hline & Gerenciar recursos humanos & & & & & & & & \\
\hline & Melhorar comunicação & Shen et al. (2004) & & & & & & & \\
\hline & Obter informações & & & & & & & & \\
\hline & $\begin{array}{l}\text { Manter as pessoas atualizadas } \\
\text { em relação ao projeto }\end{array}$ & & & & & & & & \\
\hline & Prover informações para cliente & & & & & & & & \\
\hline & Gerenciar produção & & & & & & & & \\
\hline & $\begin{array}{l}\text { Agilizar a identificação de } \\
\text { informações }\end{array}$ & & & & & & & & \\
\hline & $\begin{array}{l}\text { Desenvolver plataforma } \\
\text { colaborativa }\end{array}$ & Han, Chin e Chae (2007) & & & & & & & \\
\hline & Gerenciar dados e informações & $\begin{array}{l}\text { Wuliang, Fanbo e Decai } \\
\text { (2010); Liu et al. (2008) }\end{array}$ & & & & & & & \\
\hline & Trocar informações & $\begin{array}{l}\text { Han, Chin e Chae } \\
\text { (2007); Jin e Bouthillier } \\
(2004)\end{array}$ & & & & & & & \\
\hline & Apoiar as decisões & Caniëls e Bakens (2012) & & & & & & & \\
\hline & $\begin{array}{l}\text { Garantir comunicação entre os } \\
\text { membros das equipes }\end{array}$ & $\begin{array}{l}\text { Rodriguez e Al-Ashaab } \\
(2005), \text { Saeed (2012) }\end{array}$ & & & & & & & \\
\hline & Manter históricos de projetos & & & & & & & & \\
\hline & Planejar e controlar o projeto & & & & & & & & \\
\hline \multirow{21}{*}{$\begin{array}{l}\text { Requisitos } \\
\text { Funcional e Não- } \\
\text { Fucnional }\end{array}$} & Gerar indicadores & & & & & & & & \\
\hline & Armazenar diferentes arquivos & & & & & & & & \\
\hline & Integrar diferentes áreas & & & & & & & & \\
\hline & Gerar relatórios em pdf & & & & & & & & \\
\hline & Gerar gráfico & & & & & & & & \\
\hline & Ser baseado na intranet & & & & & & & & \\
\hline & $\begin{array}{l}\text { Obter informações de } \\
\text { fornecedores }\end{array}$ & & & & & & & & \\
\hline & Obter informações de projetos & & & & & & & & \\
\hline & Manter dados de fornecedores & & & & & & & & \\
\hline & $\begin{array}{l}\text { Armazenar documentos } \mathrm{de} \\
\text { apoio à assistência técnica }\end{array}$ & & & & & & & & \\
\hline & Integrar fornecedores & & & & & & & & \\
\hline & $\begin{array}{l}\text { Armazenar informações de } \\
\text { clientes }\end{array}$ & & & & & & & & \\
\hline & $\begin{array}{l}\text { Armazenar informações de } \\
\text { fornecedores }\end{array}$ & & & & & & & & \\
\hline & Armazenar histórico de projetos & & & & & & & & \\
\hline & Fornecer manuais & & & & & & & & \\
\hline & Fornecer documentos & & & & & & & & \\
\hline & Possibilitar um ambiente virtual & & & & & & & & \\
\hline & Interface intuitiva e moderna & & & & & & & & \\
\hline & Permitir realizar consultas & & & & & & & & \\
\hline & $\begin{array}{l}\text { Aderir a diferentes métodos de } \\
\text { gestão de projetos }\end{array}$ & & & & & & & & \\
\hline & $\begin{array}{lll}\begin{array}{l}\text { Agilizar a } \\
\text { documentos }\end{array} & \text { busca por } \\
\end{array}$ & & & & & & & & \\
\hline
\end{tabular}

Quadro 20 - Variáveis relacionadas ao modelo de componentes e requisitos técnicos (continuação) 


\begin{tabular}{|c|c|c|c|c|c|c|c|c|c|}
\hline \multirow{2}{*}{$\begin{array}{l}\text { Variáveis do modelo } \\
\text { de componentes e } \\
\text { requisitos técnicos } \\
\end{array}$} & \multirow[b]{2}{*}{ Tópico } & \multirow[b]{2}{*}{ Autores } & \multicolumn{7}{|c|}{ Empresas } \\
\hline & & & 1 & 2 & 3 & 4 & 5 & 6 & 7 \\
\hline \multirow{17}{*}{$\begin{array}{l}\text { Requisitos } \\
\text { Funcional e Não- } \\
\text { Fucnional }\end{array}$} & Planejar e controlar projetos & 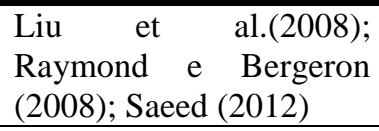 & & & & & & & \\
\hline & Controle de acesso & $\begin{array}{l}\text { Biennier e Favrel (2001); } \\
\text { Ojasalo (2008); Frame et } \\
\text { al. (2009) }\end{array}$ & & & & & & & \\
\hline & Disparar avisos por $e$-mail & $\begin{array}{l}\text { Bafoutsou e Mentzas } \\
(2001)\end{array}$ & & & & & & & \\
\hline & Ser baseado na web & $\begin{array}{l}\text { Han, Chin e Chae } \\
\text { (2007); Huang (2000), Li } \\
\text { e Qiu (2006) }\end{array}$ & & & & & & & \\
\hline & Garantir segurança dos dados & $\begin{array}{l}\text { Ojasalo } \\
\text { Raymond e } \begin{array}{r}(2008) ; \\
(2008)\end{array}\end{array}$ & & & & & & & \\
\hline & $\begin{array}{l}\text { Permitir multiusuários (vários } \\
\text { stakeholders) }\end{array}$ & $\begin{array}{l}\text { Han, Chin e Chae } \\
\text { (2007); Liu et al. (2008), } \\
\text { Li e Qiu (2006) }\end{array}$ & & & & & & & \\
\hline & $\begin{array}{l}\text { Permitir avaliar desempenho do } \\
\text { projeto/time }\end{array}$ & Saeed (2012) & & & & & & & \\
\hline & Permitir gestão visual & & & & & & & & \\
\hline & $\begin{array}{l}\text { Permitir } \quad \text { documentar } \\
\text { funcionalidades do sistema }\end{array}$ & & & & & & & & \\
\hline & Colaboração via intranet & Biennier e Favrel (2001) & & & & & & & \\
\hline & $\begin{array}{l}\text { Deve ter blogs, fóruns e wikis } \\
\text { que apoia a troca de } \\
\text { conhecimento, cria novos } \\
\text { conhecimentos e traz sugestões } \\
\text { de melhoria para a organização }\end{array}$ & $\begin{array}{l}\text { Carbone et al. (2012), } \\
\text { Saeed (2012) }\end{array}$ & & & & & & & \\
\hline & $\begin{array}{l}\text { Deve ser de fácil uso, ter } \\
\text { flexibilidade, tempo de resposta } \\
\text { e ser de fácil aprendizagem }\end{array}$ & $\begin{array}{l}\text { Raymond e Bergeron } \\
(2008)\end{array}$ & & & & & & & \\
\hline & $\begin{array}{l}\text { Informação deve estar } \\
\text { disponível, deve ser confiável }\end{array}$ & $\begin{array}{l}\text { Raymond e Bergeron } \\
(2008)\end{array}$ & & & & & & & \\
\hline & $\begin{array}{l}\text { Documentos devem ser } \\
\text { protegidos antes, durante } \mathrm{e} \\
\text { depois da transmissão }\end{array}$ & Ojasalo (2008) & & & & & & & \\
\hline & $\begin{array}{l}\text { Proteger cada envolvido na } \\
\text { colaboração }\end{array}$ & Biennier e Favrel (2001) & & & & & & & \\
\hline & $\begin{array}{l}\text { A ferramenta deve ser síncrona } \\
\text { e a assíncrona }\end{array}$ & Li e Qiu (2006) & & & & & & & \\
\hline & $\begin{array}{l}\text { Compartilhar documentos e } \\
\text { arquivos }\end{array}$ & Saeed (2012) & & & & & & & \\
\hline
\end{tabular}

Quadro 20 - Variáveis relacionadas ao modelo de componentes e requisitos técnicos (conclusão)

Quanto aos requisitos não-funcionais de um sistema, as empresas mencionaram apenas um requisito que se refere à segurança dos dados. A literatura apresenta outros considerados importantes para a qualidade do sistema como: usabilidade, confiabilidade e, disponibilidade. 


\subsection{Modelo Proposto pela Pesquisa (Estado Futuro ou To-Be)}

Nesta seção apresenta-se o principal resultado desta pesquisa que é o desenvolvimento de um modelo de referência para transferência tecnologia-produto sob o recorte analítico das redes colaborativas. $\mathrm{O}$ modelo incorpora as sugestões apresentadas pela literatura de redes colaborativas.

\subsubsection{Modelo de Objetivos}

A Figura 33 apresenta o modelo de objetivos que norteia a transferência tecnologiaproduto. Os pontos identificados na literatura que complementam este modelo são os objetivos 17 (abrir novos negócios), 18 (ter sucesso na tecnologia), 19 (abrir novas empresas), 20 (desenvolver melhores pesquisas), 21 (causar impacto no mercado), 22 (desenvolver tecnologias avançadas), 23 (obter vantagem competitiva), 24 (ter imagem positiva, visibilidade e reputação), 25 (ter liderança em mercado) e os problemas 32 (falta de competência), 33 (retorno sobre investimento), 34 (deficiência no sistema de informação), 35 (diferença procedural), 36 (diferentes objetivos estratégicos), 37 (não definir muito bem detalhes da parceria), 38 (parceiros não dispostos a cumprir os termos do acordo), 39 (mudança de objetivo).

Diferentes objetivos são definidos pelas empresas entre eles tem-se: obter lucro (Objetivo 4), lançar novos produtos (Objetivo 15), desenvolver novos produtos (Objetivo 5) o que permite ser competitivo no mercado interno e externo (Objetivo 6), crescer em termos de faturamento/ lucro (Objetivo 7), obter excelência na resolução dos problemas dos clientes (Objetivo 8), aumentar participação de mercado (Objetivo 16), abrir novos negócios (Objetivo 17), ter sucesso na tecnologia (Objetivo 18), abrir novas empresas (Objetivo 19), desenvolver melhores pesquisas (Objetivo 20), impactar o mercado (Objetivo 21), desenvolver tecnologias avançadas (Objetivo 22), obter vantagem competitiva (Objetivo 23), ter imagem positiva, visibilidade e reputação (Objetivo 24), e ter liderança em mercados (Objetivo 25).

Para lançar novos produtos (Objetivo 15) é importante estruturar a organização para usar bem o conhecimento (Oportunidade 4) que por sua vez apoia obter novos clientes (Objetivo 1.2) e acompanhar as alterações de legislação que podem influenciar no produto da empresa (Política 5). Entretanto, o avanço tecnológico (Problema 30) influencia no lançamento de novos produtos (Objetivo 15). 


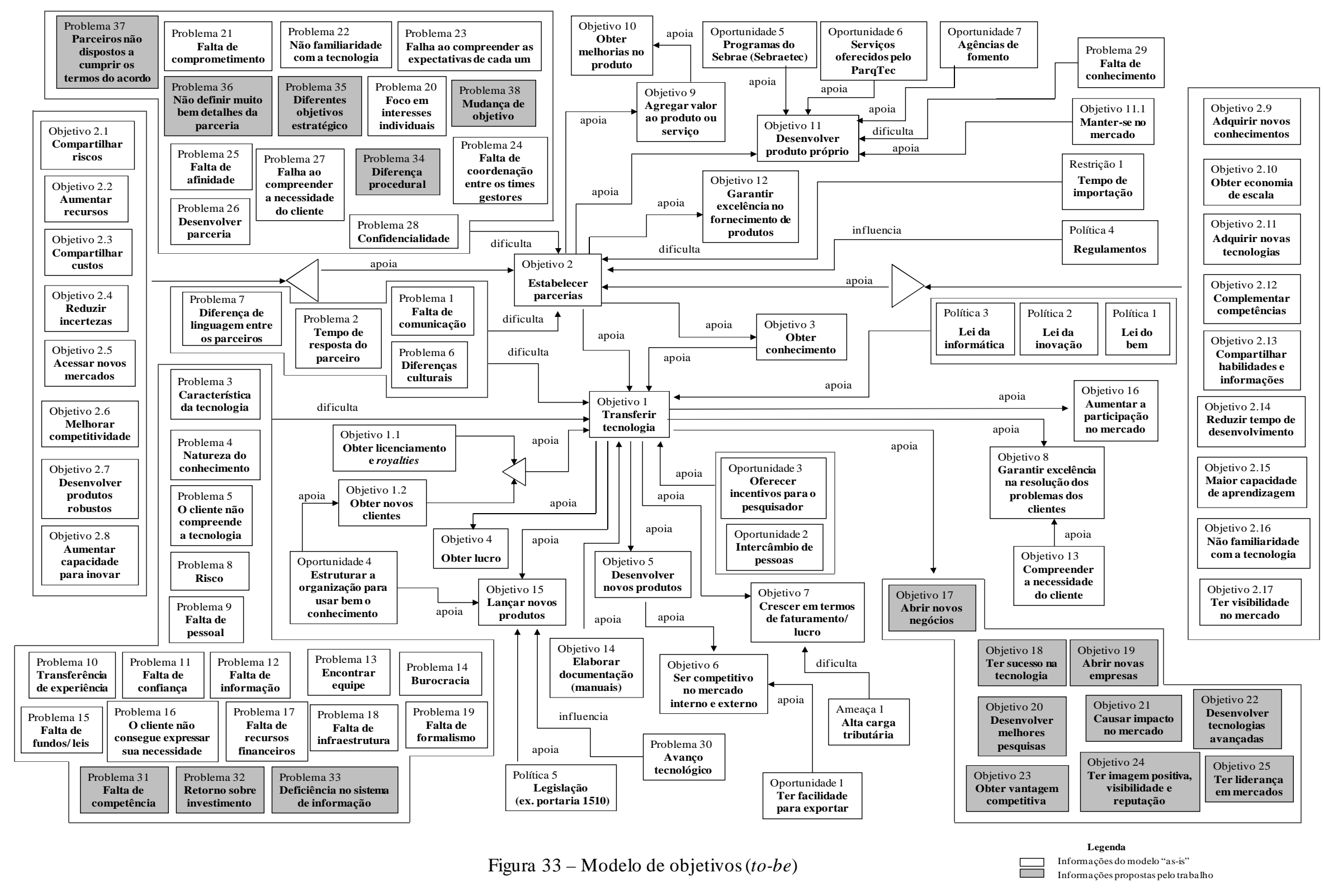


Para alcançar o objetivo de ser competitivo principalmente no mercado externo (Objetivo 6) é necessário ter facilidade para exportar (Oportunidade 1). Crescer em termos de faturamento/lucro tem sido difícil em decorrência da alta carga tributária (Ameaça 1). Obter excelência na resolução dos problemas dos clientes (Objetivo 8) é possível quando a empresa compreende a necessidade do cliente (Objetivo 13).

Um dos caminhos que as empresas possuem para atingir os objetivos 4 (obter lucro), 15 (lançar novos produtos), 5 (desenvolver novos produtos), 7 (crescer em termos de faturamento/ lucro) e 8 (obter excelência na resolução dos problemas dos clientes) é a transferência de tecnologia (Objetivo 1).

Para transferir tecnologia (Objetivo 1) a empresa se apoia na obtenção de licenciamento e royalties (Objetivo 1.1), em novos clientes (Objetivo 1.2), nas leis da informática (Política 3), da inovação (Política 2) e do bem (Política 1), na obtenção de conhecimento (Objetivo 3) e, no estabelecimento de parceria (Objetivo 2). Oferecer incentivos para o pesquisador (Oportunidade 3) e realizar intercâmbio de pessoas (Oportunidade 2) são alguns dos meios que podem facilitar e incentivar a transferência (Objetivo 1).

Vários problemas dificultam transferir tecnologia (Objetivo 1), sendo: falta de comunicação (Problema 1), tempo de reposta do parceiro (Problema 2), característica da tecnologia (Problema 3), natureza do conhecimento (Problema 4), cliente que não compreende a tecnologia (Problema 5), diferenças culturais (Problema 6), diferença de linguagem entre parceiros (Problema 7), risco (Problema 8), falta de pessoal (Problema 9), transferência de experiência (Problema 10), falta de confiança (Problema 11), falta de informação (Problema 12), encontrar equipe (Problema 13), burocracia (Problema 14), falta de fundos/ leis (Problema 15), cliente que não consegue expressar sua necessidade (Problema 16), falta de recursos financeiros (Problema 17), falta de infraestrutura (Problema 18), falta de formalismo (Problema 19), falta de competência (Problema 31), retorno sobre investimento (Problema 32), e deficiência no sistema de informação (Problema 33).

Estabelecer parceria (Objetivo 2) apoia a empresa obter conhecimento (Objetivo 3) que, conseqüentemente, apoia a transferência (Objetivo 1), garantir excelência no fornecimento de produtos (Objetivo 12), desenvolver produto próprio (Objetivo 11) e agregar valor ao produto ou serviço (Objetivo 9) que por sua vez apoia obter melhorias no produto (Objetivo 10).

Desenvolver produto próprio (Objetivo 11) apoia a empresa manter-se no mercado (Objetivo 11.1). Uma barreira encontrada para atingir o objetivo 11 é a falta de conhecimento (Problema 13). Os serviços prestados por algumas instituições auxiliam no desenvolvimento 
do produto próprio (Objetivo 4) sendo estes os programas do Sebrae, principalmente o SebraeTec (Oportunidade 1), os serviços oferecidos pelo ParqTec (Oportunidade 2), e as agências de fomento (Oportunidade 3).

Ao estabelecer parcerias (Objetivo 2) alguns problemas são identificados como foco em interesse individuais (Problema 20), falta de comprometimento (Problema 21), não familiaridade com a tecnologia (Problema 22), falha ao compreender as expectativas de cada um (Problema 23), falta de coordenação entre os times gestores (Problema 24), falta de afinidade (Problema 25), desenvolver parceria (Problema 26), falha ao compreender a necessidade do cliente (Problema 27), confidencialidade (Problema 28), tempo de importação de peças (Restrição 1), parceiros não dispostos a cumprir termos do acordo (Problema 37), não definir muito bem detalhes da parceria (Problema 36), diferentes objetivos estratégicos (Problema 35), diferença procedural (Problema 34), e mudança de objetivo (Problema 38).

As empresas estabelecem parcerias (Objetivo 2) por diferentes motivos, dentre eles estão: compartilhar riscos (Objetivo 2.1), aumentar recursos (Objetivo 2.2), compartilhar custos (Objetivo 2.3), reduzir incertezas (Objetivo 2.4), acessar novos mercados (Objetivo 2.5), melhorar competitividade (Objetivo 2.6), desenvolver produtos robustos (Objetivo 2.7), aumentar capacidade para inovar (Objetivo 2.8), adquirir novos conhecimentos (Objetivo 2.9), obter economia de escala (Objetivo 2.10), adquirir novas tecnologias (Objetivo 2.11), complementar competências (Objetivo 2.12), compartilhar habilidades e informações (Objetivo 2.13), reduzir tempo de desenvolvimento (Objetivo 2.14), maior capacidade de aprendizagem (Objetivo 2.15), não familiaridade com a tecnologia (Objetivo 2.16), e ter visibilidade de mercado (Objetivo 2.17). Além disso, existem regulamentos (Política 4) que interferem no aumento da demanda de determinados produtos das empresas exigindo a necessidade de estabelecer parcerias (Objetivo 2) para suprir essa demanda.

\subsubsection{Modelo de Regras de Negócio}

A Figura 34 apresenta o modelo de regras de negócio que norteia a transferência tecnologia-produto. Ao analisar a literatura foi possível identificar algumas regras adicionais que apoiam estabelecer parcerias e transferir tecnologia.

As regras relacionadas a transferência são as de número 30 (definir escopo e estratégia de transferência), 31 (definir papéis e responsabilidades dos envolvidos), 32 (possuir ferramenta de comunicação eficaz), 33 (detalhar a freqüência dos encontros), 34 (as responsabilidades da equipe devem estar claras), 35 (contato "cara a cara" durante as etapas 
iniciais do projeto e da aprovação), 36 (estabelecer acordo de entendimento mútuo sobre o que as partes farão), 37 (transferência acontecerá quando ambos confiar um no outro para atender os termos do acordo).

As regras relacionadas às parcerias são as de número 38 (a colaboração deve ter uma proposta), 39 (as partes devem concordar em colaborar), 40 (as partes devem conhecer as capacidades um do outro), 41 (compartilhar objetivos e ter uma visão comum), 42 (a visão de como a colaboração pode ajudar a empresa deve ser compartilhada com o parceiro), 43 (identificar parceiros e trazê-los para junto, de acordo com as capacidades individuais), 44 (estabelecer compromisso de colaborar), 45 (identificar os riscos e plano de contingência), 46 (a empresa deve investir em um relacionamento a longo prazo), 47 (existir interação do time do parceiro com outras áreas da empresa), 48 (a comunicação por meio de encontros regulares e outros meios), 49 (deve existir apoio da empresa durante e depois do contrato), 50 (o gestor de projetos facilita a comunicação intra e inter-organizacional), 51 (ambiente que facilite a colaboração), 52 (definir escopo da colaboração e resultados desejados), 53 (definir políticas de colaboração), 54 (definir estrutura da colaboração), 55 (devem ser definidas métricas para avaliação), 56 (elaborar relatórios periodicamente), 57 (definir o contexto estratégico do projeto), 58 (deve ter clareza nos acordos e termos de adesão), 59 (definir entregas precisamente), 60 (devem ter sistemas de gestão e monitoramento de projeto eficaz).

Transferir tecnologia (Objetivo 1) apoia as empresas a obter lucro (Objetivo 4) desenvolver produto próprio (Objetivo 5), lançar novos produtos (Objetivo 15), aumentar participação no mercado (Objetivo 16), e obter excelência na resolução dos problemas dos clientes (Objetivo 8).

Para obter lucro (Objetivo 4) existem algumas regras. Os custos devem ser reduzidos (Regra 18), realizar a análise PEST (Objetivo 19) e, por fim, compreender o mercado (Regra 20). A análise PEST (Objetivo 19) apoia a realização do planejamento estratégico (Regra 21) que por sua vez apoia o desenvolvimento do technology roadmap (Regra 22) que auxilia obter conhecimento (Objetivo 3).

Para desenvolver novos produtos (Objetivo 5) a prioridade é desenvolver produto internamente (Regra 16), deve-se buscar alternativas se o custo de desenvolver for alto (Regra 17), e submeter projeto para órgão de fomento (Regra 15). A submissão do projeto (Regra 15) apoia a empresa alcançar o objetivo de lançar novos produtos (Objetivo 15) que também é apoiado pela regra de participar de feiras e eventos (Regra 14). 

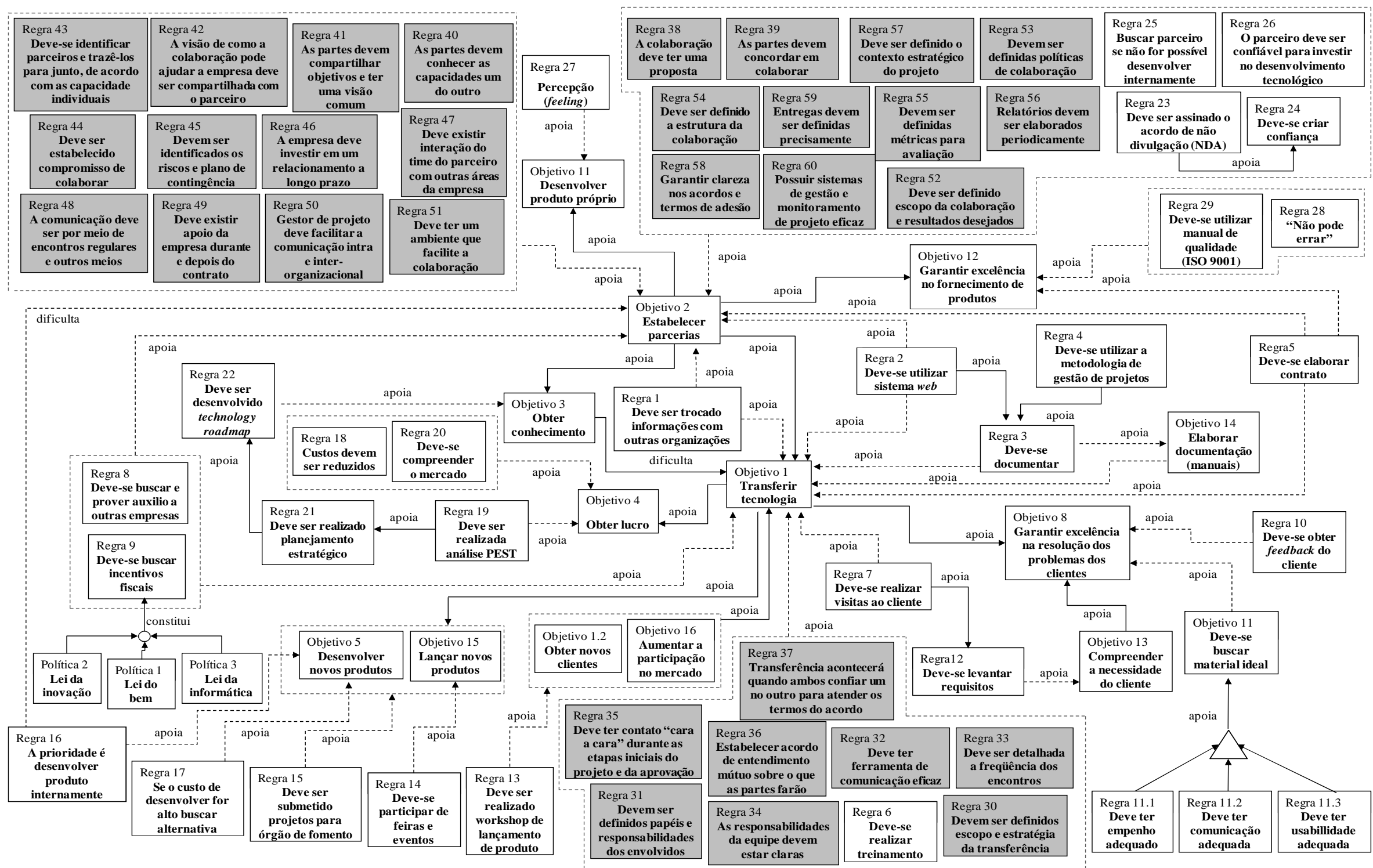

Figura 34 - Modelo de regras de negócio (to-be) da transferência

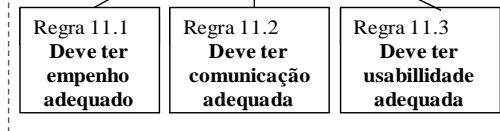

Legenda

Informaçōes do modelo "as-is"
Informą̧óes propostas pelo traball 
Os objetivos aumentar a participação no mercado (Objetivo 16) e obter novos clientes (Objetivo 1.2) são apoiados pela regra de realizar workshop de lançamento de produto (Regra 13).

Obter excelência na resolução dos problemas dos clientes (Objetivo 8) é apoiado pelo retorno do cliente (Regra 10), pela busca de material ideal (Regra 11) em termos de empenho adequado (Regra 11.1), comunicação adequada (Regra 11.2) e usabilidade adequada (Regra 11.3), e por compreender a necessidade do cliente (Objetivo 13).

Para compreender a necessidade do cliente (Objetivo 13) é necessário levantar requisitos (Regra 12). A realização de visitas ao cliente (Regra 7) é um dos meios que auxiliam a levantar os requisitos (Regra 12).

Para transferir tecnologia (Objetivo 1) as empresas se apoiam na troca de informação com outras Organizações (Regra 1) que também auxiliam no estabelecimento de parceria (Objetivo 2), na utilização de um sistema web (Regra 2) que por sua vez apoia documentar o projeto (Regra 3). Para documentar o projeto (Regra 3) utiliza-se de uma metodologia de gestão de projetos (Regra 4). Ao documentar o projeto (Regra 3) é possível alcançar o objetivo de elaborar documentação - manuais (Regra 14) que auxilia transferir tecnologia (Objetivo 1).

A transferência (Objetivo 1) é apoiada ainda pela regra elaborar contrato (Regra 5), realizar treinamento (Regra 6), realizar visitas ao cliente (Regra 7), buscar e prover auxílio a outras empresas (Regra 8), buscar incentivos fiscais (Regra 9) no que se refere a lei da inovação (Política 2), lei do bem (Política 1), e lei da informática (Política 3), ter contato "cara a cara" durante as etapas iniciais do projeto e da aprovação (Regra 35), estabelecer acordo de entendimento mútuo sobre o que as partes farão (Regra 36), possuir ferramenta de comunicação eficaz (Regra 32), detalhar a freqüência dos encontros (Regra 33), definir papéis e responsabilidades dos envolvidos (Regra 31), deixar claro as responsabilidades da equipe (Regra 34), definir o escopo e a estratégia da transferência (Regra 30), e confiar um no outro (Regra 37).

Estabelecer parcerias (Objetivo 2) apoia transferir tecnologia (Objetivo 1), obter conhecimento (Objetivo 3), garantir excelência no fornecimento de produtos (Objetivo 12) e desenvolver produto próprio (Objetivo 11).

Garantir excelência no fornecimento de produtos (Objetivo 12) apoia-se nas regras elaborar contrato (Regra 5), utilizar manual de qualidade (Regra 29) e a filosofia de "não poder errar" (Regra 28). Desenvolver produto próprio apoia-se na percepção (Regra 27). 
O objetivo de estabelecer parceria (Objetivo 2) é apoiado pelas regras trocar informações com outras organizações (Regra 1), utilizar sistema web (Regra 2), elaborar contrato (Regra 5), buscar e prover auxilio a outras organizações (Regra 8), assinar acordo de não divulgação (Regra 23) que por sua vez apoia criar confiança (Regra 24), buscar incentivos fiscais (Regra 9), buscar parceiro se não for possível desenvolver internamente (Regra 25), e o parceiro deve ser confiável para investir no desenvolvimento tecnológico (Regra 26). A regra de priorizar o desenvolvimento do produto internamente (Regra 16) impede estabelecer parceria (Objetivo 2).

Outro conjunto de regras foi identificado para apoiar o objetivo de estabelecer parceria (Objetivo 2), sendo eles:

- Identificar parceiros e trazê-los para junto conforme capacidades individuais (Regra 43);

- Compartilhar com o parceiro a visão de como a colaboração pode ajudar a empresa (Regra 42);

- As partes devem compartilhar uma visão comum (Regra 41);

- As partes devem conhecer as capacidades um do outro (Regra 40);

- Estabelecer o compromisso de colaborar (Regra 44);

- Identificar riscos e plano de contingência (Regra 45);

- Investir em um relacionamento a longo prazo (Regra 46);

- Ter interação do time do parceiro com outras áreas da empresa (Regra 47);

- A comunicação por meio de encontros regulares e outros meios (Regra 48);

- A empresa deve apoiar durante e depois do contrato (Regra 49);

- O gestor de projeto deve facilitar a comunicação intra e interorganizacional (Regra 50);

- Ter um ambiente que facilite a colaboração (Regra 51);

- A colaboração deve ter uma proposta (Regra 38);

- As partes devem concordar em colaborar (Regra 39);

- Definir escopo da colaboração e resultados desejados (Regra 52);

- Devem ser definidas políticas de colaboração (Regra 53);

- Definir estrutura da colaboração (Regra 54);

- Definir métricas para avaliação (Regra 55);

- Definir precisamente as entregas (Regra 59);

- Elaborar relatórios periodicamente (Regra 56); 
- Definir contexto estratégico do projeto (Regra 57);

- Garantir clareza nos acordos e termos de adesão (Regra 58);

- Possuir sistemas de gestão e monitoramento de projeto eficaz (Regra 60).

\subsubsection{Modelo de Conceitos}

A Figura 35 apresenta o modelo de conceitos que norteia a transferência tecnologiaproduto. Os conceitos adicionais presentes neste modelo são os de número 38 (risco), 39 (ferramenta síncrona), 40 (ferramenta assíncrona), 41 (entrega), 42 (plano de contingência), 43 (gerente de projeto), 44 (plano de transferência), 45 (caso de negócio), 46 (modelo de negócio), 47 (alinhamento tecnológico), 48 (alinhamento estratégico), 49 (alinhamento relacional), 50 (estrutura da colaboração), 51 (políticas de colaboração).

A transferência de tecnologia (Objetivo 1) é influenciada pela cultura organizacional (Conceito 8) e pela característica da tecnologia (Conceito 20) em termos de novidade (Conceito 21), complexidade (Conceito 22) e grau do conhecimento tácito (Conceito 23).

O conhecimento (Conceito 12) é um conceito importante para transferir tecnologia (Objetivo 1) e apoiar o objetivo de desenvolver produto próprio (Objetivo 11).

A comunicação (Conceito 9) apoia as empresas a estabelecerem parcerias (Objetivos 2) e transferirem tecnologia (Objetivo 1) e é influenciada pela diferença de linguagem (Conceito 10).

Documentos (Conceito 16) como manuais (Conceito 17), requisito (Conceito 18) e homologação (Conceito 19), royalties e licenciamento (Conceito 24), aplicação da tecnologia (Conceito 25), informação (Conceito 26), sistemas web (Conceito 27), lei da informática (Conceito 28), lei da inovação (Conceito 29), validação da tecnologia (Conceito 30), treinamentos (Conceito 31), formalismo (Conceito 32), equipe (Conceito 33), lei do bem (Conceito 34), confidencialidade (Conceito 35) e infraestrutura (Conceito 36) também são conceitos que apoiam o objetivo de transferir tecnologia (Objetivo 1). 


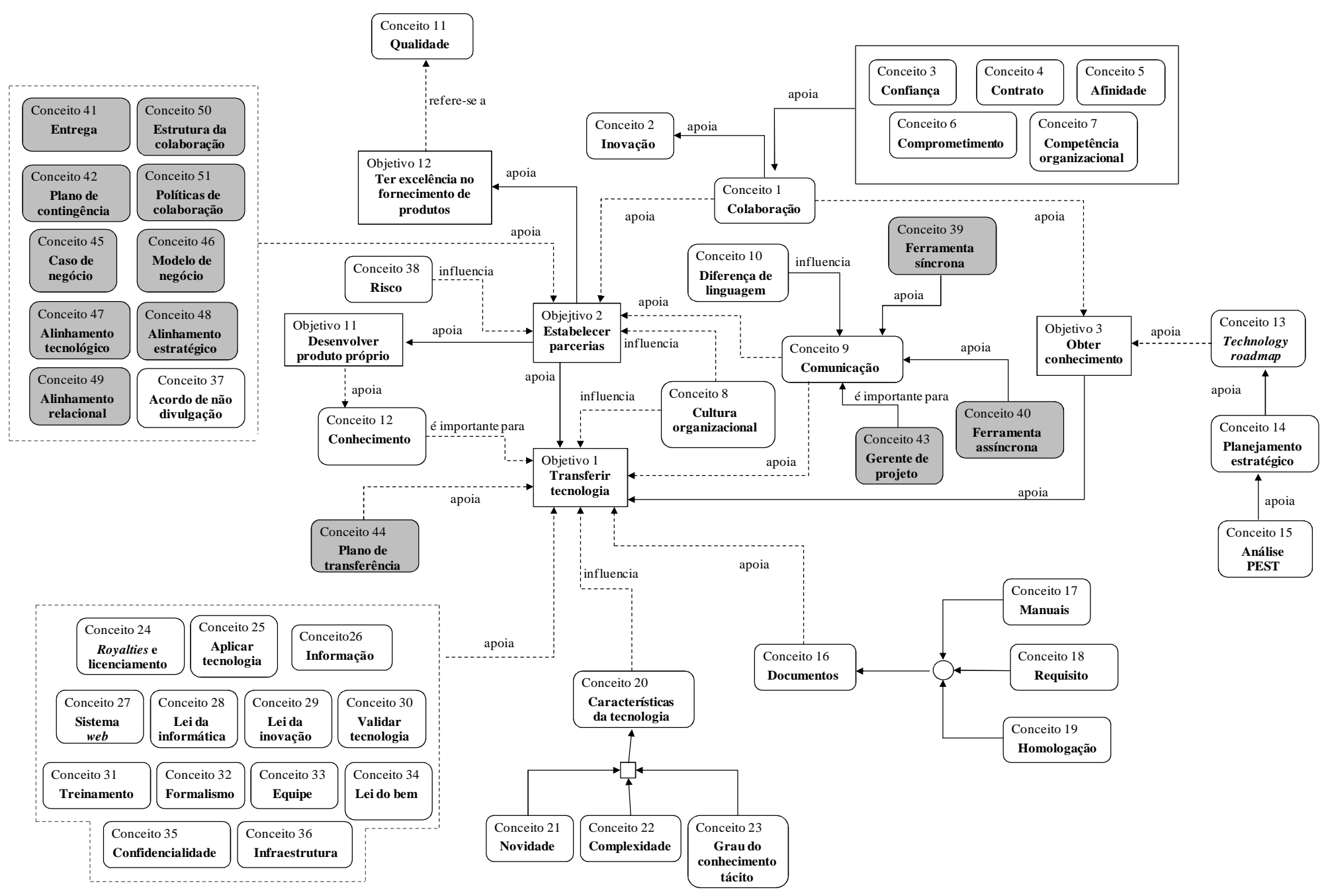

Legenda

Figura 35 - Modelo de conceitos (to-be) 
Para obter conhecimento (Objetivo 3) que auxilia transferir tecnologia (Objetivo 1) é importante realizar o technology roadmap (Conceito 13) que é apoiado pelo planejamento estratégico (Conceito 14) que por sua vez é apoiado pela análise PEST (Conceito 15).

Estabelecer parcerias (Objetivo 2) é apoiado pelos conceitos de acordo de não divulgação (Conceito 37) e de colaboração (Conceito 1) que também apoia o objetivo obter conhecimento (Objetivo 3). O conceito de colaboração apoia a inovação (Conceito 2) e é auxiliado pelos conceitos de confiança (Conceito 3), contratos (Conceito 4), afinidade (Conceito 5), comprometimento (Conceito 6) e competência organizacional (Conceito 7).

Estabelecer parcerias (Objetivo 2) apoia ter excelência no fornecimento de produtos (Objetivo 12) que é amparado pelo conceito de qualidade (Conceito 11).

\subsubsection{Modelo de Processo de Negócio a Partir do Desenvolvimento de Pesquisas}

A Figura 36 apresenta o modelo de processo de negócio que norteia a transferência tecnologia-produto. Neste modelo a proposta apresentada para complementar o processo refere-se ao de número 5 (iniciar prática de co-desenvolvimento).

O processo de transferência de tecnologia é composto por 9 processos realizados pela empresa e um processo externo realizado pelo parceiro. Inicia-se com os interesses em desenvolver novos produtos que são discutidos em reuniões entre os membros da diretoria. Posteriormente, o departamento de P\&D em conjunto com a diretoria e o departamento comercial executa a atividade de prospecção tecnológica (Processo 1) criando um portfólio de idéias. Essas ideias passam por uma análise de viabilidade técnica (Processo 2) pelo departamento de $\mathrm{P} \& \mathrm{D}$ que resulta nas especificações do produto ou sistemas, subsistemas e componentes (SSCs). Diante das especificações e de informações sobre fontes de fomento ou incentivos, o produto começa a ser desenvolvido sob a responsabilidade do departamento de P\&D (Processo 4) que desenvolve especificações de soluções.

Ao realizar a análise de viabilidade (Processo 2) realiza-se também a análise de fazer ou comprar a tecnologia (Processo 3) pelo departamento de P\&D e a diretoria. Como resultado dessa análise tem-se uma lista de possíveis parceiros, de requisitos tecnológicos, o caso de negócio, e protótipos ou códigos ou desenhos. 


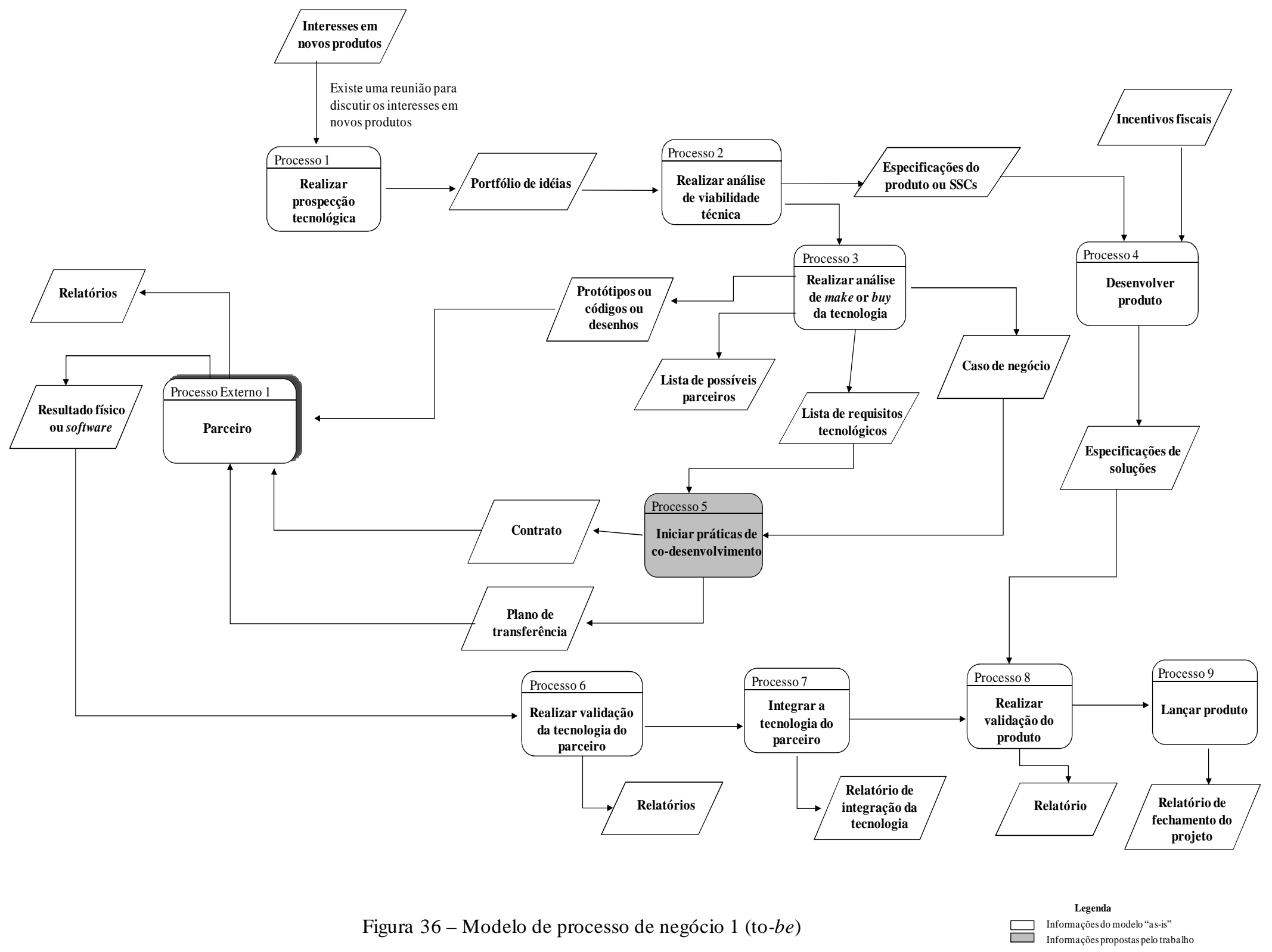


A partir da lista de parceiros e do caso de negócio inicia-se a prática de codesenvolvimento (Processo 5), que resulta em um contrato e no plano de transferência. Ambos os documentos mais o protótipo, código ou desenho são importantes para o parceiro iniciar o desenvolvimento (Processo Externo 1). Como resultado final das atividades realizadas pelo parceiro tem-se o resultado físico ou software que passará por uma validação (Processo 6) pelo departamento de P\&D que produzirá os relatórios. Depois da tecnologia validada a mesma é integrada ao produto da empresa (Processo 7) e é gerado um relatório técnico do produto. Posteriormente, ocorre a validação do produto (Processo 8) pelo cliente no qual são gerados relatórios e por fim o lançamento (Processo 9).

Quando a opção da empresa é o desenvolvimento interno não existem os processos 6 e 7 .

A seguir apresenta-se o detalhamento de cada processo.

\section{Processo 1: Realizar Prospecção Tecnológica}

A Figura 37 apresenta o processo realizar prospecção tecnológica. Nesse processo é proposto o sub-processo 1.3 (desenvolver o roadmap ou mapa para identificar tendências futuras).

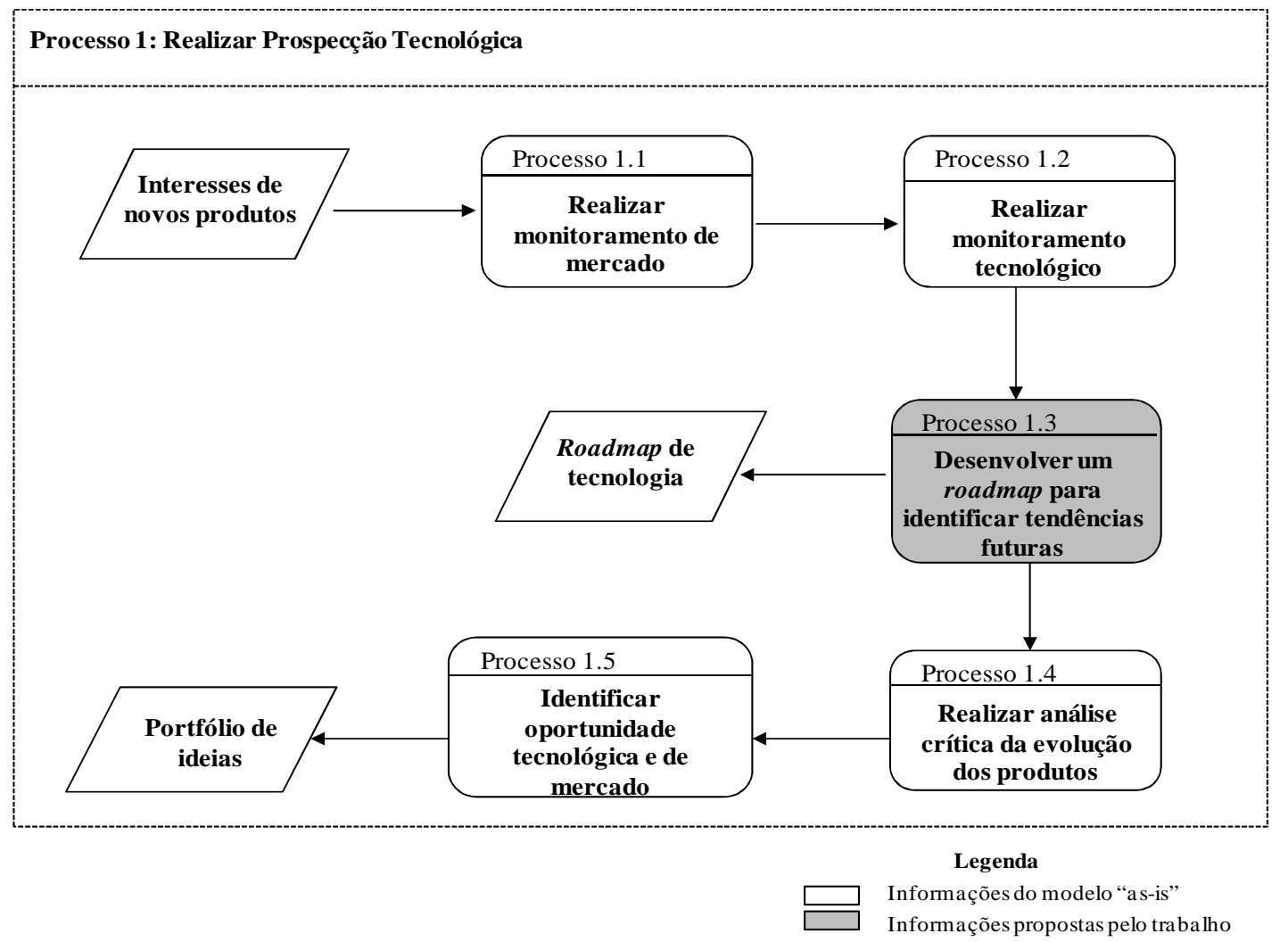

Figura 37 - Sub-processo 1 (to-be) 
O interesse em novos produtos é a principal informação para iniciar a prospecção tecnológica (Processo 1). Diante desses interesses, é realizado o monitoramento de mercado (Processo 1.1) para identificar ou acompanhar tendências e o lançamento de produtos no mercado; monitoramento tecnológico (Processo 1.2) para acompanhar os avanços científicos e tecnológicos. Posteriormente, desenvolve-se um roadmap para identificar tendências futuras (Processo 1.3), que resulta no roadmap de tecnologia. Logo após, realiza-se uma análise crítica da evolução dos produtos (Processo 1.4) para identificar problemas relevantes visando a solução dos mesmos. Posteriormente, é feita a identificação de oportunidade tecnológica e de mercado (Processo 1.5), que resulta na definição do portfólio de idéias.

\section{Processo 2: Realizar Análise de Viabilidade Técnica}

A Figura 38 apresenta o processo realizar análise de viabilidade técnica. Nesse processo é proposto o sub-processo 2.2 (realizar avaliação técnica para identificar as habilidades potenciais e recursos exigidos.

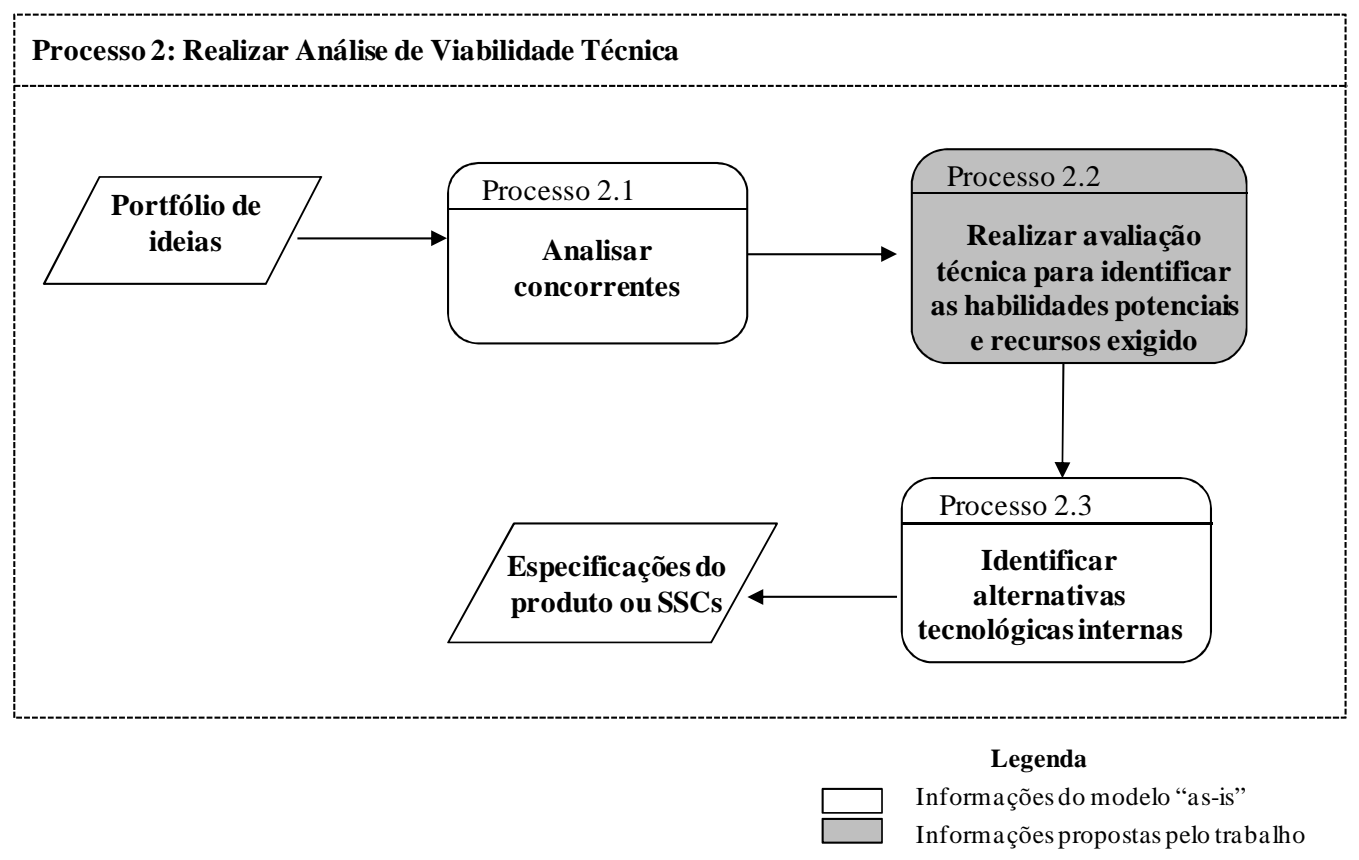

Figura 38 - Sub-processo 2 (to-be)

A partir do portfólio de ideias são analisados os possíveis concorrentes (Processo 2.1) para verificar a tecnologia que eles utilizam, como eles fazem o produto. Logo após, realiza-se uma avaliação técnica para identificar as habilidades potenciais e recursos exigidos (Processo 2.2). Em seguida, os produtos dos concorrentes são analisados e identificam-se 
alternativas tecnológicas desenvolvidas pela empresa (Processo 2.3) e são definidas as especificações do produto ou SSCs.

\section{Processo 3: Análise de Fazer ou Comprar a Tecnologia}

A Figura 39 apresenta o processo realizar análise de fazer ou comprar a tecnologia. Neste processo propõem-se dois sub-processos o 3.3 (estabelecer um conjunto de especificações para a tecnologia em questão) e o 3.6 (construir um caso de negócio).

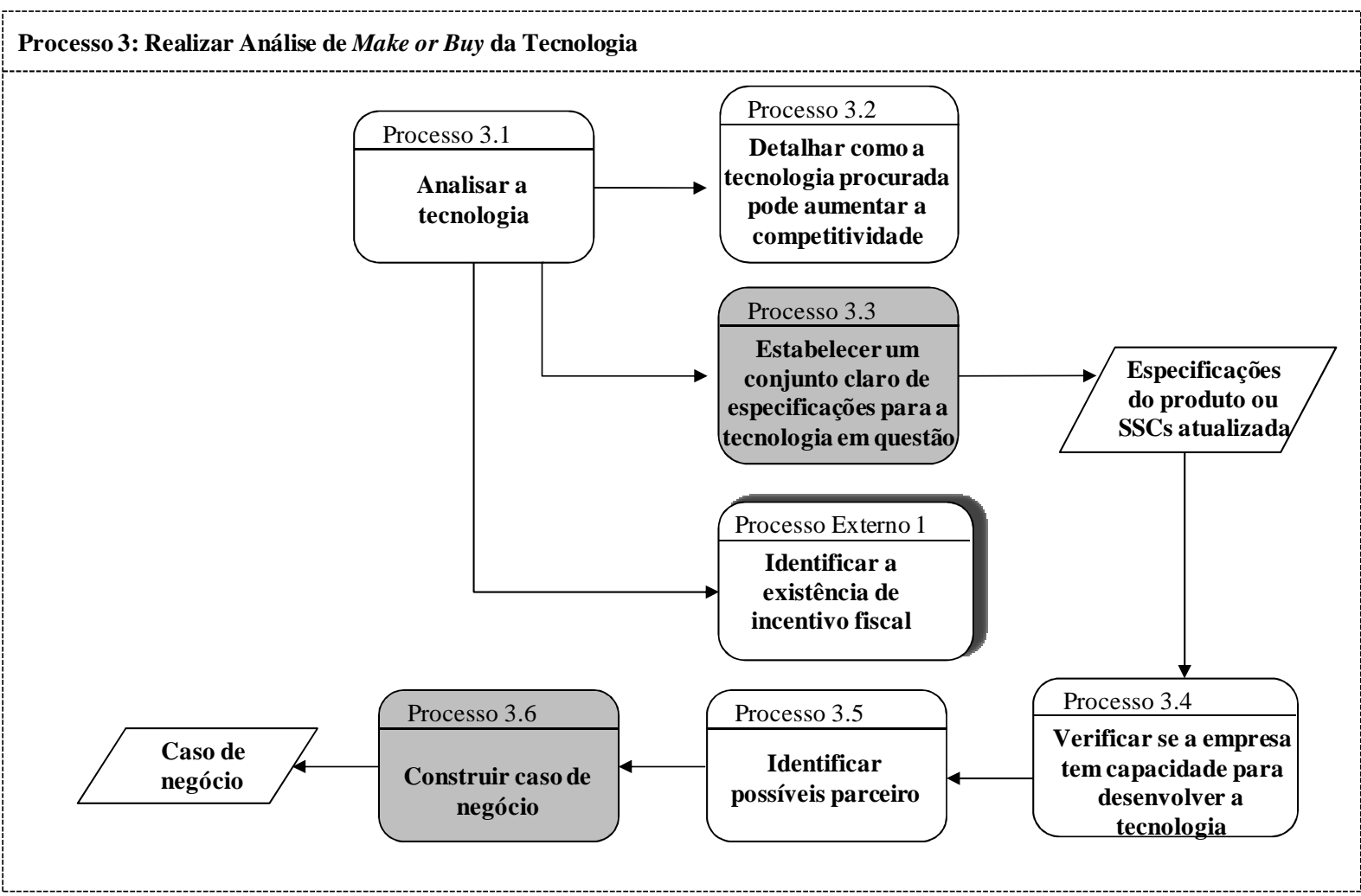

Legenda

Informações do modelo "as-is"

Informações propostas pelo trabalho

Figura 39 - Sub-processo3 (to-be)

A análise do fazer ou comprar (Processo 3) ocorre concomitantemente com o processo de desenvolvimento de produto (Processo 4) e inicia-se com a análise da tecnologia (Processo 3.1) na qual avalia-se os custos de produção e aquisição. A partir dessa análise deve-se detalhar como a tecnologia procurada pode aumentar a competitividade (Processo 3.2), estabelecer um conjunto claro de especificações para a tecnologia em questão (Processo 3.3), que resulta nas especificações do produto ou SSCs atualizada, e identificar a existência de incentivos fiscais (Processo Externo 1). Diante das especificações do produto ou SSCs atualizada, verifica-se a capacidade da empresa para desenvolver a tecnologia (Processo 3.4), 
ou seja, verifica-se os equipamentos, habilidades disponíveis na empresa para desempenhar ou apoiar determinada atividade. Posteriormente, busca-se um parceiro (Processo 3.5) que possua as qualificações necessárias para desenvolver determinada tecnologia. Identificado o parceiro, desenvolve-se o caso de negócio (Processo 3.6).

\section{Processo 4: Desenvolver produto}

A Figura 40 apresenta o processo desenvolver produto.

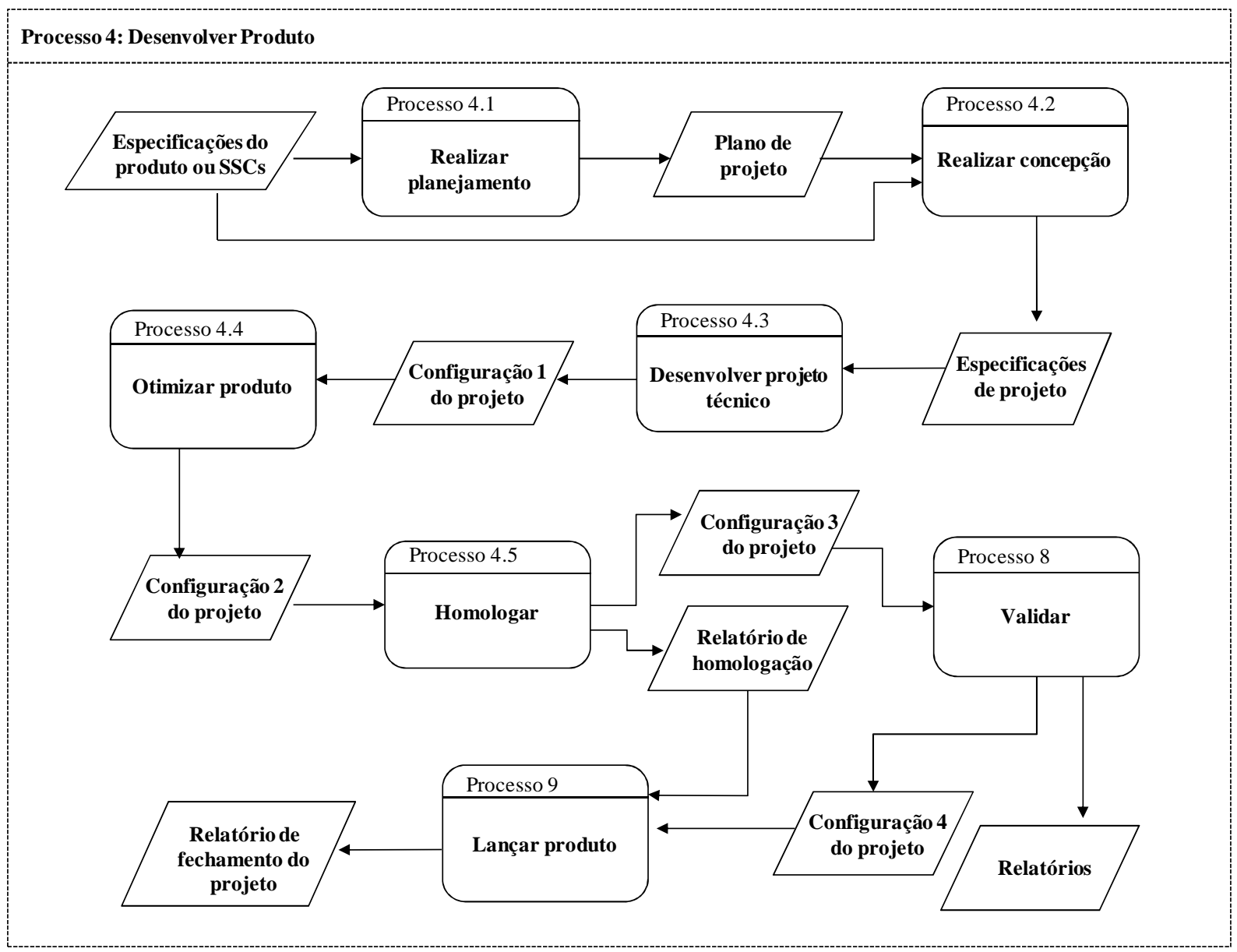

Figura 40 - Sub-processo 4 (to-be)

O desenvolvimento do produto (Processo 4) é constituído por 7 etapas. A primeira é o planejamento do projeto (Processo 4.1) que tem como entrada as especificações do produto ou SSCs. Desse planejamento (Processo 4.1) resulta o plano de projeto com informações sobre cronograma do projeto, alocação de recursos, custos e riscos do projeto.

O plano de projeto e as especificações do produto são informações utilizadas na etapa de concepção (Processo 4.2). Nesta etapa, são definidos os requisitos técnicos de 
concepção de produto, desenvolvem-se modelos técnicos e de custo do produto. Como resultado dessa etapa tem-se as especificações do projeto.

As especificações do projeto são entradas para a etapa de projeto técnico (Processo 4.3), que tem como atividades a incorporação de novas tecnologias, aquisição de materiais e componentes e o desenvolvimento e a realização de testes de protótipo. Ao final desta etapa tem-se a configuração 1 do projeto.

A configuração 1 do projeto é entrada para a etapa de otimização (Processo 4.4), que tem por objetivo aumentar a robustez, a confiabilidade do produto e melhorar os aspectos físicos do produto. Como resultado desta etapa tem-se a configuração 2 do projeto.

A configuração 2 do projeto é a entrada para a etapa de homologação (Processo 4.5). Nesta etapa, desenvolve-se a embalagem do produto, elabora-se documentação técnica detalhada sobre a fabricação e montagem, o produto é fabricado, montado e integrado, os protótipos são testados e realizam-se cálculos de capabilidade do processo. No final desta etapa, tem-se a configuração 3 do projeto e é criado um relatório de homologação informando as modificações que foram necessárias.

A configuração 3 do projeto é a entrada para a etapa de validação (Processo 8) para planejar a validação e certificação do produto de acordo com as normas técnicas. Os protótipos piloto são fabricados, montados e integrados para que passem por um processo de experimentação pelos potenciais clientes. Testes de certificação são realizados. No final desta etapa, tem-se a configuração 4 do projeto e relatórios.

A configuração 4 do projeto e o relatório de homologação são entradas para a etapa de lançamento (Processo 9). Nesta etapa, é desenvolvido um plano de marketing do produto, plano de produção, é projetada a logística de distribuição, o sistema de gestão da empresa é alimentado, o produto é monitorado até o volume de produção atinja as metas estabelecidas no planejamento do projeto. Ao final desta etapa, tem-se o relatório de fechamento do projeto.

\section{Processo 5: Iniciar Práticas de Co-desenvolvimento}

A Figura 41 apresenta o processo iniciar práticas de co-desenvolvimento. Os subprocessos apresentados a seguir são baseados na literatura, com exceção do número 5.6 que foi mencionado pelas empresas. 


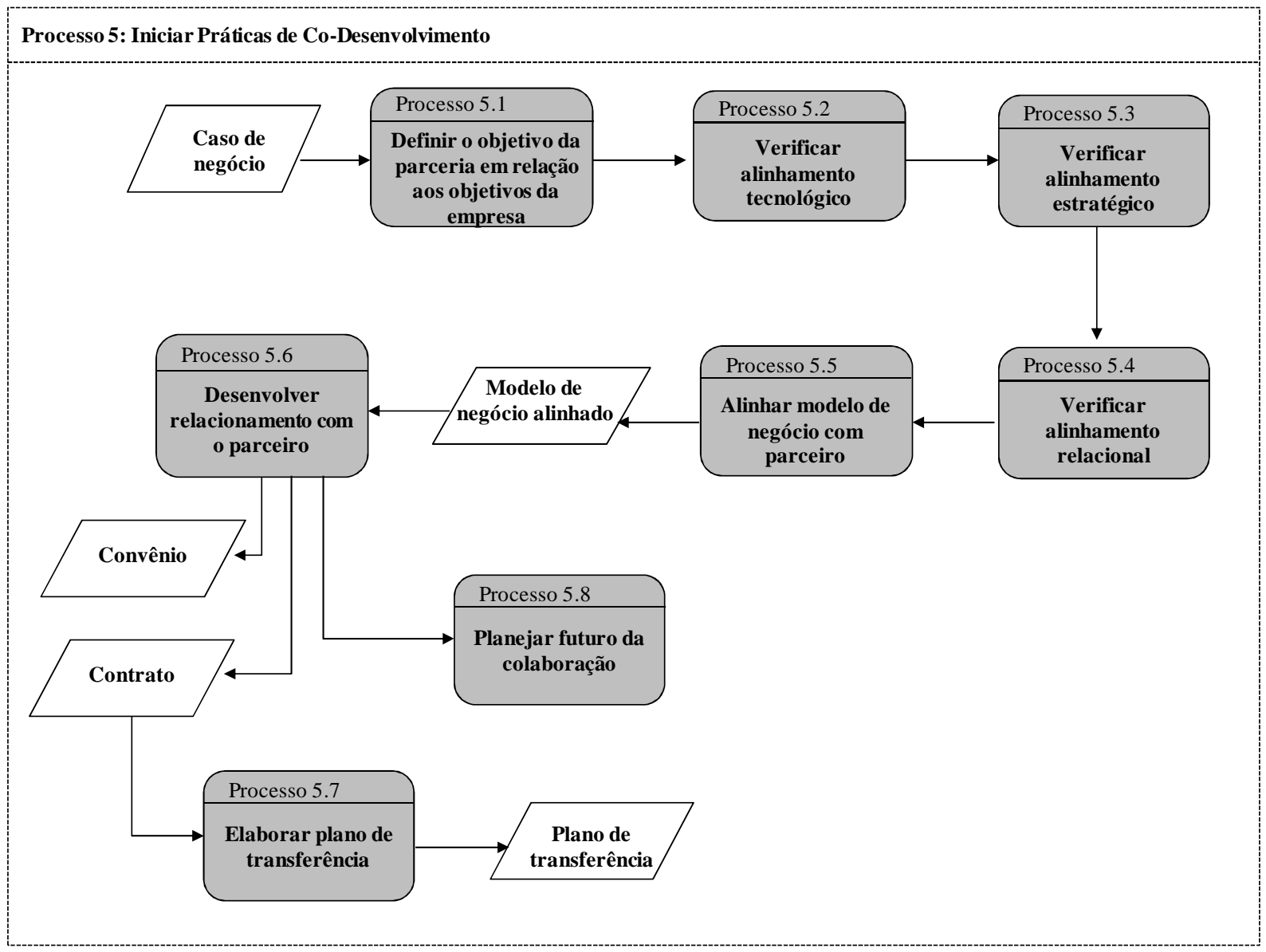

Figura 41 - Sub-processo 5 (to-be)

A partir do caso de negócio define-se o objetivo da parceria em relação aos objetivos da empresa (Processo 5.1). Em seguida, verifica-se o alinhamento tecnológico (Processo 5.2), o alinhamento estratégico (Processo 5.3) e o alinhamento relacional (Processo 5.4). Logo após, deve-se alinhar o modelo de negócio com o parceiro (Processo 5.5). Diante do modelo de negócio alinhado, desenvolve-se o relacionamento com o parceiro (Processo 5.6) que resulta em um convênio, contrato. A partir do contrato, elabora-se o plano de transferência (Processo 5.7) que resulta no plano de transferência no qual é definido o tempo da transferência, treinamento, orçamento. Por fim, deve-se planejar o futuro da colaboração (Processo 5.8).

\section{Processo 6: Realizar Validação da Tecnologia do Parceiro}

A Figura 42 apresenta o processo realizar validação da tecnologia do parceiro. 


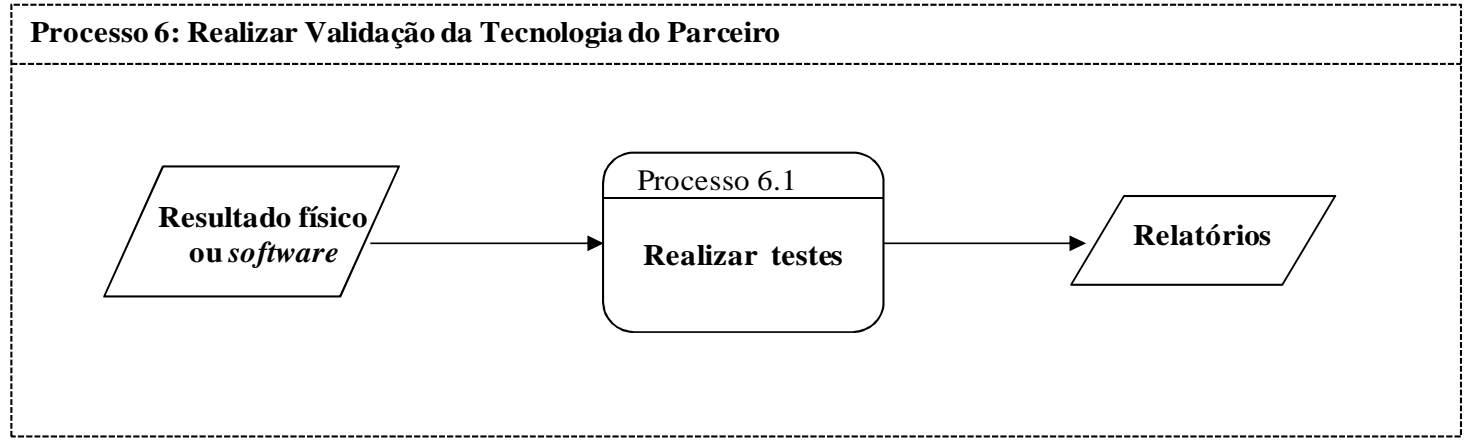

Figura 42 - Sub-processo 6 (to-be)

De posse do artefato físico ou software desenvolvido pelo parceiro, a empresa realiza testes (Processo 6.1) para verificar características e desempenho do produto. Por fim, é elaborado relatórios.

\section{Processo 7: Integrar Tecnologia do Parceiro}

A Figura 43 apresenta o processo integrar tecnologia do parceiro. Nesse processo é proposto o sub-processo 7.3 (avaliar a implementação da tecnologia).

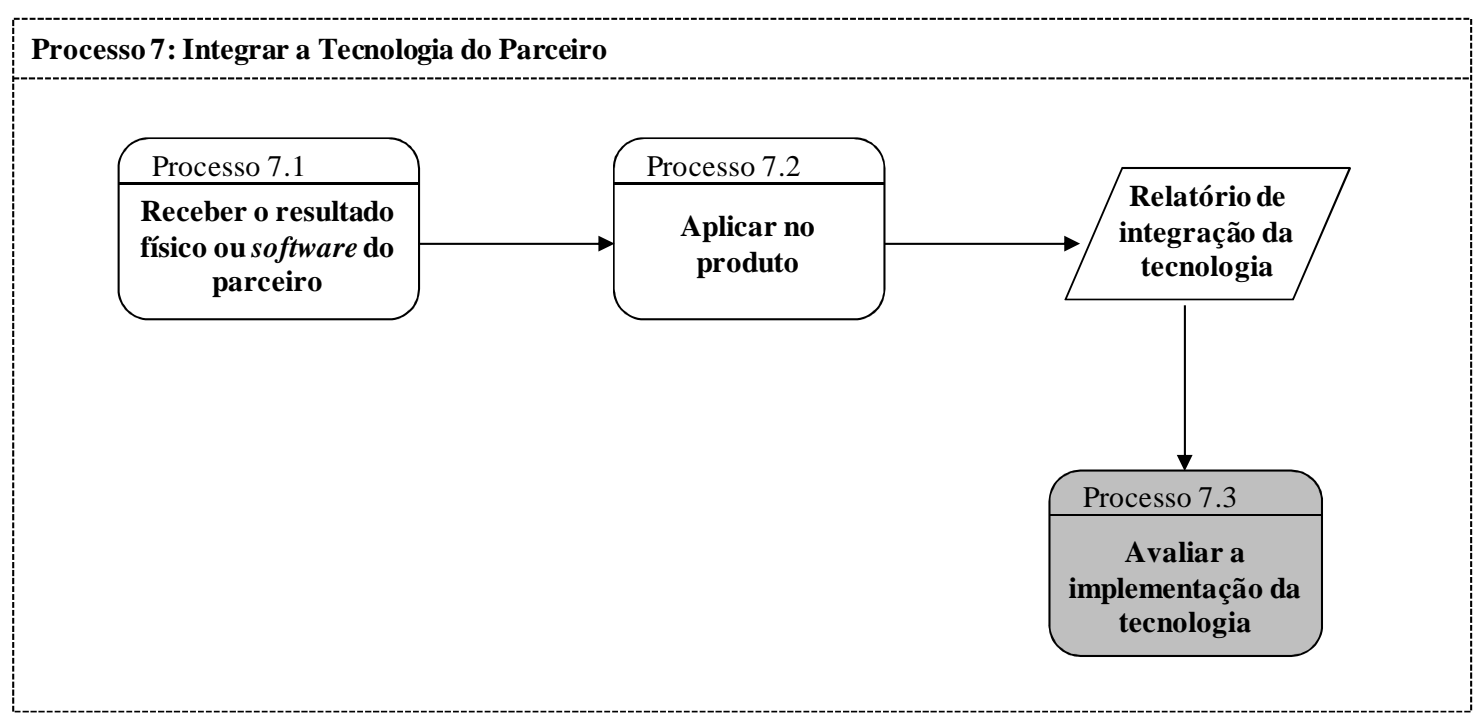

Legenda

Informações do modelo "as-is"

Informações propostas pelo trabalho

Figura 43 - Sub-processo 7 (to-be)

A empresa recebe o artefato físico ou software do parceiro (Processo 7.1) com as melhorias implementadas se necessário. Então esse artefato é aplicado (incorporado) no produto da empresa (Processo 7.2), gerando um relatório da integração da tecnologia, ou seja, 
um relatório técnico do produto que é utilizado para avaliar a implementação da tecnologia (Processo 7.3).

\section{Processo 8: Realizar validação do produto}

A Figura 44 apresenta o processo realizar validação do produto.

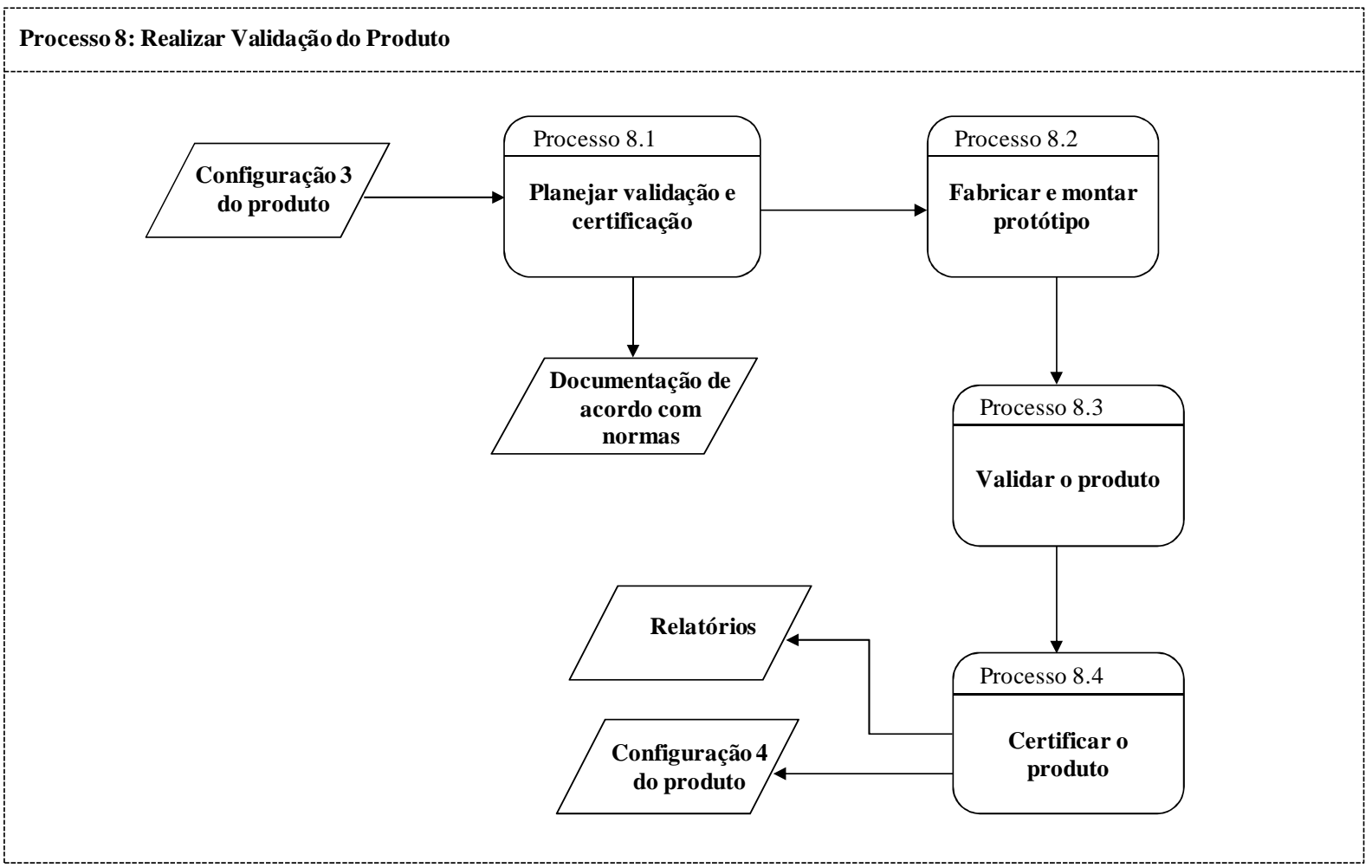

Figura 44 - Sub-processo 8 (to-be)

A configuração 3 do projeto é entrada para a etapa de validação (Processo 8) onde é planejado a validação e certificação do produto (Processo 8.1). Como resultado dessa etapa tem-se os documentos do produto de acordo com as normas técnicas. Posteriormente, o protótipo piloto é fabricado, montado e integrado (Processo 8.2) para que passe por um processo de experimentação pelos potenciais clientes (Processo 8.3). Validado o produto, o mesmo é submetido a testes de certificação (Processo 8.4). No final desta etapa obtém-se a configuração 4 do projeto e relatórios.

\section{Processo 9: Lançar Produto}

A Figura 45 apresenta o processo lançar produto. Nesse processo são propostos os sub-processos 9.2 (planejar materiais), 9.3 (planejar capacidade), 9.5 (planejar e programar 
engenharia), 9.6 (planejar e programar ferramenta e desenho de processo), 9.7 (projetar logística de distribuição), e 9.8 (elaborar plano de treinamento).

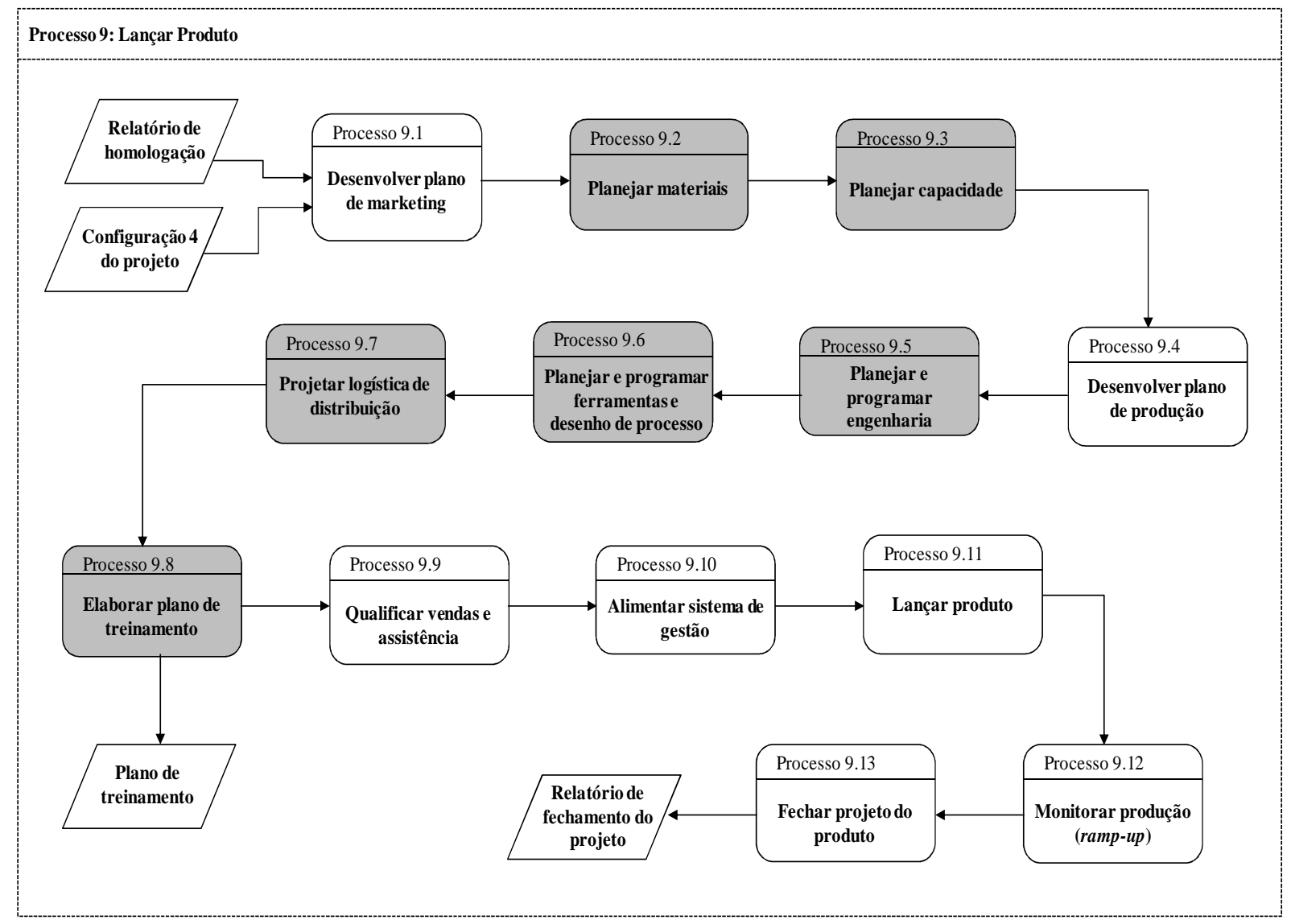

Legenda

Informações do modelo "as-is"

Informações propostas pelo trabalho

Figura 45 - Sub-processo 9 (to-be)

A configuração 4 do projeto e o relatório de homologação são as entradas para a etapa de lançamento (Processo 9). Nesta etapa, desenvolve-se um plano de marketing do produto (Processo 9.1), plano de materiais (Processo 9.2), plano da capacidade (Processo 9.3), plano de produção (Processo 9.4), plano e programa de engenharia (Processo 9.5), plano e programa das ferramentas e desenho de processo (Processo 9.6), é projetada a logística de distribuição (Processo 9.7), é elaborado o plano de treinamento (Processo 9.8) que resulta no plano de treinamento, o pessoal de vendas e a assistência recebem qualificação (Processo 9.9) o sistema de gestão da empresa é alimentado (Processo 9.10), o produto então é lançado (Processo 9.11). Posteriormente monitora-se o volume de produção (Processo 9.12) até que atinja as metas estabelecidas no planejamento do projeto. O projeto do produto é finalizado (Processo 9.13). Ao final desta etapa obtém-se o relatório de fechamento do projeto. 


\subsubsection{Modelo de Processo de Negócio a Partir da Necessidade do Cliente}

A Figura 46 apresenta o modelo de processo de negócio que norteia a transferência tecnologia-produto. A principal sugestão nesse processo é a inclusão do sub-processo 4 (iniciar práticas de co-desenvolvimento).

O processo de transferência de tecnologia é composto por 2 diferentes fluxos de processos. O primeiro fluxo refere-se ao processo de desenvolvimento da tecnologia e o segundo pelo processo de desenvolvimento de produto.

O primeiro fluxo inicia com o processo realizar abertura do projeto (Processo 1), no qual o cliente e o departamento comercial estão envolvidos e que resulta nos documentos de termo de abertura do projeto e no contrato. Esses dois documentos são entradas para o processo coletar requisitos (Processo 2) no qual o cliente, o departamento de P\&D ou engenharia ou projetos participam. Após a coleta de requisitos (Processo 2), inicia-se o desenvolvimento da tecnologia ou solução (Processo 3) pelo departamento de $\mathrm{P} \& \mathrm{D}$, compras e cliente participam e que resulta no protótipo e na lista de parceiros. A partir dessa lista inicia-se a prática de co-desenvolvimento (Processo 4), que resulta em um contrato e no plano de transferência. Ambos os documentos mais o protótipo, código ou desenho são importantes para o parceiro iniciar o desenvolvimento (Processo Externo 1). Como resultado final das atividades realizadas pelo parceiro tem-se o resultado físico ou software. Esse protótipo é validado internamente (Processo 5) pelo departamento de $\mathrm{P} \& \mathrm{D}$ e que resulta no relatório de desenvolvimento. Posteriormente, inicia-se o processo de adaptar a tecnologia para o cliente (Processo 6) no qual o cliente, departamento comercial e de P\&D estão envolvidos e que origina a documentação do desenvolvimento da tecnologia e a tecnologia adaptada. Diante da tecnologia adaptada, é realizada a validação com o cliente (Processo 7) que resulta na documentação para treinamento e no contrato de produção. Logo após, realiza-se a aplicação da tecnologia no produto do cliente (Processo 8), em que o cliente e o departamento de P\&D participam. Por fim, realiza-se a pós-venda (Processo 9) pela assistência técnica ou equipe de apoio que emite um relatório de manutenção ou serviço. 


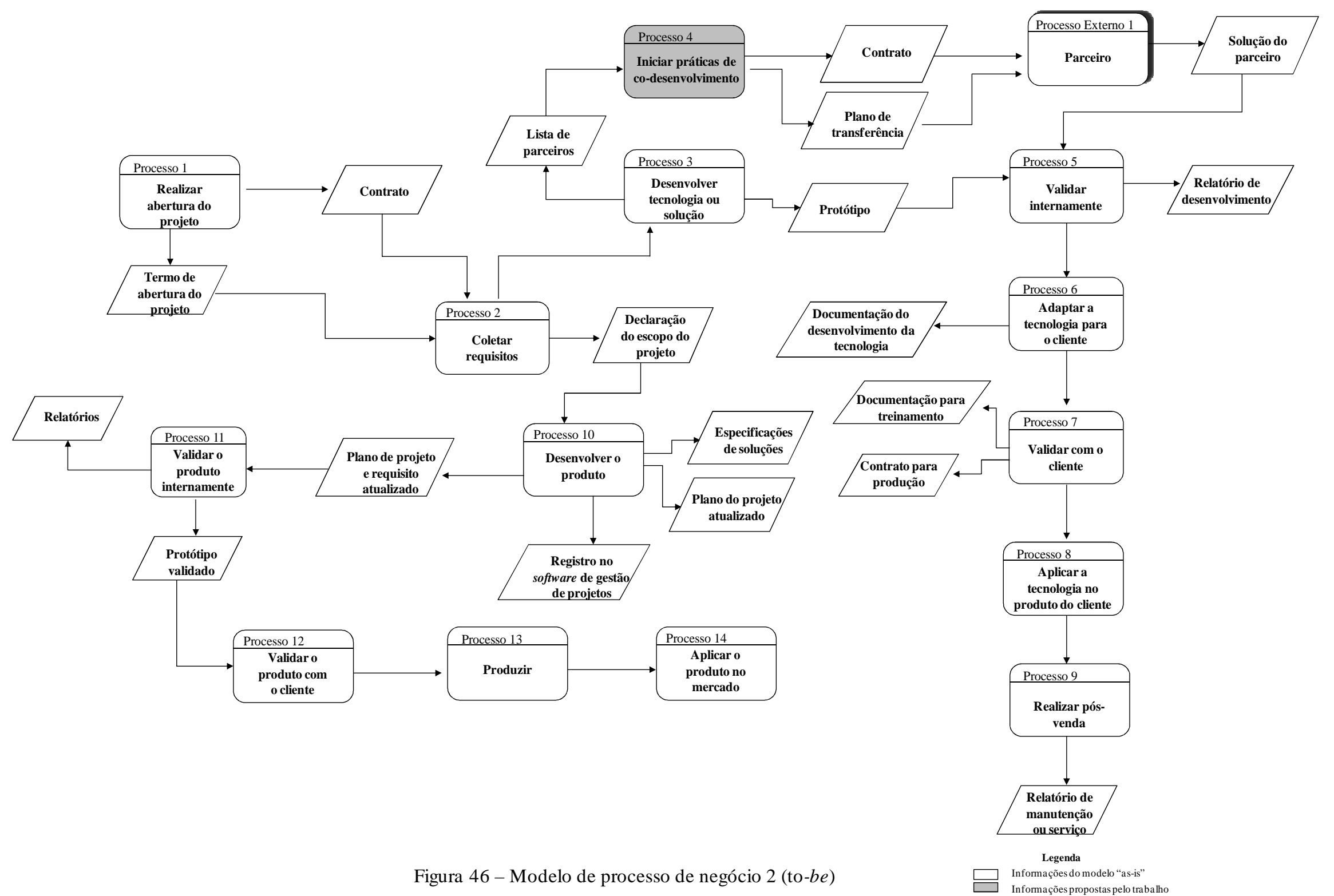


O segundo fluxo inicia-se com o processo realizar abertura do projeto (Processo 1) no qual o cliente e o departamento comercial estão envolvidos e que resulta nos documentos de termo de abertura do projeto e no contrato. Esses dois documentos são entradas para o processo coletar requisitos (Processo 2) no qual o cliente, o departamento de P\&D ou engenharia ou projetos participam e que resulta na declaração do escopo do projeto. Essa declaração é entrada para o desenvolvimento do produto (Processo 10) realizado pelo departamento de $\mathrm{P} \& \mathrm{D}$ e que resulta nas especificações de soluções, registro no software de gestão de projetos e plano do projeto e requisito atualizado. O plano de projeto é entrada para validar o produto internamente (Processo 11) que é desempenhado pelo departamento de $P \& D$ e que resulta em relatórios e protótipo validado. Posteriormente, o cliente valida o produto (Processo 12) e é iniciada a produção (Processo 13). Por fim, é aplicado o produto no mercado (Processo 14) no qual o cliente e o departamento comercial participam.

\section{Processo 1: Realizar Abertura do Projeto}

A Figura 47 apresenta o processo realizar abertura do projeto.

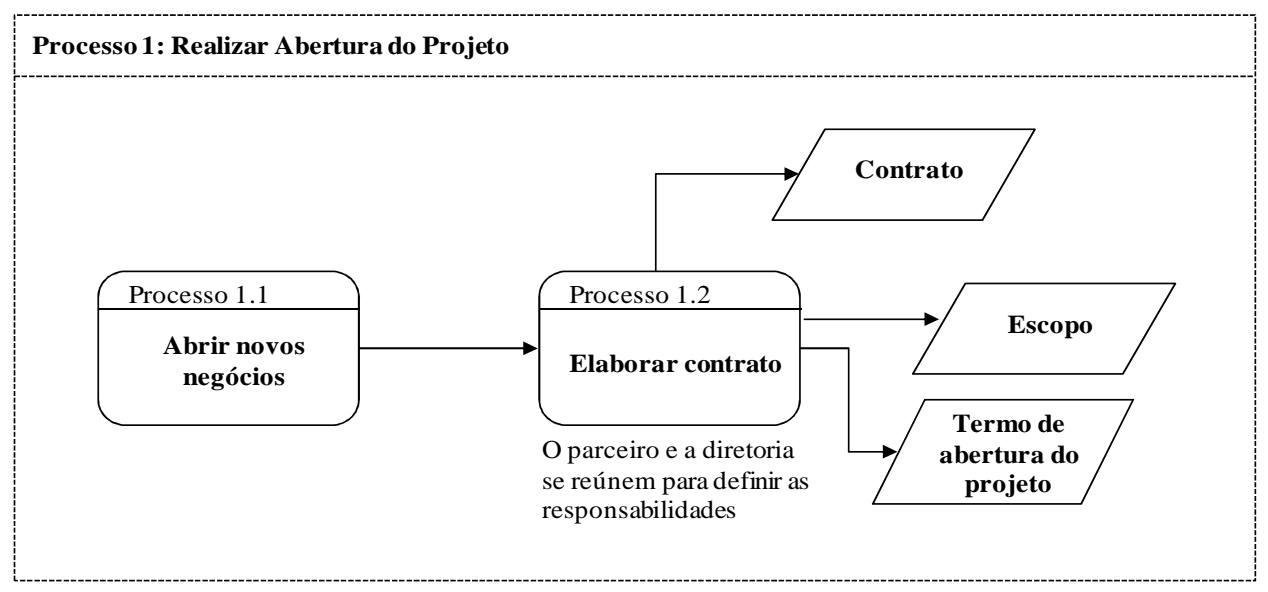

Figura 47 - Sub-processo 1 (to-be)

A abertura do projeto (Processo 1) consiste de dois sub-processos: abrir novos negócios (Processo 1.1) e elaborar contrato (Processo 1.2). Abrir novos negócios (Processo 1.1) está relacionado ao desenvolvimento de um novo produto ou a expansão de alguma área que a empresa trabalha. O processo elaborar contrato (Processo 1.2) acontece por meio de reuniões entre o parceiro e a diretoria para definir as responsabilidades das partes. Como resultado obtém-se contrato, o escopo e o termo de abertura do projeto. 


\section{Processo 2: Coletar requisitos}

A Figura 48 apresenta o processo coletar requisitos.

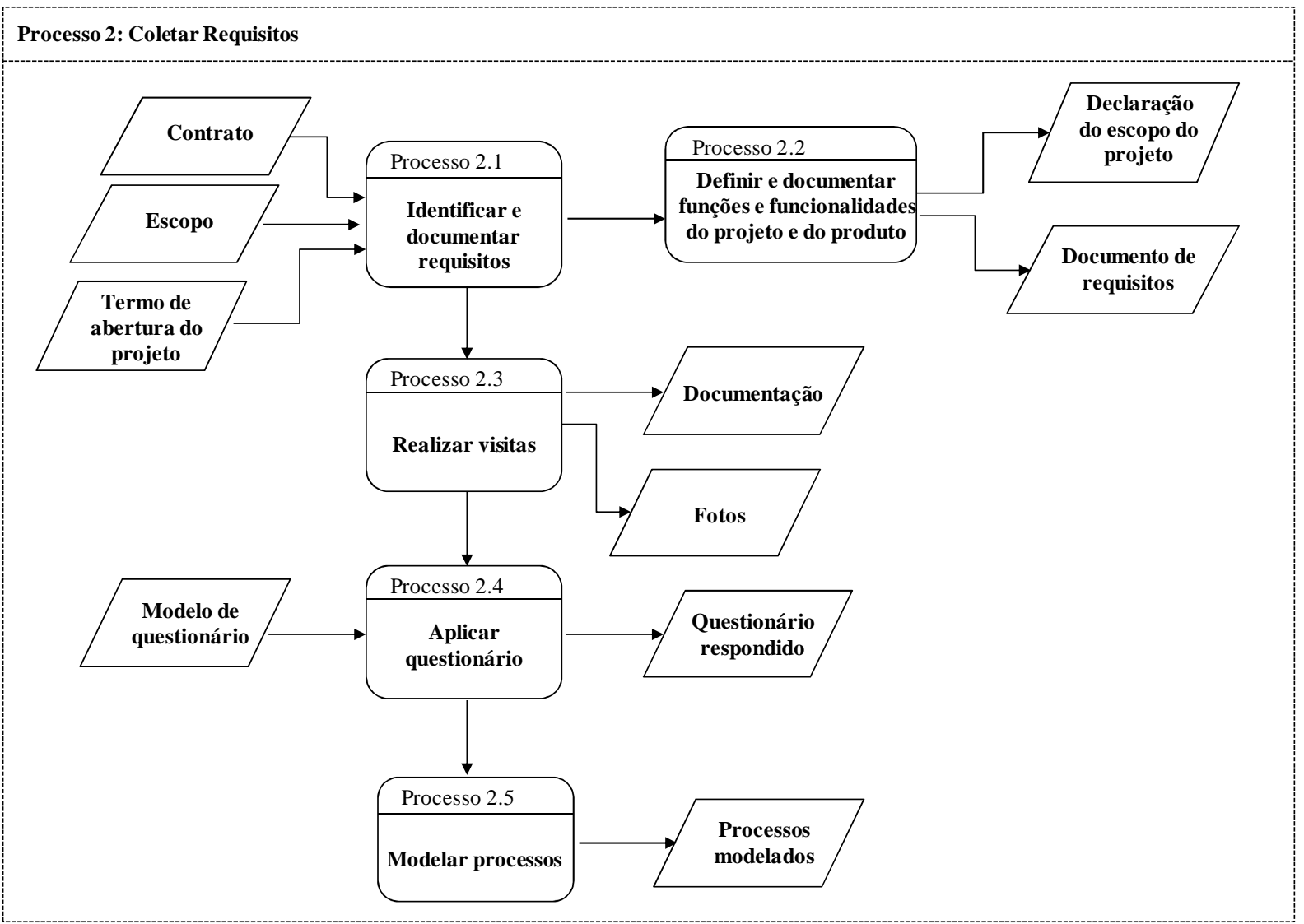

Figura 48 - Sub-processo 2 (to-be)

O contrato, o escopo e o termo de abertura do projeto são documentos que formalizam o início do projeto. A partir desses documentos, inicia-se a identificação e documentação dos requisitos (Processo 2.1) e, posteriormente, definem-se e documentam-se as funções e funcionalidades do projeto e do produto (Processo 2.2) que resultam na declaração do escopo do projeto e no documento de requisitos. São realizadas visitas ao cliente (Processo 2.3) que originam documentos e fotos. Posteriormente, aplica-se o questionário (Processo 2.4), a partir de um modelo de questionário, o que resulta no questionário respondido. Por fim, modela-se processo (Processo 2.5) que gera um documento sobre os processos modelados.

\section{Processo 3: Desenvolver tecnologia}

A Figura 49 apresenta o processo desenvolver tecnologia. Para esse processo é sugerido o sub-processo 3.8 (construir caso de negócio). 


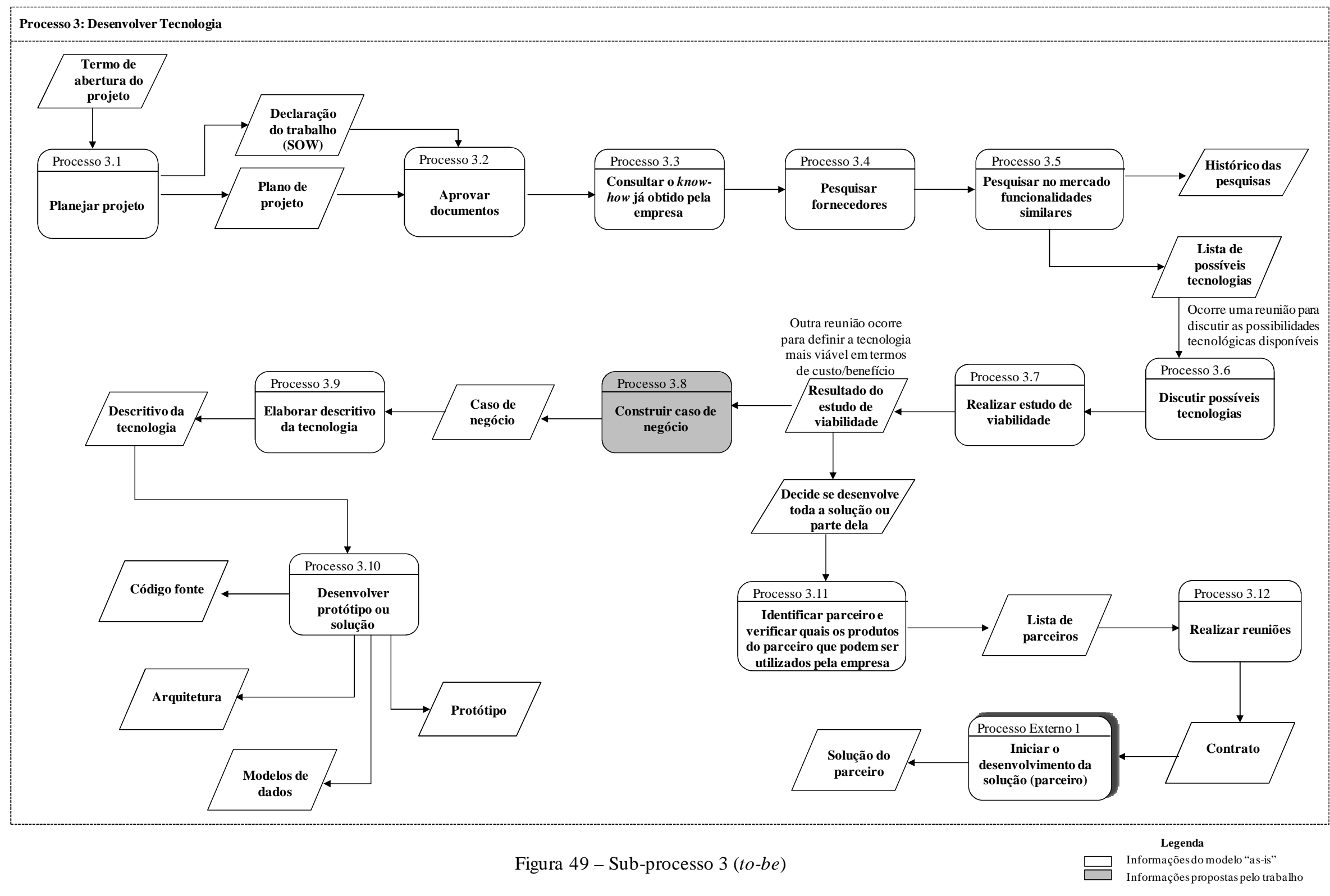


Depois de coletar os requisitos (Processo 2) inicia-se a etapa planejar projeto (Processo 3.1). Essa etapa, por exemplo, consiste de identificar os envolvidos, a equipe, estimar a duração do projeto. Nessa etapa tem-se os documentos de declaração de trabalho e o plano de projeto. O cliente deve aprovar os documentos (Processo 3.2).

Posteriormente, realiza-se uma consulta do know-how já obtido pela empresa (Processo 3.3) para verificar a existência de conhecimento que possa ser utilizado ou melhorado. Também são realizadas pesquisas de fornecedores de peças ou tecnologias (Processo 3.4) para o desenvolvimento do projeto, de mercado para verificar produtos que possam ter funcionalidades similares (Processo 3.5). Depois de buscar as informações necessárias, a empresa armazena um histórico de suas pesquisas e gera uma lista de possíveis tecnologias a ser desenvolvidas.

Há uma reunião para discutir as possibilidades tecnológicas disponíveis (Processo 3.6) e realizar o estudo de viabilidade (Processo 3.7). Diante do resultado deste estudo ocorre outra reunião para definir a tecnologia mais viável em termos de custo/benefício e também decide-se se a empresa desenvolverá toda a solução ou parte dela. Caso decida-se desenvolver parte da solução, a empresa identifica possíveis parceiros e verifica quais os produtos do parceiro que podem ser utilizados pela empresa (Processo 3.11). Uma lista de parceiros é criada. Definido o parceiro, a empresa realiza reuniões (Processo 3.12) que resultam no contrato que é o documento de entrada para o parceiro iniciar o desenvolvimento da solução (Processo Externo 1).

Após o resultado do estudo de viabilidade, desenvolve-se o caso de negócio (Processo 3.8). A partir do caso de negócio, elabora-se o descritivo da tecnologia (Processo 3.9) que resulta em documento no qual contem informações sobre as especificações da tecnologia. Esse documento é a entrada para o desenvolvimento do protótipo ou solução (Processo 3.10) que resulta em documentos de código fonte, arquitetura, modelo de dados, protótipo, e documento de requisitos.

\section{Processo 4: Iniciar Práticas de Co-desenvolvimento}

A Figura 50 apresenta o processo iniciar prática de co-desenvolvimento. Os subprocessos apresentados a seguir são baseados na literatura, com exceção do número 5.6 que foi mencionado pelas empresas. 


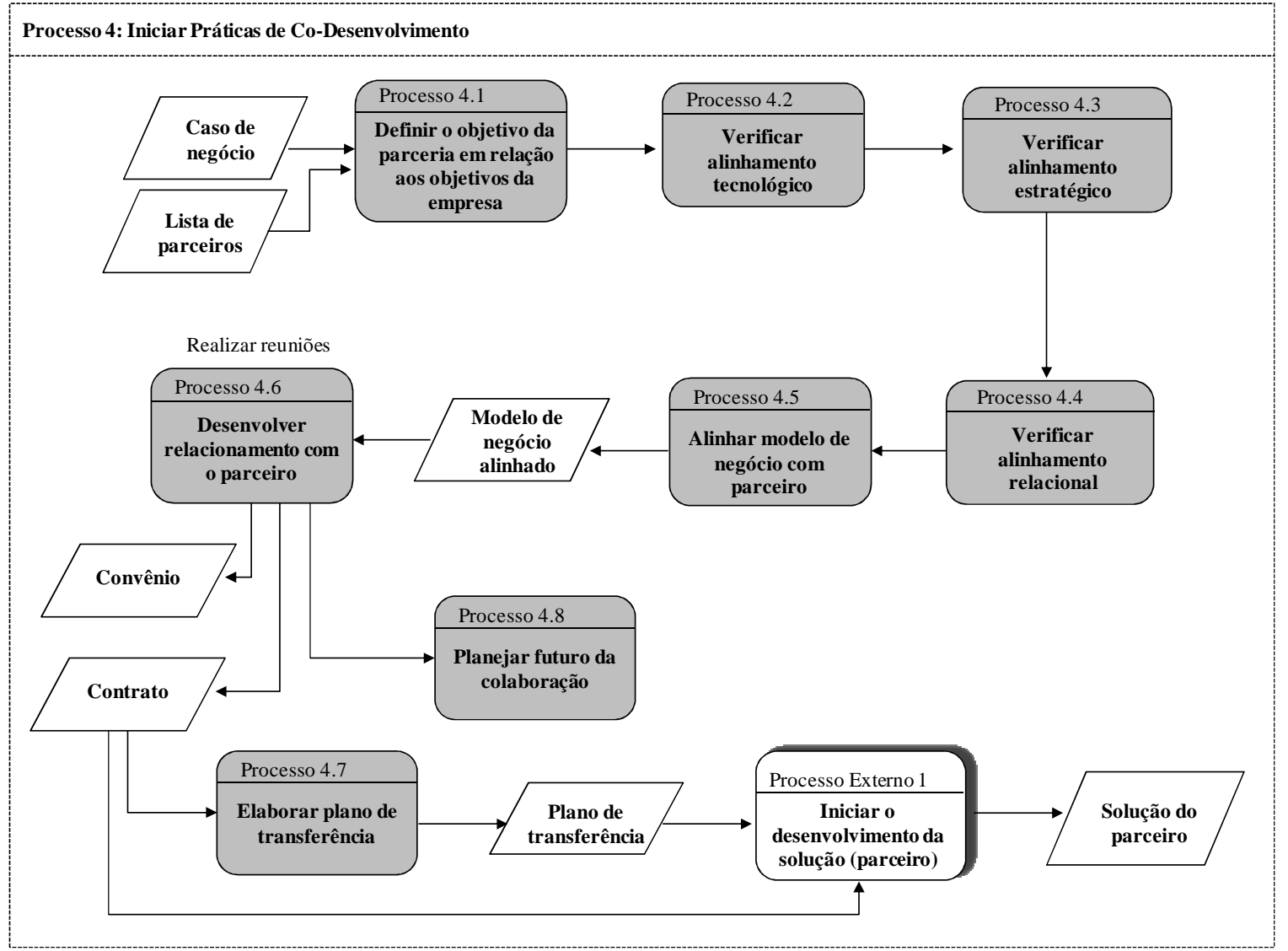

Figura 50 - Sub-processo 4 (to-be)

A partir do caso de negócio e da lista de parceiros define-se o objetivo da parceria em relação aos objetivos da empresa (Processo 4.1). Em seguida, verifica-se o alinhamento tecnológico (Processo 4.2), o alinhamento estratégico (Processo 4.3) e o alinhamento relacional (Processo 4.4). Logo após, deve-se alinhar o modelo de negócio com o parceiro (Processo 4.5). Diante do modelo de negócio alinhado desenvolve-se o relacionamento com o parceiro (Processo 4.6) que resulta em um convênio, firmado por contrato. A partir do contrato, elabora-se o plano de transferência (Processo 4.7) no qual é definido o tempo da transferência, treinamento, orçamento. Diante do plano de transferência, o parceiro inicia o desenvolvimento da solução (Processo Externo 1). Por fim, deve-se planejar o futuro da colaboração (Processo 4.8).

\section{Processo 5: Validar internamente}

A Figura 51 apresenta o processo validar internamente. Para esse processo sugeriram-se os sub-processos 5.1 (planejar validação e certificação) e 5.5 (avaliar a implementação da tecnologia). 


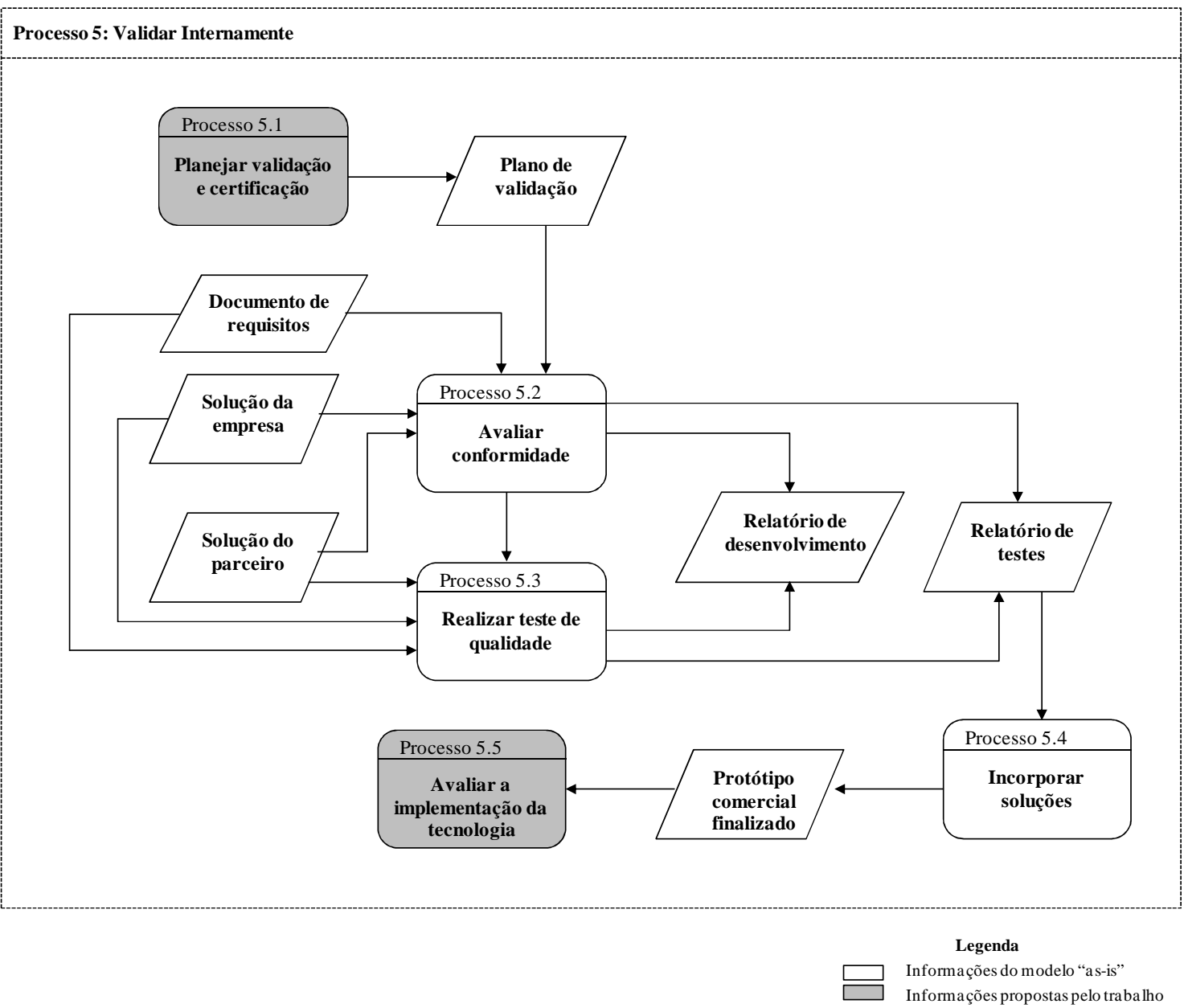

Figura 51 - Sub-processo 5 (to-be)

Inicialmente, deve-se planejar a validação e certificação do produto (Processo 5.1). Após o plano de validação e certificação, juntamente com a solução da empresa e do parceiro e do documento de requisitos, inicia-se a avaliação da conformidade (Processo 5.2). Em seguida, realizam-se os testes de qualidade (Processo 5.3) que resultam em relatórios de desenvolvimento e de testes. Posteriormente, inicia-se a etapa incorporar soluções (Processo 5.4) que por sua vez apresenta o protótipo comercial finalizado. A partir do protótipo é avaliada a implementação da tecnologia (Processo 5.5).

\section{Processo 6: Adaptar tecnologia ao cliente}

A Figura 52 apresenta o processo adaptar tecnologia ao cliente. 


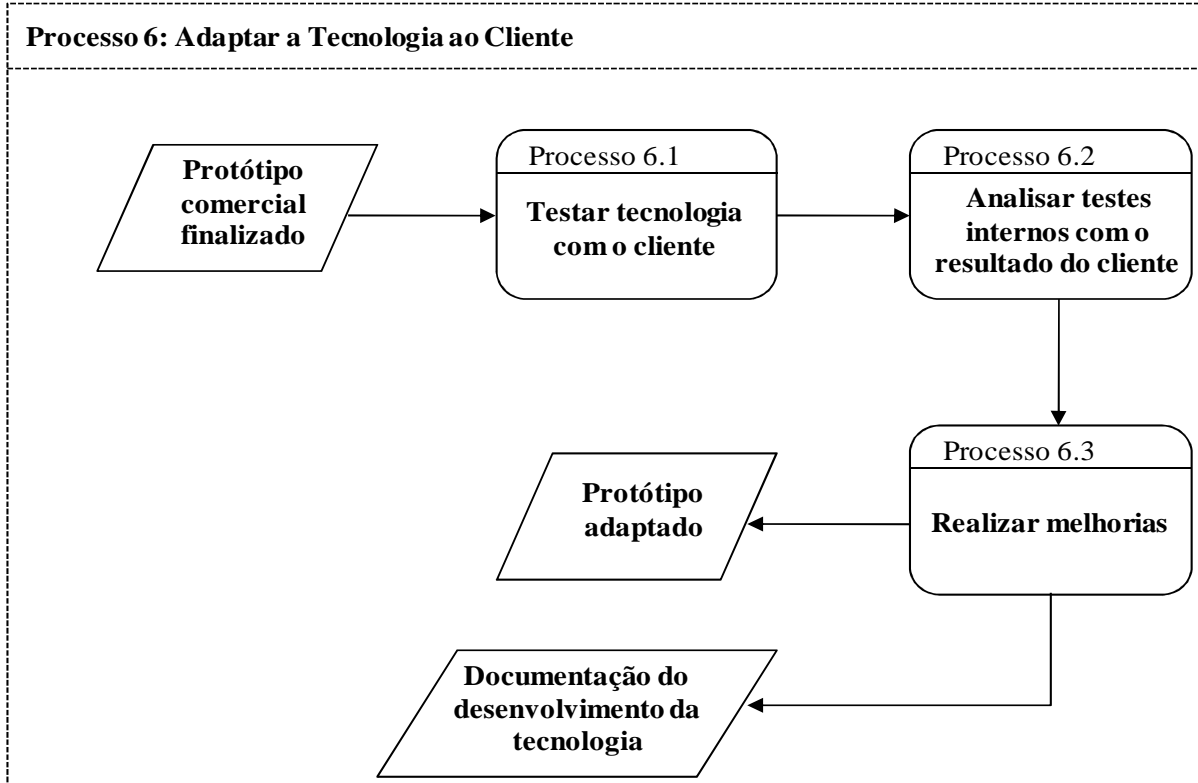

Figura 52 - Sub-processo 6 (to-be)

Diante do protótipo comercial finalizado realizam-se os testes no cliente (Processo 6.1) considerando seu ambiente. Posteriormente, os resultados obtidos são analisados em testes realizados pela empresa e pelo cliente (Processo 6.2) para que se possa identificar problemas e realizar melhorias (Processo 6.3). Por fim, elabora-se a documentação sobre o desenvolvimento da tecnologia.

\section{Processo 7: Validar com cliente}

A Figura 53 apresenta o processo validar tecnologia com cliente.

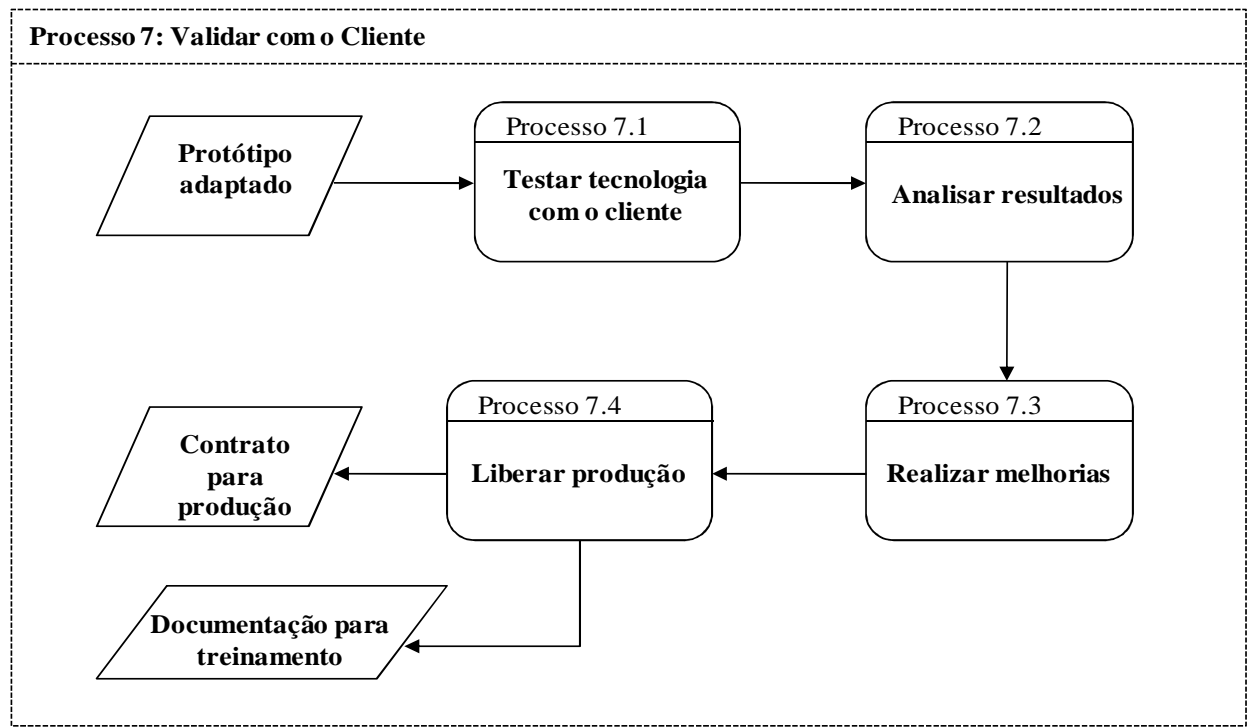

Figura 53 - Sub-processo 7 (to-be) 
O protótipo adaptado é validado com o cliente (Processo 7) por meio de novos testes (Processo 7.1) para análise dos resultados (Processo 7.2). Caso seja necessário, realizam-se novas melhorias (Processo 7.3). Quando estiver de acordo com a necessidade do cliente, libera-se a produção em escala (Processo 7.4) e elabora-se o contrato para produção e a documentação para treinamento.

\section{Processo 8: Aplicar a tecnologia no produto do cliente}

A Figura 54 apresenta o processo aplicar tecnologia no produto do cliente. Nesse processo é proposto o sub-processo 8.1 (elaborar plano de treinamento).

A partir da tecnologia finalizada, elabora-se um plano de treinamento (Processo 8.1) que resulta no plano de treinamento e realiza-se a instalação e o funcionamento inicial (startup) do equipamento ou protótipo (Processo 8.2). Com o equipamento instalado, realizam-se testes (Processo 8.3) para validar a solução que resulta na homologação.

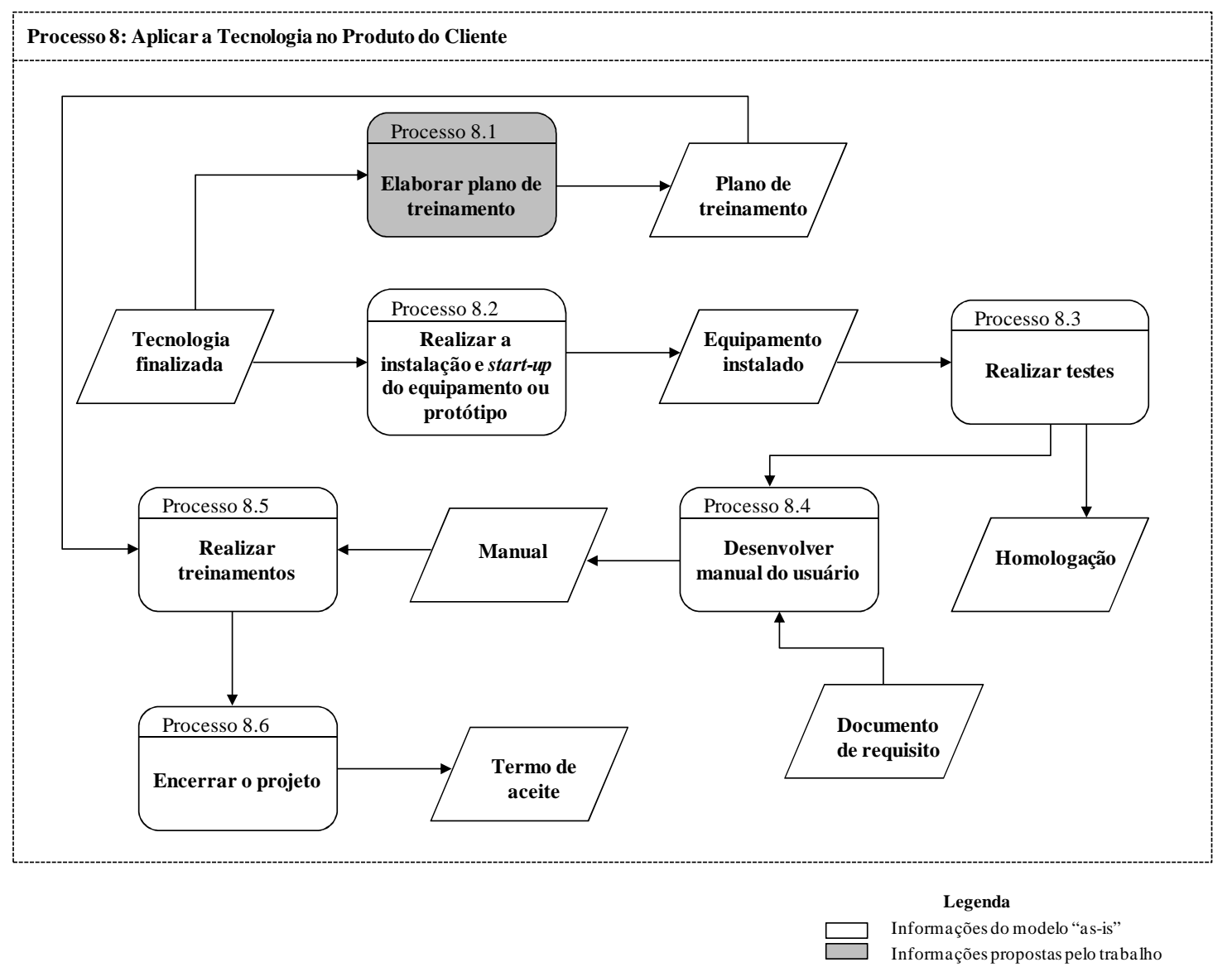

Figura 54 - Sub-processo 8 (to-be) 
Logo após, desenvolve-se o manual do usuário (Processo 8.4) a partir do documento de requisito. Diante do manual e do plano de treinamento, realiza-se o treinamento (Processo 8.5) e encerra-se o projeto (Processo 8.6) que resulta em termo de aceite.

\section{Processo 9: Realizar pós-venda}

A Figura 55 apresenta o processo realizar pós-venda.

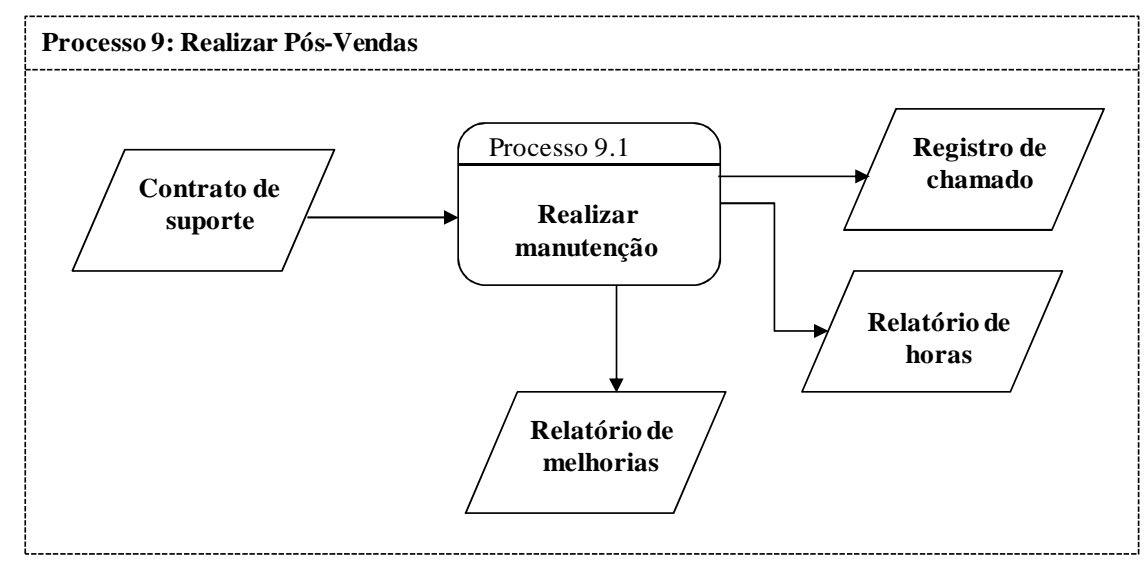

Figura 55 -Sub-processo 9 (to-be)

A partir do contrato de suporte, realiza-se a manutenção do software e/ou equipamento (Processo 9.1) que resulta no registro de chamado, no relatório de horas e de melhorias.

\section{Processo 10: Desenvolver produto}

A Figura 56 apresenta o processo desenvolver produto. O processo inicia-se com o desenvolvimento da visão (Processo 10.1) que tem por objetivo descrever o produto delimitando, por exemplo, suas características e funções. Como resultado desse processo obtém-se desenhos e esboços. Em seguida, cria-se o plano de entregas (Processo 10.2) que define a programação das entregas e iterações, resultando no plano de entregas do projeto. Posteriormente, realiza-se a análise financeira (Processo 10.3) que resulta na análise de viabilidade econômica. Por fim, é realizada análise de risco (Processo 10.4). Todos os documentos gerados nessa etapa constituem o plano de projeto inicial.

A partir do plano de projeto inicial definem-se as especificações do produto (Processo 10.5) que geram as especificações iniciais do produto. A partir das especificações, desenvolvem-se as concepções do produto (Processo 10.6) que resultam em conceitos de design e modelos virtuais. 


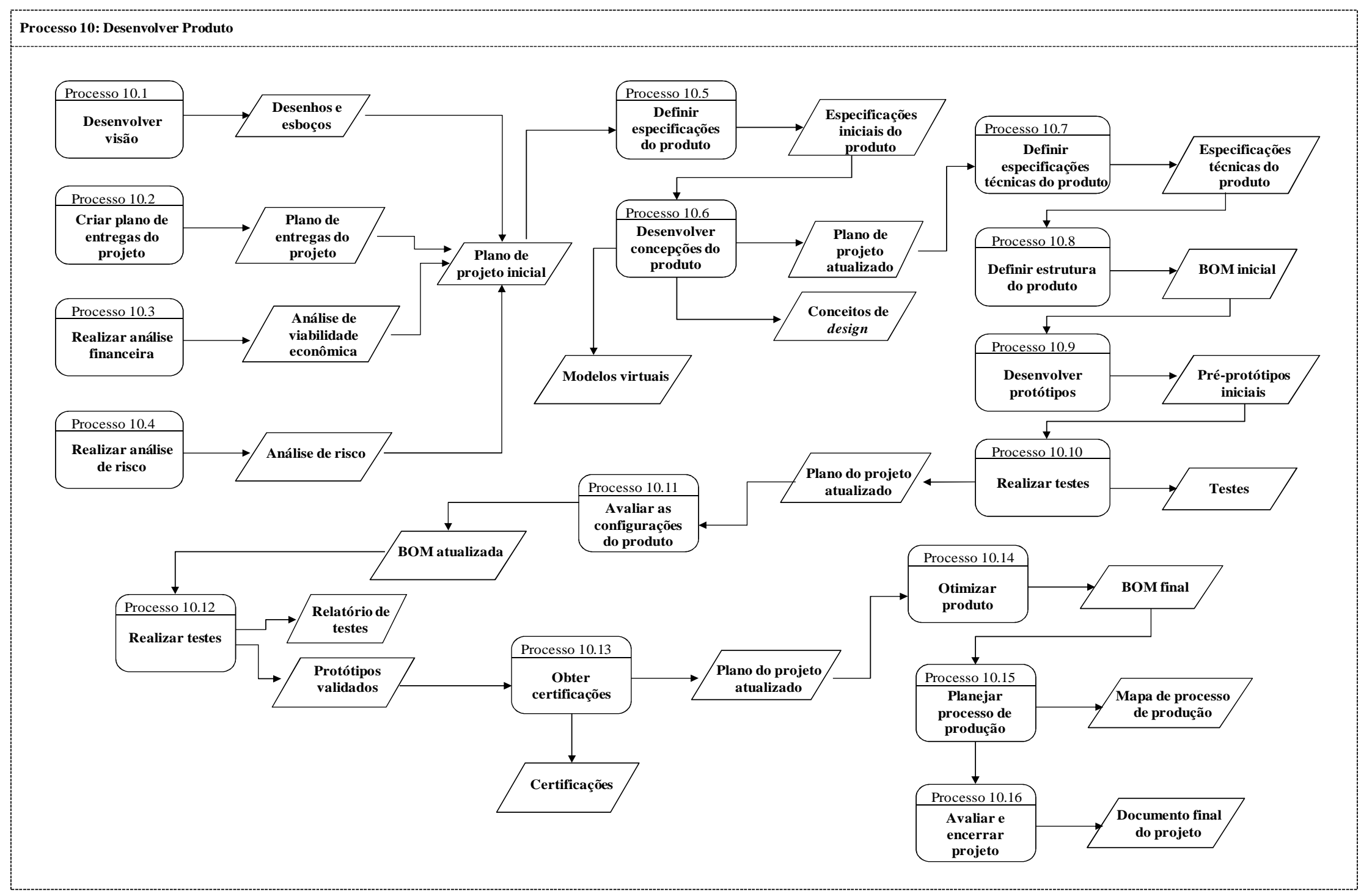

Figura 56 - Sub-processo 10 (to-be) 
A partir do plano do projeto atualizado, definem-se as especificações técnicas do produto (Processo 10.7). Diante das especificações, é definido a estrutura do produto (Processo 10.8) que resulta na BOM inicial. A BOM é utilizada para desenvolver o protótipo (Processo 10.9) que são testados (Processo 10.10) cujos resultados são apresentados no relatório de testes.

A partir do plano do projeto atualizado é iniciada a avaliação das configurações do produto (Processo 10.11) que resultam na BOM atualizada. A BOM é utilizada como entrada para realizar testes (Processo 10.12) que resulta em relatório de testes e protótipos validados. Diante do protótipo validado é iniciada a certificação (Processo 10.13) que resulta no produto certificado.

Diante do plano do projeto atualizado, o produto é otimizado (Processo 10.14) resultando na BOM final. Posteriormente, planeja-se o processo de produção (Processo 10.15) que define o mapa do processo de produção. Por fim, o projeto é avaliado e encerrado (Processo 10.16) resultando no documento final do projeto.

\section{Processo 11: Validar produto internamente}

A Figura 57 apresenta o processo validar produto internamente. Nesse processo é sugerido o sub-processo 11.1 (planejar validação e certificação).

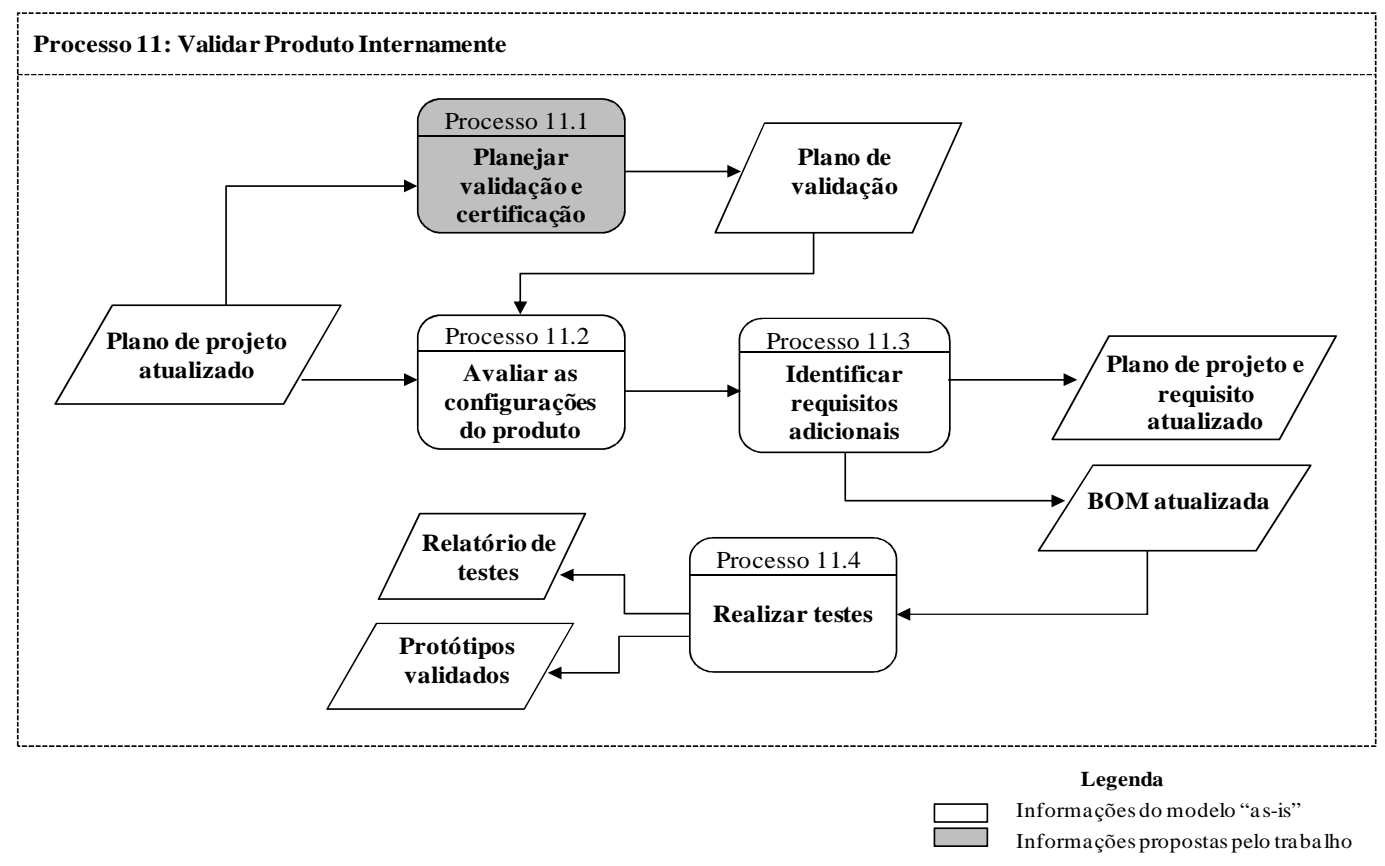

Figura 57 - Sub-processo 11 (to-be) 
A partir do plano do projeto atualizado, inicia-se o planejamento da validação e certificação (Processo 11.1) que resulta no plano de validação e a avaliação das configurações do produto (Processo 11.2). Logo após, identificam-se requisitos adicionais (Processo 11.3) que resultam no plano de projeto e requisito atualizado e na BOM atualizada. Por fim, diante da BOM, realizam-se testes (Processo 11.4) que resultam no relatório de testes e protótipos validados.

\section{Processo 12: Validar o produto com o cliente}

A Figura 58 apresenta o processo validar produto com o cliente.

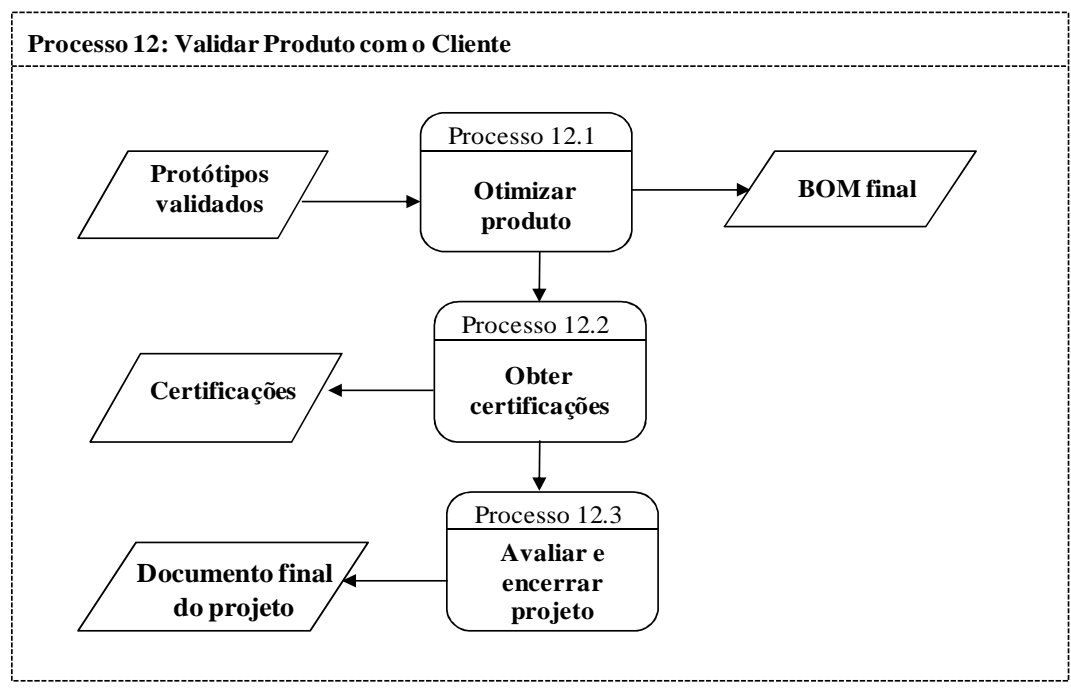

Figura 58 - Sub-processo 12 (to-be)

Com os protótipos validados inicia-se a otimização do produto (Processo 12.1) para melhorar o produto que resulta na BOM final. Posteriormente, obtém-se a certificação (Processo 12.2). Por fim, o projeto é avaliado e encerrado (Processo 12.3) no qual resultado é o documento final do projeto.

\section{Processo 13: Produzir}

A Figura 59 apresenta o processo produzir. Nesse processo é proposto os subprocessos 13.2 (planejar materiais), 13.3 (planejar capacidade e produção), 13.4 (planejar e programar engenharia), e 13.5 (planejar e programar ferramentas e desenhos de processo). 


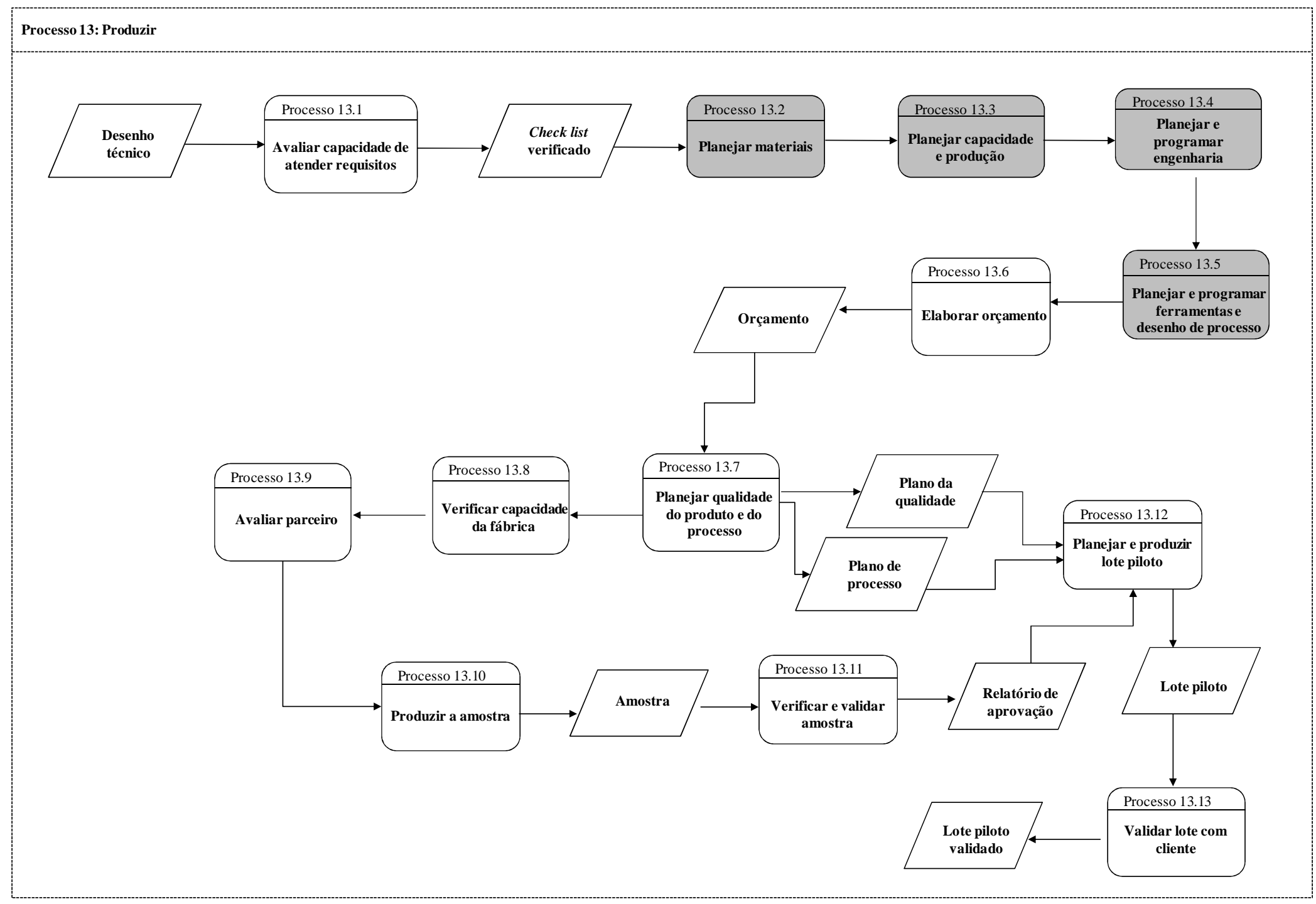

Legenda

Figura 59 - Sub-processo 13 (to-be) 
A partir do desenho técnico, a empresa avalia a capacidade de atender aos requisitos do cliente (Processo 13.1). Esse processo é baseado em um check list que busca verificar se a empresa já possui os fornecedores necessários, se tem maquinário para produzir, como será a embalado, entre outros fatores. Com o check list verificado, inicia-se o planejamento dos materiais (Processo 13.2), da capacidade e produção (Processo 13.3), da engenharia (Processo 13.4), das ferramentas e desenhos de processo (Processo 13.5).

Logo após, elabora-se o orçamento (Processo 13.6). Com a aprovação do orçamento pelo cliente, a empresa realiza o planejamento da qualidade do produto e processo (Processo 13.7) que tem por objetivo planejar a realização do produto. Como resultado do Processo 13.7, tem-se o plano da qualidade e o plano de processo. Posteriormente, é verificada a capacidade da fábrica (Processo 13.8) e avaliados os parceiros (Processo 13.9), principalmente quando há a necessidade da participação de um novo parceiro. Em seguida, é produzida a amostra (Processo 13.10). De posse da amostra, a empresa realiza a verificação e validação da mesma (Processo 13.11) e emite um relatório de aprovação. Diante desse relatório, do plano da qualidade e de processo, inicia-se o planejamento e a produção do lote piloto (Processo 13.12). Após o lote piloto ser produzido, o mesmo é encaminhado ao cliente para validação (Processo 13.13).

\section{Processo 14: Aplicar produto no mercado}

A Figura 60 apresenta o processo aplicar produto no mercado.

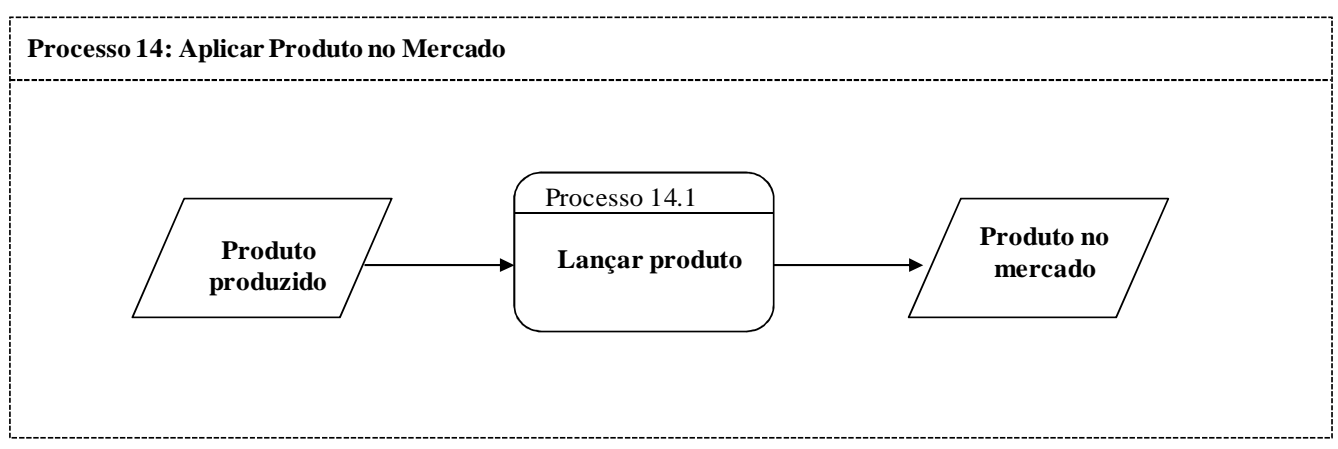

Figura 60 - Sub-processo 14 (to-be)

O produto produzido é lançado no mercado (Processo 14.1). 


\subsubsection{Modelo de Atores e Recursos: Relação entre Empresa e Cliente}

A Figura 61 apresenta o modelo de atores e recursos que norteia a transferência tecnologia-produto. Nesse modelo, identificou-se que outras instituições podem colaborar com as empresas, sendo eles os provedores de recursos que podem ser instituições privadas e o governo.

Os principais envolvidos no processo de transferência são a empresa (Unidade Organizacional 1) e o cliente (Unidade Organizacional Externa 1). O cliente (Unidade Organizacional Externa 1) contata a empresa (Unidade Organizacional 1) e é responsável por enviar o desenho técnico (Recurso 2), informar os requisitos (Recurso 5) e aprovar orçamento (Recurso 3).

A empresa (Unidade Organizacional 1) possui sete departamentos participando do processo: a diretoria (Unidade Individual 1), produção (Unidade Individual 5), departamento de qualidade (Unidade Individual 6), departamento comercial (Unidade Individual 2), departamento de engenharia ou P\&D ou projetos (Unidade Individual 3), departamento financeiro (Unidade Individual 4), e assistência técnica (Unidade Individual 7).

A diretoria (Unidade Individual 1) é composta por diretores (Papel 1.1) que é responsável pelo termo de abertura (Recurso 19), pela declaração do escopo do projeto (Recurso 20), por estabelecer o contrato (Recurso 1) junto com o cliente (Unidade Organizacional Externa 1), por enviar o orçamento (Recurso 3), e por contatar a produção (Unidade Individual 5) e o departamento de qualidade (Unidade Individual 6).

O departamento de qualidade (Unidade Individual 6) é composto pelo analista de qualidade (Papel 6.1) e pelo coordenador de qualidade (Papel 6.2) que são responsáveis pela documentação de produto e processo (Recurso 17).

O departamento comercial (Unidade Individual 2) é composto por vendedores internos (Papel 2.1) e compradores (Papel 2.2). O departamento comercial (Unidade Individual 2) é responsável por identificar fornecedores (Recurso 4), novas tecnologias (Recurso 4), identificar a lista de requisitos (Recurso 5), e informar o departamento de engenharia (Unidade Individual 3). 


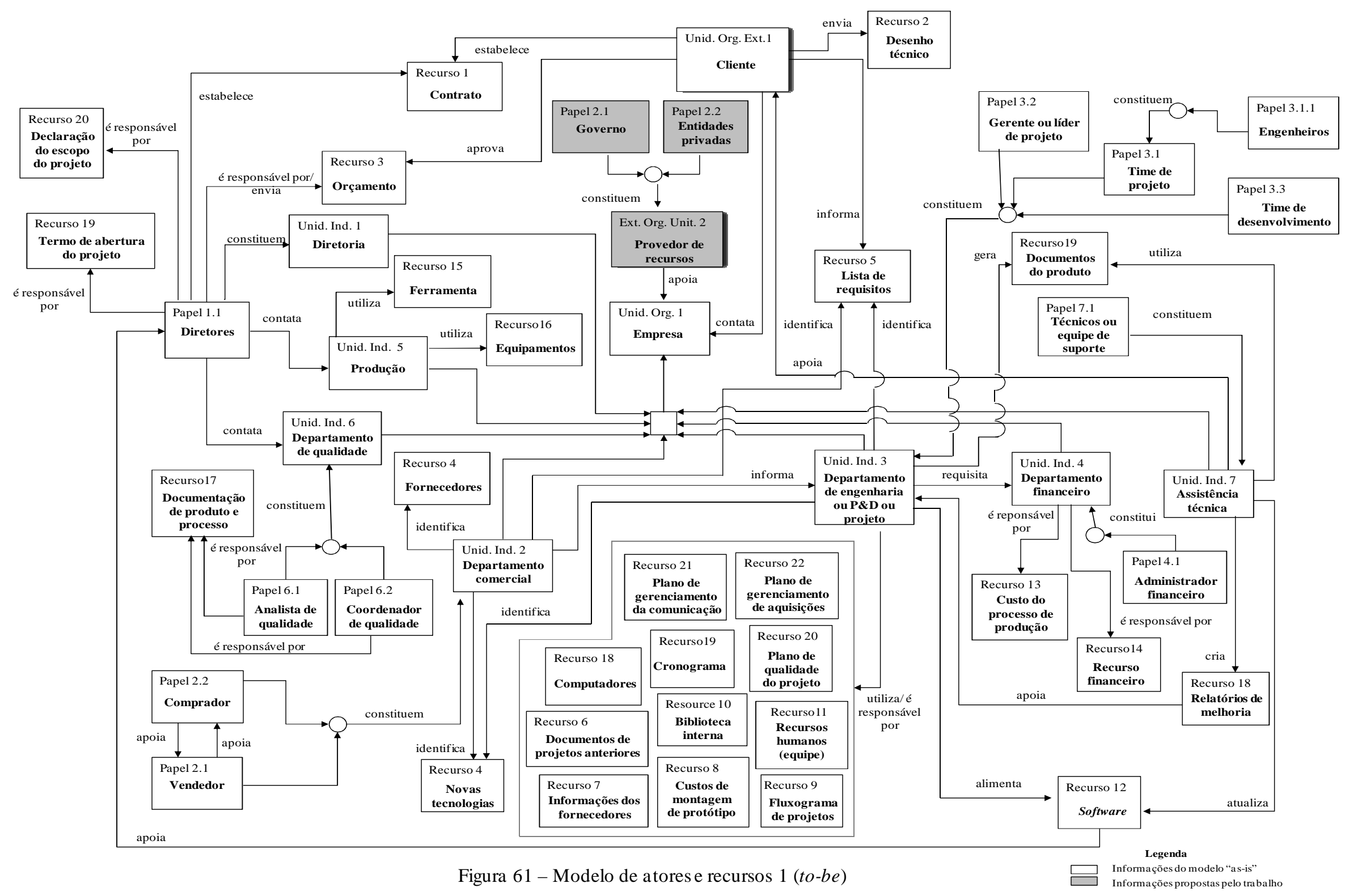


O departamento de engenharia (Unidade Individual 3) é constituído pelo gerente ou líder de projeto (Papel 3.2) e pela equipe de projetos (Papel 3.1) que por sua vez é composta por engenheiros (Papel 3.1.1) e pela equipe de desenvolvimento (Papel 3.1.2). O departamento de engenharia (Unidade Individual 3) é responsável por gerar o documento do produto (Recurso 19), alimentar software (Recurso 12), identificar novas tecnologias (Recurso 4), gerenciar o plano de comunicação (Recurso 21), plano de aquisições (Recurso 22), plano de qualidade do projeto (Recurso 20), cronograma (Recurso 19), recursos humanos (Recurso 11), utilizar computadores (Recurso 18), documentos de projetos anteriores (Recurso 6), biblioteca interna (Recurso 10), informações dos fornecedores (Recurso 7), fluxograma dos projetos (Recurso 9), e custos de montagem de protótipo (Recurso 8). Além disso, o departamento de engenharia (Unidade Individual 3) requisita o departamento financeiro (Unidade Individual 4).

O departamento financeiro (Unidade Individual 4) é auxiliado pelo administrador financeiro (Papel 4.1). O departamento é responsável pelos custos do processo de produção (Recurso 13) e pelo financeiro (Recurso 14).

A assistência técnica (Unidade Individual 7) é formada por técnicos ou equipe de suporte (Papel 7.1). A assistência técnica (Unidade Individual 7) utiliza o documento do produto (Recurso 19), atualiza software (Recurso 12), elabora relatórios de melhoria (Recurso 18) que apoiam o departamento de engenharia (Unidade Individual 3), e apoiam o cliente (Unidade Organizacional Externa 1).

A empresa (Unidade Organizacional 1) pode receber apoio dos provedores de recursos (Unidade Organizacional Externa 2) que são o governo (Papel 2.1) e as entidades privadas (Papel 2.2).

\subsubsection{Modelo de Atores e Recursos: Relação entre Empresa e Universidade}

A Figura 62 apresenta o modelo de atores e recursos que norteia a transferência tecnologia-produto. Nesse modelo, identificou-se que pode existir o cliente e outras instituições podem colaborar com as empresas, sendo eles os provedores de recursos que podem ser instituições privadas e o governo. 


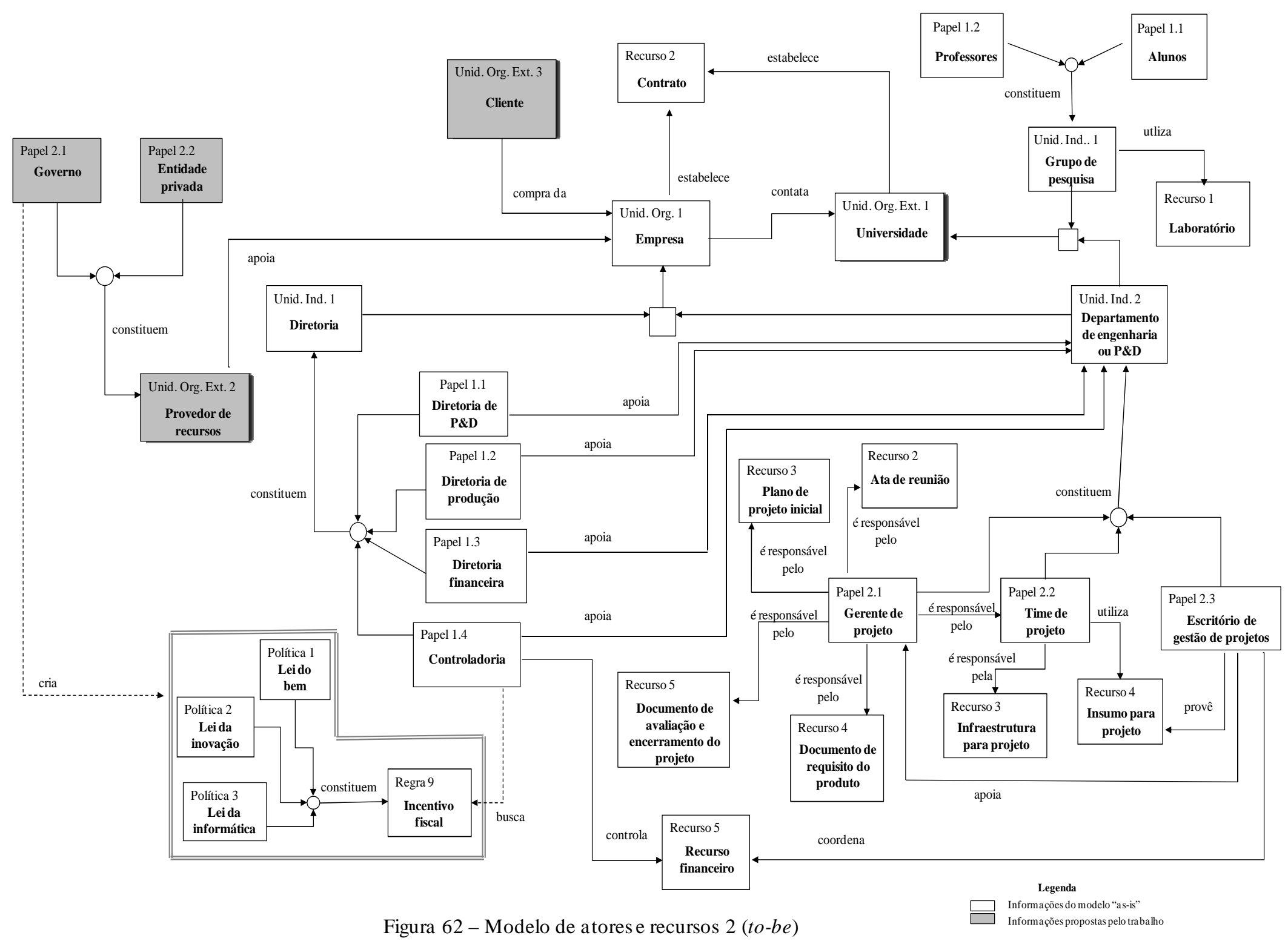

Figura 62 - Modelo de atores e recursos 2 (to-be) 
Os principais envolvidos no processo de transferência são a empresa (Unidade Organizacional 1), a universidade (Unidade Organizacional Externa 1) e o cliente (Unidade Organizacional Externa 3). O cliente (Unidade Organizacional Externa 3) compra da empresa (Unidade Organizacional 1). A empresa (Unidade Organizacional 1) contata a universidade (Unidade Organizacional Externa 1) para desenvolver uma parceria. Ambas estabelecem o contrato (Recurso 2). A universidade (Unidade Organizacional Externa 1) é constituída por grupos de pesquisa (Unidade Individual 1.1) que utilizam laboratórios. Os grupos de pesquisa (Unidade Individual 1.1) são compostos por professores (Papel 1.1.2) e alunos (Papel 1.1.1).

A empresa (Unidade Organizacional 1) tem a diretoria (Unidade Individual 1) e o departamento de Engenharia ou P\&D (Unidade Individual 2) envolvidos no processo de transferência.

A diretoria (Unidade Individual 1) é composta pela diretoria de P\&D (Papel 1.1), diretoria de produção (Papel 1.2), diretoria de tecnologia de processo (Papel 1.3) e controladoria (Papel 1.4). Todas as diretorias apoiam o departamento de engenharia ou P\&D (Unidade Individual 2). A controladoria (Papel 1.4) é responsável por verificar os incentivos fiscais (Regra 3) e controlar os recursos financeiros (Recurso 5). Os incentivos fiscais (Regra 3) são criados pelo governo (Papel 2.1) que compõe os provedores de recursos (Unidade Organizacional Externa 2) junto com as entidades privadas (Papel 2.2). Esses provedores de recursos (Unidade Organizacional Externa 2) apoiam a empresa (Unidade Organizacional $1)$.

O departamento de engenharia ou P\&D (Unidade Individual 2) é composto pelo gestor de projetos (Papel 2.1), equipe de projetos (Papel 2.2) e escritório de projetos (Papel 2.3). O gestor de projetos (Papel 2.1) é responsável pela ata de reunião (Recurso 2), pelo plano do projeto (Recurso 3), documento de avaliação e encerramento do projeto (Recurso 5), documento de requisito do produto (Recurso 4) e pela equipe de projetos (Papel 2.2). A equipe de projetos (Papel 2.2) é responsável pela infraestrutura para o projeto (Recurso 3) e utiliza insumos para projeto (Recurso 4) providos pelo escritório de projetos (Papel 2.3) que por sua vez também coordena o recurso financeiro (Recurso 5).

\subsubsection{Modelo de Componentes e Requisitos Técnicos}

A Figura 63 apresenta o modelo de componentes e requisitos técnicos que norteia a transferência tecnologia-produto. 


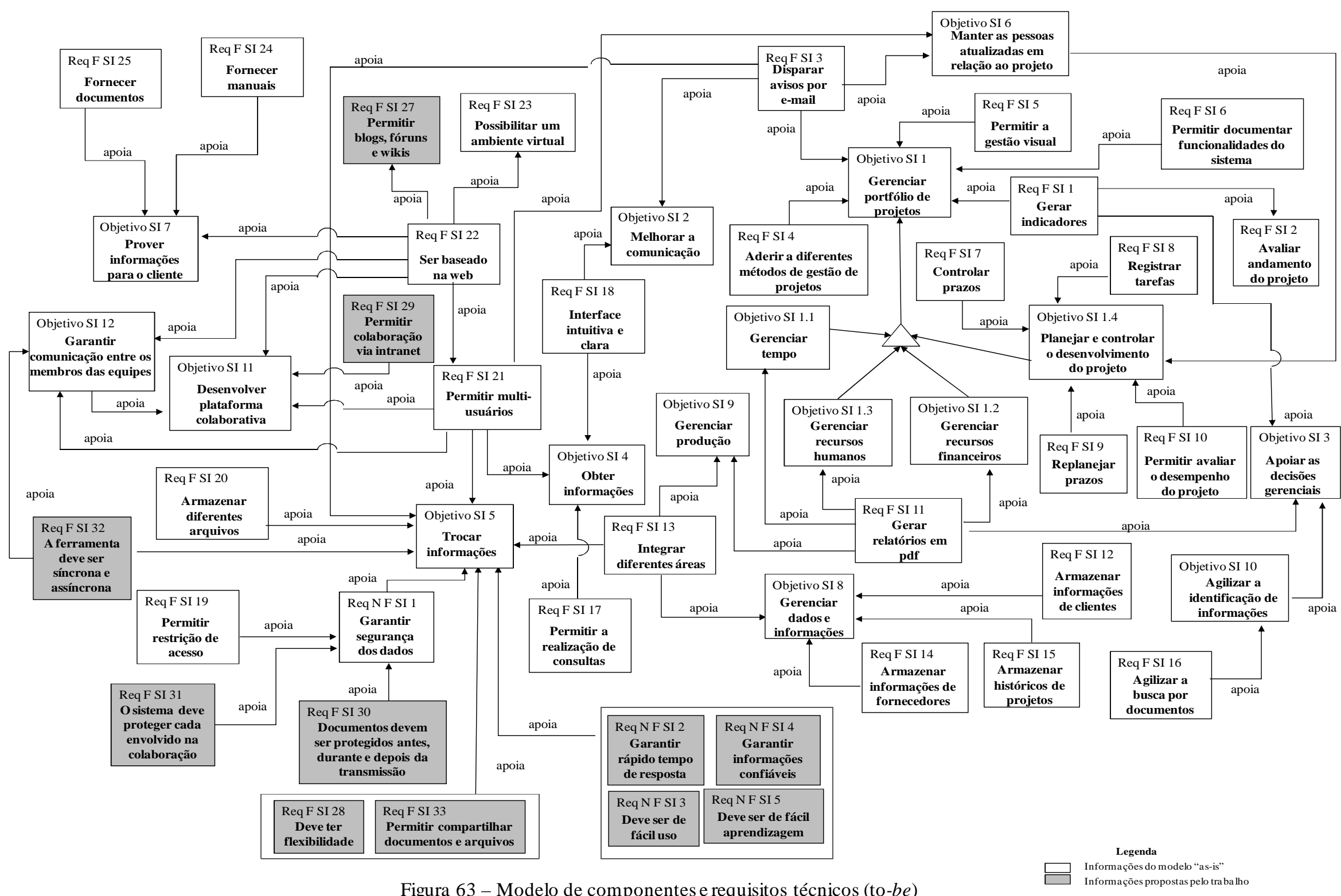

Figura 63 - Modelo de componentes e requisitos técnicos (to-be) 
Para esse modelo foram propostos os requisitos funcionais para um sistema de informação como os de número 27 (permitir blogs, fóruns e wikis), 28 (ter flexibilidade), 29 (permitir colaboração via intranet), 30 (documentos devem ser protegidos antes, durante e depois da transmissão), 31 (o sistema deve proteger cada envolvido na colaboração), 32 (a ferramenta deve ser síncrona e assíncrona), e 33 (permitir compartilhar documentos e arquivos).

Quanto aos requisitos não funcionais sugerido para o modelo foi os de número 2 (garantir rápido tempo de resposta), 3 (deve ser de fácil uso), 4 (garantir informações confiáveis), e 5 (deve ser de fácil aprendizagem).

O sistema de informação tem como objetivos gerenciar portfólio de projetos (Objetivo SI 1) em termos de gerenciar tempo (Objetivo SI 1.1), gerenciar recursos humanos (Objetivo SI 1.3), gerenciar recursos financeiros (Objetivo SI 1.2), e planejar e controlar o desenvolvimento do projeto (Objetivo SI 1.4), melhorar comunicação (Objetivo SI 2), apoiar as decisões gerenciais (Objetivo SI 3), obter informações (Objetivo SI 4), trocar informações (Objetivo SI 5), manter as pessoas atualizadas em relação ao projeto (Objetivo SI 6), prover informações para o cliente (Objetivo SI 7), gerenciar dados e informações (Objetivo SI 8), gerenciar produção (Objetivo SI 9), agilizar a identificação de informações (Objetivo SI 10), desenvolver plataforma colaborativa (Objetivo SI 11), e garantir a comunicação entre os membros das equipes (Objetivo SI 12).

Para gerenciar portfólio de projetos (Objetivo SI 1), o sistema deve permitir a gestão visual (Requisito Funcional SI 5), disparar avisos por e-mail (Requisito Funcional SI 3), aderir a diferentes métodos de gestão de projetos (Requisito Funcional SI 4), permitir documentar funcionalidade do sistema (Requisito Funcional SI 6), e gerar indicadores (Requisito Funcional SI 1), que apoiam avaliar o andamento do projeto (Requisito Funcional SI 2).

Para gerenciar tempo (Objetivo SI 1.1), gerenciar recursos humanos (Objetivo SI 1.3) e recursos financeiros (Objetivo SI 1.2) o sistema deve gerar relatórios em pdf (Requisito Funcional SI 11). Para planejar e controlar o andamento do projeto (Objetivo SI 1.4) o sistema deve permitir controlar prazo (Requisito Funcional SI 7), registrar tarefas (Requisito Funcional SI 8), re-planejar prazos (Requisito Funcional SI 9), permitir avaliar o desempenho do projeto (Requisito Funcional SI 10), e manter as pessoas atualizadas em relação ao projeto (Objetivo SI 6). 
Para melhorar a comunicação (Objetivo SI 2), o sistema deve disparar avisos por $e$ mail (Requisito Funcional SI 3) e ter uma interface intuitiva e moderna (Requisito Funcional SI 18). Não existe fórum de discussão para desenvolvimento do projeto.

Para apoiar as decisões gerenciais (Objetivo SI 3), o sistema deve gerar relatórios em pdf (Requisito Funcional SI 11), gerar indicadores (Requisito Funcional SI 1), e agilizar a identificação de informações (Objetivo SI 10).

Para obter informações (Objetivo SI 4) é necessário que o sistema tenha uma interface intuitiva e clara (Requisito Funcional SI 18), que permita multiusuários (Requisito Funcional SI 21) e a realização de consultas (Requisito Funcional SI 17)

Para trocar informações (Objetivo SI 5), o sistema deve armazenar diferentes arquivos (Requisito Funcional SI 20), ser uma ferramenta síncrona e assíncrona (Requisito Funcional SI 32), permitir compartilhar documentos e arquivos (Requisito Funcional SI 33), ter flexibilidade (Requisito Funcional SI 28), disparar avisos por e-mail (Requisito Funcional SI 3), e permitir multiusuários (Requisito Funcional SI 21). Para permitir multiusuários (Requisito Funcional SI 21), o sistema deve ser baseado na web (Requisito Funcional SI 22) o que possibilita também um ambiente virtual (Requisito Funcional SI 23), blogs, fóruns e wikis (Requisito Funcional SI 27) e, garantir a segurança dos dados (Requisito NãoFuncional SI 1). Para garantir a segurança (Requisito Não Funcional SI 1) é importante que o sistema permita restrição de acesso (Requisito Funcional SI 19), proteja cada envolvido na colaboração (Requisito Funcional SI 31), proteja documentos antes, durante e depois da transmissão (Requisito Funcional SI 30). Além disso, deve garantir rápido tempo de resposta (Requisito Não-Funcional SI 2), informações confiáveis (Requisito Não-Funcional SI 4), ser de fácil uso (Requisito Não-Funcional SI 3), e ser de fácil aprendizagem (Requisito NãoFuncional SI 5).

Para manter as pessoas atualizadas em relação ao projeto (Objetivo SI 6), o sistema deve disparar e-mails (Requisito Funcional SI 3) e permitir multiusuários (Requisito Funcional SI 21).

Para prover informações para o cliente (Objetivo SI 7), o sistema deve ser baseado na web (Requisito Funcional SI 22), fornecer documentos (Requisito Funcional SI 25) e fornecer manuais (Requisito Funcional SI 4).

Para gerenciar dados e informações (Objetivo SI 8), o sistema deve armazenar informações de fornecedores (Requisito Funcional SI 14), armazenar histórico de projetos (Requisito Funcional SI 15), armazenar informações de clientes (Requisito Funcional SI 12), e integrar diferentes áreas (Requisito Funcional SI 13). 
Para gerenciar a produção (Objetivo SI 9), é necessário integrar diferentes áreas (Requisito Funcional SI 13) e gerar relatórios em pdf (Requisito Funcional SI 11).

Para agilizar a identificação de informações (Objetivo SI 10), o sistema deve agilizar a busca por documentos (Requisito Funcional SI 16).

Para desenvolver uma plataforma colaborativa (Objetivo SI 11) o sistema deve ser baseado na web (Requisito Funcional SI 22), permitir multiusuário (Requisito Funcional SI 21), e permitir a colaboração via intranet (Requisito Funcional SI 29).

Para garantir a comunicação entre os membros das equipes (Objetivo SI 12), o sistema deve ser baseado na web (Requisito Funcional SI 22), permitir multiusuário (Requisito Funcional SI 21), e ser uma ferramenta síncrona e assíncrona (Requisito Funcional SI 32).

\subsection{Discussão dos Resultados}

Transferir uma tecnologia de uma organização para outra e utilizá-la em uma organização de interesse é um processo difícil e muitas vezes sem sucesso (STOCK; TATIKONDA, 2000) por diferentes motivos: falha ou falta de comunicação, estratégia e operação (NOBELIUS, 2004), pouca interação, coordenação e cooperação (STOCK; TATIKONDA, 2004).

Visando minimizar esses problemas, esta pesquisa buscou sistematizar o processo de transferência tecnologia-produto sob o recorte analítico de redes colaborativas desenvolvendo um modelo de referência para redes colaborativas para a transferência tecnologia-produto. Esse modelo pode ser um instrumento importante para orientar as empresas sobre qual o procedimento seguir para estruturar ou reestruturar o processo de transferência tecnologiaproduto para que seja colaborativo e não simplesmente uma relação de mercado.

Pesquisas de Jugend e Silva (2012), Tatikonda e Stock (2003), Camarinha-Matos e Abreu (2007) têm abordado a transferência de tecnologia ou a colaboração e em outros casos, Lin et al. (2009), Nieto e Santamaría (2007) têm relacionado os dois assuntos analisado-os estatisticamente. Estes estudos são importantes para verificar a existência da relação ou a influencia de um assunto em relação a outro. Mas também são importantes, estudos que apresentam detalhes de como as coisas são ou ocorrem para melhorar a compreensão.

Com o desenvolvimento do modelo do estado atual ou "as-is" foi possível compreender e representar a realidade de como o processo de transferência ocorre e a sua 
relação com a colaboração em sete empresas. Apesar das empresas terem consciência sobre as oportunidades que a colaboração pode proporcionar, elas fazem pouco uso dessa prática.

A análise da necessidade de mudança (need for change) foi a etapa que contribuiu para a construção do modelo do estado futuro. Essa análise tem por objetivo desenvolver soluções para problemas de negócio ou melhorar a eficiência de um. A análise da necessidade de mudança permitiu identificar práticas consideradas de sucesso sobre transferência tecnologia-produto e colaboração recomendadas pela literatura que orientam as empresas a se organizarem ou se reorganizarem para alcançar seus objetivos. Diante dessa análise foi possível propor o modelo desta pesquisa denominado de modelo do "estado futuro" ou " $t o$ be”.

O modelo do estado futuro pode ser considerado um modelo de referência por possuírem características semelhantes. O modelo de referência pode ser desenvolvido a partir de teorias ou situações reais em que processos são conhecidos e praticados em várias Organizações, sendo o know-how de um processo documentado para que possa ser reutilizado para agilizar e habilitar as empresas a aplicar práticas consideradas de sucesso (SCHEER, 2000; MATOOK; INDULSKA, 2009; REINHARTZ-BERGER; SOFFER; STURM, 2010). O modelo do estado futuro foi desenvolvido considerando teorias e práticas de várias empresas, as quais foram documentadas e sistematizadas para que possa orientar outras empresas.

Além disso, Keller e Teufel (1998) consideram que o modelo do estado futuro é um modelo de referência. Para os autores o desenvolvimento de um modelo que descreve uma empresa pode ser considerado um modelo de referência, pois é uma referência de representação das atividades da empresa.

O modelo do estado futuro enquanto um modelo de referência tem por objetivo:

- Formalizar e sistematizar o conhecimento prático e teórico sobre colaboração e transferência tecnologia-produto;

- Ser utilizado como base por outras empresas para analisarem sua realidade atual, proporcionando oportunidades de melhoria tanto para a colaboração quanto para a transferência tecnologia-produto;

- Orientar empresas de alta tecnologia sobre quais os requisitos são necessários para que exista colaboração no processo de transferência;

- Agilizar o processo de identificação de necessidades de melhorias e mudanças;

- Melhorar a comunicação entre os diferentes envolvidos no processo de transferência; 
- Melhorar a qualidade das operações e das relações entre os envolvidos;

- Agilizar projetos de modelos parciais de empresas que irão estruturar o processo de transferência;

- Permitir que todos os envolvidos tenham uma linguagem comum, ou seja, que os termos utilizados sejam claros para todos.

\subsection{Considerações Finais}

Este capítulo apresentou os resultados e análises obtidos a partir da pesquisa de campo. A estruturação desse capítulo foi baseada nas três atividades propostas pela metodologia de modelagem EKD que são a modelagem do estado atual, a necessidade para a mudança, e o estado futuro.

A modelagem do estado atual foi desenvolvida com base na modelagem das sete empresas que participaram da pesquisa. Para a construção dos modelos consideraram-se todas as informações fornecidas durante a entrevista, pois a pesquisa parte do princípio de que possam existir outras organizações estruturadas de maneira semelhante. A modelagem do estado atual possibilitou identificar que as empresas pesquisadas apresentam poucas práticas relacionadas à colaboração, sendo que a preferência delas é desenvolver o produto internamente. Isso pôde ser percebido pelas regras de negócio que foram explicitamente declaradas e pela falta de regras que também apoiam o estabelecimento de parcerias.

Com relação à segunda atividade, a necessidade para a mudança, foi desenvolvida a partir das informações dos modelos do estado atual e da literatura. Nessa etapa foi possível identificar situações que acontecem nas empresas e que não foram encontradas na literatura. Assim, como situações apontadas pela literatura e que não acontecem nas empresas.

Diante da identificação dessas lacunas é que foi possível desenvolver a terceira atividade da metodologia EKD que é o modelo do estado futuro que por sua vez é a proposta dessa pesquisa. O modelo do estado futuro apresenta os problemas que as empresas possam vir a ter com relação à colaboração, as regras que podem orientá-las a conduzir essa relação, atividades que podem auxiliar na identificação do parceiro, os possíveis atores que podem auxiliar na transferência da tecnologia, além de componentes e requisitos que um sistema deve ter para apoiar a colaboração e o processo de transferência. 


\section{CONCLUSÕES}

Com as rápidas mudanças tecnológicas e de mercado, as empresas encontram dificuldades de alcançar com sucesso uma inovação por meio apenas de recursos e capacidades internas. As empresas precisam adquirir, aprender e transferir tecnologia a partir da colaboração com fontes externas, as quais permitem acelerar seu processo de inovação e sustentar sua vantagem competitiva. Colaborar com outras organizações pode resultar em benefícios, pois possibilita prover diferentes recursos que faltam às empresas.

Nesse sentido, foi proposta a seguinte questão de pesquisa: "como organizar o processo de transferência tecnologia-produto sob o recorte analítico de redes colaborativas?" Essa questão foi respondida por meio da metodologia EKD em conjunto com o método de pesquisa empregado, ou seja, o levantamento bibliográfico e o estudo de caso. Os resultados mostraram que essa combinação também possibilitou atingir o principal objetivo da pesquisa que foi desenvolver o modelo de referência para a formação de redes colaborativas para a transferência tecnologia-produto.

Os objetivos específicos também foram alcançados. O primeiro objetivo que era identificar empiricamente como ocorre o processo de transferência tecnologia-produto e quais conceitos de redes colaborativas podem contribuir nesse processo foi alcançado por meio do levantamento bibliográfico e pelos estudos de casos.

O último objetivo específico que era desenvolver um modelo com o propósito de orientar as empresas a conduzir a colaboração no processo de transferência tecnologiaproduto é alcançado ao desenvolver a Seção 4.3 do Capítulo 4. O modelo desenvolvido foi construído considerando as práticas teóricas e empíricas.

Durante o desenvolvimento da pesquisa, algumas dificuldades foram encontradas. A primeira foi com relação à disponibilidade das empresas em agendarem as entrevistas. Algumas pediram para que fosse enviado um e-mail, pois havia a necessidade de passar pela diretoria. Mesmo realizando várias ligações e enviando vários e-mails não foram obtidos retornos. Outra dificuldade foi trabalhar com informações do processo de negócio de empresas de diferentes setores, sendo que cada uma tem suas especificidades.

A pesquisa permitiu identificar que apesar do assunto colaboração ser discutido constantemente pela literatura, este não é uma prática das empresas pesquisadas colaborarem com frequiência para desenvolver inovações. Isso se deve ao fato de experiências anteriores sem sucesso, a própria política da empresa, questões de propriedade intelectual, entre outros. Com relação à transferência, observou-se que a literatura apresenta poucos processos de 
transferência relacionando-os com a colaboração e as empresas também não tem incorporado muitas práticas colaborativas em seu processo.

Considerando essas lacunas, a pesquisa contribui tanto com a literatura quanto com a prática ao incorporar aspectos de redes colaborativas no processo de transferência tecnologiaproduto. A pesquisa contribui com a literatura tendo em vista que os assuntos são interrelacionados, mas apresentam-se de maneira separada. Além disso, contribui com as empresas por alertar problemas e orientar a condução da colaboração e do processo de transferência. Apesar do modelo não ter sido analisado, acredita-se que ele pode auxiliar as empresas nesse processo.

O estudo contribui para a readequação do processo de transferência sob o recorte analítico das redes colaborativas, considerando casos de empresas que desenvolvem suas tecnologias a partir da pesquisa básica ou de mercado.

Outra contribuição refere-se à visão e a sistematização da organização que a metodologia EKD proporcionou em relação aos assuntos estudados nesta pesquisa. Os modelos permitiram apresentar os objetivos, os problemas, as oportunidades, políticas, regras de negócio, conceitos, processos, atores, recursos, e requisitos de sistema de informação que auxiliam a melhorar a coordenação da colaboração e da transferência. Assim, a pesquisa é considerada original, pois não foi identificado na literatura trabalhos que apresentassem essas múltiplas perspectivas organizacionais, preenchendo a lacuna da interface entre colaboração e transferência tecnologia-produto.

Os modelos foram desenvolvidos considerando diferentes realidades de micro, pequena e médias empresas de alta tecnologia para ter um caráter mais abrangente para a realidade dessas empresas, entretanto, isto não significa que não possa ser submetido a alterações conforme as especificidades de cada empresa. É importante destacar que o objetivo do modelo é recomendar algumas práticas e não instruir como realizá-las.

Com relação à metodologia EKD, a flexibilidade proporcionada por ela facilitou ao pesquisador conduzir o estudo. Inicialmente, houve a necessidade de adaptar as questões sugeridas pelo guia. Nem todas as questões contidas nele foram utilizadas e outras necessitaram ser operacionalizadas para que os respondentes pudessem compreender a questão. Outro ponto é que a ordem para realizar a modelagem não seguiu a ordem do roteiro do EKD. A modelagem teve início a partir do modelo de processos de negócio, seguidos pelos modelos de atores e recursos, objetivos, regras de negócio, componentes e requisitos técnicos e de conceitos. Essa ordem foi escolhida por facilitar a condução da entrevista e o entendimento do pesquisador. Por fim, outro ponto importante é que esboçar o modelo 
durante as entrevistas permitiu visualizar a situação modelada e eliminar algumas dúvidas que surgiram.

Com relação às limitações, a primeira limitação da pesquisa refere-se à dificuldade em atender todas as sugestões propostas pela metodologia EKD, como é o caso de reunir um grupo de pessoas das empresas para realizar a modelagem. Em decorrência desse fato, sugerese como pesquisa futura a realização de entrevistas com um grupo de pessoas envolvidas no processo, pois possibilita encontrar diferentes pontos de vistas que poderiam enriquecer o conteúdo do modelo.

Outra limitação é que o modelo desenvolvido nesta pesquisa não foi avaliado e nem implementado em uma empresa, já que este não era o foco da pesquisa. Desse modo, sugerese que outras pesquisas avaliem o modelo com empresários e especialistas de tal forma a melhorar as informações contidas nele. Além disso, sugere-se implementar para verificar seus pontos positivos e negativos e avaliar o quanto ele pode trazer melhorias para as empresas.

Tendo em vista que as empresas utilizam basicamente e-mails e telefone para compartilhar informações quando colaboram, esta pesquisa sugere que estudos futuros desenvolvam um sistema de informação direcionado à colaboração que auxilie no processo de transferência tecnologia-produto.

Como complemento desta pesquisa uma sugestão de estudo futuro é a realização da modelagem em empresas de grande porte para que as práticas dessas empresas também possam ser consideradas e também para verificar as diferenças existentes de acordo com o porte das empresas.

Outros estudos poderiam investigar o panorama da colaboração das empresas de alta tecnologia brasileira, ou seja, identificar o grau da colaboração com diferentes tipos de parceiros, a finalidade dessa colaboração, as barreiras e benefícios, se existem avaliações do parceiro, antes, durante e depois desse processo e que mecanismos são utilizados para essa avaliação. Estudos como esses poderiam auxiliar outras pesquisas a desenvolverem redes colaborativas direcionadas as necessidades das empresas brasileiras, além de poder ser utilizado para complementar o modelo apresentado nesta tese.

Por fim, futuras pesquisas poderiam identificar métodos, técnicas e ferramentas que poderiam auxiliar as empresas em cada etapa do processo da transferência tecnologia-produto. 


\section{REFERÊNCIAS}

ABBASNEJAD, T.; BAERZ, A. M.; ROSTAMY, A. A. A.; AZAR, A. Factors affecting on collaboration of industry with university. African Journal of Business Management, v. 5, n. 32, p. 12401-12407, 2011.

ABETTI, P. A. Technology: a key strategic resource. Management Review, v. 78, n. 2, p. 37-41, 1989.

ABRAHAM, S.; BLAND, H. Successful technology transfer, process validation, and partnership with a CMO. Biopharm International, v. 24, n. 3, p. 10-14, 2011.

AHUJA, G. Collaboration networks, structural holes, and innovation: a longitudinal study. Administrative Science Quarterly. v. 45, n. 3, p. 425-455, 2000.

AKHAVAN, A. N.; BAGHERI, A.; JABBARI, N. An empirical studying of barriers for technology transfer: The case of Iran. Management of Innovation and Technology, 2008. ICMIT 2008. 4th IEEE International Conference on, p. 92-97, 21-24 Sept, 2008.

ALAVI, M.; LEIDNER, D. E. Review: knowledge management and knowledge management systems: conceptual foundations and research issues. MIS Quartely, v. 25, n. 1, p. 107-136, 2001.

ALBORS, J.; SWEENEY, E.; HIDALGO, A. Transnational technology transfer networks for SMEs. A review of the state-of the art and an analysis of the European IRC network. Production Planning \& Control, v. 16, n. 4, p. 413-423, 2005.

AHLEMANN, F. Towards a conceptual reference model for project management information systems. International Journal of Project Management, v. 27, p. 19-30, 2009.

ARAGON-CORREA, J. A.; GARCIA-MORALES, V. J.; CORDO'N-POZO, E. Leadership and organizational learning's role on innovation and performance: Lessons from Spain. Industrial Marketing Management, v. 36, n. 3, p. 249-359, 2007.

AUTIO, E.; HAMERI, A. P.; VUOLA, O. A framework of industrial knowledge spillovers in big-science centers. Research Policy, v. 33, n. 1, p. 107-126, 2004.

AUTIO, E.; LAAMANEN, T. Measurement and evaluation of technology transfer: review of technology transfer mechanisms and indicators. International Journal of Technology Management, v. 10, n. 7-8, p. 643-664, 1995.

BAFOUTSOU, G.; MENTZAS, G. A comparative analysis of web-based collaborative systems. $12^{\text {th }}$ International Workshop on Database and Expert Systems Applications. University of Athens, Greece, p. 496-500, 2001.

BARRATT, M.; CHOI, T. Y.; LI, M. Qualitative case studies in operations management: trends, research outcomes, and future research implications. Journal of Operations Management, v. 29, p. 329-342, 2011. 
BAYONA, C.; GARCÍA-MARCO, T.; HUERTA, E. Firms' motivations for cooperative R\&D: an empirical analysis of Spanish firms. Research Policy, v. 30, p. 1289-1307, 2001.

BENNETT, D.; VAIDYA, K.; HONGYU, Z. Valuing transferred machine tool technology: relating value to product attributes and preferences of acquirers. International Journal of Operations \& Production Management, v. 19, n. 5/6, p. 491-514, 1999.

BIENNIER, F.; FAVREL, J. Secure collaborative information system for enterprise alliances: a workflow based approach. International Conference on Emerging Technologies and Factory Automation, Villeurbanne, France, v. 2,p. 33-40, 2001.

BITITCI, U.; TURNER,T.; MACKAY, D.; KEARNEYS,D.; PARUNG, J.; WALTERS, D. Managing synergy in collaborative enterprises. Production Planning \& Control, v. 18, n. 6,p. 454-465, 2007.

BOGDAN, R.; BIKLEN, S. Investigação Qualitativa em Educação. Porto: Porto Editora, 1994.

BOHN, R. E. Measuring and managing technological knowledge. Sloan Management Review, v. 36, n. 1, p. 61-73, 1994.

BOSCH-SIJTSEMA, P. M.; POSTMA, T. J. B. M. Governance factors enabling knowledge transfer in interorganisational development projects. Technology Analysis \& Strategic Management, v. 22, n. 5, p. 593-608, 2010.

BOSSINK, B. A. G. The interorganizational innovation processes of sustainable building: a Dutch case of joint building innovation in sustainability. Building and Environment, v. 42, p. 4086-4092, 2007.

BOZEMAN, B. Technology transfer and public policy: a review of research a theory. Research Policy, v. 29, p. 627-655, 2000.

BUBENKO Jr., J. A.; BRASH, D.; STIRNA, J. EKD user guide. Dpt of Computer and Systems Sciences. Stockholm: Royal Institute of Technology, 1998.

BUBENKO Jr, J. A; PERSSON, A.; STIRNA, J. EKD user guide, 2001. Dep. of Computer and Systems Sciences. Stockholm, Royal Institute of Technology. Disponível em < ftp://ftp.dsv.su.se/users/js/ekd_user_guide_2001.pdf> Acesso em 01 de maio de 2009.

BULLINGER, H-J.; AUERNHAMMER, K.; GOMERINGER, A. Managing innovation networks in the knowledge-driven economy. International Journal of Production Research, v. 42, n. 17, p. 3337-3353, 2004.

BURATTI, N.; PENCO, L. Assisted technology transfer to SMEs: lessons from an exemplary case. Technovation, v. 21, p. 35-43, 2001.

BURGELMAN, R. A.; MAIDIQUE, M. A.; WHEELWRIGHT, S. C. Strategic management of technology and innovation. 3. ed. New York: McGraw-Hill, 2001. 
BÜYÜKÖZKAN, G.; ARSENYAN, J. Collaborative product development: a literature overview. Production Planning \& Control: The Management of Operations, v. 23, n. 1, p. 47-66, 2012.

CALIA, R. C.; GUERRINI, F. M.; MOURA, G. L. Innovation networks: from technological development to business model reconfiguration. Technovation, v. 27, n. 8, p. 426-432, 2007.

CAMARINHA MATOS, L. M. Collaborative networked organizations: status and trends in manufacturing. Annual Reviews in Control, v. 33, p. 199-208, 2009.

CAMARINHA MATOS L. M.; ABREU, A. Performance indicators for collaborative networks based on collaboration benefits. Production Planning \& Control, v. 18, n. 7, p. 592-609, 2007.

CAMARINHA MATOS, L. M.; AFSARMANESH, H. Collaborative networks: a new scientific discipline. Journal of Intelligent Manufacturing, v. 16, p. 439-452, 2005.

CAMARINHA MATOS, L. M.; AFSARMANESH, H. Collaborative networks: reference modeling. New York: Springer. 2008.

CAMARINHA MATOS, L. M.; AFSARMANESH, H. Collaborative networks: value creation in a knowledge society. In: Wang, K.; Kovács, G. L.; Wozny, M. J.; Fang M. (Eds.): Knowledge Enterprise: Proceedings of Prolamat 2006. Boston, USA: Springer, p. 26-40, 2006.

CAMARINHA MATOS, L. M.; AFSARMANESH, H.; GAELANO, N.; MOLINA, A. Collaborative networked organizations - concepts and practice in manufacturing enterprises. Computers \& Industrial Engineering, v.57, p. 46-60, 2009.

CANIËLS, M. C. J.; BAKENS, R. J. J. M. The effects of project management information systems on decision making in a multi project environment. International Journal of Project Management, v. 30, p. 162-175, 2012.

CARBONE, F.; CONTRERAS, J.; HERNÁNDESZ, J. Z.; GOMEZ-PEREZ,J. M. Open innovation in an enterprise 3.0 framework: three case studies. Expert Systems with Applications, v. 39,p. 8929-8939, 2012.

CASSIMAN, B.; VEUGELERS, R. External technology sources: embodied or disembodies technology acquisition. Working Paper. 2000.

CHAUDHRY, A. S.; FEN, F. P. (2006).Validating the Indicators for the Knowledge-Based Economy: A Case Study of Economic Development Board of Singapore. Information Resources Management Association International Conference - Emerging Trends and Challenges in Information Technology Management. Washington, DC, p. 804-806

CHEN, C-J. The effects of knowledge attribute, alliance characteristics, and absorptive capacity on knowledge transfer performance. R\&D Management, v. 34, n. 3, p. 311-321, 2004. 
CHEN, C-Y.; TSENG, K-H. Knowledge transfer and innovation performance of competitive knowledge communities: case of a high-tech firm in Taiwan. African Journal of Business Management, v. 5, n. 22, p. 9665-9675, 2011.

CHESBROUGH, H. Open Innovation: The New Imperative for Creating and Profiting from Technology. Harvard Business School Press, Boston, Massachusetts, 2003.

CHESBROUGH, H.; SCHWARTZ, K. Innovating business models with co-development partnerships. Research Technology Management, v. 50, n. 1, p.55-59, 2007.

CHIESA, V.; MANZINI, R. Organizing for technological collaborations: a managerial perspective. R\&D Management, v. 28, n. 3, p. 199-212, 1998.

CHITUC, C. M.; TOSCANO, C.; AZEVEDO, A. Interoperability in collaborative networks: Independent and industry-specific initiatives - the case of the footwear industry. Computers in Industry, v. 59, n. 7, p. 741-757, 2008.

CIOFFI, D. F. Designing project management: a scientific notation and an improved formalism for earned value calculations. International Journal of Project Management, v. 24, p. 136-144, 2006.

CLARK, K. B.; FUJIMOTO, T. Product development performance: strategy, organization and management in the world auto industry. Boston, Mass.: Harvard Business School Press. 1991.

CLARK, K. B.; WHEELWRIGHT, S. C. Managing new product and process development: text and cases. New York: Free Press. 1993.

CMMI PRODUCT TEAM. CMMI for development- version 1.2. Software Engineering Institute, Carnegie Mellon University, 2006. Disponível em: <http://www.sei.cmu.edu/library/abstracts/reports/06tr008.cfm $>$.

COHEN, G. Technology transfer: strategic management in developing countries. Sage Publications, 2004.

COLOMBO, M. G.; GRILLI, L.; PIVA, E. In search of complementary assets: the determinants of alliance formation of high-tech start-ups. Research Policy, v. 35, p. 11661199, 2006.

CORMICAN, K.; O'CONNOR, M. Technology transfer for product life cycle extension: a model for successful implementation. International Journal of Innovation and Technology Management, v. 6, n. 3, p. 265-282, 2009.

CORSTEN, D.; GRUEN, T.; PEYINGHAUS, M. The effects of supplier-to-buyer identification on operational performance - an empirical investigation of inter-organizational identification in automotive relationships. Journal of Operations Management, v. 29, p. 549-560, 2011. 
CUI, A. S.; GRIFFITH, D. A.; CAVUSGIL, S. T.; DABIC, M. The influence of market and cultural environmental factors on technology transfer between foreign MNCs and local subsidiaries: a croatian illustration. Journal of World Business, v. 41, p. 100-111, 2006.

CUSUMANO, M. A.; ELENKOV, D. Linking international technology transfer with strategy and management: a literature commentary. Research Policy, v. 23, n. 2, p. 195-215, 1994.

DEBRESSON, C.; AMESSE, F. Networks of innovators: a review and introduction to the issue. Research Policy, v. 20, n. 5, p. 363-379, 1991.

DECK, M.; STROM, M. Model of co-development emerges. Research Technology Management, v. 45, n. 3, p. 47-53, 2002.

DE TONI, A.; NASSIMBENI, G. Small and medium district enterprises and the new product development challenge: evidence from Italian eyewear district. International Journal of Operations \& Production Management, v. 23, n. 6, p. 678-697, 2003.

DIETRICH, P.; ESKEROD, P.; DALCHER, D. SANDHAWALIA,B. The dynamics of collaboration in multipartner projects. Project Management Journal, v.41, n. 4, p. 59-78, 2010 .

DIEZ, J. D. Metropolitan innovation systems: a comparison between Barcelona, Stockholm, and Vienna. International Regional Science Review, v. 25, n. 1, p. 63-85, 2002.

de la FUENTE,M. V.; ROS, L.; ORTIS, A. Enterprise modelling methodology for foward and reverse supply chain flows integration. Computers in Industry, v. 61, p. 702-710, 2010.

DOLOREUX, D. Regional networks of small and medium sized enterprises: evidence from the metropolitan area of Ottawa in Canada. European Planning Studies, v. 12, n. 2, p. 173189, 2004.

DODGSON, M. The management of technological innovation: an international and strategic approach. New York: Oxford University Press, 2000.

DODGSON, M.; GANN, D.; SALTER, A. The role of technology in the shift towards open innovation: the case of Procter \& Gamble. R\&D Management, v. 30, n. 3, p. 333-346, 2006.

DOWLING, M.; HELM, R. Product development success through cooperation: a study of entrepreneurial firms. Technovation, v. 26, p. 483-488, 2006.

EASTERBY-SMITH, M.; LYLES, M. A.; TSANG, E. W. K. Inter-organizational knowledge transfer: current themes and future perspectives. Journal of Management Studies, v. 45, n. 4, p. 677-690, 2008.

EISENHARDT, K. M. Building theories from case study research. The Academy of Management Review ,v. 14,n. 4, p. 532- 550, 1989.

EISENHARDT, K. M.; GRAEBNER, M. E. Theory building from cases: opportunities and challenges. Academy of Management Journal, v. 50, n. 1, p.25-32, 2007. 
EMDEN, Z.; CALANTONE, R. J.; DROGE, C. Collaborating for new product development: selecting the partner with maximum potential to create value. Journal of Product Innovation Management, v. 23, p. 330-341, 2006.

FAEMS, D.; JANSSENS, M.; van LOOY, B. The initiation and evolution of interfirm knowledge transfer in R\&D relationships. Organization Studies, v. 28, n. 11, p. 1699-1728, 2007.

FAEMS,D.; LOOY, B. V.; DEBACKERE, K. Interorganizational collaboration and innovation: toward a portfolio approach. Journal of Product Innovation Management, v.22, p. 238-250, 2005.

FARIA, P.; LIMA, F.; SANTOS, R. Cooperation in innovation activities: the importance of partners. Research Policy, v. 39, n. 8, p. 1082-1092, 2010.

FETTKE, P.; LOSS, P. Classification of reference models: a methodology and its application. Information Systems and e-Business Management, v. 1, n. 1, p. 35-53, 2003.

FETTKE, P.; LOOS, P. Perspectives on Reference Modeling. In: FETTKE, P.; LOOS, P. (Eds.). Reference modeling for business systems analysis. 1rd ed. Hershey: Idea Group Publishing. cap. 1, p. 1-20, 2007.

FLAMHOLTZ, E.; HUA, W. Searching for competitive advantage in the black box. European Management Journal, v. 21, n. 2, p. 222-236, 2003.

FONTES, M.; COOMBS, R. Contribution of new technology-based firms to the strengthening of technological capabilities in intermediate economies. Research Policy, v. 30, p. 79-97, 2001.

FRAME, I.; AUSTEN,K. F.; CALLEJA,M.; DOVE,M. T.; WHITE,T. O. H.; WILSON, D. J. New tools to support collaboration and virtual organizations. Philosophical Transactions of the Royal Society: A Mathematical, Physical and Engineering Sciences, v. 367, p. 10511056, 2009.

FREDDI, D. The integration of old and new technological paradigms in low- and mediumtech sectors: the case of mechatronics. Research Policy, v. 38, n. 3, p. 548-558, 2009.

FUKUGAWA, N. Determining factors in innovation of small firm networks: a case of cross industry groups in Japan. Small Business Economics, v. 27, n. 2-3, p.181-193, 2006.

FULLER-LOVE, V.; THOMAS, E. Networks in small manufacturing firms. Journal of Small Business and Enterprise Development, v. 11, n. 2, p. 244-253, 2004.

GARVIN, D. A. What does "product quality" really mean?. Sloan Management Review, v. 26, n. 1, p. 25- 34, 1984.

GIBSON, D. V.; SMILOR, R. W. Key variables in technology transfer: a field-study based empirical analysis. Journal of Engineering and Technology Management, v. 8, p. 287-312, 1991. 
GREINER, M. A.; FRANZA, R. M. Barriers and bridges for successful environmental technology transfer. The Journal of Technology Transfer, v. 28, n. 2, p. 167-177, 2003.

GRINSTEIN, A.; GOLDMAN, A. Characterizing the technology firm: an exploratory study. Research Policy, v. 35, p. 121-143, 2006.

HAGEDOORN, J. Understanding the rationale of strategic technology partnering: interorganizational modes of cooperation and sectoral differences. Strategic Management Journal, v. 14, p. 371-385, 1993.

HAGEDOORN, J.; SCHAKKENRAAD, J. Leading companies and networks of strategic alliances in information technologies. Research Policy, v. 21, p. 163-190, 1992.

HALLIKAS, J.; KÄRKKÄINEN, H.; LAMPELA, H. Learning in networks: an exploration form innovation perspective. International Journal of Technology Management, v. 45, $\mathrm{n}$. 3/4, p. 229-243, 2009.

HAN, S. H.; CHIN, K. H.; CHAE, M. J. Evaluation of CITIS as a collaborative virtual organization for construction project management. Automation in Construction, v. 16, p. 199-211, 2007

HANNA, V.; WALSH, K. Interfirm cooperation among small manufacturing firms. International Small Business Journal, v. 26, p. 299-321, 2008.

HANSEN, M. T.; MORS, M. L.; LOVAS, B. Knowledge sharing in organizations: multiple networks, multiple phases. The Academy Management Journal, v. 48, n. 5, p. 776-793, 2005 .

HARDY, C., PHILlIPS, E., LAWRENCE, T. B. Resources, knowledge and influence: The organizational effects of interorganizational collaboration. Journal of Management Studies, v. 40, n. 2 , p. $321-347,2003$.

HEALEY, N. M. The transition economies of central and eastern Europe: a political, economic, social and technological analysis. The Columbia Journal of World Business, v. 29, n. 1, p. 62-70, 1994.

HENTTONEN, K. Exploring social networks on the team level - a review of the empirical literature. Journal of Engineering and Technology Management, v. 27, p. 74-109, 2010.

HERNÁNDEZ, J. E.; MULA, J., FERRIOLS, F. J. A reference model for conceptual modelling of production planning processes. Production Planning \& Control, v. 19, n. 8, p. 725-734, 2008.

HEWITT-DUNDAS, N. Resource and capability constraints to innovation in small and large plants. Small Business Economics, v. 26, n. 3, p.257-277, 2006.

HEYDEBRECK, P. KLOFSTEN, M.; MAIER, J. C. Innovation support for new technologybased firms: the Swedish teknopol approach. R\&D Management, v. 30,n. 1, p. 89-100, 2000. 
HORNBY, A. S. Oxford Advanced Learner's Dictionary. 7th Edition. Oxford and New York: Oxford University Press. 2005.

HSU, C. W. Formation of industrial innovation mechanisms through the research institute. Technovation, v. 25, n. 11, p. 1317-1329, 2005.

HUANG, G. Q.; HUANG, J.; MAK, K. L. Agent-based workflow management in collaborative product development on the internet. Computer-Aided Design, v. 32, p. 133$144,2000$.

HUANG, K-F.; YU, C-M. J. The effect of competitive and non-competitive R\&D collaboration on firm innovation. Journal of Technology Transfer, v.36, p. 383-403, 2011.

HUYLEBROECK, G. G. Technology transfer from RTOs: definition/ setting the scene p. 5768. In: INZELT, A.; HILTON, J. (Orgs.). Technology transfer: from invention to Innovation. Netherlands: Kluwer Academic Publisers. 1999.

IANSITI, M. Technology Integration: Making Critical Choices in a Dynamic World. Harvard Business School Press. 1998.

JAGODA, K.; MAHESHWARI, B.; LONSETH, R. Key issues in managing technology transfer projects: experiences from a Canadian SME. Management Decision, v. 48, n. 3, p. 366-382, 2010.

JASINSKI, A. H. Barriers for technology transfer: the case of a country in transition. Journal of Technology Management in China, v. 4, n. 2, p. 119-131, 2009.

JIN, T.; BOUTHILLIER, F. Facilitating access to information through collaboration: examination of the role of collaborative technology in competitive intelligence. In: AMITABHA GHOSE. HYDERABAD. Competitive Intelligence: An Introduction. India: ICFAI University Press. pp. 52-70, 2007.

JOLLY, V. K. Commercializing new technologies: getting from mind to market. Harvard Business School Press, New York, 1997.

JUGEND, D.; SILVA, S. L. Integration in new product development: case study in a large Brazilian high-technology company. Journal of Technology Management \& Innovation, v. 7, n.1, 2012.

KAHN, K. B. The PDMA handbook of new product development. 2ed. New Jersey: John Wiley \& Sons. 2005.

KAPLAN, S.; TRIPSAS, M. Thinking about technology: applying a cognitive lens to technical change. Research Policy, v. 37, n. 5, p. 790-805, 2008.

KARLSSON, C.; TAYLOR, M.; TAYLOR, A. Integrating new technology in established organizations: a mapping of integration mechanisms. International Journal of Operations \& Production Management, v. 30, n.7, p. 672-699, 2010. 
KAUFMANN, A.; TODTLING, F. How effective is innovation support for SMEs? An analysis of the region of Upper Austria. Technovation, v. 22, n. 3, 2002, p. 147-159, 2002.

KELLER, G.; TEUFEL, T. SAP R/3 Process Oriented Implementation - Iterative Process Prototyping. Harlow, England: Addison Wesley Longman, 1998.

KELLEY, D. J.; NAKOSTEEN, R. A. Technology resources, alliances, and sustained growth in new, technology-based firms. IEEE Transactions on Engineering Management, v. 52, n. 3, p. 292-300, 2005.

KIM, K. K.; PARK, S-H.; RYOO, S. Y.; PARK, S. K. Inter-organizational cooperation in buyer-supplier relationships: both perspectives. Journal of Business Research, v. 63, p. 863869, 2010.

KIRIKOVA, M. Explanatory capability of enterprise models. Data \& Knowledge Engineering, v.33,p. 119-136, 2000.

KIRWAN, P.; van der SIJDE, P.; GROEN, A. Assessing the needs of new technology based firms (NTBFs): and investigation among spin-off companies from six European universities. International Entrepreneurship and Management Journal, v. 2, n.2, p. 173-187, 2006.

KNOBEN, J.; OERLEMANS, L. A. G.; RUTTEN, R. P. J. H. Radical changes in interorganizational network structures: the longitudinal gap. Technological Forecasting \& Social Change, v. 73, p. 390-404, 2006.

KNUDSEN, M. P. The relative importance of interfirm relationships and knowledge transfer for new product development success. Journal of Product Innovation Management, v. 24, p. 117-138, 2007.

KONTOGHIORGHES, C. Factors affecting training effectiveness in the context of the introduction of new technology - a US case study. International Journal of Training and Development, v. 5 n. 4, p. 248-60, 2001.

KOSANKE, K. CIMOSA - Overview and status. Computer in industry, v.27, p. 101-109, 1995.

KOTABE, M.; MARTIN, X.; DOMOTO, H. Gaining from vertical partnerships: knowledge transfer, relationship duration, and supplier performance improvement in the U. S. and Japanese automotive industries. Strategic Management Journal, v.24, p. 293-316, 2003.

KOUBARAKIS, M.; PLEXOUSAKIS, D. A formal framework for business process modelling and design. Information Systems, v. 27, n. 5, p. 299-319, 2002.

KREMIC, T. Technology transfer: a contextual approach. Journal of Technology Transfer, v. 28, p. 149-158, 2003.

LANE, J. P. Knowledge translation for technology transfer: making R\&D matter to stakeholders. In: EMILIANI et al. Assistive Technology from Adapted Equipment to Inclusive Environments - AAATE 2009. Amstersdam ; Washington, DC : IOS Press. Cap. 26, p. 742-747. 2009. 
LANE, J. P. The state of the science in technology transfer: implications for the field assistive technology. Journal of Technology Transfer, v. 28, p. 333-354, 2003.

LANE, J. P. Understanding technology transfer. Assistive Technology, v. 11, n. 1, p. 5-19, 1999.

LANE, P. J.; Lubatkin, M. Relative absorptive capacity and interorganizational learning. Strategic Management Journal, v. 19, p. 461-477, 1998.

LEE, J.; WIN, H. N. Technology transfer between university research centers and industry in Singapore. Technovation, v. 24, p. 433-442, 2004.

LEE, Y.; CAVUSGIL, S. T. Enhancing alliance performance: the effects of contractual-based versus relational-based governance. Journal of Business Research, v.59, p. 896-905, 2006.

LEONARD-BARTON, D.; SINHA, D. K. Developer-user interaction and user satisfaction in internal technology transfer. The Academy of Management Journal, v. 36, n. 5, p. 11251139, 1993.

LEWIS, M. A. Success, failure and organizational competence: a case study of the new product development process. Journal of Engineering and Technology Management, v. 18, p. 185-206, 2001.

LI, L.; ZHANG, H. Confidentiality and information sharing in supply chain coordination. Management Decision, v. 54, n. 8, p. 1467-1481, 2008.

LI, W. D.; QIU, Z. M. State-of-the-art technologies and methodologies for collaborative product development systems. International Journal of Production Research, v. 44, n. 13, p. 2525-2559, 2006.

LIM, S. H.; JUSTER, N.; DE PENNINGTON, A. Enterprise modeling and integration: a taxonomy of seven key aspects. Computers in Industry, v. 34, p. 339-359, 1997.

LIN, B-W.; BERG, D. Effects of cultural difference on technology transfer projects: an empirical study of Taiwanese manufacturing companies. International Journal of Project Management, v. 19, p. 287-293, 2001.

LIN, J. L.; FANG, S-C.; FANG, S-R.; TSAI, F-S. Network embeddedness and technology transfer performance in R\&D consortia in Taiwan. Technovation, v. 29, p. 763-774, 2009.

LIU, W.; ZHAO, S. SUN, Y.; YIN, M. An approach to project management information system requirements analysis. International Conference on Intelligent Computation Technology and Automation (ICICTA), p. 957-961, 2008.

LÖFSTEN, H.; LINDELÖF, P. R\&D networks and product innovation patterns-academic and non-academic new technology-based firms on Science Parks. Technovation, v. 25, n. 9, p. 1025-1037, 2005.

LOUCOPOULOS, P.; KAVAKLI, V. Enterprise knowledge management and conceptual modeling. Conceptual Modeling, LNCS 1565, p. 123-143, 1999. 
LOWE, D. Web system requirements: an overview. Requirements Engineering, v. 8, n. 2, p. 101-113, 2003.

LUNDQUIST, G. A rich vision of technology transfer: technology value management. Journal of Technology Transfer, v. 28, p. 265-284, 2003.

LUO, Y. Contract, cooperation, and performance in international joint ventures. Strategic Management Journal, v. 23, p. 903-919, 2002.

LUUKKONEN, T. Networking impacts of the EU framework programme. In: OECD (ed) Innovative networks, co-operation in national innovation systems: p.193-208. 2001.

MALHOTRA, M. K.; GROVER, V. An assessment of survey research in POM: from constructs to theory. Journal of Operations Management, v. 16, p. 407-425, 1998.

MALIK, K. Aiding the technology manager: a conceptual model for intra-firm technology transfer. Technovation, v. 22, p. 427-436, 2002.

MANCINELLI, S.; MAZZANI, M. Innovation, networking and complementarity. Evidence on SME performances for a local economic system in North-Eastern Italy. Annals of Regional Science, v. 43, n.3, p. 567-597, 2009.

MATOOK, S.; INDULSKA, M. Improving the quality of process reference models: a quality function deployment-based approach. Decision Support Systems, v. 47, p. 60-71, 2009.

MCKAY, A. PENNINGTON, A.; BAXTER, J. Requirements management: a representation scheme for product specifications. Computer-Aided Design, v. 33, p. 511-520, 2001.

MINISTÉRIO DA CIÊNCIA E TECNOLOGIA. Lei da informática. Disponível em < http://www.mct.gov.br/index.php/content/view/2189/Lei_de_Informatica.html>. Acesso em: 02 Out. 2012.

MINISTÉRIO DA CIÊNCIA E TECNOLOGIA. Lei da inovação. Disponível em < http://www.mct.gov.br/index.php/content/view/8477.html>. Acesso em: 02 Out. 2012.

MINISTÉRIO DA CIÊNCIA E TECNOLOGIA. Lei do bem. Disponível em < http://www.mct.gov.br/index.php/content/view/8586.html>. Acesso em: 02 Out. 2012.

MOHAN, S. R.; RAO, A. R. Strategic for technology development in public R\&D institutes by partnering with the industry. Technovation, v. 25, p. 1484-1491, 2005.

MORGAN, R. M.; HUNT, S. D. The commitment-trust theory of relationship marketing. Journal of Marketing, v. 58, p. 20-38, 1994.

MOSTERT, J. N.; BUYS, A. J. The practice of technology transfer. PICMET: Portland International Center for Management of Engineering and Technology, p. 2281-2286, 2008.

MOWERY, D. C.; OXLEY, J. E.; SILVERMAN, B. S. Strategic alliances and interfirm knowledge transfer. Strategic Management Journal, v. 17, p. 77-91, 1996. 
NARULA, R. R\&D collaboration by SMEs: new opportunities and limitations in the face of globalization. Technovation, v. 24, p. 153-161, 2004.

NIETO, M. J.; SANTAMARÍA, L. Technological collaboration: bridging the innovation gap between small and large firms. Journal of Business Management, v.48,n. 1,p. 44-69, 2010.

NIETO, M. J.; SANTAMARÍA, L. The importance of diverse collaborative networks for the novelty of product innovation. Technovation, v. 27, p. 367-377, 2007.

NOBELIUS, D. Linking product development to applied research: transfer experiences from automotive company. Technovation, v. 24, n. 4, p. 321-334, 2004.

NOOTEBOOM, B. Innovation and diffusion in small firms: theory and evidence. Small Business Economics, v. 6, p. 327-347, 1994.

NOOTEBOOM, B. Inter-firm collaboration, networks and strategy: an integrated approach. Routledge, New York, 2003.

NOOTEBOOM, B.; VAN HAVERBEKE, W.; DUYSTERS, G.; GILSING, V.; VAN DEN OORD, A. Optimal cognitive distance and absorptive capacity. Research Policy, v. 36, p. 1016-1034, 2007.

NORMAN, P. M. Protecting knowledge in strategic alliances: resource and relational characteristics. Journal of High Technology Management Research, v. 13, p. 177-202, 2002.

OKAMURO, H. Determinants of successful R\&D cooperation in Japanese small businesses: the impact of organizational and contractual characteristics. Research Policy, v.36, p. 15291544, 2007.

ORGANIZAÇÃO PARA A COOPERAÇÃO E DESENVOLVIMENTO ECONÔMICO OCDE. Manual de Oslo: proposta de diretrizes para coleta e interpretação de dados sobre Inovação tecnológica. 3. ed. Brasília, OCDE, Finep. 2005.

OJASALO, J. Management of innovation networks: a case study of different approaches. European Journal of Innovation Management, v. 11, n. 1, p. 51-86, 2008.

O'REAGAN, N.; SIMS, M. A. Identifying high technology small firms: a sectoral analysis. Technovation, v. 28, n. 7, p. 498-423, 2008.

OSMAN-GANI, A. M.; JACOBS, R. L. Technological change and human resource development practices in Asia: a study of Singapore-based companies. International Journal of Training and Development, v. 9 n. 4, p. 271-80, 2005.

PARK, J. S. Opportunity recognition and product innovation in entrepreneurial hi-tech startups: a new perspective and supporting case study. Technovation, v. 25, p. 739-752, 2005.

PARTANEN, J.; MÖLLER, K.; WESTERLUND, M.; RAJALA, R.; RAJALA, A. Social capital in the growth of science-and-technology-based SMES. Industrial Marketing Management, v. 37, p. 513-522, 2008. 
PÉREZ, M. P.; SÁNCHES, A. M. The development of university spin-offs: early dynamics of technology transfer and networking. Technovation, v. 23, p. 823-831, 2003.

PERKS, H.; JEFFERY, R. Global network configuration for innovation: a study for international fibre innovation. R\&D Management, v. 36, n. 1, p. 67-83, 2006.

PERTUZÉ, J. A.; CALDER, E. S.; GREITZER, E. M.; LUCAS, W. A. Best practices for industry-university collaboration. MIT Sloan Management Review, v. 50, n. 4, p. 82-90, 2010.

PHAAL, R.; FARRUKH, C. J. P.; PROBERT, D. R. Technology roadmapping - a planning framework for evolution and revolution. Technological Forecasting \& Social Change, v. 71, n. 1/2, p. 5-26, 2004.

PINHEIRO, F. A. C.; LEITE, J. C. S. P.; CASTRO, J. F. B. Requirements engineering technology transfer: an experience report. Journal of Technology Transfer, v. 28, p. 159$165,2003$.

PLISSON, J.; LJUBIC; MOZETIC, I.; LAVRAC, N. An ontology for virtual organization breeding environments. IEEE Systems, Man, and Cybernetics - Part C: Applications and Reviews, v. 37, n. 6, p. 1327-1341, 2007.

POPPO, L.; ZENGER, T. Do formal contracts and relational governance function as substitutes or complements. Strategic Management Journal, v. 23, p. 707-725, 2002.

POWEL, W. W.; KOPUT, K. W.; SMITH-DOERR, L. Interorganizational collaboration and the locus of innovation: networks of learning in biotechnology. Administrative Science Quartely, v.41, p. 116-145, 1996.

PROJECT MANAGEMENT INSTITUTE - PMI. Guia PMBOK: um guia do conjunto de conhecimentos do gerenciamento de projetos. Pennsylvania: Project Management Institute, 3rd. ed, 2004.

PYKA, A.; KÜPPERS, G. Innovation Networks. Edward Elgar Publishing Limited. 2002.

QURESHI, S.; LIU, M.; VOGEL, D. The effect of electronic collaboration in distributed project management. Group Decision and Negotiation, v. 15, p. 55-75, 2006.

RAMPERSAD, G.; QUESTER, P.; TROSHANI, I. Managing innovation networks: exploratory evidence from ICT, biotechnology and nanotechnology networks. Industrial Marketing Management, v. 39, p. 793-805, 2010.

RAYMOND, L.; BERGERON, F. Project management information systems: an empirical study of their impact on project managers and project success. International Journal of Project Management, v. 26, p. 213-220, 2008

REAGAN, R.; MCEVILY, B. Network structure and knowledge transfer: the effects of cohesion and range. Administrative Science Quartely, v. 48, p. 240-267, 2003. 
REINHARTZ-BERGER, I.; SOFFER, P.; STURM, A. Extending the adaptability of reference models. IEEE Transactions on Systems, Man, and Cybernetics - Part A: Systems and Humans, v. 40, n. 5, p. 1045-1056, 2010.

RIKKIEV, A.; MÄKINEN, S. Success factors for technology integration convergence collaborations: empirical assessment. Proceedings of the Portland International Center for Management of Engineering and Technology (PICMET), Portland, Oregon, USA, p. 374-382, 2009.

RODRIGUEZ, K.; AL-ASHAAB, A. Knowledge web-based system architecture for collaborative product development. Computers in Industry, v. 56, p. 125-140, 2005.

ROGERS, E. M. The nature of technology transfer. Science Communication, v. 23, n. 3, p. 323-341, 2002.

ROGERS, E. M.; CARAYANNIS, E. G.; KURIHARA, K.; ALLBRITTON, M. M. Cooperative research and development agreements (CRADAs) as technology transfer mechanisms. R\&D Management, v. 28, n. 2, p. 79-88, 1998.

ROGERS, E. M.; TAKEGAMI, S.; YIN, J. Lessons learned about technology transfer. Technovation, v. 21, p. 253-261, 2001.

ROLLAND, C.; NURCAN, S.; GROSZ, G. A decision-making pattern for guiding the enterprise knowledge development process. Information and Software Technology, v. 42, p. 313-331, 2000.

ROZENFELD, H. et al. Gestão do desenvolvimento de produtos - uma referência para a melhoria do processo. Saraiva: São Paulo, 2006.

RYCROFT, R. W.; KASH, D. E. Self-organizing innovation networks: implications for globalization. Technovation, v. 24, n. 3, p. 187-197, 2004.

SAAD, M.; CICMIL, S.; GREENWOOD, M. Technology transfer projects in developing countries - furthering the project management perspectives. International Journal of Project Management, v. 20, p. 617-625, 2002.

SAEED, K. A. Evaluating the value of collaboration systems in collocated teams: a longitudinal analysis. Computers in Human Behavior, v. 28, p. 552-560, 2012.

SANTORO, M. D.; SAPARITO, P. A. Self-interest assumption and relational trust in university-industry knowledge transfers. IEEE Transactions on Engineering Management, v. 53, n. 3, p. 335-347, 2006.

SANTORO, M. D.; SAPARITO, P. A. The firm's trust in its university partner as a key mediator in advancing knowledge and new Technologies. IEEE Transactions on Engineering Management, v. 50, n. 3, p. 362-373, 2003.

SCHEER, A. W. ARIS - business process frameworks. Springer-Verlag. 1999.

SCHEER, A. W. ARIS - business process modeling. Springer-Verlag. 2000. 
SCHEER, A. W.; NÜTTGENS, M. ARIS Architecture and Reference Models for Business Process Management. In: van der AALST, W.M.P.; DESEL, J.; OBERWEIS, A.: Business Process Management - Models, Techniques, and Empirical Studies, LNCS 1806, p. 366379, 2000.

SEBRAE - SERVIÇO BRASILEIRO DE APOIO ÀS MICRO E PEQUENAS EMPRESAS. Conhecendo as MPEs, 2011. Disponível em: 〈http://www.sebrae.sp.com.br>. Acesso em: 5 de maio de 2011.

SHAH, S. K.; CORLEY, K. G. Building better theory by bridging the quantitative-qualitative divide. Journal of Management Studies, v. 43,n. 8, p. 1821-1835, 2006.

SHEN, H.; WALL, B.; ZAREMBA, M.; CHEN, Y.; BROWNE, J. Integration of business modelling methods for enterprise information system analysis and user requirements gathering. Computers in Industry, v. 54, n. 3, p. 307-323, 2004.

SCHON, D. Technology and Change. Pergamon, London, 1967.

SCHRADER, S. Informal technology transfer between firms: cooperation through information trading. Research Policy, v. 20, p. 153-170, 1991.

SCHULZ, A. P.; CLAUSING, D. P.; FRICKE, E.; NEGELE H. Development and integration of winning technologies as key to competitive advantage. Systems Engineering, v. 3, n. 4, p. 180-211, 2000.

SHERWOOD, A. L.; COVIN, J. G. Knowledge acquisition in university-industry alliances: an empirical investigation from a learning theory perspective. Journal of Product Innovation Management, v.25, p. 162-179, 2008.

SIMONIN, B. L. Ambiguity and the process of knowledge transfer in strategic alliances. Strategic Management Journal, v. 20, p. 595-623, 1999.

SIU, W-S.; BAO, Q. Network strategies of small chinese high-technology firms: a qualitative study. Journal of Product Innovation Management, v. 25, p. 79-102, 2008.

SLOWINSKI, G.; HUMMEL, E.; KUMPF, R. J. Protecting know-how and trade in collaborative R\&D relationships. Research Technology Management, v. 49, n. 4, p. 30-38, 2006.

SMALL, H. Visualizing science by citation mapping. Journal of the American Society for Information Science, v. 50, n. 9, 799-813, 1999.

SPEE, A. P.; JARZABKOWSKI, P. Strategic planning as communicative process. Organization Studies, v. 32, n. 9, p. 1217-1245, 2011.

STEENSMA, H. K. Acquiring technological competencies through inter-organizational collaboration: an organizational learning perspective. Journal of Engineering and Technology Management, v. 12, p. 267-286, 1996. 
STOCK, G. N; TATIKONDA, M. V. A typology of project-level technology transfer processes. Journal of Operations Management, v. 18, p. 719-737, 2000.

STONEHOUSE, G.; PEMBERTON, J. Strategic planning in SMEs - some empirical findings. Management Decision, v. 40, n. 9, p. 853-861, 2002.

STREET, C. T.; CAMERON, A-F. External relationships and the small business: a review of small business alliance and network research. Journal of Small Business Management, v. 45, n. 2, p. 239-266, 2007.

SUNG, T. K. Technology transfer in the IT industry: a Korean perspective. Technological Forecasting \& Social Change, v. 76, p. 700-708, 2009.

TATIKONDA, M. V.; STOCK, G. N. Product technology transfer in the upstream supply chain. Journal of Product Innovation Management, v. 20, n. 6, p. 444-467, 2003.

TIDD, J.; BESSANT, J.; PAVITT, K. Managing Innovation: Integrating technological, market and organizational change. 3.ed. John Wiley \& Sons, 2005.

TROTT, P. Innovation management and new product development. 3. ed. Harlow: Prentice Hall, 2005.

TROTT, P.; CORDEY-HAYES, M.; SEATON, R. A. F. Inward technology transfer as an interactive process. Technovation, v. 15, n. 1, p. 25-43, 1995.

TSAI, K-H. Collaborative networks and product innovation performance: toward a contingency perspective. Research Policy, v. 38, p. 765-778, 2009.

UN, C. A.; CUERVO-CAZURRA, A.; ASAKAWA, K. R\&D collaborations and product innovation. Journal of Product Innovation Management, v. 27, p. 673-689, 2010.

VAN AKEN, J. E.; WEGGEMAN, M. P. Managing learning in informal innovation networks: overcoming the daphne-dilemma. R\&D Management, v. 30, n. 2, p. 139-149, 2000.

VANHAVERBEKE, W.; CLOODT, M. Open innovation in value networks. In: CHESBROUGH, H.; VANHAVERBEKE, W.; WEST, J. Open innovation: researching a new paradigm. Oxford University Press, 2006.

VERNADAT, F.B. Enterprise modeling and integration: principles and applications. Chapman \& Hall. 1996.

VOSS, C.; TSIKRIKTSIS, N.; FROHLIC, M. Case research in operations management. International Journal of Operations \& Production Management, v. 22, n. 2, p. 195-219, 2001.

WANG, L.; YEUNG, J. H. Y.; ZHANG, M. The impact of trust and contract on innovation performance: the moderating role of environmental uncertainty. International Journal of Production Economics, v. 134, p. 114-122, 2011. 
WICKRAMASINGHE, V.; GARUSINGHE, S. An exploratory study of human resource aspects of international technology transfers to Sri Lankan private sector manufacturing firms. International Journal of Operations \& Production Management, v. 30, n. 6, p. 584-611, 2010 .

WILLIAMS, T. Cooperation by design: structure and cooperation in interorganizational networks. Journal of Business Research, v. 58, p. 223-231, 2005.

WU, J. Technological collaboration in product innovation: the role of market competition and sectoral technological intensity. Research Policy, v. 41, p. 489-496, 2012.

WULIANG, P.; FANBO, M.; DECAI, K. A project management system for product development. ISIP, Third International Symposium on Information Processing, p.78-82, 2010.

WUYTS, S.; COLOMBO, M. G.; DUTTA, S.; NOOTEBOOM, B. Empirical tests of optimal cognitive distance. Journal of Economic Behavior \& Organization, v. 58, p. 277-302, 2005.

ZENG, S. X.; XIE, X. M.; TAM, C. M. Relationship between cooperation networks and innovation performance of SMEs. Technovation, v. 30, n. 3, p. 181-194, 2010.

ZIKMUND, W. G. Business Research Methods. $7^{\mathrm{a} E d i c ̧ a ̃ o . ~ K e n t u c k y: ~ T h o m s o n ~}$ Southwestern.

ZINS, C. Conceptual approaches for defining data, information, and knowledge. Journal of the American Society for Information Science and Technology, v. 58, n. 4, p. 479-493, 2007.

YAO, B.; MCEVILY, S. Absorptive capacity and social network: internal ability and external opportunity for product innovation. Management of Innovation and Technology, 2000. ICMIT 2000. Proceedings of the 2000 IEEE International Conference on, v.2, p.708-714, 2000 .

YIN, R. K. Estudo de caso: planejamento e métodos. 2. ed. Porto Alegre: Bookman. 2001. 


\section{GLOSSÁRIO}

Capacidade de absorção - habilidade para compreender outros diferentes níveis de distância cognitiva, ou seja, diferenças de conhecimentos e especialidades.

Capacidade de inovação - refere-se a uma melhoria contínua da capacidade das empresas para gerar inovação para o desenvolvimento de novos produtos para atender as necessidades do mercado.

Conhecimento - é a informação que está na mente das pessoas: é a informação personalizada (que pode ou não ser novo, único, útil ou preciso) relacionadas a fatos, procedimentos, conceitos, interpretações, idéias, observações e julgamentos.

Custo - valor monetário ou preço de uma atividade ou componente do projeto que inclui o valor monetário dos recursos necessários para realizar e terminar a atividade ou o componente ou para produzir o componente.

Economia de escala - é definida como a situação em que há um aumento da escala em que o negócio opera em ou uma redução do custo por unidade.

Escopo do projeto - O trabalho que deve ser realizado para entregar um produto, serviço ou resultado com as características e funções especificadas.

Estrutura de relacionamento - refere-se a configuração das relações como posicionamento na rede, tipo e força do nó, densidade, centralidade, estabilidade entre outros.

Habilidade - o fato de alguém ser capaz de fazer ou entender alguma coisa.

Informação - mensagem utilizada por um remetente para representar um ou mais conceitos dentro de um processo de comunicação, destinado a aumentar o conhecimento do receptor.

Incerteza - é a incapacidade de atribuir probabilidades para os resultados em decorrência da falta de informação. Existem diversos tipos de incertezas como técnica, de mercado e tecnológica.

Inovação - é a implementação de um produto (bem ou serviço) novo ou significativamente melhorado, ou um processo, ou um novo método de marketing, ou um novo método organizacional nas práticas de negócios, na organização do local de trabalho ou nas relações externas.

Modelagem de empresa - conjunto de modelos que representam as diferentes visões da empresa. Representam as operações, recursos e fluxo de informações. 
Modelagem de negócio - é a formalização dos objetivos, estratégias de negócio, políticas da empresa.

Modelagem organizacional - representam níveis hierárquicos, as autoridades, responsabilidades, recursos humanos e de hardware.

Produto robusto - é um produto no qual o desempenho é minimamente sensível a fatores que são difíceis de controlar.

Recursos - algo que pode ser utilizado para atingir um objetivo. Existem diferentes tipos de recursos como, por exemplo, humano que se refere a habilidades, capacidade, conhecimento que são utilizados para a produção de bens; financeiro se refere ao dinheiro necessário para realizar um investimento; tecnológico se refere a tecnologia utilizada como computador, impressora, sistema, etc.

Rede mista - acordo envolvendo pelo menos um concorrente e um sub-contratante ou um cliente.

Risco - um evento ou uma condição que pode ou não ocorrer. Se caso ocorrer algo impactará na capacidade de alcançar um determinado objetivo. O risco pode ser financeiro, de inovação, técnico, de mercado, entre outros. 


\section{APÊNDICE A - ROTEIRO DE ENTREVISTAS}

Data: Horário de início: $\mathrm{h}$ ; término: h

Empresa:

Entrevistado: Função: Tempo na função: (anos)

Parte I - Caracterização da empresa

1. Quais mercados a empresa atende?

2. Quais os principais clientes e fornecedores (setor)?

3. Número de novos produtos desenvolvidos e lançados nos últimos $\mathbf{5}$ anos?

\section{Parte II - Caracterização da rede}

Objetivo: busca-se compreender as relações inter-organizacionais e sua configuração no que se refere às motivações, as dificuldades, e as regras que permeiam a colaboração. Além disso, pretende-se identificar através das características das relações, das diferenças cognitivas, da comunicação a capacidade da empresa em utilizar o conhecimento.

\section{Qual o grau da relação e o tempo dela com:}

\begin{tabular}{|l|c|c|c|c|c|c|}
\hline Parceiro Intensidade & $\begin{array}{c}\text { Muito } \\
\text { fraco }\end{array}$ & Fraco & Moderado & Forte & $\begin{array}{c}\text { Muito } \\
\text { forte }\end{array}$ & $\begin{array}{c}\text { Tempo da } \\
\text { relação }\end{array}$ \\
\hline Universidade & 1 & 2 & 3 & 4 & 5 & \\
\hline Centro de pesquisa & 1 & 2 & 3 & 4 & 5 & \\
\hline Fornecedores & 1 & 2 & 3 & 4 & 5 & \\
\hline Clientes & 1 & 2 & 3 & 4 & 5 & \\
\hline Redes de cooperação & 1 & 2 & 3 & 4 & 5 & \\
\hline Institutos & 1 & 2 & 3 & 4 & 5 & \\
\hline Outras empresas & 1 & 2 & 3 & 4 & 5 & \\
\hline
\end{tabular}

2. Quais são os motivadores para participar de uma colaboração?

( ) Compartilhar riscos

( ) Aumentar recursos

( ) Adquirir novos conhecimento

( ) Adquirir novas tecnologias

( ) Obter economia de escala

( ) Compartilhar habilidades

( ) Compartilhar informação

( ) Compartilhar custos

( ) Desenvolver produtos robustos
( ) Reduzir incertezas

( ) Aumentar a capacidade para inovar

( ) Acessar novos mercados

( ) Maior capacidade de aprendizagem

( ) Reduzir o tempo de desenvolvimento do produto

( ) Complementar competências

( ) Não familiaridade com a tecnologia

( ) Melhorar a competitividade

Outros motivadores:

3. Quais os reais benefícios obtidos? 
4. O que foi necessário para ser bem sucedido em uma colaboração?

( ) Adaptar a forma atual de trabalhar com as necessidades do outro

( ) Desenvolver competências adicionais

( ) Alinhar diferentes estratégias, criando uma visão comum de resolução de problema

( ) Integrar clientes no processo de desenvolvimento

( ) Identificar e explorar idéias em conjunto

( ) Aquisição de competência de acordo com as capacidades individuais dos parceiros

( ) Comunicação

( ) Flexibilidade

Outras opções:

5. Quais os instrumentos utilizados para coordenar as atividades colaborativas?

( ) Contratos

( ) Dependência mútua

( ) Confiança

( ) Reputação

Outros:

6. Quais as dificuldades que a empresa encontrou para trabalhar colaborativamente?

( ) Foco em interesses individuais

( ) Falta de comprometimento

( ) Falta de confiança

( ) Falha ao compreender a necessidade de cada um

( ) Falta de comunicação

( ) Falha ao compreender as expectativas de cada um
( ) Falta de coordenação entre os times gestores

( ) Estilo de liderança diferente

( ) Diferença cultural

( ) Falha de compreender a necessidade do cliente

( ) Falta de um sistema operacional para gerenciar as atividades

Outras:

7. Como pode ser caracterizada a relação entre sua empresa e os parceiros?

\begin{tabular}{|l|l|l|l|}
\hline & Sim & Não & \\
\hline $\begin{array}{l}\text { Existe uma interação próxima } \\
\text { entre as duas organizações }\end{array}$ & & & \\
\hline $\begin{array}{l}\text { A relação entre as duas } \\
\text { organizações é caracterizada } \\
\text { pela confiança mutua }\end{array}$ & & & \\
\hline $\begin{array}{l}\text { A relação entre as duas } \\
\text { organizações é caracterizada } \\
\text { pelo respeito mutuo }\end{array}$ & & \\
\hline $\begin{array}{l}\text { O relacionamento com a outra } \\
\text { organização é amigável }\end{array}$ & & & \\
\hline $\begin{array}{l}\text { A relação entre as organizações } \\
\text { são caracterizadas pelo alto nível } \\
\text { de reciprocidade }\end{array}$ & & \\
\hline
\end{tabular}




\section{Indique se:}

\begin{tabular}{|l|l|l|l|}
\hline & Sim & Não & Comente \\
\hline $\begin{array}{l}\text { Membros das duas organizações } \\
\text { compartilham uma linguagem } \\
\text { comum }\end{array}$ & & & \\
\hline $\begin{array}{l}\text { Existe alta complementaridade } \\
\text { entre recursos e capacidades }\end{array}$ & & & \\
\hline $\begin{array}{l}\text { A capacidade das duas } \\
\text { organizações é similar. }\end{array}$ & & & \\
\hline $\begin{array}{l}\text { A cultura organizacional é } \\
\text { compatível oel operação é }\end{array}$ & & & \\
\hline $\begin{array}{l}\text { O estilo de gestão e operativel } \\
\text { compatín }\end{array}$ & & \\
\hline
\end{tabular}

9. Como ocorre a comunicação inter e intra-empresa?

\begin{tabular}{|c|c|c|c|}
\hline & Sim & Não & Comente \\
\hline \multicolumn{4}{|l|}{ Existem conversas informais } \\
\hline \multicolumn{4}{|l|}{$\begin{array}{l}\text { Encontros são organizados para } \\
\text { discutir o desenvolvimento e as } \\
\text { tendências da organização. } \\
\text { Como são esses encontros e a } \\
\text { frequiência? }\end{array}$} \\
\hline \multicolumn{4}{|l|}{ 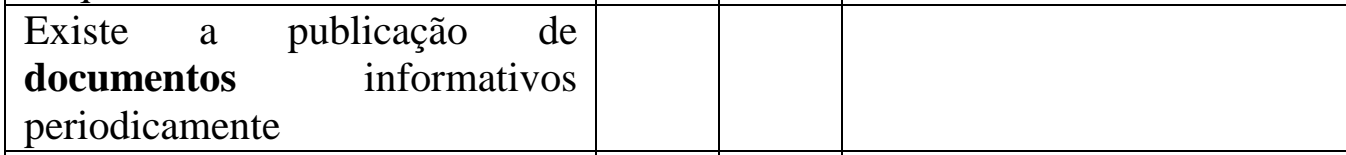 } \\
\hline \multicolumn{4}{|l|}{$\begin{array}{l}\text { Dados importantes são } \\
\text { transmitidos regularmente para } \\
\text { todos. Como são transmitidos? }\end{array}$} \\
\hline \multicolumn{4}{|l|}{$\begin{array}{l}\text { Quando algo importante ocorre, } \\
\text { todos são } \\
\text { imediatamente. Como sarmados } \\
\text { informados? }\end{array}$} \\
\hline $\begin{array}{l}\text { A organização tem a capacidade } \\
\text { ou habilidade para assegurar o } \\
\text { fluxo do conhecimento dentro da } \\
\text { organização. O que é feito para } \\
\text { isso? }\end{array}$ & & & \\
\hline
\end{tabular}

\section{Parte III - Processo de transferência de tecnologia}

Objetivo: Identificar os atores envolvidos e compreender as atividades, informações, fluxo de material que compõe o processo de transferência de tecnologia, as barreiras e mecanismos para enfrentar as dificuldades, assim como a avaliação desse processo. 


\section{Quais as barreiras enfrentadas no processo de transferência de tecnologia?}
( ) Característica da tecnologia
( ) Diferenças de linguagem entre parceiros
( ) Natureza do conhecimento
( ) Falta de confiança
( ) Risco
( ) Transferência de experiência
( ) Falta de fundos; leis governamentais
( ) Falta de informação
( ) Falta de recursos financeiros
( ) Falta de infra-estrutura
( ) Falta de comunicação
( ) Falta de pessoal
( ) Diferenças culturais
( ) Falta de competência

\section{Outras:}

\section{Que mecanismos foram utilizados para enfrentar cada barreira?}

( ) Treinamento e a participação de supervisores e alta gerência

( ) Definição da unidade responsável pela transferência da tecnologia

( ) Definição de líderes-chave

( ) Envolvimento antecipado do usuário

( ) Melhoria nos canais de comunicação (capacidade para transmitir e receber informações)

( ) Transferência de pessoas

( ) Documentação

( ) Credibilidade das partes envolvidas

Outros:

\section{Parte IV - Modelagem}

Objetivo: Compreender a relação entre colaboração e a transferência tecnologia-produto de maneira teórica e empírica.

\section{Processo de negócio}

1. Quais são os principais processos da transferência da tecnologia?

2. Quais fluxos de informações e materiais são necessários?

3. Quais atores são responsáveis por realizar e apoiar esse processo?

\section{Atores e recursos}

4. Quais são os principais atores envolvidos no processo de transferência?

5. Como os atores estão relacionados?

6. Por que o ator é necessário? (quais papéis/tarefas desempenham)

7. Por quais recursos (humanos e não humanos) esse ator é responsável?

\section{Objetivos}

8. Quais são as estratégias/objetivos da organização em relação à transferência de tecnologia? 
9. Quais políticas externas, convenções, regras, regulamentos e leis podem influenciar os objetivos?

10. O que a organização gostaria de alcançar?

11. Existe algum problema particular impedindo um objetivo?

12. Qual é a causa desse problema?

13. Como esse problema poderia ser eliminado?

14. Quais ações poderiam ser tomadas para melhorar a situação?

15. Como esse objetivo pode ser alcançado?

16. Esse objetivo pode ser definido em termos operacionais, dando um número de subobjetivos de apoio?

\section{Regras do negócio}

17. Existem regras declaradas e políticas com a companhia que podem influenciar esse modelo? (O que precisa ter pra alcançar os objetivos)

18. Por quais regras os objetivos da organização podem ser alcançados?

19. Essa regra pode ser definida em uma forma operacional?

20. Como validar se a regra é cumprida?

21. Quais regras disparam/ apoiam tal processo?

22. Quais regras do negócio são de responsabilidade desse ator?

\section{Componentes e requisitos técnicos}

23. Que sistemas são ou poderiam ser utilizados para a troca de informação entre sua empresa e outras instituições?

24. Quais os objetivos do sistema?

25. Quais requisitos são importantes em relação a requisitos não funcionais do tipo $X$, no qual X pode ser segurança, disponibilidade, desempenho, etc.? 
